INTERNATIONAL JOURNAL OF

Vol. 19, No. 4 SYSTEMATIC BACTERIOLOGY

Copyright 1969, Iowa State University Press

pp. $391-512$

\title{
COOPERATIVE DESCRIPTION OF TYPE CULTURES OF STREPTOMYCES. IV. SPECIES DESCRIPTIONS FROM THE SECOND, THIRD AND FOURTH STUDIES**
}

Elwood B. Shirling and David Gottlieb

Department of Botany and Bacteriology

Ohio Wesleyan University, Delaware, Ohio, and

Department of Plant Pathology, University of Illinois, Urbana, Illinois

\begin{abstract}
The International Streptomyces Project is a cooperative effort by more than 40 collaborating laboratories representing 18 nations to assemble and re describe authentic type strains or acceptable neotype strains for species of the genera streptomyces and Streptoverticillium. Descriptions baseduponcurrent ly acceptablecriteria and methods are published in the International Journal of Systematic Bacteriology. Specimens of the redescribed type strains are deposited in the American Type Culture Collection, the Centraalbureau voor Schimmelcultures, the U.S.S.R. Research Institute for Antibiotics and the Institute for Fermentation, Japan. This report adds descriptions for type strains of 100 additional species to the 200 species previously deposited in the collections and described in Parts II and III of this series.
\end{abstract}

Collaborators and authors of descriptions:

\section{Group B-1*}

Sanchez-Marroquin, A. Miami 40, Mexico 18/d.f., Mexico.

Baldacci, E., G. Farina and R. Locci. Ist. Patol. Vegetale, Univ. Milano, Milano, Via Celoria N. 2, Italy.

Gauze, G.F., T.P. Preobrazhenskaya, E.S. Kudrina, T.S. Maximova and M. A. Sveshnikova. Acad. Med. Sciences of U.S.S.R., Inst. New Antibiotics, Bolshaia Pirogovskaia 11, Moscow, U.S.S.R.

* A letter-number combination is assigned to each collaborating group. To conserve space, this code is used to indicate the author group for each emended description. The letter A indicates collaborating groups for the first 130 type strains distributed for study; B designates groups participating in the second study, etc.

** Reprints of this article may be purchased from the International Microbiological Fund, 221 Science Hall, Iowa State University, Ames, Iowa 50010, U.S.A. Price for single copies: $\$ 2.00$. 


\section{Group B-4}

Crook, Kenneth E., Jr. and Carol S. Cassidy. Bristol Labs., Inc. Syracuse, New York, U.S.A.

Mach, F. Inst. für Mikrobiologie, Greifswald, Ludwig-Jahn-Str. 15, German Democratic Republic.

Kuznetsov, V.D. U.S.S.R. Research Inst. for Antibiotics, Moscow, U.S.S.R.

\section{Group B-7}

Hirsch, P. Dept. Microbiology and Public Health, Michigan State Univ., East Lansing, Michigan, U.S.A.

Tanaka, Nobuo. Div. Antibiotics, Inst, of Applied Microbiology, Univ. of Tokyo, Bunkyo-ku, Tokyo, Japan.

Wallhaüs eer, KarlH. Mikrobiolog. Unters ab., Farbwerke Hoechst AG, Frankfurt a/M - Höchst, Germany.

\section{Group B-8}

McClung, Norvel M.* and Gene Michaels. Dept. Microbiol., Univ. Georgia, Athens, Ga., U.S.A. *(Present address: Dept. Bot. and Bact., Univ. South Florida, Tampa, Florida.)

Spyvee, J. and J. Elliott. Boots Pure Drug Co., Ltd., Antibiot. and Ferm. Div., Nottingham, England.

Nakazawa, K., M. Shibata, K. Yamamoto, E. Higashide, T. Iwasa and T. Hasegawa. Takeda Chem. Ind., Ltd., Juso-Higashiyodogawaku, Osaka, Japan.

\section{Group B-9}

Dietz, Alma. Upjohn Co., Kalamazoo, Michigan, U.S.A.

Woźnicka, Wanda. Państwowy Higieny, U1. Chocimska 24, Warszawa 12, Poland.

Ohara, Y. and H. Nonomura. Faculty of Engineering, Yamanashi Univ., Kofu, Japan.

\section{Group C-1}

Gauze, G.F., T.P. Preobrazhenskaya, E.S. Kudrina, T.S. Maximova and M. A. Sveshnikova. Acad. Med. Sciences of U.S.S.R., Inst. New Antibiotics, Bolshaia Pirogovskaia 11, Moscow, U.S.S. R.

Nishimura, H., M. Mayama and K. Tawara. Shionogi Res. Lab., Shionogi and Co., Ltd. Fukushima-ku, Osaka, Japan.

Spyvee, J. and J. Elliott. Boots Pure Drug Co., Ltd., Antibiot. and Ferm. Div., Nottingham, England.

\section{Group C-2}

Johanides, Vera and Tea Blazekovic. Laboratorij za industrijsku mikrobiologiju, Tehnološki fakultet, Pierottijeva 6, Zagreb, Jugoslavija. 
Baldacci, E., G. Farina and R. Locci. Ist. Patol. Vegetale, Univ. Milano, Via Celoria N. 2, Milano, Italy.

Michaels, Eugene. Dept. Microbiol., Univ. Georgia, Athens, Ga., U.S.A.

\section{Group C-3}

Krasil'nikov, N.A. Inst. Microbiology. Academy of Sciences, Moscow, B-133, U.S.S.R.

Sanchez-Marroquin, A. Miami 40, Mexico 18/D. F., Mexico.

Routien, J.B. and Corinne Clevenger. Charles Pfizer and Co., Inc. Groton, Connecticut, U.S.A.

\section{Group C-4}

Kuznetsov, V.D. USSR Research Inst. for Antibiotics, Moscow, U.S.S.R. Cross, T. and A. Maciver. Postgraduate School of Studies in Biological Sciences, Univ, of Bradford, 7, Yorkshire, England.

Srivastava, O.P. Antibiotics Div., Central Drug Res. Inst., Lucknow, (U. P.), India.

\section{$\underline{\text { Group C-5 }}$}

Szabó, I. Magyar Tudományos Akadémia, Talajtana És Agrokémiai, Kutató Intézete, Budapest, Hungary.

deVries, G.A. Centraalbureau voor Schimmelcultures, Baarn, Netherlands.

Dietz, Alma. Upjohn Co., Kalamazoo, Michigan, U.S.A.

\section{Group C-6}

Tsyganov, V.A. Res. Inst. of Antibiotics, Leningrad, L-20, U.S.S.R. Falcão de Morais, J.O. Inst. de Quimica da Univ. Fed. de Pernambuco, Recife, Pernambuco, Brazil.

Trejo, Wm. E. R. Squibb and Sons, New Brunswick, New Jersey, U.S.A.

\section{Group C-7}

Wallhaüsser, Karl H. Mikrobiolog. Unters, Farbwerke Hoechst AG, Frankfurt a/M - Höchst, Germany.

Higgens, Calvin E. and R. E. Kastner. Eli Lilly and Co., Indianapolis, Indiana, U.S.A.

Wóznicka, Wanda. Pánstwowy Higieny, Ul, Chocimska 24, Warszawa 12 , Poland.

\section{Group C-8}

Nakazawa, K., M. Shibata, K. Yamamoto, E. Higashide, T. Iwasa and T. Hasegawa. Takeda Chem. Ind., Ltd., Juso-Higashiyodogawaku, Osaka, Japan.

Trejo, Wm. E. R. Squibb and Sons, New Brunswick, New Jersey, U.S.A. Routien, John B, and Corinne Clevenger. Charles Pfizer and Co., Inc. Groton, Connecticut, U.S.A. 


\section{Group C-9}

Ohara, Y. and H. Nonomura. Faculty of Engineering, Yamanashi Univ., Kofu, Japan.

Mitchell, T.G.* Torry Research Station, Aberdeen, Scotland. (*Present address: British American Tobacco Co., Ltd., Regents Park Rd., Southampton, U.K.)

Prauser, H. Inst. Mikrobiol. Exptl. Therapie, Jena, Beuthenbergstr. 11, German Democratic Republic.

\section{Group D-2}

Baldacci, E., G. Farina and R. Locci. Ist. Patol. Vegetale, Univ. Milano, Via Celoria N. 2, Milano, Italy.

Johanides, Vera and T. Kos. Laboratorij za industrijsku mikrobiologiju, Tehnoloski fakultet, Pierottijeva 6, Zagreb, Jugoslavija.

Michaels, Eugene. Dept. Microbiol., Univ. Georgia, Athens, Ga., U.S.A.

\section{Group D-3}

Krasil'nikov, N.A. Inst. Microbiology. Academy of Sciences, Moscow, B-133, U.S.S.R.

Routien, John B. Charles Pfizer and Co., Inc. Groton, Connecticut, U. S. A. Sanchez-Marroquin, A. Miami 40, Mexico 18/D. F., Mexico.

\section{Group D-4}

Kuznetsov, V. D. USSR Research Inst, for Antibiotics, Moscow, U.S.S.R. Srivastava, O.P. Antibiotics Div., Central Drug Res. Inst., Lucknow, (U. P.) India.

Williams, S.T. Hartley Botan. Labor., Univ. of Liverpool, Liverpool, England

\section{Group D-5}

Dietz, Alma. Upjohn Co., Kalamazoo, Michigan, U.S.A.

deVries, G. A. Centraalbureau voor Schimmelcultures, Baarn, Netherlands.

Szabó, I. Magyar Tudományos Akadémia, Talajtana És Agrokémiai, Kutató Intézete, Budapest, Hungary.

\section{Group D-6}

Falcão de Morais, J.O. Inst. de Quimica da Univ. Fed. de Pernambuco, Recife, Pernambuco, Brazil.

Trejo, Wm. H. E. R. Squibb and Sons, New Brunswick, New Jersey, U.S.A.

Tsyganov, V.A. Res. Inst. of Antibiotics, Leningrad, L-20, U.S.S.R.

\section{Group D-7}

Gauze, G.F., T.P. Preobrazhenskaya, E.S. Kudrina, T.S. Maximova and M.A. Sveshnikova. Acad. Med. Sciences of U.S.S.R., Inst. New Antibiotics, Bolshaia Pirogovskaia 11, Moscow, U.S.S.R. 
Higgens, Calvin E. and R. E. Kastner. Eli Lilly and Co., Indianapolis, Indiana, U.S. A.

Woźnicka, Wanda. Pánstwowy Higieny, Ul. Chocimska 24, Warszawa 12 , Poland.

\section{Group D-8}

Cross, T. and A. Maciver. Postgraduate School of Studies in Biological Sciences, Univ. of Bradford, Bradford, 7, Yorkshire, England.

Mitchell, T.G.* Torry Research Station, Aberdeen, Scotland. (*Present address: British American Tobacco Co., Ltd., Regents Park Rd., Southampton, U. K.)

Nakazawa, K., M. Shibata, K. Yamamota, E. Higashide, T. Iwasa and T. Hasegawa. Takeda Chem. Ind. Ltd., Juso-Higashiyodogawaku, Osaka, Japan.

\section{Group D-9}

Margalith, P. Labor. of Microbiol., Dept. of Food and Biotechnology, Technion, Haifa, Israel.

Ohara, Y. and H. Nonomura. Faculty of Engineering, Yamanashi Univ., Kofu, Japan.

Prauser, H. Inst. Microbiol. Exptl. Therapie, Jena, Beuthenbergstr. 11, German Democratic Republic.

\section{Group D-10}

Mach, F. Inst. für Mikrobiologie, Greifswald, Ludwig-Jahn-Str. 15, German Democratic Republic.

Okami, Y. Nat'l Inst. of Health of Japan, Shinagawa, Tokyo, Japan.

Wallhaüsser, Karl H. Mikrobiolog. Unters, Farbwerke Hoechst AG, Frankfurt, a/M - Höchst, Germany.

\section{ACKNOW LEDGMENTS}

The Subcommittee on Actinomycetes of the Committee on Taxonomy, ASM, participated in the planning of the project, preparation of descriptions and editing of the manuscript. Members of the Subcommittee (other than the authors) during the period covered by this report were: T.G. Pridham, E. J. Backus, George Luedemann and S. Gaylen Bradley.

We are grateful to A. A. Ichida, Jann M. Ichida and Louise Hoffhines of the Ohio Wesleyan ISP staff for technical services, for assistance in locating authentic type cultures and descriptive literature and for help in collating data from cooperating laboratories.

C. W. Christensen of Difco Laboratories rendered valuable assistance in directing the formulation of dehydrated culture media according to ISP specifications. The technical and financial assistance of Difco Laboratories, Detroit, Michigan, in supplying these standardized media to collaborators throughout the world is gratefully acknowledged.

This research was supported by National Science Foundation Grant GB 4365. The Subcommittee on Actinomycetes of the Committee on Taxonomy, ASM, and the Subcommittee on Taxonomy of Actinomycetes of the International Committee on Nomenclature of Bacteria are cosponsoring advisors. 


\section{INTRODUCTION}

This is the fourth in a series of reports related to the comprehensive international effort to clarify taxonomy in the genera Streptomyces and Streptoverticillium through standardized collaborative study of the authentic type strain (or an acceptable neotype) for each of the named species. The cooperative study, known as the International Streptomyces Project (ISP) is sponsored by the Subcommittee on Actinomycetes of the Committee on Taxonomy, ASM and the corresponding subcommittee of the International Committee on Bacteriological Nomenclature. The rationale, scope, extensive background preparation and general plan for the project are explained in detail in the first paper of the series (Gottlieb and Shirling 1967); descriptive criteria and methods for ISP characterization of Streptomyces and Streptoverticillium species are given under the title, Methods for Characterization of Streptomyces Species (Shirling and Gottlieb 1966). Illustrated descriptions for 200 type strains or suggested neotypes are given in Parts II and III of the series (Shirling and Gottlieb $1968 \mathrm{a}, \mathrm{b}$ ).

This report (Part IV of the series) continues with the description of 100 additional type strains. It may be helpful to consult Part II (op. cit. pp. 73-79) for analysis of a typical entry and guidance in interpretation of the abbreviated descriptions.

For each species a lyophilized specimen of the type strain, identified only by ISP code number, was sent to three independent laboratories for study under the standardized conditions described in the Methods Manual (Shirling and Gottlieb 1966). Data submitted by the se collaborators were used for preparing the ISP description which becomes an emendation to previous descriptions. The collaborators who studied the species are to be regarded as the authors for the emendation. They are listed as cooperating groups at the beginning of this paper and identified by group number in each description. Earlier descriptions for each culture, including the description ascribed to the original author, are cited whenever possible to complete the characterization.

The 300 type strains included in Parts II, III and IV of this series are deposited as reference cultures in the American Type Culture Collection, the Centraalbureau voor Schimmelcultures, the U.S.S.R. Research Institute for Antibiotics and the Institute for Fermentation, Japan. Cooperative studies characterizing approximately 214 species are in progress and it is possible that 100 or more additional species may be obtainable for study. Descriptions for these species will be included in subsequent reports and the type strains will be deposited in the culture collections. as the descriptions are published. 
Streptomyces actuosus Pinnert, Ninet and Preud'homme. Description: Pinnert et al., U.S. Patent 3,155,581 Nov. 1964; French Patent 1,392,453 Aug. 1965, Type strain: NRRL 2954 (U.S. Pat. 3, 155,581) = Rhone-P\&ulenc 40.37. ISP 5337 from C. W. Hesseltine as NRRL 2954. ISP description by Group C-7.

Spore chain morphology: Section Rectiflexibiles. Mature spore chains moderately long with 10 to 50 spores per chain (Fig. 1). This morphology is seen on yeast-malt agar, oatmeal agar, salts-starch agar and glycerol-asparagine agar. Spore surface: Smooth (Fig. 2).

Color of colony: Aerial mass color in the Gray color-series on yeastmalt agar, oatmeal agar, salts-starch agar and glycerol-asparagine agar,

Buverse side of colony: No distinctive pirments (grayish yellow to yellowish brown or light brown) on yeast-malt agar, oatmeal agar, salts starch agar and glycerol-a sparagine agar.

Color in medium: Melanoid pigments are formed in peptone-yeastiron agar, tyrosine agar and tryptone-yeast broth. No pigment is found in medium in yeast-malt agar, oatmeal agar or salts-starch agar. One observer, only, found a trace of red pigment in the medium in glycerolasparagine agar. This pigment, when present, is $\mathrm{pH}$ sensitive changing from pink to colorless with addition of $0.05 \mathrm{~N} \mathrm{HCl}$.

Carbon utilization: D-Glucose, L-arabinose, sucrose, D-xylose, i-inositol, D-mannitol, $\underline{D}$-fructose, rhamnose and raffinose are utilized for growth.

Streptomyces albidoflavus (Rossi-Doria) Waksman and Henrici. Descriptions: Streptotrix albido-flava (sic) Rossi-Doria 1891, 407. Description by Waksman and Henrici 1948 , 949, is based upon a description of Actinomyces albidoflavus Rossi-Doria (sic) in Duché 1931, 294 300. Type strain: CBS 416.34, strain Duché is the strain upon which descriptions by Duché and Waksman are based. It is suggested here as a neotype for Streptotrix albido-flava (sic) Rossi-Doria. ISP 5455 from G.A. deVries as CBS 416.34 , strain Duché. ISP description by Group D-6.

Spore chain morphology: Section Rectiflexibiles. Two of three observers were unable to find sporulating aerial mycelium. Mature spore chains, when formed, are generally short with 3 to 10 spores per chain (Fig. 3). Sporulating aerial mycelium is sometimes found on yeastmalt agar and glycerol-asparagine agar, bat is not seen on oatmeal agar or salts-starch agar. Spore surface: Smooth (Fig. 4).

Special morphological characteristics: Substrate mycelium fragments, forming conidia-like or irregular spores. Unusually large spores may sometimes be formed by fragmentation of aerial hyphae (Fig. 4, 5). Two observers questioned placing this culture in the genus Streptomyces.

Color of colony: Aerial mass color in the White or Gray color-series on yeast-malt agar. Sporulating aerial mycelium is not produced on other ISP media.

Reverse side of colony: No distinctive pigments (light yellow to grayish yellow or orange yellow) on yeast-malt agar, oatmeal agar, salts starch agar and glycerol-asparagine agar.

Color in medium: Melanoid pigments are not formed in paptoneyeast-iron agar, tyrosine agar or tryptone-yeast broth. No pigment is found in the medium in yeast-malt agar, oatmeal agar, salts-starch agar or glycerol-asparagine agar. 


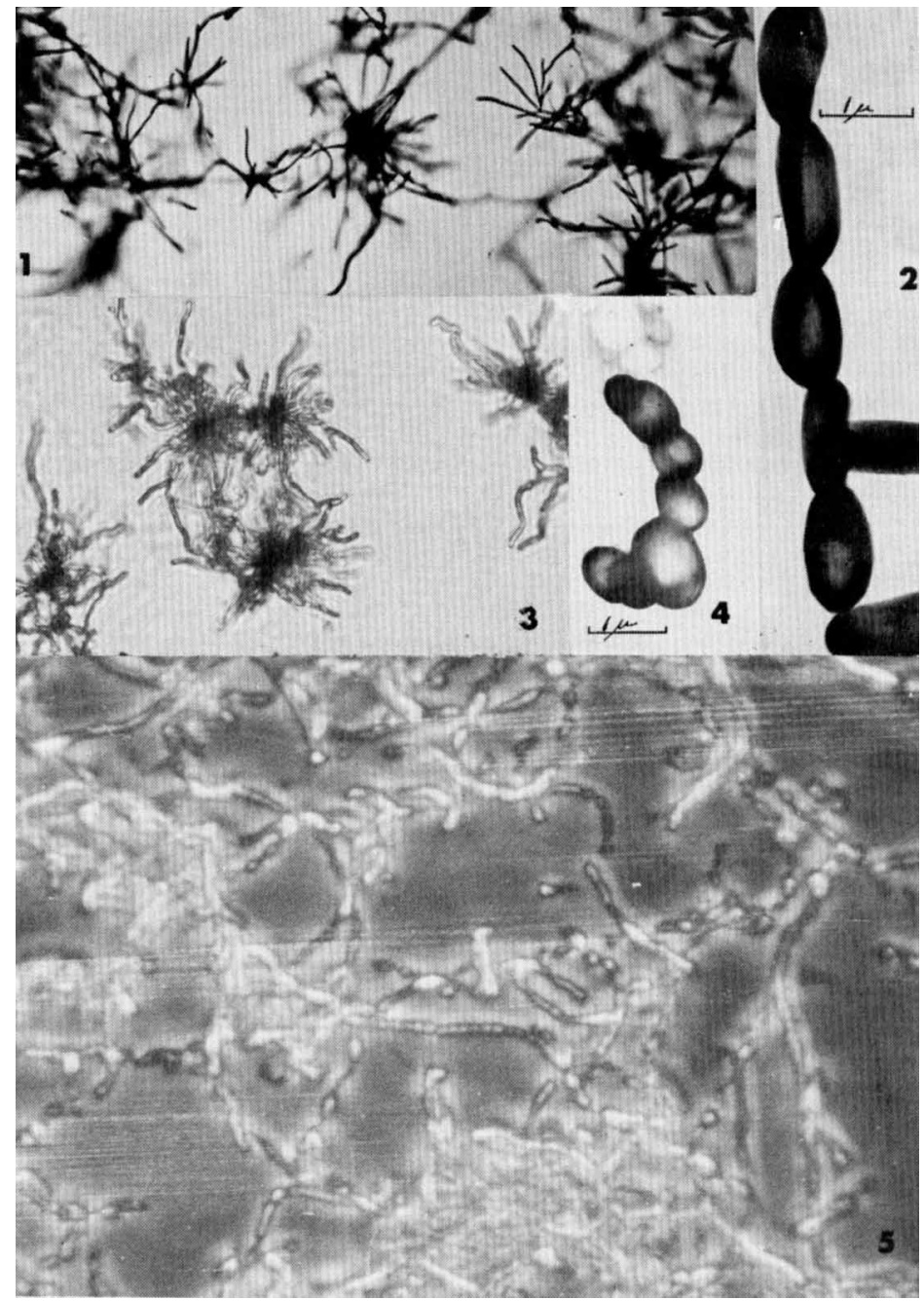

(Sources of illustrations are tabulated following the bibliog raphy.)

Figure 1. S. actuosus. RF spore chains (X 150) on yeast-malt agar, 7 days.

Figure 2. S. actuosus. Smooth spores; electron micrograph from 21 day culture on oatmeal agar.

Figure 3. S. albidoflavus. RF spore chains (X 480) on yeast-malt agar, 14 days.

Figure 4. S. albidoflavus. Smooth spores of irregular size; electron micrograph from 28 day culture on g lycerol-asparagine agar.

Figure 5. S. albidoflavus. Large, irregular spores formed by fragmentation of aerial mycelium; adhesive tape mount; 28 day culture on yeast-malt agar (X 1478). 
Carboo atilization: D-Glucose, L-arabinose, D-xylose, D-mannitol and D-fructose are utilized for growth. No growth or only trace of growth with sucrose, $\underline{i}$-inositol, rhamnose and raffinose.

Streptomyces albidus (Duché) Waksman. Description: Actinomyces a lbidus Duché 1934, $266-271$; Streptomyces a lbidus (Duché) Waksman 1953,84. Type strain: CBS 100.34 (G.A. deVries, CBS, personal

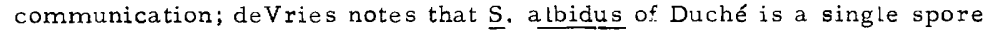
isolate from A. microflavus, strain Krainsky CBS. The original description of Duché 1934 states that the type strain was received from Baarn inder the label, microflavus, but differed in color of aerial myceLium and abundance of growth on potato). ISP 5320 from G.A. deVries (CBS) as CBS 100.34. ISP description by Group C-2.

Spore chain morphology: Section Rectiflexibiles (Fig. 6). Mature spore chains generally long with 10 to 50 or more than 50 spores per chain. This morphology is seen on yeast-malt agar, oatmeal agar, salts starch agar and glycerol-asparagine agar. Spore surface: Smooth (Fig. 7). Some surface irregularities may be present. (Fig. 8).

Color of colony: Aerial mass color in the Yellow color-series on yeast-malt agar, salts-starch agar and glycerol-asparagine agar; Yellow or White color-series on oatmeal agar.

Reverse side of colony: No distinctive pigments (light grayish yellow to light olive brown) on yeast-malt agar, oatmeal agar, salts-starch agar and glycerol-asparagine agar.

Color in medium: Melanoid pigments are not formed in peptoneyeast-iron agar, tyrosine agar or tryptone-yeast broth. A trace of yellow or greenish yellow pigment may be found in the medium in yeastmalt agar and oatmeal agar. This pigment is not $\mathrm{pH}$ sensitive when tested with $0.05 \mathrm{~N} \mathrm{NaOH}$ or $\mathrm{HCl}$.

Carbon utilization: D-Glucose, D-xylose, D-mannitol, D-fructose and rhamnose are utilized for growth. Reports vary on atilization of sucrose. Utilization of $\underline{L}$-arabinose is doubt ful. No growth or only trace of growth with $\underline{i}$-inositol and raffinose.

Actinomyces albohelvatus Krasil'nikov, Korenyako and Nikitina. Description: Krasil'nikov, Korenyako and Nikitina in Krasil'nikov 1965 , 228-229. Type strain: INMI 1349 (ibid.). ISP 5410 from N.A. Krasil' nikov as INMI 1349. ISP description by Group D-6.

Spore chain morphology: Section Spirales or Retinaculiaperti. Regular spirals are rare (Fig. 9). Long flexuous spore chains which may or may not terminate in spirals or hooks are most common (Fig. 10). Mature spore chains generally long with 10 to 50 or often more than 50 spores per chain. This morphology is seen on yeast-malt agar, oatmeal agar, salts-starch agar and glycerol-asparagine agar. Spore surface: Smooth (Fig. LL).

Color of colony: Aerial mass color in the Yellow to White colorseries on yeast-malt agar, oatmeal agar, salts-starch agar and glycerolasparagine agar.

Reverse side of colony: No distinctive pigments (colorless to pale yellow) on yeast-malt agar, oatmeal agar, salts-starch agar and glycerol-asparagine agar.

Color in medium: Melanoid pigments are not formed in peptone-yeast iron agar, tryosine agar or tryptone-yeast broth. No pigment is found in 


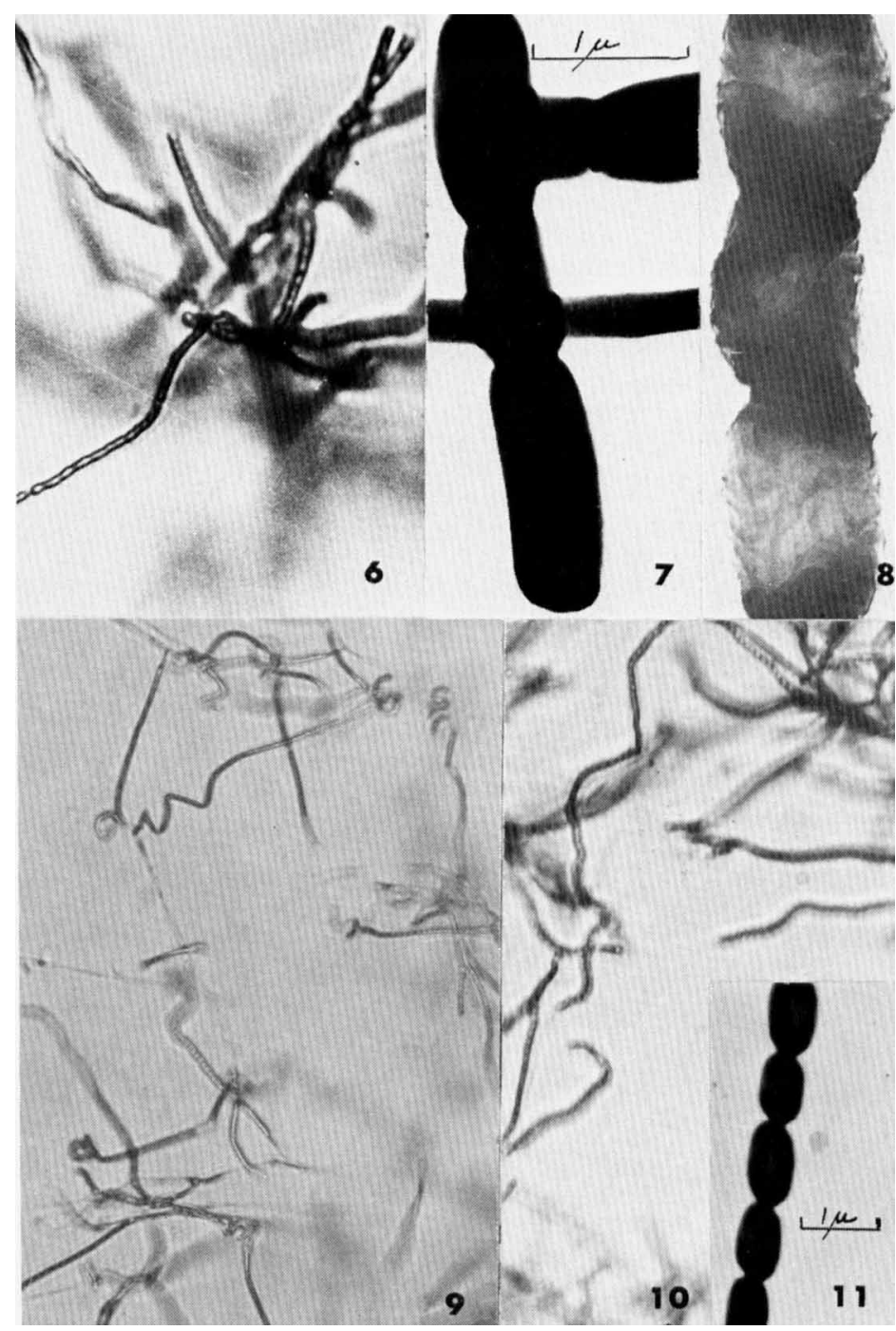

Figure 6. S. albidus. RF spore chains (X 780) on oatmeal agar, 21 days.

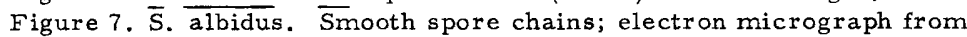
14 day culture on glycerol-asparagine agar.

Figure 8. S. albidus. Surface irregularities on "smooth" spores. Electron micrograph from 19 day culture on yeast-malt agar.

Figure 9. A. albohelvatus. Spiral to RA spore chains (X 480) on oatmeal agar, 14 days.

Figure 10. A. albohelvatus. Flexuous to RA spore chains (X 600) on yeast-malt agar, 21 days.

Figure 11. A. albohelvatus. Smooth spore chains; electron micrograph from 20 day culture on salts-starch agar. 
the medium in yeast-malt agar, oatmeal agar, salts-starch agar or glycerol-asparagine agar.

Carbon utilization: D-Glucose and L-arabinose are utilized for growth. Utilization of sucrose, D-xylose, i-inositol and D-fructose is doubtful. No growth or onty trace of growth with D-mannitol, rhamnose and raffinose.

Streptomyces alboviridis (Duché) Pridhem, Hesseltine and Benedict. Descriptions: Actinomyces alboviridis Duché 1934, 317-323. Streptomyces alboviridis Pridham et al. 1958, 74. Type Strain: LCP 68 (neotype, Madame J. Nicot, personal communication, 1966; Hutter 1967, 71). ISP 5326 from Madame J. Nicot as LCP 68. ISP description by Group $\mathrm{C}-6$.

Spore chain morphology: Section Rectiflexibiles (Fig. 12). Mature spore chains generally long with 10 to 50 or more spores per chain on yeast-malt agar, oatmeal agar, salts-starch agar and glycerol-a sparagine agar. Spore surface: Smooth (Fig. 13).

Color of colony: Aerial mass color in the Yellow color-series on yeast-malt agar and salts-starch agar; Yellow or White color-series on oatmeal agar and glycerol-asparagine agar.

Reverse side of colony: No distinctive pigments (pale yellow or grayish yellow) on yeast-malt agar, oatmeal agar, salts-starch agar and glycerol-asparagine agar.

Color in medium: Melanoid pigments are not formed in peptoneyeast-iron agar, tyrosine agar or tryptone-yeast broth. No pigment is found in the medium in yeast-malt agar, oatmeal agar, salts-starch agar or glycerol-a sparagine agar.

Carbon utilization: D-Glucose, D-xylose, D-mannitol, D-fructose and rhamnose are utilized for growth. Reports vary on utilization of $\underline{L}$-arabinose. No growth or only trace of growth with sucrose, i-inositol and raffinose.

Streptomyces albus (Rossi-Doria) Waksman and Henrici. Descriptions: For review and critical evaluation of early descriptions of Streptothrix foeresterii Cohn and Streptotrix (sic) a lba Rossi-Doria 1891, Actinomyces albus Krainsky 1914, A. albus (Krainsky) Waksman and Curtis 1916, Waksman 1919, Jensen 1931, Duché 1934, Baldacci 1939, Krasil'nikov 1941, 1949, see: Pridham 1961, 431 -441; Baldacci, Locci and Farina 1965, 1-11. Streptomyces albus (Rossi-Doria) Waksman and Henrici 1943, 337-341; Pridham and Lyons 1961, $431-441$; Lyon and Pridham.1962, 370-380. Type strain: ATCC 3004 (= IMRU 3004) neotype strain for Streptomyces albus (Rossi-Doria) Waksman and Henrici 1943 (Judicial Commission of the International Committee on Bacteriological Nomenclature 1963,123-124); type species of genus Streptomyces Waksman and Henrici 1943, 339. ISP 5313 from C. W. Hesseltine, NRRL as "culture which Dr. Pridham designated as neotype" NRRL B-1811 = IMRU $3004=$ ATCC 3004. ISP description by Group C -4 .

Spore chain morphology: Section Spirales. Spirals are most abundant on oatmeal agar (Fig. 14) and may be poorly developed on yeastmalt agar, salts-starch agar and glycerol-asparagine agar. Mature spore chains generally 10 to 50 spores per chain, but shorter chains may be common on some media. Spore surface: Smooth (Fig. 15). 


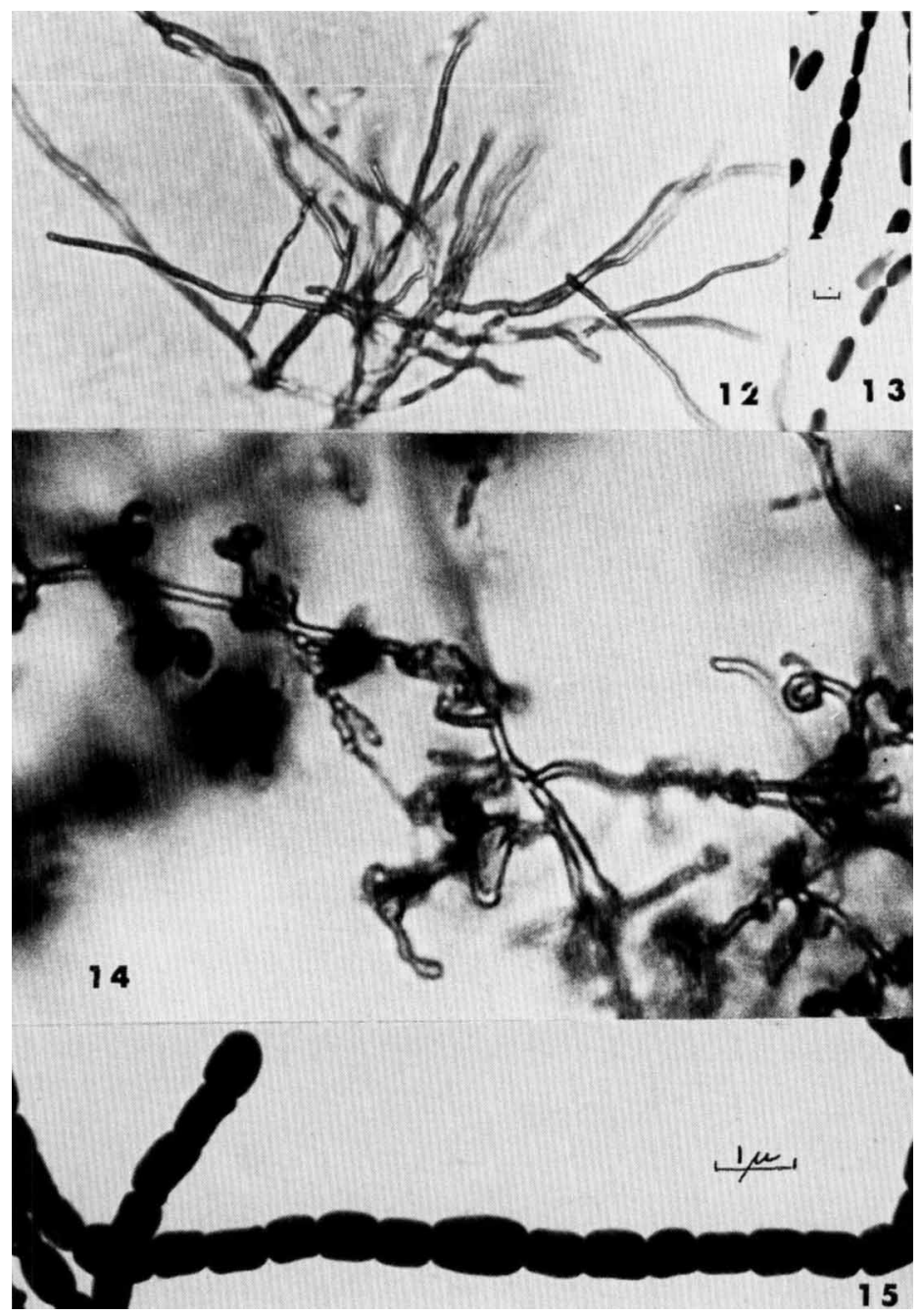

Figure 12. S. alboviridis. RF spore chains (X 600) on glycerol-asparagine agar, 20 days.

Figure 13. S. alboviridis. Smooth spores; electron micrograph from 20 day culture on glycerol-asparagine agar.

Figure 14. S. albus. Spiral spore chains (X 1000) on oatmeal agar, 14 days.

Figure 15. S. albus. Smooth spores; electron micrograph from 14 day culture on yeast-malt agar. 
Color of colony: Aerial mass color in the White color-series on oatmealagar and salts-starch agar; White or Yellow color-series on yeast malt agar and glycerol-a sparagine agar.

Reverse side of colony: No distinctive pigments (colorless to pale yellow) on yeast-malt agar, oatmeal agar, salts-starch agar and glycerol-a sparagine agar.

Color in medium: Melanoid pigments are not formed in peptone yeast-iron agar, tyrosine agar or tryptone-yeast broth. No pigment is found in the medium in yeast-malt agar, oatmeal agar, salts-starch agar or glycerol-asparagine agar.

Carbon utilization: D-Glucose, D-xylose, D-mannitol and Dfructose are utilized for growth. Reports vary on utilization of $\underline{\text { L- }}$ arabinose and raffinose. No growth or only trace of growth with i-inositol, rhamnose and sucrose.

Streptomyces almquisti (Duché) Pridham, Hesseltine and Benedict. Descriptions: Actinomyces almquisti Duché 1934, 278-283; Streptomyces almquisti (Duché) Pridham et al. 1958, 74. Type strain: ATCC618 (Hutter 1934, 68 and 70). Synonomy: A TCC 618 is a strain of S. albus (Rossi-Doria) Waksman and Henrici according to Pridham and Lyons 1961, 431-441; Lyons and Pridham 1961 6-10 and 1962, 370-380.; also Hutter 1961,367-383 and 1967, 68-70; and Baldacci et al. 1965, 1-11. The strain designated A. almquisti was obtained by Duché from CBS as $\underline{A}$. albus Krainsky (Waksman et Curtis). Hutter (1968, p. 68-70) gives evidence that ATCC 618 is a descendant of this same CBS strain. ISP 5447 from E.F. Lessel, ATCC as Streptomyces 3 lbus A TCC 618. ISP description by Group D-4.

Spore chain morphology: Section Spirales; many straight to flexuous aerial hyphae or immature spore chains may also be present. Mature spore chains generally have 10 to 50 or more spores per chain. This morphology is seen on yeast-malt agar, oatmeal agar, salts-starch agar and glycerol-asparagine agar. Spore surface: Smooth.

Color of colony: Aerial mass color is in the White color series on yeast-malt agar, oatmeal agar, salts-starch agar and giycerol-asparagine agar.

Reverse side of colony: No distinctive pigments (colorless to pale grayish yellow) on yeast-malt agar, oatmeal agar, salts-starch agar and glycerol-asparagine agar.

Color in medium: Melanoid pigments are not formed in peptoneyeast-iron agar, tyrosine agar or tryptone-yeast broth. No pigment is found in the medium in yeast-malt agar, oatmeal agar, salts-starch agar or glycerol-asparagine agar.

Carbon utilization: D-Glucose, D-xylose, D-mannitol and $\underline{D}$-fructose are utilized for growth. Reports vary on utilization of L-arabinose and i-inositol. No growth or only trace of growth with rhamnose, sucrose or raffinose.

Streptomyces arenae Pridham, Hesseltine and Benedict. Descriptions: Abbott Laboratories, British Pat. Specification 719, 230,Dec. 1, 1954; Pridham et al. 1958, 67. Type strain: Abbott Lab. NA 269-M2 = NRRL 2377 (T. J. Oliver, Abbott Laboratories, personal communication, Jan. 1965; British Pat. 719, 230). ISP 5293 from T.J. Oliver, Abbott Laboratories as NA 269-M2 = NRRL 2377. ISP description by Group C -1 . 
Spore chain. morphology: Section Spirales (Fig. 16 and 17). Mature spore chains moderately long with 10 to 50 or more spores per chain. This morphology is seen on yeast-malt agar, salts-starch agar, glycerol-asparagine agar. Spore surface: Spiny (Fig. 17).

Color of colony: Aerial mass color in the Red or Gray color-series on yeast-malt agar, oatmeal agar, salts-starch agar and glycerolasparagine agar. Observers selected color tabs 5 fe (light grayish reddish brown) from the Gray color wheel and $5 \mathrm{cb}$ or $5 \mathrm{dc}$ (grayish yellowish pink) from the Red color-series. One observer selected tab llec from the Violet color-series as nearest matching color for sporulating aerial growth on salts-starch agar, oatmeal agar and glycerol-asparagine agar.

Reverse side of colony: No distinctive pigments (pale yellow to yellowish brown) on yeast-malt agar, oatmeal agar, salts-starch agar and glycerol-asparagine agar.

Color in medium: Melanoid pigments are formed in peptone-yeastiron agar, tyrosine agar and tryptone-yeast broth. Yellow pigment may be found in yeast-malt agar, oatmeal agar and salts-starch agar. This pigment is not $\mathrm{pH}$ sensitive when tested with $0.05 \mathrm{~N} \mathrm{NaOH}$ or $\mathrm{HCl}$.

Carbon utilization: D-Glucose, L-arabinose, D-xylose, i-inositol D-mannitol, D-fructose, rhamnose, sucrose and raffinose are utilized for growth.

Streptomyces aurantiacus (Gasperini emend. Krasil'nikov) Waksman. See Actinomyces aurantiacus (Rossi-Doria) Krasil'nikov.

Actinomyces aurantiacus (Rossi-Doria) Krasil'nikov. Descriptions and nomenclature: Streptotrix (sic) aurantiaca Rossi-Doria 1891, 417 419; actinomyces (sic) aurantiacus (Rossi-Doria) Gasperini 1292, 222; Actinomyces aurantiacus (Rossi-Doria) Gasperini synonym of $\underline{A}$. asteriodes (Eppinger) Gasperini 1894, 84 and 86; Actinomyces aurantiacus (Rossi-Doria) Krasil'nikov 1941, 36-37 (emend. Krasil'nikor 1965, 33); Streptomyces aurantiacus (Gasperini emend. Krasil'nikov) Waksman 1953, 53. Type strain: INMI 1373 (neotype, Krasil'nikov, personal communication, Dec., 1966; Krasil'nikov 1965, 33). ISP 5412 from N.A. Krasil'nikov as INMI 1373. ISP description by Group D-6.

Spore chain morphology: Section Spirales. Short spore chains of 3 to I0 or more spores per chain form irregular hooks and loops of small diameter and imperfect spirals of one to three turns (Fig. 18). Sporulating aerial mycelium is often absent or poorly developed on yeast-malt agar, oatmeal agar, salts-starch agar and glycerol-asparagine agar. Spore surface: Smooth (Fig. 19).

Special morphological characteristics: Fragmenting substrate mycelium may be seen after 12 to 14 days on yeast-malt agar, oatmeal agar, salts-starch agar and glucose agar. One observer also notes irregular terminal swellings on some substrate hyphae as well as the presence of subglobose to clavate bodies 5-8u in diameter.

Color of colony: Aerial mycelium is generally poorly developed or absent on ISP media. When adequate sporulating aerial mycelium is produced, it is in the Red color-series ( $5 \mathrm{cb}$ or $6 \mathrm{ec}$, grayish yellowish pink) on yeast-malt agar, oatmeal agar or salts-starch agar.

Reverse side of colony: Yellow to yellow brown is modified by red to reddish brown on yeast-malt agar and salts-starch agar and to 


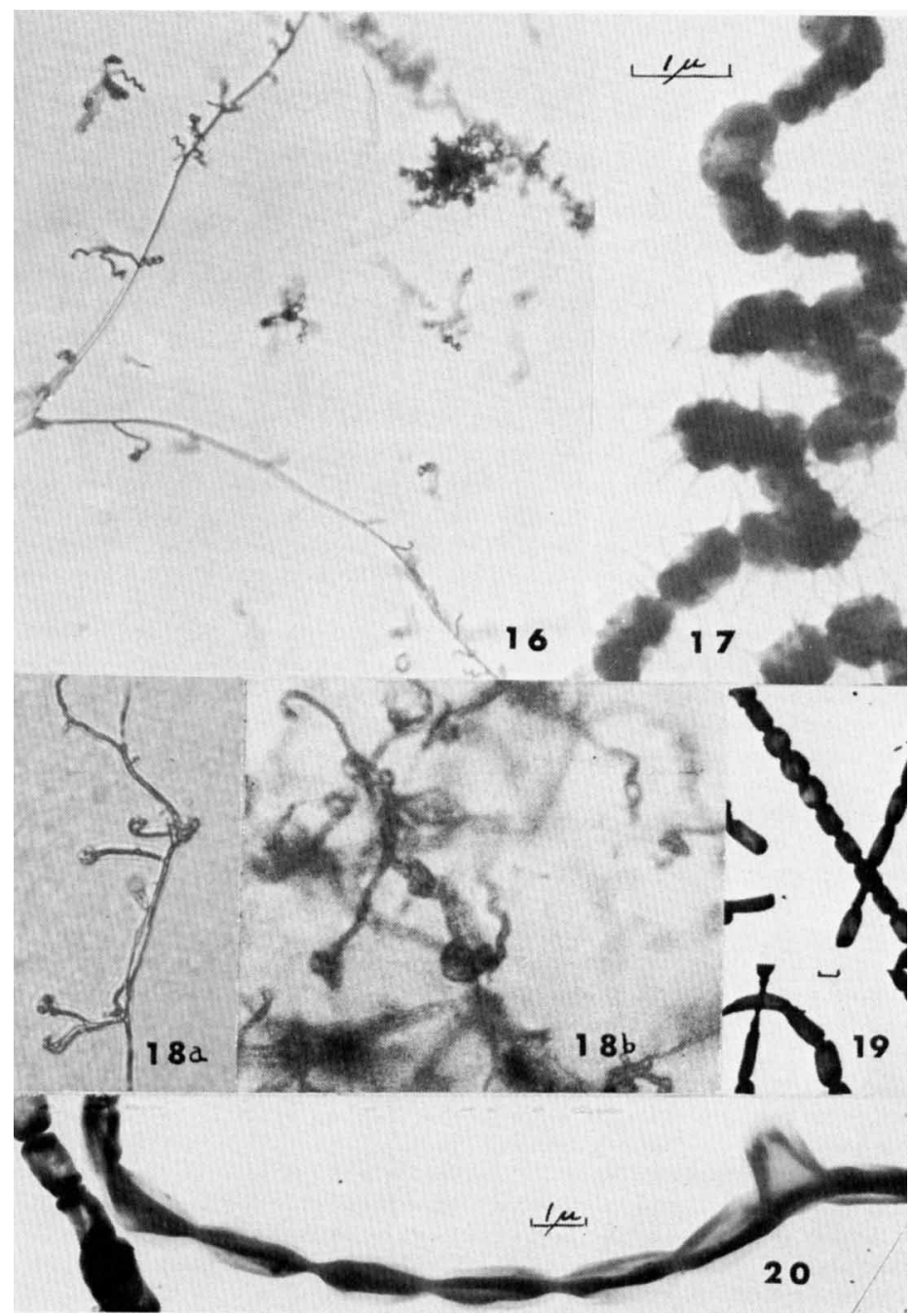

Figure 16. S. arenae. Spiral spore chains (X 200) on salts-starch agar, 14 days.

Figure 17. S. arenae. Spiny spores in spiral chains; electron micrograph from 21 day culture on yeast-malt agar.

Figure 18. A. aurantiacus. Imperfect spirals, hooks and loops; (a) On oatmeal agar, 14 days (X 480). (b) On oatmeal agar, 14 days (X 660).

Figure 19. A. aurantiacus. Smooth spores; electron micrograph from 20 day culture on oatmeal agar.

Figure 20. A. aureocirculatus. Smooth spores; electron micrograph from 12 day culture on Czapek's sucrose agar. 
grayish yellowish pink or reddish orange on oatmeal agar and glycerolasparagine agar. The substrate pigment is not a $\mathrm{pH}$ indicator.

Color in medium: Melanoid pigments are not formed in peptoneyeast-iron agar, tyrosine agar or tryptone-yeast broth. No pigment is found in the medium in yeast-malt agar, oatmeal agar, salts - starch agar or glycerol-aspargine agar.

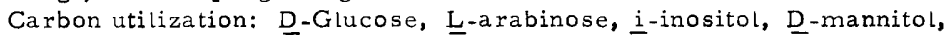
D-fructose and rhamnose are utilized for growth. Two of three observers also record utilization of D-xylose, sucrose and raffinose.

Actinomyces aureocirculatus Krasil'nikov and Yuan. Descriptions: Yuan, Chi-shen, 1961. Dissertation for rank of Candidate of Biological Sciences, Institute of Mikrobiology, Akademy of Sciences, U.S.S.R., summarized (1962) with name, but no description in Mikrobiologiya 31: 188. Validly published in Krasil'nikov and Yuan in Krasil'nikov 1965, 48-49. Type strain: RIA 682 = INMI 735 (V.D. Kuznetsov, RIA, personal communication, July, 1966). ISP 5386 from V.D. Kuznetsov as RIA 682. ISP description by Group D-5.

Spore chain morphology: Section Rectiflexibiles with some irregular hooks and loops or imperfect spirals. Mature spore chains when present, generally long, sometimes with more than 50 spores per chain. Aerial mycelium is poorly developed on all ISP media. Mature spore chains may be found on yeast-malt agar, oatmeal agar and salts-starch agar. One observer records fragmentation of substrate mycelium on glycerol-asparagine agar at 21 days. Another observer notes presence of globular bodies and sclerotia on yeast-malt agar, oatmeal agar and salts-starch agar and conidia-like spores on the substrate mycelium on salts-starch agar at 7 days. Spore surface: Smooth (Fig. 20).

Color of colony: Sporulating aerial mycelium is inadequate for determination of aerial mass color on yeast-malt agar, oatmeal agar, salts-starch agar and glycerol-asparagine agar. The scant aerial mycelium that develops on yeast-malt agar, oatmeal agar and salts starch agar is in the White color-series.

Reverse side of colony: No distinctive pigments (pale yellow to light grayish yellow) on yeast-malt agar, oatmeal agar, salts-starch agar and glycerol-asparagine agar.

Color in medium: Melanoid pigments are not formed in peptone yeast-iron agar, tyrosine agar or tryptone-yeast broth. Yellow pigment is found in the medium in yeast-malt agar, oatmeal agar and salts starch agar. This pigment is not $\mathrm{pH}$ sensitive when tested with 0,05 $\mathrm{N} \mathrm{NaOH}$ or $\mathrm{HCl}$.

Carbon utilization: D-Glucose, D-xylose, $\underline{\text { i-inositol, D-mannitol }}$ and D-fructose are utilized for growth. Reports vary on utilization of L-a rabinose, rhamnose, sucrose and raffinose. (Only one of three observers records utilization of rhamnose and raffinose).

Actinomyces aureofasciculus Krasil'nikov and Yuan. Description: Krasil'nikov and Yuan in Krasil'nikov 1965, 54-56. Type strain: INMI 738 (N.A. Krasil'nikov, personal communication, Dec., 1966). ISP 5414 from N.A. Krasil'nikov as INMI 738. ISP description by Group $\mathrm{D}-7$.

Spore chain morphology: Probably Section Rectiflexibiles, but sporulating aerial mycelium is very thin or almost absent on yeast-malt 
agar, oatmeal agar, salts-starch agar and glycerol-asparagine agar. Spore surface: Smooth spores can sometimes be found on electronmicrographs (Fig. 21).

Color of colony: Aerial mass color could not be determined because of absence of mature sporulating aerial mycelium. A white aerial mycelium with few spores may be found on yeast-malt agar, oatmeal agar and sa!ts-starch agar.

Reverse side of colony: Yellow to yellow brown is modified by red in some areas, producing distinctive reddish orange, grayish red, or reddish brown reverse color on yeast-malt agar, oatmeal agar, salts-starch agar and glycerol-asparagine agar. Substrate pigment is not a $\mathrm{pH}$ indicator.

Color in medium: Melanoid pigments are formed in peptone-yeastiron aga $x$ and tryptone-yeast broth, but not in tyrosine agar. No pigment is found in the medium in yeast-malt agar, oatmeal agar, salts starch agar or glycerol-asparagine agar.

Carbon utilization: D-Glucose, L-arabinose, D-xylose, i-inositol, D-mannitol, D-fructose, rhamnose and raffinose are utilized for growth. Utilization of sucrose is doubtful.

Actinomyces aureomonopodiales Krasil'nikov and Yuan. Description: Krasil'nikov, N.A. and Yuan Chi-Shen in Krasil'nikov 1965, 43 46. Type strain: INMI 1510 (selected by N. A. Krasil'nikov, personal communication, Dec. 1966). ISP 5416 from N.A. Krasil'nikov as INMI 1510. ISP description by Group D-7.

Spore chain morphology: Section Rectiflexibiles. Mature spore chains generally short with 3 to 10 , or sometimes more than 10 , spores per chain. Sporulating aerial mycelium is seen on oatmeal agar and salts-starch agar. Aerial mycelium may be absent or sterile on yeastmalt agar; sterile aerial mycelium is usually present on glycerolasparagine agar. One observer records fragmentation of the substrate mycelium in 20 days (Fig. 22; Gause medium No. 1 was used for this observation). Spore surface: Smooth (Fig. 23).

Color of colony: Aerial mass color in the White cqlor-series on oatmeal agar; White or Yellow color-series on salts-starch agar. Sterile aerial mycelium on glycerol-asparagine agax is in the Yellow color-series ( $11 / 2 \mathrm{db}$, pale greenish yellow or $1 \mathrm{ba}$, pale yellow).

Reverse side of colony: No distinctive pigments (grayish yellow to yellowish brown or olive brown on yeast-malt agar, oatmeal agar and glycerol-asparagine agar; one observer records both orange yellow and moderate reddish orange color on the reverse side of the colony on salts-starch agar.

Color in medium: Melanoid pigments are formed in peptone-yeast iron agar and tryptone-yeast broth, but may or may not be present in tyrosine agar. No pigment is found in the medium in yeast-malt agar, oatmeal agar and salts-starch agar; yellow pigment may be found in the medium in glycerol-asparagine agar.

Carbon utilization: D-Glucose, L-arabinose, D-xylose, 1 -inositol, D-mannitol, D-fructose and raffinose are utilized for growth. No growth or only trace of growth with sucrose or rhamnose.

Actinomyces aureoversales. Yuan. Description: Yuan, Chi-shen 1961. Dissertation for rank of Candidate of Biol. Sci., Inst. Microbiol, Acad. of Sci., U.S.S.R. Summarized (1962) with name but no description 


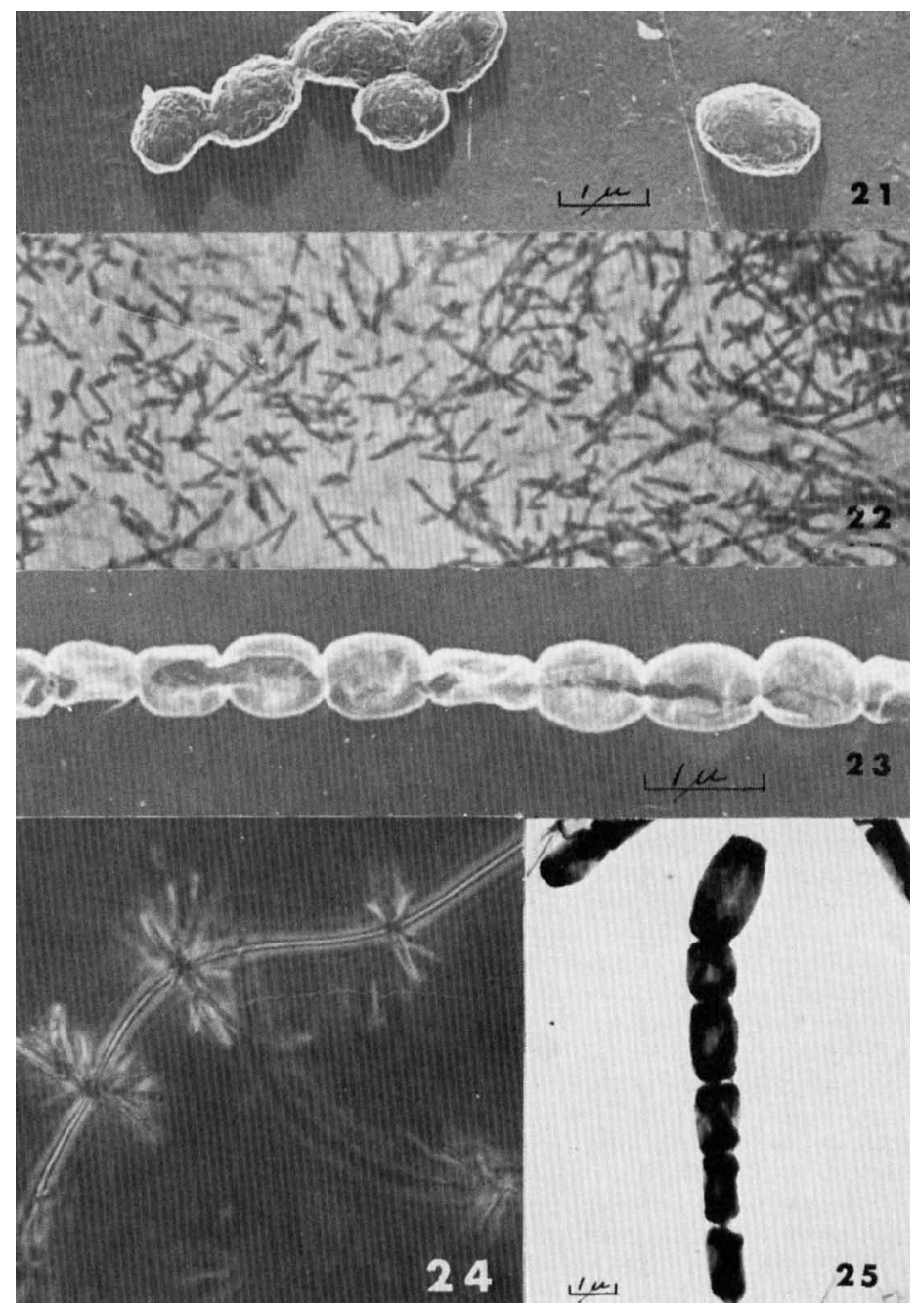

Figure 21. A. aureofasciculus. Smooth spores; electron micrograph from 14 day culture on yeast-malt agar.

Figure 22. A. aureomonopodiales. Fragmentation of substrate mycelium in 20 days on Gauze medium No. 1 (X 640).

Figure 23. A. aureomonopodiales. Smooth spores; electron micrograph from 14 day culture on oatmeal agar.

Figure 24. A. aureoversales. Umbellate monoverticillate sporophores (X 500) on Czapek's sucrose agar, 7 days.

Figure 25. A. aureoversales. Smooth spores; electron micrograph from 12 day culture on Czapek's sucrose agar. 
in Mikrobiologiya 31:188. Type strain: RIA 681 (V.D. Kuznetsov, personal communication, July 1966). ISP 5387 from V. D. Kuznetsov as RIA 681. ISP Description by Group D-5.

Spore chain morphology: Section Verticillati; mature sporophores are predominantly umbellate monoverticillate (biverticillate) (Fig. 24). Mature spore chains generally short with 3 to 10 or more spores per chain. This morphology is seen on yeast-malt agar, oatmeal agar, salts-starch agar and glycerol-asparagine agar. Spore surface: Smooth (Fig. 25).

Color of colony: Aerial mass color in the Red color-series on yeast-malt agar, oatmeal agar and salts-starch agar; Red or Yellow color-series on glycerol-asparagine agar.

Reverse side of colony: Yellow to yellow brown is modified by red to reddish orange or reddish brown on yeast-malt agar, oatmeal agar, salts-starch agar and glycerol-asparagine agar. Only one of three observers records a change in substrate color after addition of 0.05 $\mathrm{N} \mathrm{NaOH}$ or $\mathrm{HCl}$. According to this observer the color shifts from reddish brown to orange or yellowish brown with addition of $\mathrm{NaOH}$ and from reddish brown to pinkish red or violet with addition of $\mathrm{HCl}$.

Color in medium: Melanoid pigments are formed in peptone-yeast iron agar and tryptone-yeast broth, but only a trace of melanin is seen in tyrosine agar. Yellow pigment is found in the medium in oatmeal agar, salts-starch agar and glycerol-asparagine agar. Only a trace of yellow is seen in salts-starch agar. Yellow or red pigment is found in yeast-malt agar. According to one observer this pigment is $\mathrm{pH}$ sensitive, changing from yellow to pale reddish brown with addition of 0.05 $\mathrm{N} \mathrm{NaOH}$.

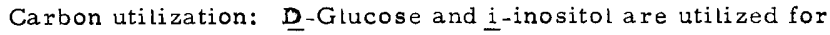
growth. No growth or only trace of growth with $\underline{L}$-arabinose, D-xylose, D-mannitol, D-fructose, rhamnose, sucrose or raffinose (a trace of growth on D-xylose and D-fructose.is somewhat greater than on a carbon-free control).

Actinomyces aurigineus Krasil'nikov, Korenyako and Nikitina. Description: Kra sil'nikov, Korenyako and Nikitina in Krasil'nikov 1965, 205-229. Type strain: INMI 2375 (ibid.; N.A. Krasil'nikov, personal communication, Dec., 1966). ISP 5417 from N.A. Krasil'nikov as INMI 2375. ISP description by Group D-7.

Spore chain morphology: Section Spirales (Fig. 26): Mature spore chains generally 10 to 50 , or sometimes more than 50 spores per chain. This morphology is seen on oatmeal agar, salts-starch agar and glycerolasparagine agar, but sporulation may be poor or absent on yeast-malt agar. Spore surface: Smooth (Fig. 27).

Color of colony: Aerial mass color in the Yellow color-series on oatmeal agar, salts-starch agar and glycerol-asparagine agar; aerial mycelium may be poorly developed on yeast-malt agar.

Reverse side of colony: Colorless to pale yellow or grayish yellow on yeast-malt agar, oatmeal agar, salts-starch agar and glycerolasparagine agar; or yellow may be modified to orange or grayish reddish orange on yeast-malt agar, salts-starch agar or glycerol-asparagine agar. One observer, only, notes a change from yellow to orange or pinkish yellow by addition of $0.05 \mathrm{~N} \mathrm{HCl}$.

Color in medium: Melanoid pigments are not formed in peptone- 
yeast-iron agar, tyrosine agar or tryptone-yeast broth. Yellow pigment is found in the medium in oatmeal agar, salts-starch agar and glycerolasparagine agar. This pigment is $\mathrm{pH}$ sensitive, changing from yellow to orange or pinkish yellow with addition of $0.05 \mathrm{~N} \mathrm{HCl}$.

Carbon utilization: D-Glucose, L-arabinose and D-fructose are utilized for growth. Utilization of $\underline{D}-x y l o s e$ and rhamnose is doubtful

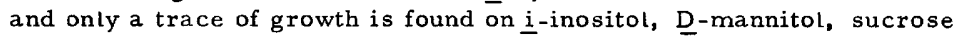
or raffinose.

Streptomyces bottropensis Waksman. Descriptions: Koninklijke Nederlandsche Gist-en Spiritusfabriek N.V., British Pat. Specification 762, 736, Dec. 5, 1956; Waksman 1961, 182-183. Type strain: B - 35 (J.C. Hoogerheide, Koninklijke Nederlandsche Gist-en Spiritusfabriek N.V., personal communication, Aug, 1964). ISP 5262 from J.C. Hoogerheide as B - 35. ISP description by Group B - 7.

Spore chain morphology: Section Spirales. Hooks, primitive spirals and terminal spirals of only one or two turns are common, together with open spirals of several turns (Fig. 28, 29). Mature spore chains generally 10 to 50 spores per chain. This morphology is seen on yeast-malt agar, oatmeal agar, salts-starch agar and glycerol-asparagine agar, but spirals are best developed on salts-starch agar (Fig. 29). Spore surface: Smooth (Fig. 30).

Color of colony: Aerial mass color in the Gray color-series on yeast-malt agar, oatmeal agar, salts-starch agar and glycerol-a sparagine agar.

Reverse side of colony: Yellow to strong brown, reddish brown or sometimes very dark brown.

Color in medium: Melanoid pigments are formed in peptone-yeastiron agar, tyrosine agar and tryptone-yeast broth. Brown pigment is found in the medium in yeast-malt agar and glycerol-asparagine agar; this pigment is not $\mathrm{pH}$ sensitive.

Carbon utilization: D-Glucose, L-arabinose, D-xylose, i-inositol, D-mannitol, D-fructose, rhamnose, sucrose and raffinose a re utilized for growth, but growth on raffinose is less abundant than on other carbon sources.

Streptomyces capuensis Baldacci, Farina, Locci and Ragni. Description: Baldacci et al. 1965, 45-62. Note: The type strain upon which the original species characterization is based was obtained "after a series of mutagenic and selective treatments from a strain previously isolated, together with others from a soil of S. America" (Baldacci et al., op cit., p. 60). Type strain: N.1703 (= C11-765) (ibid.) = IPV I 703 (Baldacci, personal communication, Nov. 1966). ISP 5402 from E. Baldacci as IPV 1703. ISP description by Group D-9.

Spore chain morphology: Section Spirales (Fig. 31). Mature spore chains generally long with 10 to 50 or more spores per chain. Aerial mycelium is poorly developed or absent on yeast-malt agar, oatmeal agar and glycerol-asparagine agar. Spore chain morphology can be observed on salts-starch agar or on the carbon utilization media. Spore surface: Smooth (Fig. 32).

Color of colony: Aerial mass color probably in the Gray colorseries on salts-starch agar; production of aerial mycelium is generally inadequate for observation of mass color on all ISP media. This 


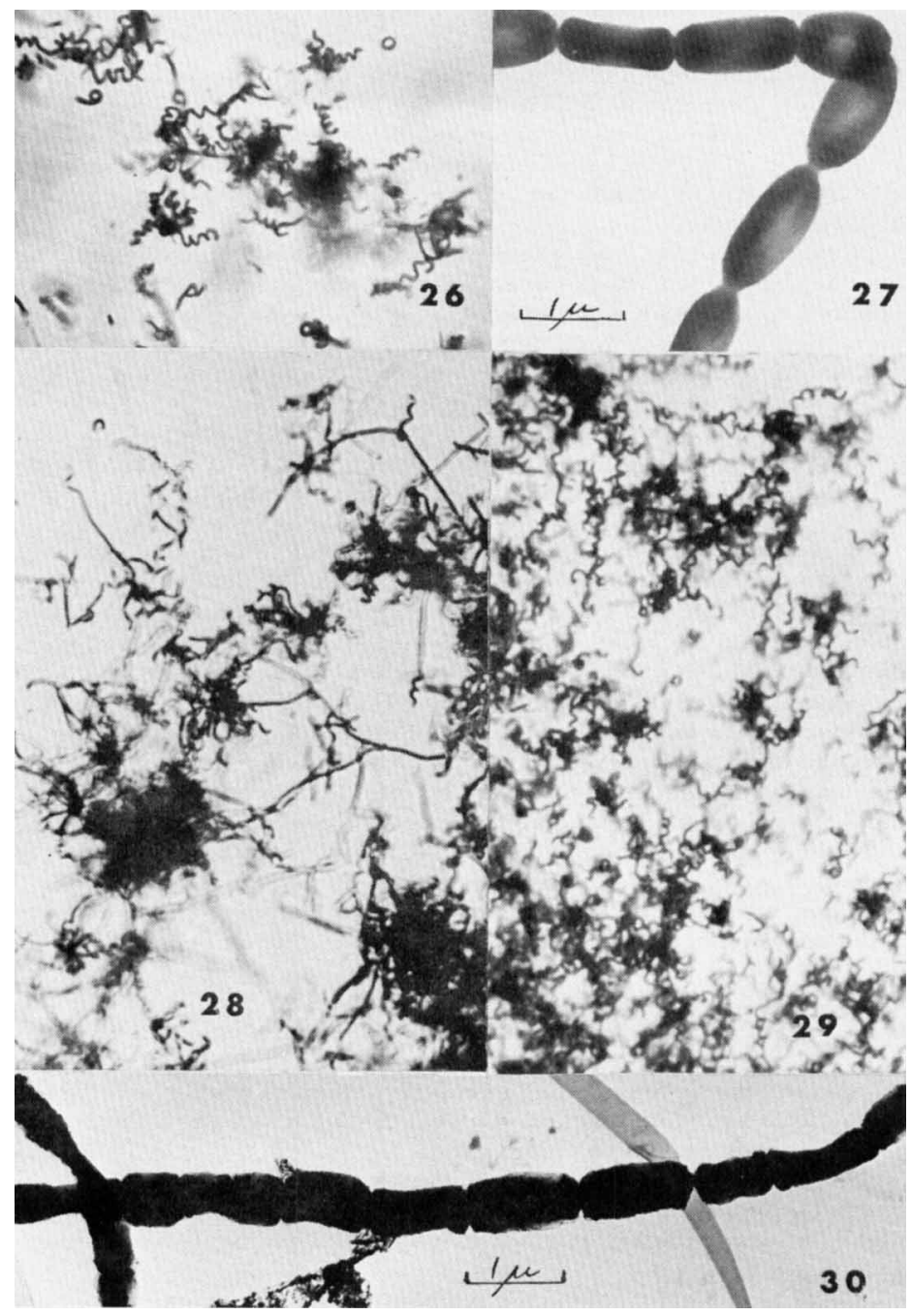

Figure 26. A. aurigineus. Spiral spore chains (X 300) on salts-starch agar, $1 \overline{4}$ days.

Figure 27. A. aurigineus. Smooth spores; electron micrograph from 14 day culture on glycerol-asparagine agar.

Figure 28. S. bottropensis. Hooks and primitive spirals on glycerolasparagine agar.

Figure 29. S. bottropensis. Open spirals on salts-starch agar.

Figure 30. $\bar{S}$. bottropensis. Smooth spores; electron micrograph from 14 day culture on yeast-malt agar. 
characteristic absence of good sporulating aerial mycelium is noted in the original description (op:cit.).

Reverse side of colony: Grayish yellow on oatmeal agar; reddish brown, strong brown or sometimes very dark brown on yeast-malt agar, salts-starch agar and glycerol-asparagine agar. Substrate pigment is not a $\mathrm{pH}$ indicator.

Color in medium: Melanoid pigments are not formed in peptoneyeast-iron agar or tyrosine agar. Brown pigment may be found in the medium in yeast-malt agar and traces of yellow or brown pigment may sometimes be present in oatmeal agar, salts-starch agar, glycerolasparagine agar and tryptone-yeast broth. This pigment is not $\mathrm{pH}$ sensitive when tested with $0.05 \mathrm{~N} \mathrm{NaOH}$ or $\mathrm{HCl}$.

Carbon utilization: D-Glucose, L-arabinose, i-inositol, D-mannitol, D-fructose and raffinose are utilized for growth. Utilization of D-xylose is doubtful. No growth or only trace of growth with sucrose or rhamnose.

Streptomyces carnosus (Millard and Burr) Waksman. Description: Actinomyces carnosus Millard and Burr 1926, 602-604; Streptomyces carnosus (Millard and Burr) Waksman in Waksman and Lechevalier, 1953, 105. Type strain: PSA 126-Strain Millard (L. Silvestri, personal communication, Jamary 1965). ISP 5294 from L. Silvestri as PSA 126-Strain Millard. ISP description by Group C-2.

Spore chain morphology: Section Retinaculiaperti or Spirales. Spore chains are strongly flexuous with primitive open spirals (Fig. 33), irregular turns and some terminal spirals or hooks (Fig. 34). Mature spore chains generally have 10 to 50 spores per chain. This morphology is seen on yeast-malt agar, oatmeal agar, salts-starch agar and glycerolasparagine agar. Spore surface: Smooth (Fig. 35).

Color of colony: Aerial mass color in the Gray (or Red) colorseries on yeast-malt agar and oatmeal agar. Two observers selected color tab $2 \mathrm{dc}$ (yellowish gray) from the Gray color-series as the nearest matching color; one observer selected tab $5 \mathrm{dc}$ (grayish yellowish pink) from the Red color-series as the nearest matching color on yeast-malt agar and tabs $2 \mathrm{dc}$ and $5 \mathrm{cb}$ (yellowish gray and grayish yellowish pink) for oatmeal agar. Sporulating aerial mycelium is poorly developed on salts-starch agar and glycerol-asparagine agar; when present on these media, it is in the White color-series.

Reverse side of colony: No distinctive pigment (Grayish yellow to orange yellow or brown on yeast-malt agar; colorless to pale grayish yellow on oatmeal agar, salts-starch agar and glycerol-asparagine agar).

Color in medium: Melanoid pigments are not formed in peptoneyeast-iron agar, tyrosine agar or tryptone-yeast broth. A trace of red (pale pink) or yellow pigment is usually found in the medium in oatmeal agar and glycerol-a sparagine agar. This pigment is not $\mathrm{pH}$ sensitive when tested with $0.05 \mathrm{~N} \mathrm{NaOH}$ or $\mathrm{HCl}$.

Carbon utilization: D-Glucose and rhamnose are utilized for growth. Utilization of L-arabinose, sucrose, D-xylose, i-inositol, D-mannitol and $\underline{D}$-fructose is doubtful. Reports vary on utilization of these carbon sources, but observers agree that growth is significantly less than on D-glucose"or rhamnose. There is no growth with raffinose. 


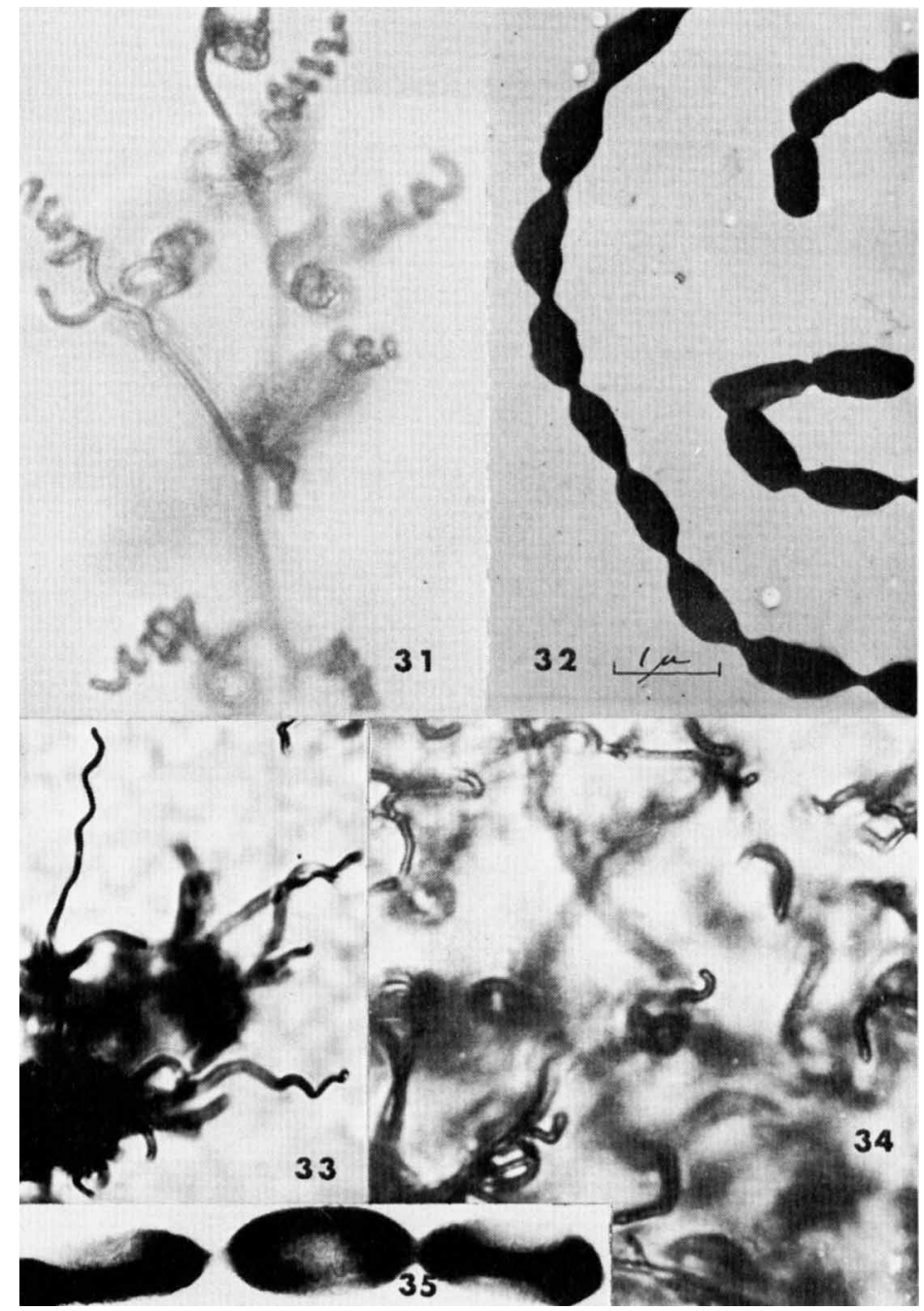

Figure 31. S. capuensis. Spiral spore chains (X 1000) on salts-starch agar, 10 days.

Figure 32. S. capuensis. Smooth spores; electron micrograph from 21 day culture on salts-starch agar.

Figure 33. S. carnosus. Primitive open spirals on yeast-malt agar, 19 days.

Figure 34. S. carnosus. Irregular open spirals and hooks (X 830) on glycerol-asparagine agar, 21 days.

Figure 35. S. carnosus. Smooth spores; electron micrograph from 21 day culture on glycerol-asparagine agar. 
Streptomyces cavourensis Giolitti. Descriptions: Streptomyces 829 Giolitti 1958a, Abstr. 22k. Streptomyces cavourensis Belgian Pat. 590, 930 March 18, $1958 \mathrm{~b}$ and British Pat. 850,325 Oct. 5, 1960. Streptomyces cavourensis Giolitti in Waksman 1961, 191. Type strain: $829=$ CMI 70852 (Giolitti, 1958a, b and 1960; Giolitti, personal communication April, 1965). ISP 5300 from G. Giolitti as $829=\mathrm{CMI}$ 70852. ISP description by Group C-3.

Spore chain morphology: Section Rectiflexibiles (Fig. 36). Mature spore chains generally flexuous and very long, with more than 50 spores per chain. This morphology is seen on yeast-malt agar, oatmeal agar, salts-starch agar and glycerol-asparagine agar. Spore surface: Smooth (Fig. 37), or sometimes with minor surface irregularities (Fig. 38).

Color of colony: Aerial mass color in the Yellow color-series (2ab or $2 \mathrm{ba}$, pale yellow) on yeast-malt agar, oatmeal agar and salts starch agar; Yellow or White color-series on glycerol-asparagine agar.

Reverse side of colony: No distinctive pigments (moderate to strong brown on yeast-malt agar; yellow, orange yellow or olive brown on oatmeal agar, salts-starch agar and glycerol-asparagine agar).

Color in medium: Melanoid pigments are formed in peptone-yeastiron agar and tryptone-yeast broth, but not in tyrosine agar. No pigment (other than brown) is found in the medium in yeast-malt agar, oatmeal agar, salts-starch agar or glycerol-asparagine agar.

Carbon utilization: D-Glucose, L-arabinose, D-xylose, D-mannitol and $\underline{D}$-fructose are utilized for growth. No growth or only trace of growth with $\underline{i}$-inositol, rhamnose, sucrose and raffinose.

Streptomyces cellulosae (Krainsky) Waksman and Henrici, Descriptions: Actinomyces cellulosae Krainsky 1914, 680 and 683; Streptomyces cellulosae (Krainsky) Waksman and Henrici 1948, 938. Type strain:CBS 122.18, strain Krainsky, from Beijerinck's laboratory in March, 1918 (= ETH 13493) (G.A. deVries, personal communication, Sept., 1966). ISP 5362 from G.A. deVries as CBS 122.18 . ISP description by Group D-10.

Spore chain morphology: Section Rectiflexibiles. Mature spore chains are of ten difficult to find. Long a sporogenous aerial hyphae may be curled and interwoven into knots and tangles, but spore chains are usually short with 3 to 10 spores per chain (Fig. 39,40). This morphology is seen on yeast-malt agar, salts-starch agar and glycerol-asparagine agar. Spore surface: Smooth (Fig. 40).

Color of colony: Sporulating aerial mass color is usuatly in the Yellow or Gray color-series (2ba or 2db, pale yellow; 2dc, yellowish gray) on yeast-malt agar, salts-starch agar and glycerol-asparagine agar. Immature or non-sporulating aerial mycelium is white.

Reverse side of colony: No distinctive pigments (nearly colorless, pale grayish yellow, light yellow or grayish orange yellow) on yeastmalt agar, oatmeal agar, salts-starch agar and glycerol-asparagine agar.

Color in medium: Melanoid pigments are not formed in peptoneyeast-iron agar, tyrosine agar or tryptone-yeast broth. No pigment (or only a trace of yellow) is found in the medium in yeast-malt agar, oatmeal agar, salts-starch agar or glycerol-asparagine agar. 


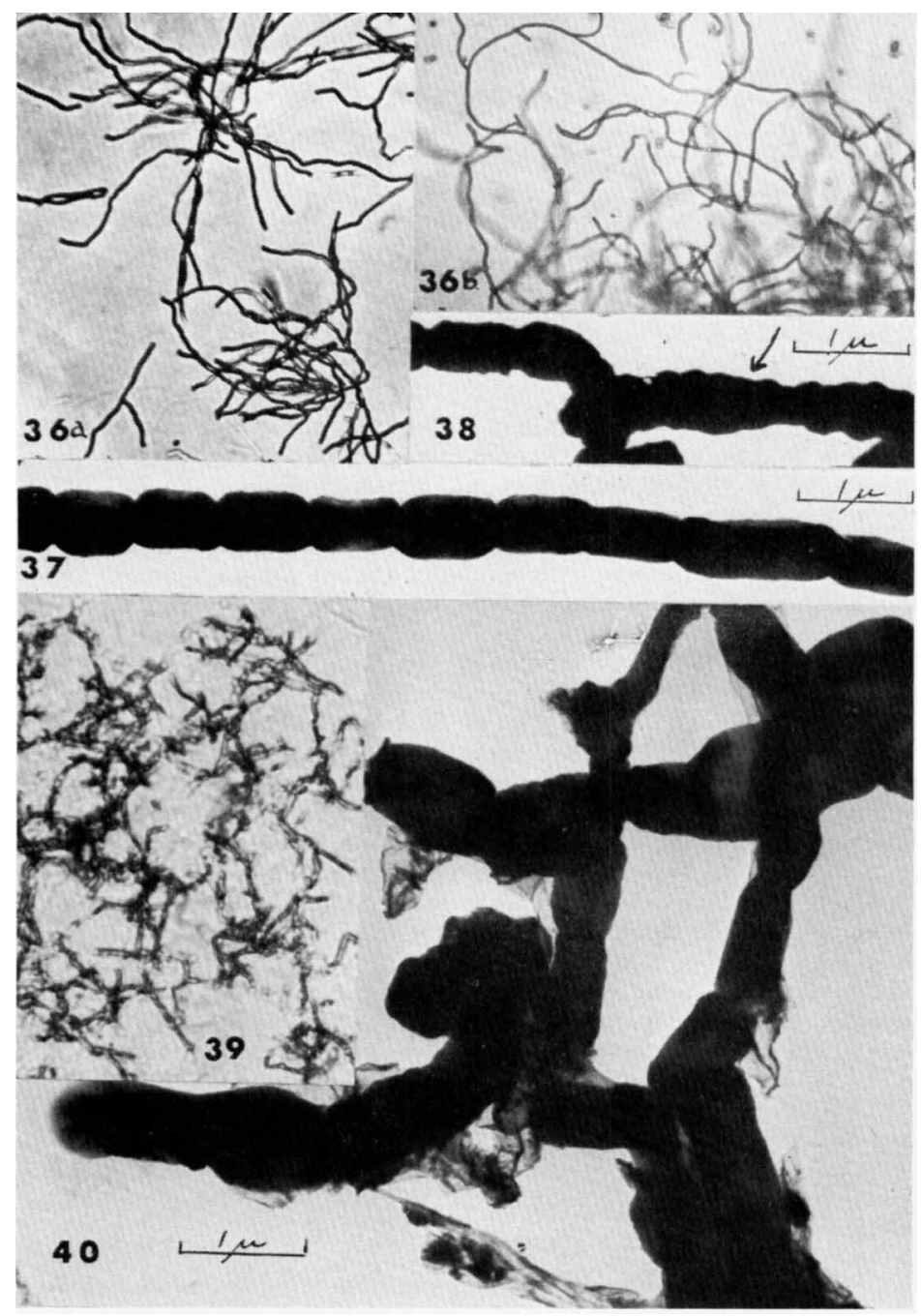

Figure 36. S. cavourensis. Long RF spore chains (X 300). (a) On yeastmalt agär, 14 days. (b) On salts-starch agar, 7 days.

Eigure 37. S. cavourensis. Smooth spores; electron micrograph from 7 day culture on yeast-malt agar.

Figure 38. S. cavourensis. Smooth spores with minor surface irregularities; electron micrograph from 7 day culture on salts-starch agar.

Figure 39. S. cellulosae. Short, irregular spore chains on glycerolasparagine agar, 21 days.

Figure 40. S. cellulosae. Smooth spores of irregular size and shape in short spore chains; electron micrograph from 14 day culture on glycerol-asparagine agar. 
Carbon utilization: $\underline{\text {-Glucose, }}$ L-arabinose, $\underline{\text {-xylose, }}$ - -inositol, D-mannitol, D-fructose, rhamnose and sucrose are utilized for growth. Only a trace of growth is found on raffinose.

Actinomyces cinnabarinus Ryabova and Preobrazhenskaya. Des cription: Preobrazhenskaya et al. in Gauze et al. 1957, 196. Type strain: INA 1242 (neotype selected by G.F. Gauze, personal communication, March, 1967). Streptomyces cinnabarinus (Ryabova and Preobrazhenskaya) Pridham et al. 1958, 62. ISP 5467 from G.F. Gauze as INA 1242. ISP description by Group D-4.

Spore chain morphology: Section Rectiflexibiles (Fig. 41) but a very small proportion of strongly flexuous spore chains may suggest

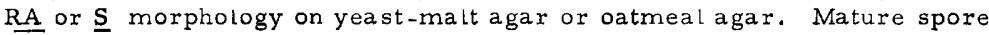
chains generally long, often with more than 50 spores per chain. This morphology is seen on yeast-malt agar, oatmeal agar and salts-starch agar. Sporulating aerial mycelium is poorly developed or absent on glycerol-asparagine agar and yeast-malt agar. Spore surface: Smooth (Fig. 42); spores of phalangeal type are common (Fig. 43).

Color of colony: Aerial mass color in the Red color-series (3ca, pale orange yellow) on oatmeal agar and salts-starch agar and also on yeast-malt agar when adequate sporulation occurs on this medium. White aerial mycelium may also be seen on these media. Mature sporulating mycelium is inadequate for aerial mass color determination on glycerol-a sparagine agar.

Reverse side of colony: Pale yellow or grayish on yeast-malt agar; yellow is modified by red to yellowish pink or reddish gray on oatmeal agar and to reddish orange, grayish red or reddish brown on salts starch agar and glycerol-asparagine agar. Substrate pigment is not a $\mathrm{pH}$ indicator or is changed only slightly by addition of $0.05 \mathrm{~N} \mathrm{NaOH}$ or $\mathrm{HCl}$.

Color in medium: Melanoid pigments are formed in peptone-yeast iron agar and tryptone-yeast broth. Red or lavender pigment is found in the medium in oatmeal agar and salts-starch agar. One observer, only, found this pigment to be $\mathrm{pH}$ sensitive when tested with 0.05 $\mathrm{N} \mathrm{NaOH}$; he records a change from light violet to yellow-colorless. Two observers record no change.

Garbon utilization: D-Glucose, L-arabinose, D-xylose, i-inositol, D-mannitol, D-fructose, rhamnose, sucrose and raffinose are all utilized for growth.

Streptomyces citreus Waksman and Henrici. Descriptions: Actinomyces citreus Krainsky 1914, 681 and 684; Actinomyces citreus (sensu Krainsky) Waksman and Curtis 1916, 118 and 127; Waksman 1919 , 108-109; Streptomyces citreus Waksman and Henrici 1948, 946; synonym of S. griseus Waksman and Henrici 1948 according to Ettlinger et al. 1958, 349. Not Actinomyces citreus Gasperini 1894, 84. Type strain: CBS strain Waksman (G.A. deVries). ISP 5364 from G.A. deVries as CBS strain Waksman. ISP description by Group D-10.

Spore chain morphology: Section Rectiflexibiles. Flexuous chains are the most common (Fig. 44) and some flexuous chains may suggest RA morphology. Mature spore chains moderately long with 10 to 50 spores per chain. This morphology is seen on yeast-malt agar, oatmeal agar, salts-starch agar and glycerol-asparagine agar. Waksman's 


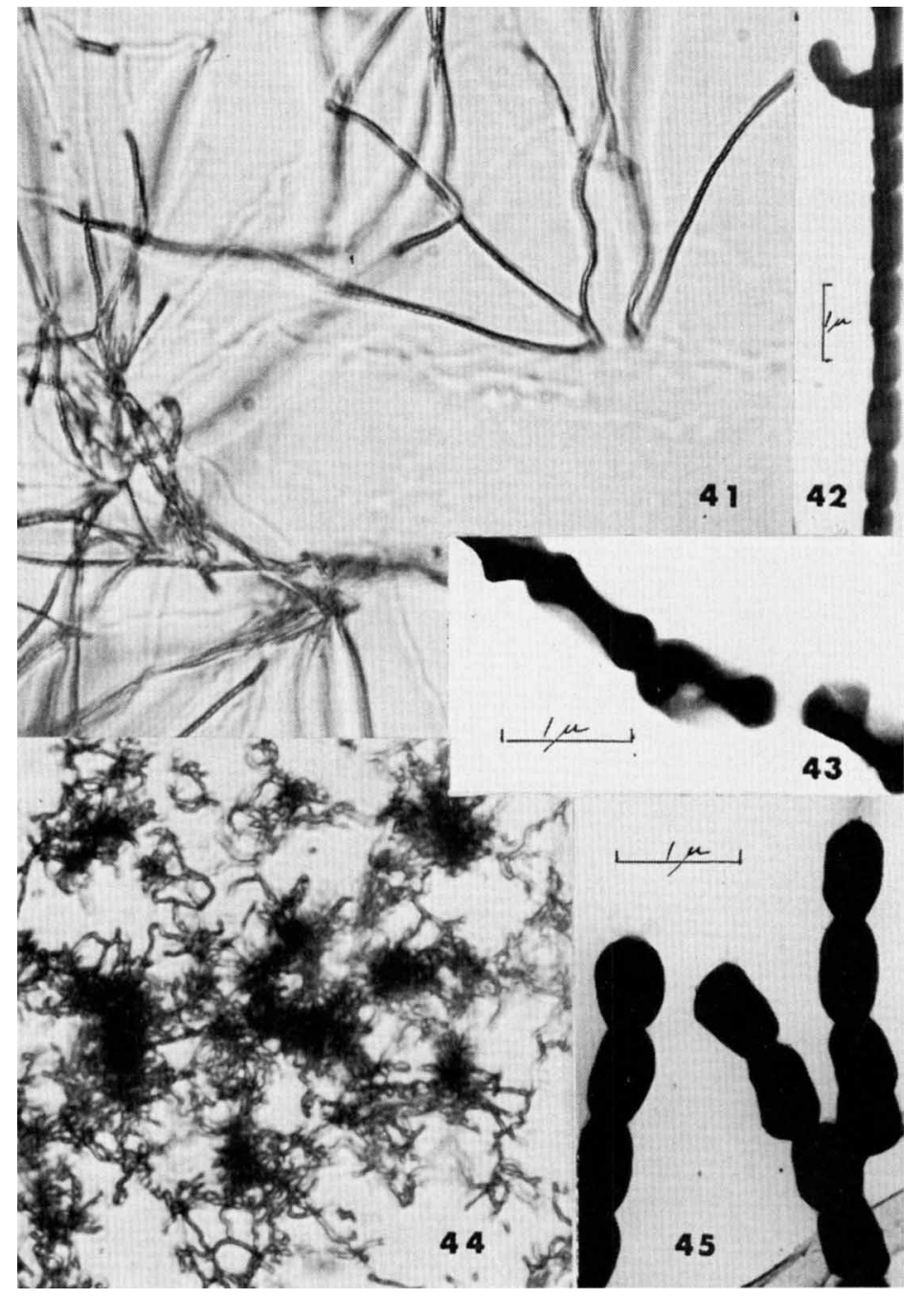

Figure 41. $\underline{\text { S. cinnabarinus. }} \underline{\mathrm{R} F}$ spore chains (X 800) on oatmeal agar, 21 days.

Figure 42. S. cinnabarinus. Smooth spores; electron micrograph from 14 day culture on oatmeal agar.

Figure 43. S. cinnabarinus. Smooth spores of phalangeal type; electron micrograph from 21 day culture on oatmeal agar.

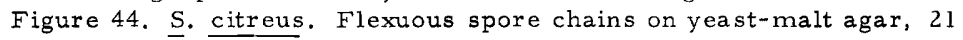
days.

Figure 45. S. citreus. Smooth spores; electron micrograph from 14 day culture on yeast-malt agar. 
description of 1919 (op. cit.) mentions "long narrow and open spirals on dextrose agar and starch agar". Spirals were not mentioned in the description of Krainsky (1914 op. cit.) or in the first description by Waksman (1916, op. cit.). Ettlinger et al. (op.cit.) regard this strain as belonging to $\underline{\mathrm{S}}$. griseus Waksman and Henrici 1948, which has $\mathrm{RF}$ spore chains. Spore surface: Smooth (Fig. 45).

Color of colony: Aerial mass color in the Yellow color-series on yeast-malt agar, oatmeal agar and salts-starch agar; Yellow or White color-series on glycerol-asparagine agar.

Reverse side of colony: Yellow to yellow brown on yeast-malt agar, oatmeal agar, salts-starch agar and glycerol-asparagine agar.

Color in medium: Melanoid pigments are not formed in peptoneyeast-iron agar, tyrosine agar or tryptone-yeast broth. A trace of yellow may or may not be found in the medium in yeast-malt agar, oatmeal agar, salts-starch agar and glycerol-asparagine agar. This pigment, if present, is not $\mathrm{pH}$ sensitive.

Carbon utilization: D-Glucose, L-arabinose, D-xylose, D-mannitol and D-fructose are utilized for growth. Reports vary on utilization of i-inositol, sucrose and raffinose but utilization of these carbon sources is doubtful. No growth or only trace of growth with rhamnose.

Actinomyces coeliatus Krasil'nikov, Sorokina, Alferova and Bezubenkova. Description: Krasil'nikov etal. in Krasil'nikov 1965, 89-90. Type strain: INMI 37- 9 (ibid.; Krasil'nikov, personal communication, Dec., 1966). ISP 5422 from N.A. Krasil'nikov as INMI 37-Я. ISP description by group D-9.

Spore chain morphology: Section Spirales; tight spirals often have 4 to 8 turns (Fig. 46). Mature spore chains generally long, of ten with more than 50 spores per chain. This morphology is seen on yeast-malt agar, oatmeal agar, salts-starch agar and glycerol-asparagine agar. Spore surface: Spiny (Fig. 47).

Color of colony: Aerial mass color usually in the Blue color-series (color tab 19dc, pale blue) on yeast-malt agar, oatmeal agar, saltsstarch agar, glycerol-asparagine agar; but Gray or White aerial mycelium may sometimes be seen on these media.

Reverse side of colony: Dark grayish blue to dark purplish gray or blackish purple on yeast-malt agar, oatmeal agar, salts-starch agar and glycerol-asparagine agar. Reverse mycelium pigment is a $\mathrm{pH}$ indicator changing from violet to blue with addition of $0.05 \mathrm{~N} \mathrm{NaOH}$ and from blue or violet to reddish violet or red with addition of $0.05 \mathrm{~N} \mathrm{HCl}$.

Color in medium: Melanoid pigments are formed in peptone-yea st iron agar, tyrosine agar and tryptone-yeast broth. Blue or violet pigment (depending on $\mathrm{pH}$ ) is found in the medium in yeast-malt agar, oat meal agar, salts-starch agar and glycerol-asparagine agar. This pigment is $\mathrm{pH}$ sensitive showing the same color changes noted for the reverse mycelium pigment.

Carbon utilization: D-Glucose, L-arabinose, D-xylose, $\underline{\text { in-inositol, }}$ D-mannitol, D. fructose, rhamnose, sucrose and raffinose are all utilized for growth.

Actinomyces coerulatus Krasil'nikov, Sorokina, Alferova and Bezubenkova. Description: Krasil'nikov et al. in Krasil'nikov 1965, 88. Type strain: INMI 1059 (ibid, ; Krasil'nikov, personal communica- 


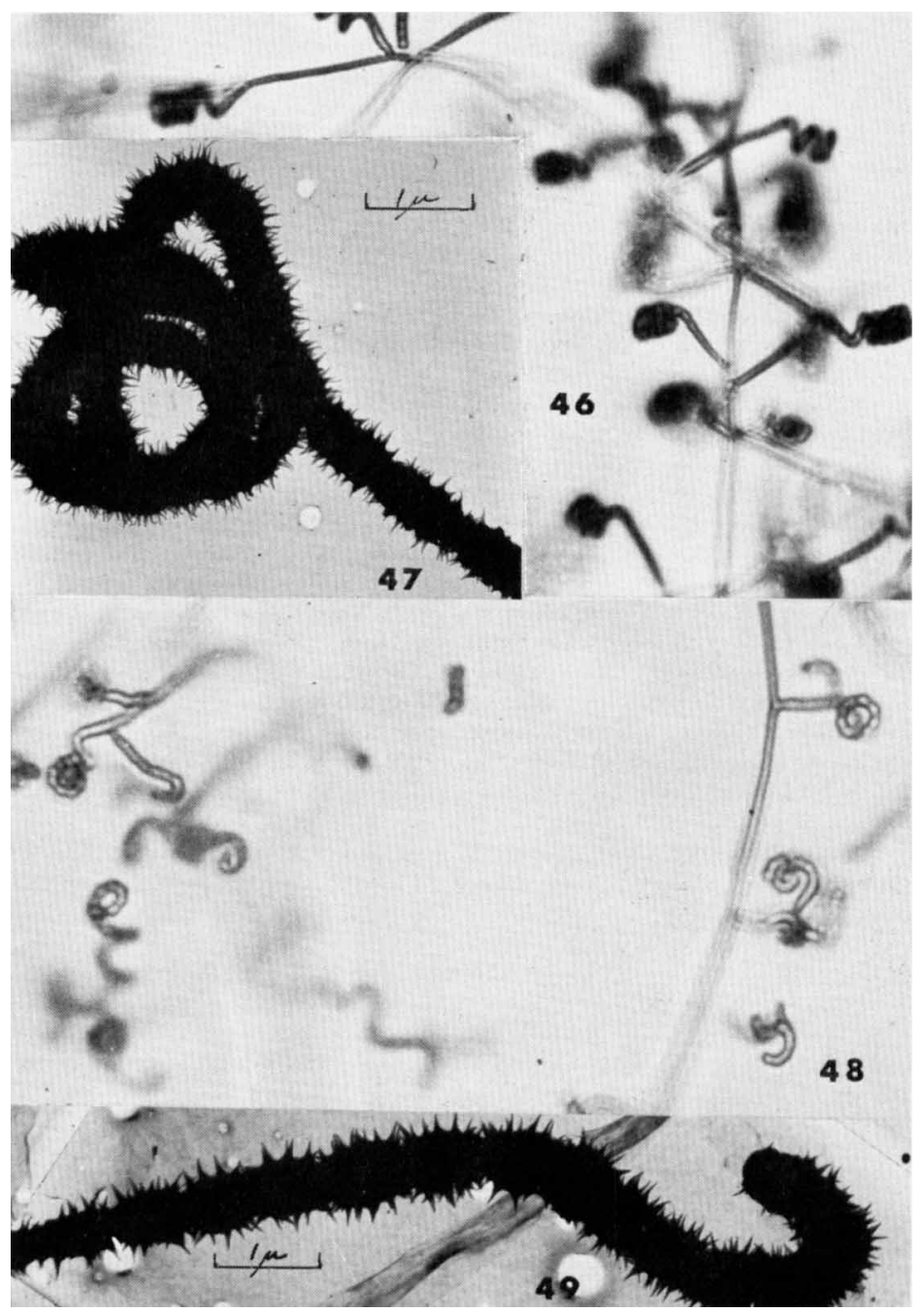

Figure 46. A. coeliatus. Tight spirals of 4 to 8 turns $(X 800)$ on oatmeal agar, $1 \overline{0}$ days.

Figure 47. A. coeliatus. Spiny spores and spiral spore chains; electron micrographfrom 11 day culture on salts-starch agar.

Figure 48. A. coerulatus. Spiral spore chains (X 1000) on oatmeal agar, 10 days.

Figure 49. A. coerulatus. Spiny spores; electron micrograph from 28 day culture on oatmeal agar. 
tion, Dec., 1966). ISP 5424 from N.A. Krasil'nikov as INMI 1059. ISP description by Group D-9.

Spore chain morphology: Section Spirales (Fig. 48). Mature spore chains moderately long with 10 to 50 or sometimes more than 50 spores per chain. Sporulating aerial mycelium with typical morphology is usually formed on yeast-malt agar and oatmeal agar. It may be thin or absent on these media and on salts-starch agar and glycerol-asparagine agar. Spore surface: Spiny (Fig. 49).

Color of colony: Aerial mass color in the Blue color-series on yeast-malt agar when adequate sporulating aerial mycelium is formed. Growth of aerial mycelium is usually not adequate for color determination on oatmeal agar, salts-starch agar and glycerol-asparagine agar. If aerial mycelium is formed on these media it is usually white.

Reverse side of colony: Yellow to yellow-brown is usually modified by grayish red, grayish blue or grayish purple depending on $\mathrm{pH}$ of the medium. Reverse mycelium pigment is a $\mathrm{pH}$ indicator, changing from reddish gray or violet to blue with addition of $0.05 \mathrm{~N} \mathrm{NaOH}$ and from blue or blue violet to reddish purple or red with addition of $0.05 \mathrm{~N} \mathrm{HCl}$.

Color in medium: Melanoid pigments are formed in peptone-yeastiron agar and tryptone-yeast broth. Melanoid pigment production is weak in tyrosine agar. Bluish gray, blue-violet or red pigment (depending on $\mathrm{pH}$ ) may be found in the medium in yeast-malt agar, oatmeal agar, salts-starch agar or glycerol-asparagine agar. This pigment is $\mathrm{pH}$ sensitive, changing from reddish gray or violet to blue with addition of $0.05 \mathrm{~N} \mathrm{NaOH}$ and from blue or blue-violet to reddish purple or red with addition of $0.05 \mathrm{~N} \mathrm{HCl}$.

Carbon utilization: D-Glucose, L-arabinose, D-xylose, $\underline{\text { i-inositol, }}$ D-mannitol, D-fructose, rhamnose, sucrose and raffinose are utilized for growth.

Streptomyces corchorusii Ahmad and Bhuiyan. Description: Ahmad and Bhuiyan 1958, $137-143$. Type strain: NCIB 9476 (received by NCIB from K. Ahmad; T.G. Mitchell, personal communication, March, 1966). ISP 5340 from T.G. Mitchell as NCIB 9476. ISP description by Group C-9.

Spore chain morphology: Section Spirales to Rectiflexibiles. Incomplete spirals (hooks) and flexuous or straight spore chains are common (Fig. 50); spirals usually have only 1 to 3 turns. Hooks and primitive spirals are on relatively short chains and are therefore not representative of typical RA or RF morphology. Mature spore chains generally have 10 to 20 spores per chain. This morphology is seen on yeast-malt agar, oatmeal agar, salts-starch agar and glycerol-asparagine agar. Spore surface: Smooth. Electron micrographs show spores of irregular size and shape (Fig. 51); some surface irregularities may be present.

Color of colony: Aerial mass color in the Gray color-series (color tabs 3 ge, light grayish yellowish brown and 3 fe or $41 i$, brownish gray) on yeast-malt agar, oatmeal agar, salts-starch agar and glycerolasparagine agar.

Reverse side of colony: No distinctive pigments (y ellow to yellowish brown or olive brown) on yeast-malt agar, oatmeal agar, salts starch agar and glycerol-a sparagine agar. 
Color in medium: Melanoid pigments are not formed in peptoneyeast-iron agar, tyrosine agar or tryptone-yeast broth. No pigment (or only a trace of yellow) is found in the medium in yeast-malt agar, oatmeal agar, salts-starch agar and glycerol-asparagine agar.

Carbon utilization: D-Glucose, L-arabinose, D-xylose, i-inositol, D-mannitol, D-fructose, rhamnose, sucrose and raffinose are all utilized for growth.

Streptomyces craterifer (Millard and Burr) Waksman. Descriptions: Actinomyces craterifer Millard and Burr 1926, 637-638; Streptomyces craterifer (Millard and Burr) Waksman 1953, 105. Type strain: PSA 119 = Strain Millard and Burr (L. Silvestri, personal communication, January, 1965). ISP 5296 from L. Silvestri as PSA 119. ISP description by Group C -4 .

Spore chain morphology: Section Rectiflexibiles to Spirales. The predominantly flexuous or crooked spore chains (Fig. 52 ) may also form occasional hooks and irregular spirals (rare) (Fig. 53). Mature spore chains are generally short with 3 to 10 or sometimes more than 10 spores per chain. Long chains characteristic of true RA morphology are not present. This morphology is seen on yeast-malt agar, oatmeal agar, salts-starch agar and glycerol-asparagine agar. Spore surface: Spiny (Fig. 54).

Color of colony: Aerial mass color in the White color-series on oatmeal agar and glycerol-asparagine agar; White or Gray (color tab d, light gray) color-series on yeast-malt agar and salts-starch agar.

Reverse side of colony: No distinctive pigments (colorless to light yellow or grayish yellow) on yeast-malt agar, oatmeal agar, saltsstarch agar and glycerol-asparagine agar.

Color in medium: Melanoid pigments are not formed in peptoneyeast-iron agar, tyrosine agar or tryptone-yeast broth. No pigment is found in the medium in yeast-malt agar, oatmeal agar, salts-starch agar or glycerol-asparagine agar.

Carbon utilization: D-Glucose, L-arabinose, D-xylose and rhamnose are utilized for growth. Keports vary on the utilization bf D-mannitol and $D$-fructose, and the utilization of sucrose and raffinose is doubtful. No growth or only trace of growth with $\underline{i}$-inositol.

Actinomyces cyanocolor Krasil'nikov, Sorokina, Alferova and Bezubenkova. Description: Krasil'nikov et al. in Krasil'nikov 1965, 114. Type strain: INMI $31-23$ (ibid.; Krasil'nikov, personal communication, Dec., 1966). ISP 5425 from N.A. Krasil'nikov as INMI $31-23$. ISP description by Group D-9.

Spore chain morphology: Section Spirales or Retinaculiaperti. Open spirals or primitive spirals may be seen on oatmeal agar, salts starch agar (Fig. 55) and glycerol-asparagine agar, but they are not the predominant form. Straight to flexuous spore chains (Fig. 56) are most common on yeast-malt agar, oatmeal agar, salts-starch agar and glycerol-asparagine agar. Spore chains are moderately long with 10 to 50 , or often more than 50 spores per chain. Spore surface: Smooth (Fig. 57).

Color of colony: Aerial mass color in the Gray color-series on oatmeal agar; Red or Gray color-series (5ce, grayish yellowish pink; $5 \mathrm{fe}$, grayish reddish brown or $7 \mathrm{fe}$, pale purple) on yeast-malt aga $\mathbf{r}$; 


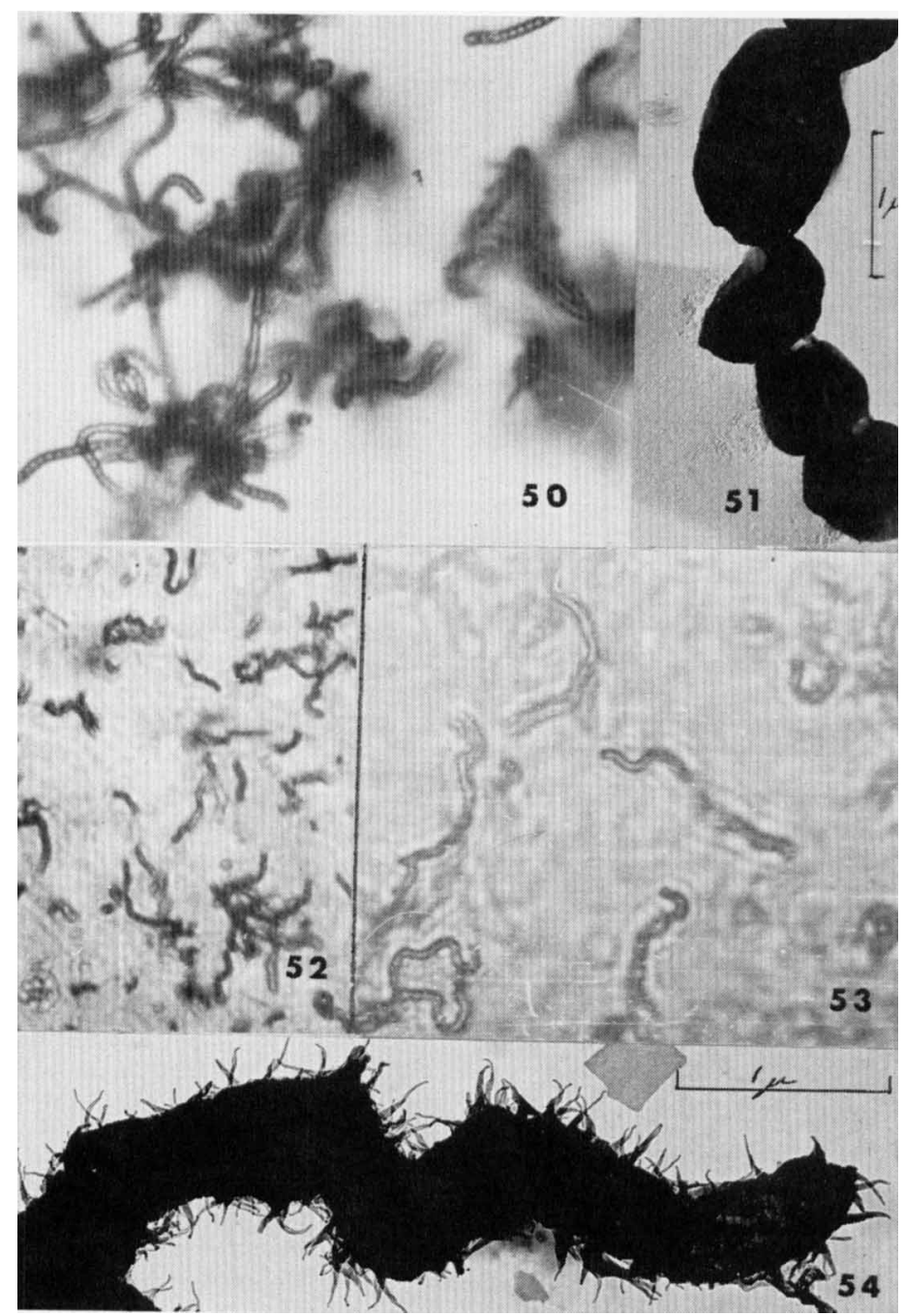

Figure 50. S. corchorusii. Imperfect spirals, hooks and flexuous chains (X 800) on oatmeal agar, 10 days.

Figure 51. S. corchorusii. Smooth spores of irregular size and shape; electron micrograph silver palladium shadowed.

Figure 52. S. craterifer. Flexuous or crooked spore chains (X 450) on glycerol-a sparaine agar, 14 days.

Figure 53. S. craterifer. Hooks and irregular spirals (X 500) on glycerol-asparagine agar, 14 days.

Figure 54. S. craterifer. Spiny spores; electron micrograph from 21 day culture on salts-starch agar. 
Gray or Blue color-series (d or e, Light or medium gray and $7 f e$, pale purple or 19dc, pale blue) on salts-starch agar and glycerol-asparagine agar. The variability in aerial mass color reported by observers may be related to $\mathrm{pH}$ differences (see below).

Reverse side of colony: Yellow to yellow-brown is strongly modified by blue, violet or red depending on $\mathrm{pH}$. The reverse side of the mycelium tends to become dark grayish purple on salts-starch agar and glycerol-asparagine agar in 14 to 21 days; colors are more variable (yellowish brown, pale blue or reddish gray or brown on yeast-malt agar and oatmeal agar). Reverse mycelium pigment is a $\mathrm{pH}$ indicator, changing from red or violet to blue with the addition of $0.05 \mathrm{~N} \mathrm{NaOH}$ and from blue or violet to reddish purple or red with the addition of $0.05 \mathrm{~N} \mathrm{HCl}$.

Color in medium: Melanoid pigments are not formed in peptoneyeast-iron agar, tyrosine agar or tryptone-yeast broth. Violet (or blue or red) pigment is found in the medium in oatmeal agar, salts starch agar and glycerol-asparagine agar. This pigment is $\mathrm{pH}$ sensitive when tested with $0.05 \mathrm{~N} \mathrm{NaOH}$ or $\mathrm{HCl}$, showing essentially the same changes recorded for the reverse mycelium pigment.

Carbon utilization: D-Glucose, L-arabinose, D-xylose, i-inositol, D-mannitol, D-fructose and rhamnose are utilized for growth. Utilization of sucrose and raffinose is doubtful.

Actinomyces cyanogenus Krasil'nikov, Sorokina, Alferova and Bezubenkova. Description: Krasil'nikov et al. in Krasil'nikov 1965, 114. Type strain INMI III2-7 (ibid., N. A. Krasil'nikov, personal communication, Dec. 1966). ISP 5426 from N.A. Krasil'nikov as INMI $1112-7$. ISP description by Group D-10.

Spore chain morphology: Section Spirales (Fig. 58). Mature spore chains generally long, often with more than 50 spores per chain. This morphology is seen on yeast-malt agar, oatmeal agar, salts-starch agar and glycerol-asparagine agar. Spore surface: Smooth (Fig. 59).

Color of colony: Mature aerial mass color usually in the Gray color-series on salts-starch agar and Red color-series $\{5 \mathrm{cb}$, grayish yellowish pink) on glycerol-asparagine agar; Gray (5fe, light grayish reddish brown or 3fe, light brownish gray) or Red (5dc, grayish yellowish pink) color-series is reported on yeast-malt agar and oatmeal agar. Variation in reports for aerial mass color may be related to $\mathrm{pH}$ changes (see below).

Reverse side of colony: Yellow to yellow-brown may persist or may be modified by red or blue (depending on $\mathrm{pH}$ ) to grayish blue, or pale reddish purple on yeast-malt agar, oatmeal agar, salts-starch agar or glycerol-asparagine agar. Reverse mycelium pigment is a $\mathrm{pH}$ indicator, changing from reddish to bluish color with addition of $0.05 \mathrm{~N} \mathrm{NaOH}$ or from bluish to reddish color with addition of $0.05 \mathrm{~N} \mathrm{HCl}$.

Color in medium: Melanoid pigments are not formed in peptoneyeast-iron agar, tyrosine agar or tryptone-yeast broth. Pigment may or may not be found in the medium in yeast-malt agar, oatmeal agar, salts-starch agar and glycerol-asparagine agar. When present, this pigment is $\mathrm{pH}$ sensitive, showing the same color changes recorded for the reverse mycelium pigment.

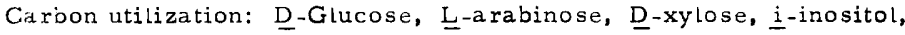
D-mannitol, D-fructose, rhamnose, sucrose and raffinose are utilized 


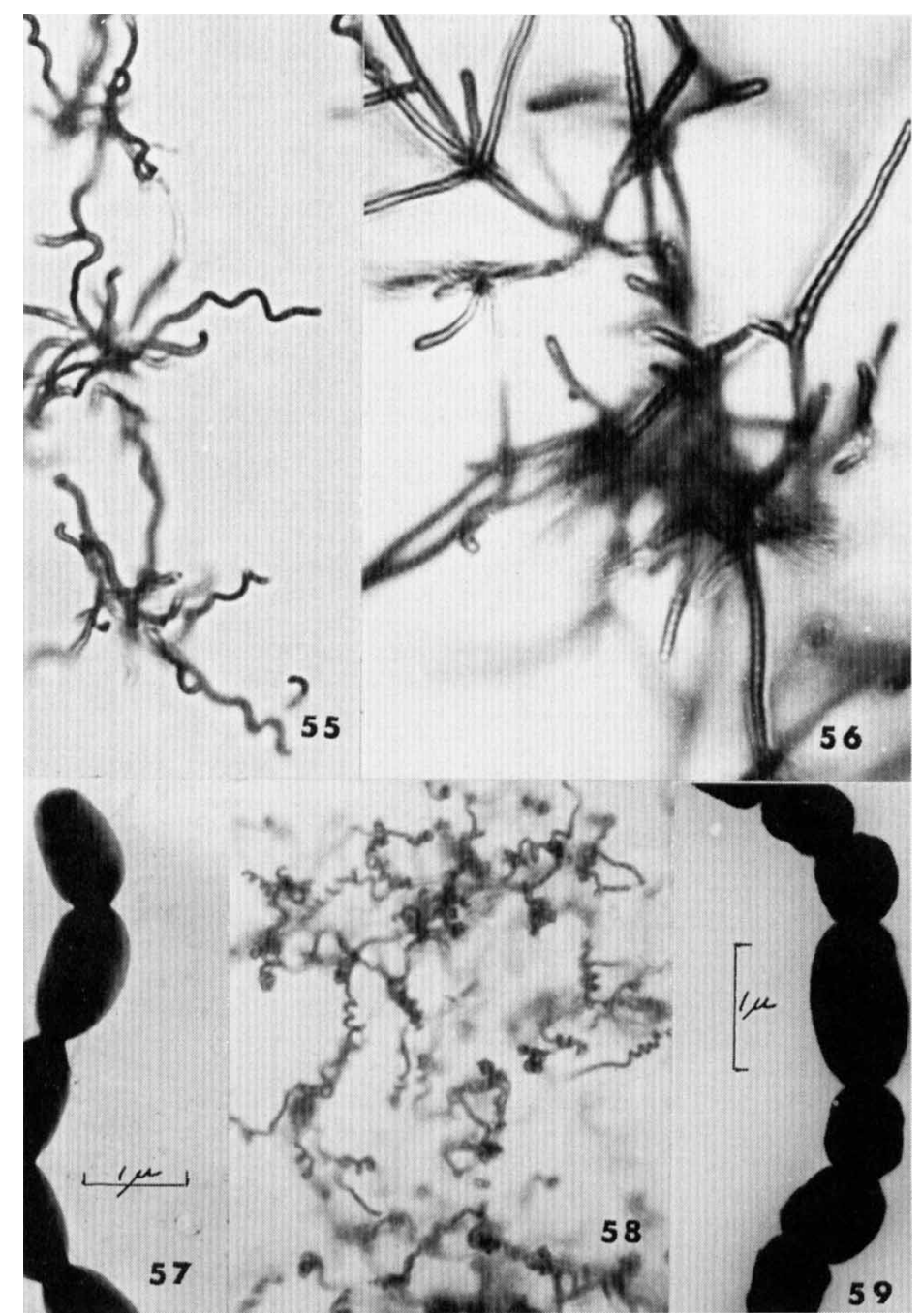

Figure 55. A. cyanocolor. Open spirals on salts-starch agar, 10 days (X 500).

Figure 56. A. cyanocolor. Straight (RF) spore chains (X 1000) on saltsstarch agar, 10 days.

Figure 57. A. cyanocolor. Smooth spores; electron micrograph from 11 day culture on oatmeal agar.

Figure 58. A. cyanogenus. Spiral spore chains on salts-starch agar, 20 days.

Figure 59. A. cyanogenus. Smooth spores; electron micrograph from 20 day culture on yeast-malt agar. 
for growth. Growth on sucrose is generally somewhat less than on other carbon sources.

Actinomyces cyanoglomerus subsp. cellulose (sic) Krasil'nikov, Sorokina, Alferova and Bezubenkova. Description: Krasil'nikov et al. in Krasil'nikov 1965, 86. Type strain: INMI 26-p (ibid. This strain was sent to ISP as type strain for the species $A$. cyanoglomerus, personal communication, N.A. Krasil'nikov, Dec. 1966. The original description designates INMI $31-\mathrm{M}$ as the type for the species; strain 26-p is given as type for A. cyanoglomerus subsp. cellulose., p. 86, op. cit.). ISP 5427 from $\bar{N}$.A. Krasil'nikov as INMI 26-p. ISP description by Group D-10.

Spore chain morphology: Section Spirales (Fig. 60). Although tight spirals are often clustered along an axial filament (Fig. 61), true whorls representative of verticillate cultures are not seen. Mature spore chains generally 10 to 50 spores per chain. This morphology is seen on yeast-malt agar, oatmeal agar, salts-starch agar and glycerolasparagine agar, but sporulation may be poor on glycerol-asparagine agar. Spore surface: Spiny (Fig. 62), but smooth to warty spores may also be found (Fig. 63).

Color of colony: Aerial mass color in the Blue color-series on yeast-malt agar, oatmeal agar, salts-starch agar and glycerol-asparagine agar.

Reverse side of colony: Dark grayish blue, grayish purple or grayish red depending on $\mathrm{pH}$ on yeast-malt agar, oatmeal agar, salts starch agar and glycerol-asparagine agar. Reverse mycelium pigment is a $\mathrm{pH}$ indicator, changing from red or purple to blue with addition of $0.05 \mathrm{~N} \mathrm{NaOH}$ and from purple to red with addition of $0.05 \mathrm{~N} \mathrm{HCI}$.

Color in medium: Melanoid pigments are formed in peptone-yeast iron agar, but reports vary on melanoid pigment production on tyrosine agar or tryptone-yea st broth. Blue, violet or red pigment (depending on $\mathrm{pH}$ ) is found in the medium in yeast-malt agar, oatmeal agar, salts starch agar and glycerol-asparagine agar. This pigment is $\mathrm{pH}$ sensitive showing the same color changes noted for the reverse mycelium pigment.

Carbon utilization: D-Glucose, L-arabinose, D-xylose, i-inositol, D-mannitol, D-fructose, rhamnose, sucrose and raffinose are all utilized for growth.

Streptomyces feofaciens (Bellenghi, M. German Pat. Appl. L

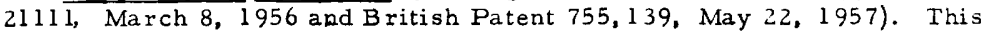
binomial is not validly published (Buchanan, Holt and Lessel 1966) and is based upon the same type strain (Univ. Pavia S 4623/33 = P-19) as Streptomyces psammoticus Virgilio and Hengeller 1960. (Personal communication, Lepetit S.p.a. Feb. 1966; G.A. deVries, CBS, March 1966). See Virgilio and Hengeller 1960, p. 165 (footnote) for explana. tion for change of the name from S. feofaciens to $\underline{S}$. psammoticus. Strain Univ. Pavia S 4623/33 = P-19 (CBS 175.61) is described by ISP Group C-5 under the binomial Streptomyces psammoticus, q.v.

Streptomyces fimicarius (Duché) Waksman and Henrici. Descriptions: Actinomyces fimicarius Duché 1934, 316-353; Streptomyces fimicarius (Duché) Waksman and Henrici 1948, 940. Type strain: CBS 420.34, strain of Duché (G.A. deVries, CBS, personal communication, 

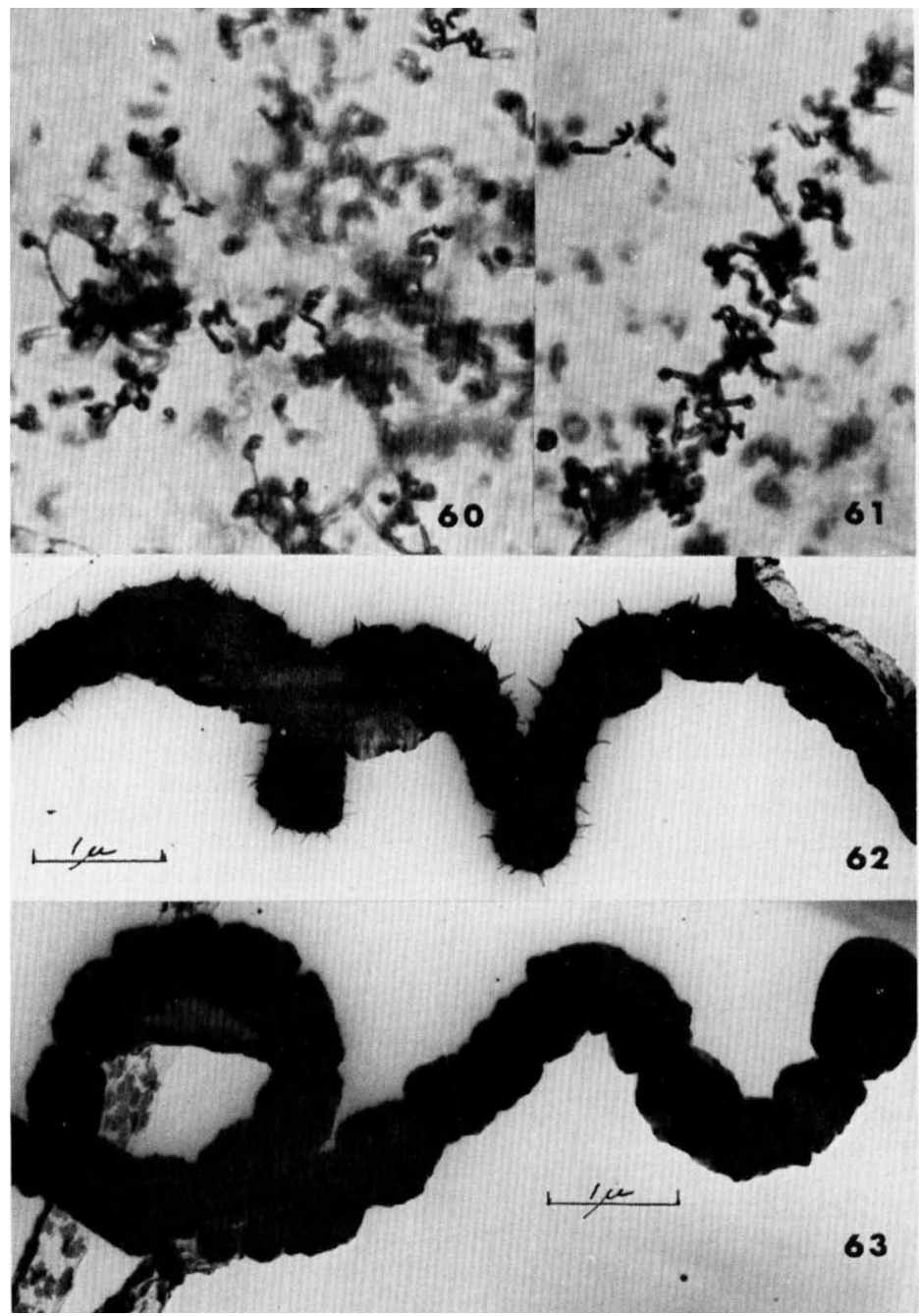

Figure 60. A. cyanoglomerus. Tight spirals on oatmeal agar, 20 days. Figure 61. $\bar{A}$. cyanoglomerus. Spirals apparently distributed along an axial filament; yeast-malt agar, 20 days.

Figure 62. A. cyanoglomerus. Spiny spores; electron micrograph from 14 day culture on yeast-malt agar. See also Figure 63.

Figure 63. A. cyanoglomerus. Smooth to warty spores; electron micrograph from 14 day culture on yeast-malt agar. Compare with Figure 62. 
Jan., 1966). ISP 5322 from G. A. deVries as CBS 420.34. ISP description by Group C -4 .

Spore chain morphology: Section Rectiflexibiles (Fig. 64). Mature spore chains generally long with 10 to 50 or more spores per chain. This morphology is seen on yeast-malt agar, oatmeal agar, salts-starch agar and glycerol-asparagine agar. Spore surface: Smooth (Fig. 65).

Special morphological characteristics: Fragmentation of the substrate mycelium may be seen on glycerol-asparagine aga $r$ in 16 days (Fig. 66).

Color of colony: Aerial mass color in the Yellow or White colorseries on yeast-malt agar, oatmeal agar, salts-starch aga $\mathbf{r}$ and glycerol-asparagine agar.

Reverse side of colony: No distinctive pigments (pale or grayish yellow to yellowish brown) on oatmeal agar, salts-starch agar and glycerol-asparagine agar; yellow is modified by red (to orange or reddish brown) on yeast-malt agar. This pigment changes from reddish brown to pale brown with addition of $0.05 \mathrm{~N} \mathrm{HCl}$.

Color in medium: Melanoid pigments are not formed in peptoneyeast-iron agar, tryosine agar or tryptone-yeast broth (but according to one observer, some brown pigment is formed in the medium in Gauze's Medium No. 2). Red (pink to light reddish brown) pigment is found in the medium in yeast-malt agar and oatmeal agar; it may or may not be seen in salts-starch agar and glycerol-asparagine agar. This pigment is $\mathrm{pH}$ sensitive, changing from pink or reddish brown to yellow when tested with $0.05 \mathrm{~N} \mathrm{HCl}$.

Carbon utilization: D-Glucose, L-arabinose, D-xylose, D-mannitol, D-fructose and rhamnose are utilized for growth. Only a trace of growth is seen with i-inositol, sucrose or raffinose.

Actinomyces flavescens Krasil'nikov, Korenyako and Nikitina. Description: Krasil'nikov, Korenyako and Nikitina in Krasil'nikov 1965, 220. Type strain: INMI 1015B (ibid.; N.A. Krasil'nikov, personal communication, Dec., 1966). ISP 5428 from N.A. Krasil'nikov as INMI 1015B. I SP description by Group D-10.

Spore chain morphology: Section Spirales or RA. Open spirals with 4-7 turns, primitive spirals, strongly flexuous spore chains (Fig. 67) and chains terminating in partial spirals or hooks are all common. Mature spore chains are long, often with more than 50 spores per chain. This morphology is seen on yeast-malt agar, oatmeal agar and salts starch agar. Spore surface: Smooth (Fig. 68).

Color of colony: Aerial mass color in the White or Yellow color series on yeast-malt agar, oatmeal agar, salts-starch agar and glycerolasparagine agar.

Reverse side of colony: Light yellow to deep orange yellow on yeast-malt agar, oatmeal agar, salts-starch agar and glycerol-asparagine agar.

Color in medium: Melanoid pigments are not formed in peptoneyeast-ivon agar, tyrosine agar or tryptone-yeast broth. Yellow or orange-yellow pigment is found in the medium in yeast-malt agar, oatmeal agar, salts-starch agar and glycerol-a sparagine agar. This pigment is not $\mathrm{pH}$ sensitive when tested with $0.05 \mathrm{~N} \mathrm{NaOH}$ or $\mathrm{HCl}$.

Carbon utilization: D-Glucose and $\underline{L}$-arabinose are utilized for growth. Some growth occurs on the basal medium without carbon and 


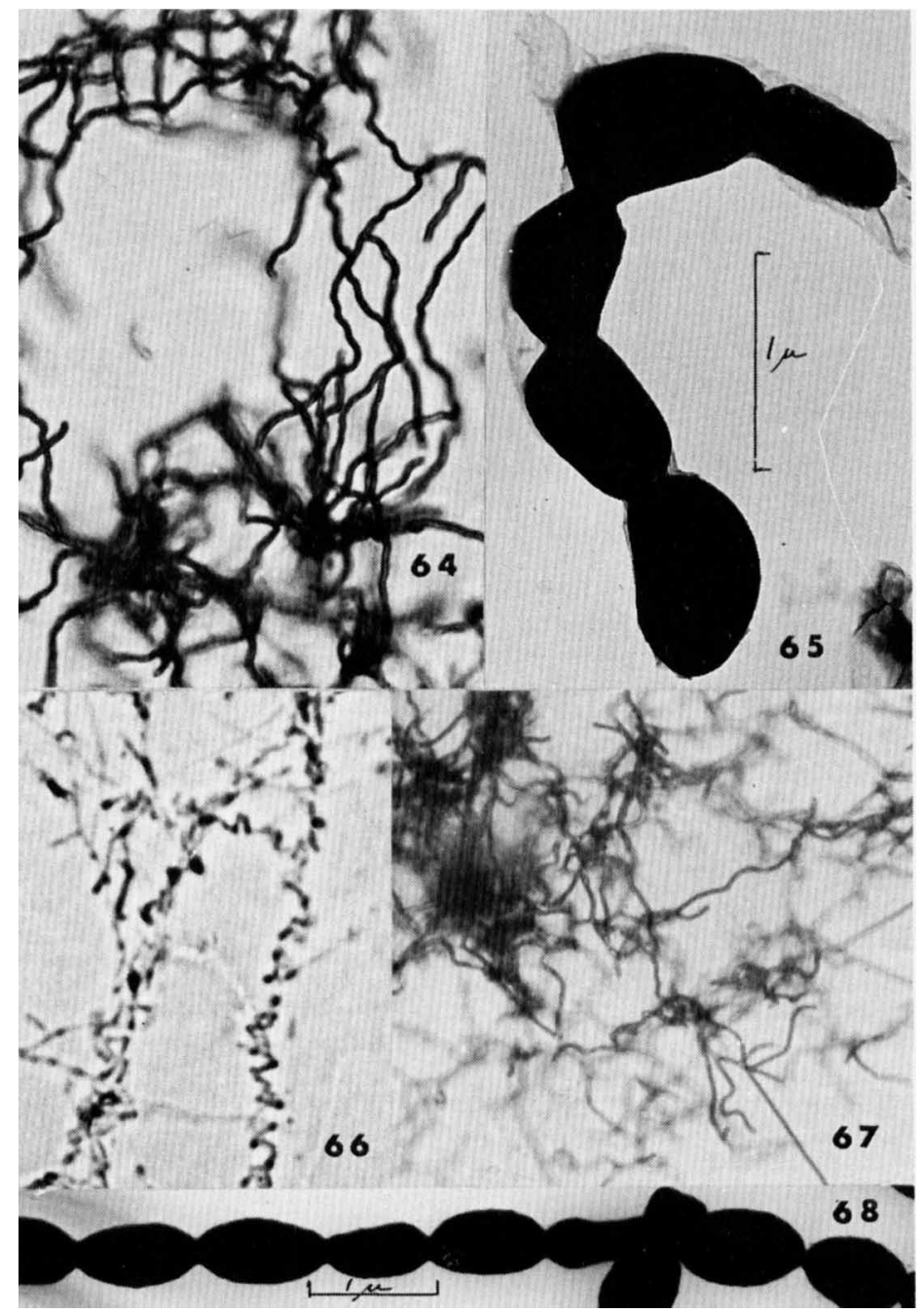

Figure 64. S. fimicarius. Flexuous ( $\underline{\mathrm{RF}}$ ) spore chains (X 315) on yeastmalt agar, 14 days.

Figure 65. S. fimicarius. Smooth spores; electron micrograph from 21 day culture on glycerol-as paragine agar.

Figure 66. S. fimicarius. Fragmentation of substrate mycelium on glycerol-a sparagine agar, 16 days (X 800).

Figure 67. A. flavescens. Primitive spirals and strongly flexuous spore chains $\overline{\text { on }} \overline{\text { yeast-malt }}$ agar, 20 days.

Figure 68. A. flavescens. Smooth spores; electron micrograph from 14 day culture on yeast-malt agar. 
reports vary on the utilization of D-xylose, i-inositol, D-mannitol, D-fructose, rhamnose, sucrose and raffinose; utilization of these carbon sources is doubtful.

Actinomyces flavidovirens Kudrina. Description: Kudrina in Gauze et al. 1957, 90 and 92. Type strain: INA 12287 (ibid.; Preobrazhenskaya, personal communication). Streptomyces flavidovirens (Kudrina) Pridham et al. 1958, 66. ISP 5150 from T.P. Preobrazhenskaya as INA 12287 . ISP description by Group C-2.

Spore chain morphology: Section Retinaculiaperti or RF. Preponderance of very flexuous spore chains (Fig. 69), some of which appear as imperfect or open spirals together with some straight or slightly flexuous chains (Fig. 70) makes this strain difficult to categorize in respect to spore chain morphology. The illustration accompanying the original description (op. cit.) would place this species in Section Spirales but regular spirals were not found by ISP observers. Mature spore chains moderately long with 10 to 50 or more spores per chain. This morphology is seen on yeast-malt agar, oatmeal agar, salts-starch agar and glycerol-a sparagine agar. Spore surface: Smooth (Fig. 71).

Color of colony: Aerial mass color in the Yellow or White colorseries on yeast-malt agar, oatmeal agar, salts-starch agar and glycerolasparagine agar. The nearest matching color tab in the Yellow series is $2 \mathrm{ba}$, pale yellow.

Reverse side of colony: No distinctive pigments (colorless to pale yellow or light grayish yellow) on yeast-malt agar, oatmeal agar, saltsstarch agar and glycerol-asparagine agar.

Color in medium: Melanoid pigments are not formed in peptoneyeast-iron agar, tyrosine agar or tryptone-yeast broth. Trace of yellow pigment may or may not be found in the medium in yeast-malt agar, oatmeal agar, salts-starch agar or glycerol-asparagine agar. This pigment, when present, is not $\mathrm{pH}$ sensitive when tested with 0.05 $\mathrm{N} \mathrm{NaOH}$ or $\mathrm{HCl}$.

Carbon utilization: $\underline{D}-G$ lucose, L-arabinose and $\underline{D}$-xylose are utilized for growth. Reports vary on utilization of i-inositol, D-fructose, rhamnose and sucrose. No growth or only trace of growth with Dmannitol and raffinose.

Streptomyces flavogriseus (Duché) Waksman. Descriptions: Actinomyces flavogriseus Duché 1934, 341 -346; Streptomyces flavogriseus (Duché) Waksman 1953, 55. Type strain: Strain of Heim (Duché, op cit.) = CBS 101.34 (G.A. deVries, personal communication, Jan., 1966.) ISP 5323 from G.A. deVries as CBS 101.34. ISP description by Group C -5 .

Spore chain morphology: Section Rectiflexibiles (Fig. 72). Mature spore chains have 3 to 10 , or often more than 10 spores ser chain; long chains are not common. This morphology is seen on yeast-malt agar, oatmeal agar, salts-starch agar and glycerol-asparagine agar. Spore surface: Smooth (Fig. 73).

Color of colony: Aerial mass color in the Gray color-series on yeast-malt agar, oatmeal agar, salts-starch agar and glycerol-asparagine agar.

Reverse side of colony: Strong yellow or orange-yellow on yeast malt agar, grayish yellow to olive brown on oatmeal agar, greenish 


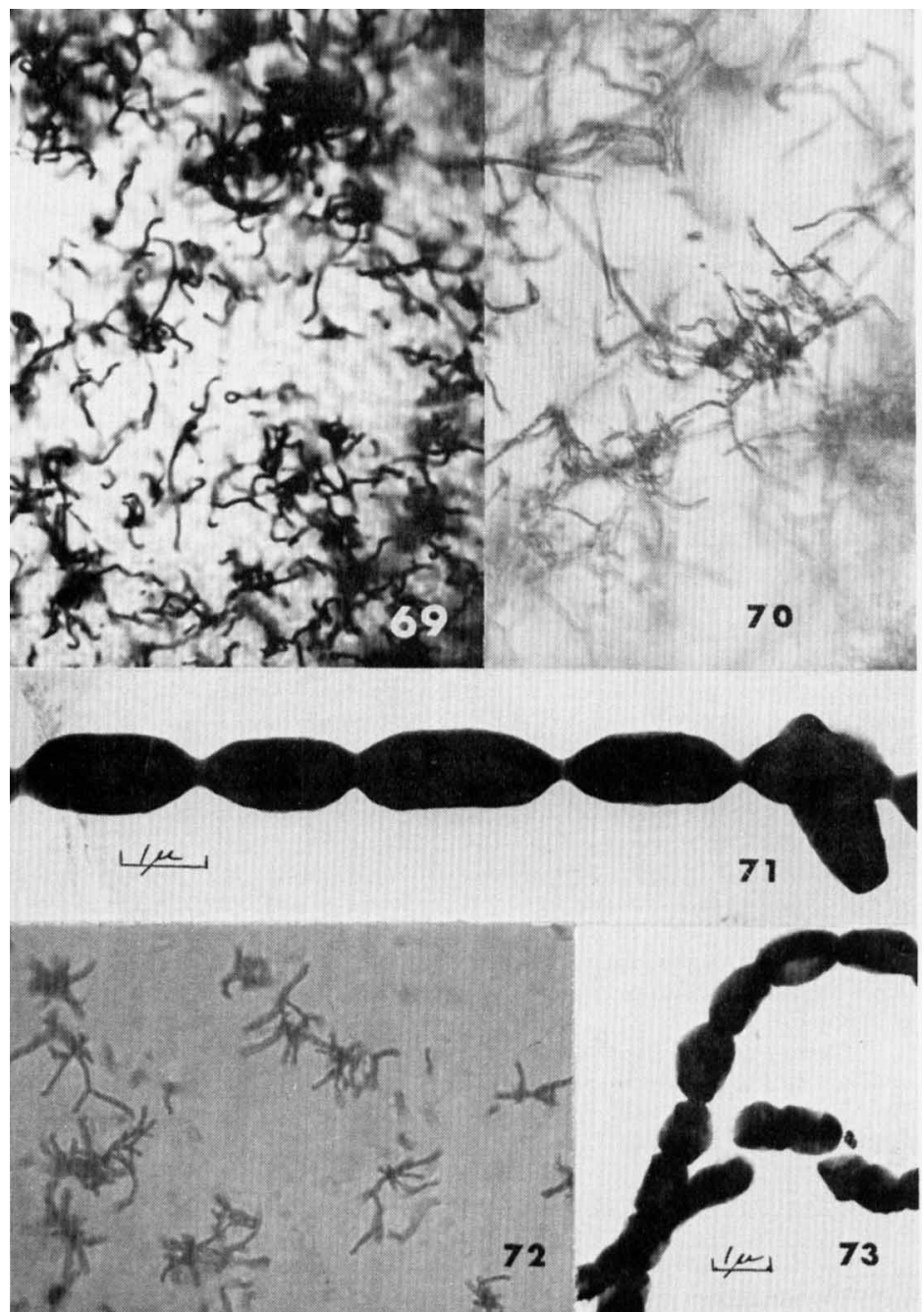

Figure 69. A. flavidovirens. Flexuous spore chains with hooks and imperfect spirals suggesting RA morphology on yeast-malt agar, 18 days.

Figure 70. A. flavidovirens, RF spore chains on yeast-malt agar, 21 days.

Figure 7 I. A. flavidovirens. Smooth spores; electron micrograph from 21 day culture on glycerol-as paragine agar.

Figure 72. S. flavogriseus, RF spore chains (X 537) on yeast-malt agar, $1 \overline{4}$ days.

Figure 73. S. flavogriseus. Smooth spores; electron micrograph from 10 day culture on salts-starch agar. 
yellow on salts-starch agar; reverse mycelium pigment is not a $\mathrm{pH}$ indicator.

Color in medium: Melanoid pigments are not formed in peptoneyeast-iron agar, tyrosine agar or tryptone-yeast broth. No pigment, or only a trace of yellow, is found in the medium in yeast-malt agar, oatmeal agar, salts-starch agar and glycerol-asparagine agar.

Carbon utilization: D-Glucose, L-arabinose, D-xylose, D-mannitol, D-fructose and rhamnose are utilized for growth. No growth or only trace of growth with $\underline{i}$-inositol, sucrose and raffinose.

Streptomyces flocculus (Duché) Waksman and Henrici. Descriptions: Actinomyces flocculus Duché 1934, 300-305. Streptomyces flocculus (Duché) Waksman and Henrici 1948, 955. Type strain: No. $373=$ ETH 24454 (Madame J. Nicot, personal communication, Jan., 1965). ISP 5327 from Madame J. Nicot as No. 373 ( =ETH 24454). ISP description by Group C-7.

Spore chain morphology: Section Spirales. Spiral spore chains are usually formed on oatmeal agar; spirals of two or more turns may be formed or short chains of only 3 to 10 spores may form loops, partial spirals or hooks. Sporulating aerial mycelium is usually poorly developed on yeast-malt agar, salts-starch agar and glycerol-a sparagine agar so that spirals and hooks may be sparse or absent. The weak growth of this strain on most media was noted by Duché in his original description (op. cit). Spore surface: Smooth (Fig. 74).

Color of colony: Aerial mass color in the White or Yellow color series on yeast-malt agar, oatmeal agar, salts-starch agar and glycerolasparagine agar. The most representative color tab in the Yellow colorseries is 2 ba (pale yellow).

Reverse side of colony: No distinctive pigments (colorless or pale grayish yellow) on yeast-malt agar, oatmeal agar, salts-starch agar and glycerol-asparagine agar.

Color in medium: Melanoid pigments are not formed in peptoneyeast-iron agar, tyrosine agar or tryptone-yeast broth. No pigment is found in the medium in yeast-malt agar, oatmeal agar, salts-starch agar or glycerol-asparagine agar.

Carbon utilization: D-Glucose, L-arabinose, D-xylose, $\underline{\text { in-inositol, }}$ D-mannitol, D-fructose and sucrose are utilized for growth. Utilization of rhamnose and raffinose is doubtful.

Actinomyces fumanus Sveshnikova. Description: Sveshnikova in Gauze et al. 1957, 59 and 61. Type strain INA 10256/54 (Preobrazhenskaya, personal communication, Jan., 1964). Streptomyces fumanus (Sveshnikova) Pridham et al. 1958, 67. ISP 5154 from T.P. Preobrazhenskaya as INA 10256/54. ISP description by Group B - 7 .

Spore chain morphology: Section Spirales (Fig. 75). Mature spore chains moderately long with 10 to 50 or more spores per chain. This morphology is seen on yeast-malt agar, oatmeal agar, salts-starch agar and glycerol-asparagine agar. Spore surface: Smooth (Fig. 76).

Color of colony: Aerial mass color in the Red color-series on yeast-malt agar and glycerol-asparagine agar; Red or sometimes Yellow color-series on oatmeal agar and salts-starch agar.

Reverse side of colony: Light grayish yellow may or may not change to dark brown on salts-starch agar and glycerol-asparagine agar 


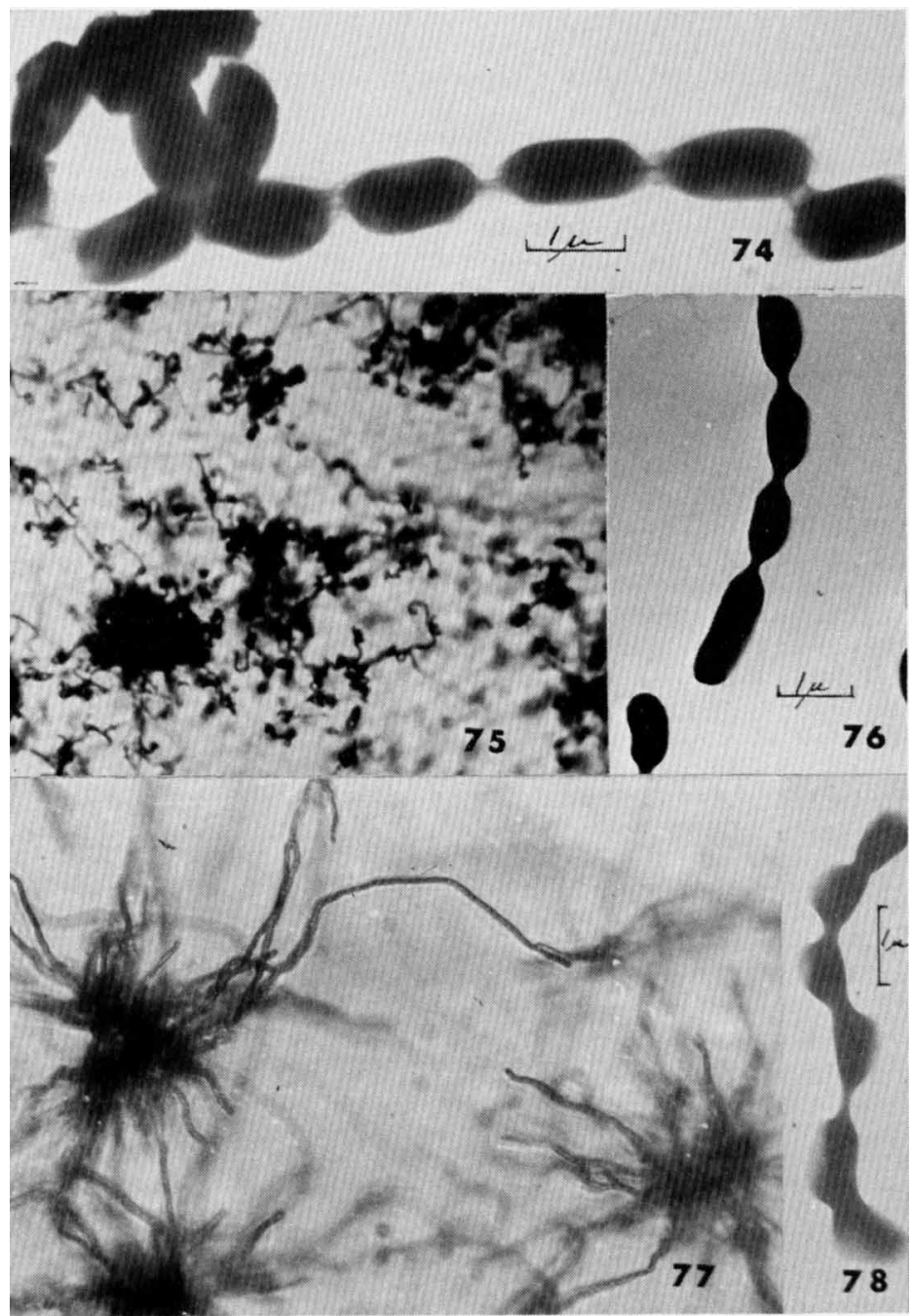

Figure 74. S. flocculus. Smooth spores; electron micrograph from 20 day culture on yeast-malt agar.

Figure 75. S. fumanus. Spiral spore chains on oatmeal agar.

Figure 76. $\overline{\text { S. }}$ fumanus. Smooth spores; electron micrograph from 14 day culture on yeast-malt agar.

Figure 77. S. gougeroti. RF spore chains (X 600) on yeast-malt agar, 14 days.

Figure 78 . S. gougeroti. Smooth spores; electron micrograph from I 4 day culture. 
or to orange-yellow or strong brown on yeast-malt agar and oatmeal agar.

Color in medium: Malnoid pigments are not formed in peptoneyeast-iron agar, tyrosine agar or tryptone-yeast broth. No pigment (or only a trace of yellow or greenish yellow) is found in the medium in yeast-malt agar, oatmeal agar, salts-starch agar or glycerola sparagine agar.

Carbon utilization: D-Glucose, L-arabinose, D-xylose, D-mannitol, D-fructose, rhamnose and raffinose are utilized for growth. No growth or only trace of growth on $\underline{i}$-inositol and sucrose.

Streptomyces gougeroti (Duché) Waksman and Henrici. Descriptions: Actinomyces gougeroti Duché 1934, 272-278. Streptomyces gougeroti (Duché) Waksman and Henrici 1948, 947. Type strain: CBS 422. 34 Duché strain from Gougerot (G.A. deVries, personal communication, Jan., 1966). ISP 5324 from G.A. deVries as CBS 422.34. ISP description by Group C-6.

Spore chain morphology: Section Rectiflexibiles on yeast-malt agar (Fig. 77); aerial mycelium is very thin on this medium and is usually not produced on oatmeal agar, salts-starch agar and glycerol-a sparagine agar. Spore chains, when produced, are moderately short with 3 to 10 or more spores per chain. Two observers recorded fragmentation of the substrate mycelium and this characteristic is also mentioned in Duché's original description (op. cit.). Spore surface: Smooth (Fig. 78).

Color of colony: Aerial mass color in the White or Yellow (2ba, pale yellow) color-series on yeast-malt agar. Aerial mycelium is usually thin on yeast-malt agar and is often inadequate for color observation on all other ISP media.

Reverse side of colony: No distinctive pigments (colorless to grayish yellow) on yeast-malt agar, oatmeal agar, salts-starch agar and glycerol-asparagine agar.

Color in medium: Melanoid pigments are not formed in tyrosine agar or tryptone-yeast broth; reports vary on production of a dark pigment in peptone-yeast-iron agar. No pigment is found in the medium in yeast-malt agar, oatmeal agar, salts-starch agar or glycerolasparagine agar.

Carbon utilization: D-Glucose, D-xylose, D-mannitol and D-fructose are utilized for growth. Reports vary on utilization of L-arabinose, i-inositol and rhamnose. No growth or only trace of growth on sucrose and raffinose.

Streptomyces griseoflavus (Krainsky) Waksman and Henrici. Descriptions: Actinomyces griseoflavus Krainsky, 1914, 680 and 684 . Streptomyces griseoflavus (Krainsky) Waksman and Henrici 1948, 948. Type strain: Ciferri A28 Nr. 1118 = CBS 409.52 (= ETH 10249): Neotype (Hutter 1967, 20). ISP 5456 from G.A. deVries as CBS 409.52 = Ciferri A28 Nr. 1118 . ISP description by Group D-7.

Spore chain morphology: Section Spirales (Fig. 79). Mature spore chains generally 10 to 50 spores per chain, although shorter chains may also be common. This morphology is seen on yeast-malt agar, oatmeal agar, salts-starch agar and glycerol-asparagine agar. Spore surface: Spiny (Fig. 80).

Color of colony: Aerial mass color in the Gray color-series on yeast-malt agar, oatmeal agar, salts-starch agar and glycerol- 
asparagine agar (immature cultures may appear to be in the Yellow color-series on glycerol-asparagine agar).

Reverse side of colony: Yellow to orange-yellow on yeast-mait agar, oatmeal agar, salts-starch agar and glycerol-asparagine agar. Reverse mycelium pigment is not a $\mathrm{pH}$ indicator.

Color in medium: Melanoid pigments are not formed in peptoneyeast-iron agar, tyrosine agar or tryptone-yeast broth. No pigment is found in the medium in yeast-malt agar, oatmeal agar, salts-starch agar or glycerol-asparagine agar.

Carbon utilization: D-Glucose, L-arabinose, D-xylose, i-inositol, D-mannitol, D-fructose and rhamnose are utilized for growth. No growth or only trace of growth with sucrose or raffinose.

Streptomyces griseolavendus Sumiki. Description: Sumiki 1957, Japanese Patent 32-6296. Type strain: IAM 11 A-458 (ibid.). Note: This strain number also designates the type strain for $\underline{\mathrm{S}}$. lavendulae subsp. grasserius Kutschaeva et al. 1962, 103-122. ISP $\overline{5385 \text { from }}$ H. Yonehara, Inst. Appl. Microbiol., Univ. of Tokyo via Akio Seino, Tokyo, as IAM 2A-458. ISP description by Group D-5.

Spore chain morphology: Section Retinaculiaperti with many RF spore chains. Mature spore chains are generally very long with more than 50 spores per chain. Straight or slightly flexuous chains are most common, but some chains show terminal spirals, hooks or loops. Collapse of terminal loops and adhesion of spores may give rise to clusters of spores or small masses of spores at the ends of the long chains. This morphology is seen on yeast-malt agar, oatmeal agar, salts-starch agar and glycerol-asparagine agar. One observer found terminal spirals or hooks to be more numerous on Czapek's sucrose agar than on ISP media. Spore suxface: Smooth (Fig. 81).

Special morphological characteristics: In addition to the terminal clusters of spores noted above, observers record sclerotia formation and aggregation of spores in moisture droplets.

Color of colony: Aerial mass color in the Red color-series on yeast-malt agar, oatmeal agar, salts-starch agar and glycerol-asparagine agar; nearest matching color tabs include 4 ge (light grayish reddish brown) and $5 e c, 5 \mathrm{dc}$ or $5 \mathrm{cb}$ (grayish yellowish pink).

Reverse side of colony: No distinctive pigments (light brown to light grayish reddish brown on yeast-malt agar, pale yellow or grayish yellow on oatmeal agar, salts-starch agar and glycerol-asparagine agar).

Color in medium: Melanoid pigments are formed in peptone-yeastiron agar and tryptone-yeast broth; a trace of dark pigment may also be found in tyrosine agar. A greenish yellow pigment is found in the medium in yeast-malt agar, oatmeal agar and salts-starch agar, this pigment is not $\mathrm{pH}$ sensitive when tested with $0.05 \mathrm{~N} \mathrm{NaOH}$ or $\mathrm{HCl}$.

Carbon utilization: D-Glucose and D-fructose are utilized for growth. No growth or only trace of growth with L-arabinose, D-xylose, i-inositol, D-mannitol, rhamnose, sucrose or raffinose. 


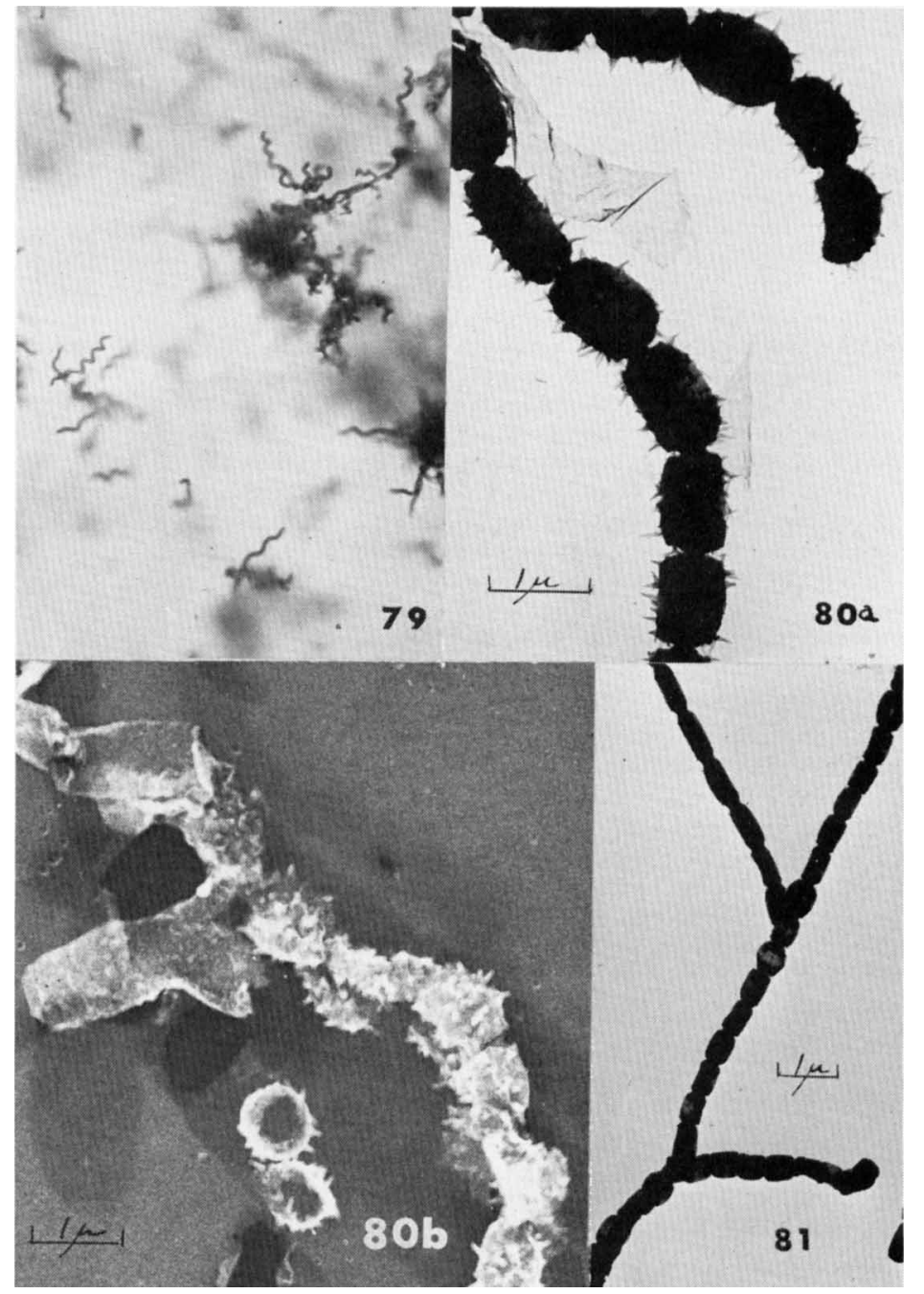

Figure 79. S. griseoflavus. Spiral spore chains (X 300) on oatmeal agar, 14 days.

Figure 80. S. griseoflavus. Spiny spores. (a) Electron micrograph silhouette from 14 day culture on oatmeal agar. (b) Electron micrograph preparation from 14 day culture on yeast-malt agar.

Figure 81 . S. griseolavendus. Smooth spores; electron micrograph from $20^{-}$day culture on yeast-malt agar. 
Actinomyces griseoloalbus Kxdrina. Description: Kudrina in Gauze etal. 1957, 112-115. Type strain: INA 1875/54 (ibid.; Gauze in Gottlieb, 1968). Streptomyces griseoloalbus (Kudrina) Pridham et al. 1958, 58. ISP 5468 from G. F. Gauze as INA 1875/54. ISP description by Group D-4.

Spore chain morphology: Section Rectiflexibiles (Fig. 82). Aerial hyphae may be sterile or spores may be poorly defined as shown in Fig. 83. Spore surface: Smooth. Terminal swellings of two types are sometimes seen on aerial hyphae (Fig. 84). Aerial mycelium is best developed on yeast-malt agar and salts-starch agar, but a good sporulating aerial mycelium is not found on any of the ISP media.

Special morphological characteristics: In addition to the terminal swellings noted above, one observer records fragmentation of the substrate mycelium on yeast-malt agar and salts-starch agar.

Color of colony: Aerial mass color in the White or Yellow (2ba, pale yellow) color-series on yeast-malt agar and salts-starch agar; a white aerial mycelium may or may not be formed on oatmeal agar and glycerol-asparagine agar, but this mycelium is usually sterile.

Reverse side of colony: Light yellow or grayish yellow to orangeyellow on yeast-malt agar, oatmeal agar, salts-starch agar and glycerol-asparagine agar.

Color in medium: Melanoid pigments are not formed in peptoneyeast-iron agar, tyrosine agar or tryptone-yeast broth. A trace of yellow to orange-yellow pigment may be found in the medium in yeastralt agar, oatmeal agar, salts-starch agar or glycerol-asparagine agar. This pigment is not $\mathrm{pH}$ sensitive when tested with $0.05 \mathrm{~N} \mathrm{NaOH}$ or $\mathrm{HCl}$.

Carbon utilization: D-Glucose, L-arabinose, D-xylose, i-inositol, D-mannitol, D-fructose, rhamnose and sucrose are utilized for growth. Reports vary on the utilization of raffinose. 


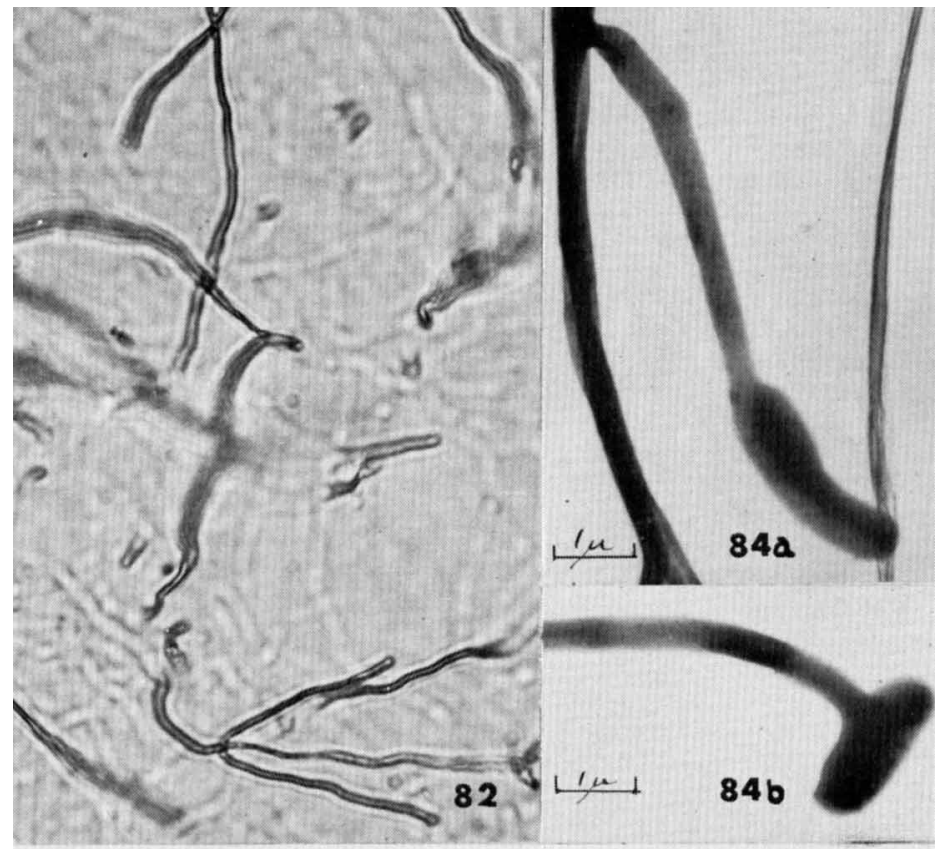

83

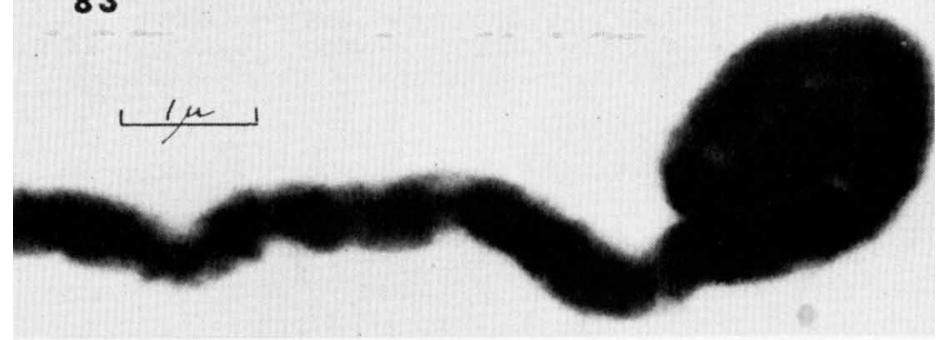

Figure 82. A. griseoloalbus. RF spore chains (X 800 ) on salts-starch agar, $2 \overline{\mathrm{l}}$ days.

Figure 83. A. griseoloalbus. Smooth, but poorly defined spores; electron micrograph from 21 day culture on yeast-malt agar.

Figure $84 \mathrm{a}, \mathrm{b}$. A. griseoloalbus. Terminal swellings of two types on sterile aerial hyphae; electron micrograph from 14 day culture on glycerol-asparagine agar. 
Actinomyces griseorubiginosus Ryabova and Preobrazhenskaya. Description: Ryabova and Preobrazhenskaya in Gauze et al. 1957 , 186 and 193. Type strain: INA 7712 (neotype, G.F. Gauze, personal communication, April, 1967). Streptomyces griseorubiginosus (Ryabova and Preobrazhenskaya) Pridham et al. 1958, 62. ISP 5469 from G.F. Gauze as INA 7712. ISP description by Group D-5.

Spore chain morphology: Section Rectiflexibiles. The very long spore chains of more than 50 spores per chain may also form a few open loops and terminal hooks suggestive of RA morphology. This morphology is seen on yeast-malt agar, oatmeal agar, salts-starch agar and glycerol-asparagine agar. Spore surface: Smooth (?); two observers found only smooth spores (Fig. 85), a third observer found both smooth and spiny spores (Fig. 86).

Special morphological characteristics: Long aerial hyphae may be entangled, forming knots (Fig. 87) and sclerotia-like bodies on yeastmalt agar, oatmeal agar, glycerol-a sparagine agar or on Czapek's sucrose agar. One observer records in situ germination of spores in 7 days on Czapek's sucrose agar.

Color of colony: Aerial mass color in the Gray color-series (2dc, yellowish gray to 3 fe, light brownish gray or $5 \mathrm{fe}$, light grayish reddish brown) on yeast-malt agar, oatmeal agar, salts-starch agar and glycerol-asparagine agar.

Reverse side of colony: Brown, grayish reddish brown or dark brown on yeast-malt agar, oatmeal agar, salts-starch agar and glycerol-asparagine agar. Reverse mycelium pigment is a pH indicator changing from yellowish brown to pink or red with addition of $0.05 \mathrm{~N}$ $\mathrm{NaOH}$ and from yellowish brown to gray with addition of $0.05 \mathrm{~N} \mathrm{HCl}$.

Color in medium: Melanoid pigments are formed in peptone-yeastiron agar, tyrosine agar and tryptone-yeast broth. Red or reddish brown pigment is found in the medium in yeast-malt agar, oatmeal agar and glycerol-asparagine agar and yellow or yellowish brown pigment is found in the medium in salts-starch agar. This pigment is $\mathrm{pH}$ sensitive showing the same changes noted for reverse mycelium pigment.

Carbon utilization: D-Gluclose, L-arabinose, D-xylose, i-inositol, D-mannitol, D-fructose, rhamnose, sucrose and raffinose are all utilized for growth.

Streptomyces hei ini (Duché) Pridham, Hesseltine and Benedict. Descriptions: Actinomyces heimi Duché 1934, 359-364; Streptomyces heimi (Duché) Pridham et al. 1958, 74; Actinomyces 168, Waksman 1919, 134-136; Streptomyces flaveolus (Waksman) Waksman and Henrici 1948, 936. Type strain: Waksman No. 168 (Dưché 1934, op. cit.), hence an objective synonym for Streptomyces flaveolus (Waksman) Waksman and Henrici 1948. ISP 5328 from Madame J. 


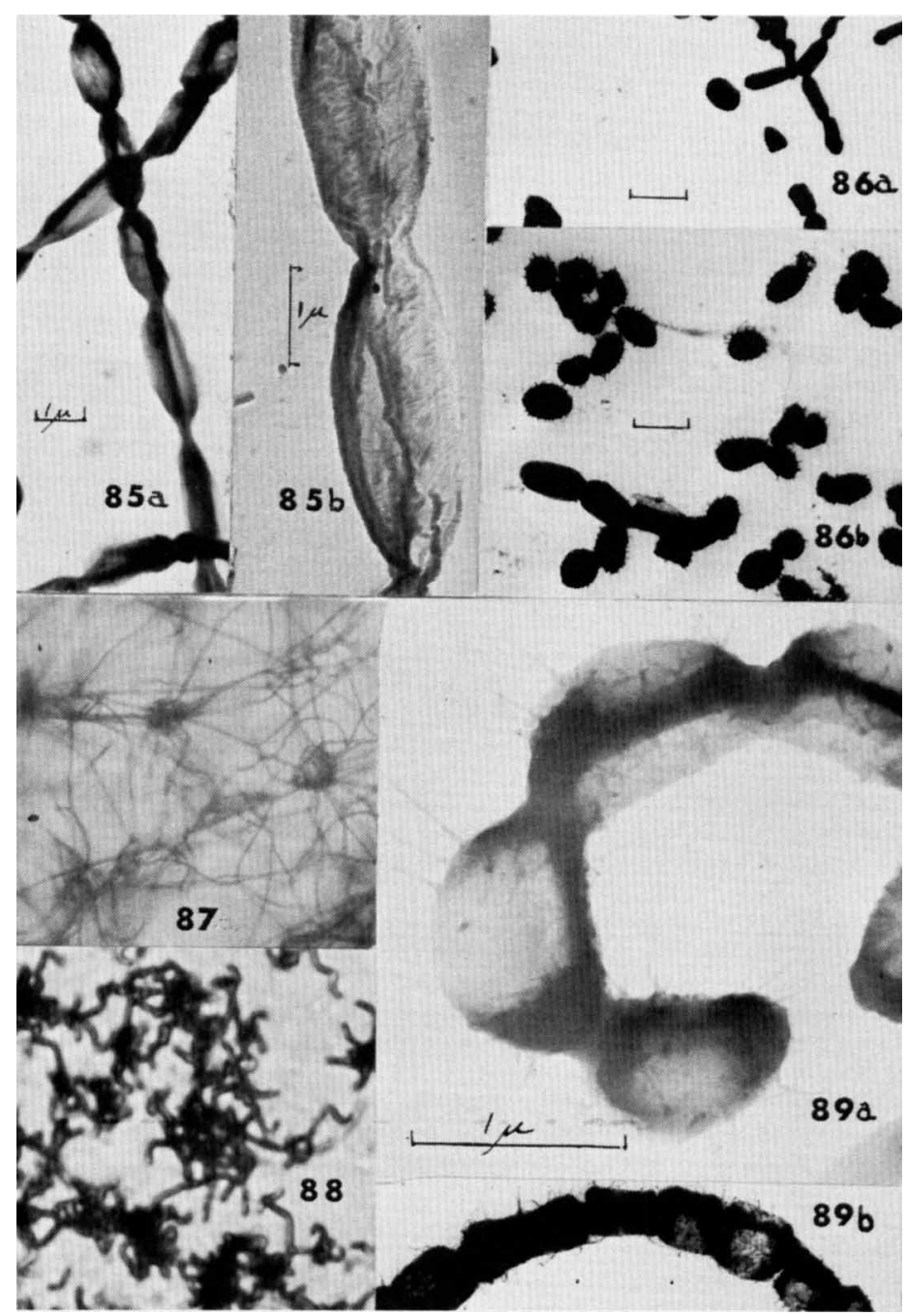

Figure 85. A, griseorubiginosus. Smooth spores. (a) Direct impression mount from 12 day culture on 'Czapek's sucrose agar. (b) Carbon repligraph from same preparation. See also Fig. $86 \mathrm{a}, \mathrm{b}$,

Figure $86 \mathrm{a}, \mathrm{b}$. A. griseorubiginosus. Spiny and smooth spores from same preparation; yeast-malt agar, 20 days.

Figure 87. A. griseorubiginosus. Knots in long aerial hyphae on oatmeal agar (X 250), 7 days).

Figure 88. A. heimi. Ir regular open spirals and flexuous spore chains (X 500) on yeast-malt agar, I 4 days.

Figure 89. A. heimi. Hairy to spiny spore chains. (a) Electron micrograph from 20 day culture on yeast-malt agar. (b) Electron micrograph from 14 day culture on yeast-malt agar. 
Nicot as No. 374 LC Paris = strain received by Duché from Baarn as "No. 168 Waksman". ISP Description by Group C-8.

Spore chain morphology: Section Spirales, but short spore chains of 3 to 10 spores usually form hooks, incomplete spirals or open irregular spirals of only 1 or 2 turns (Fig. 88). This morphology is seen on yeast-malt agar, oatmeal agar, salts-starch agar and glycerolasparagine agar. Spore surface: Hairy to spiny (Fig. 89).

Color of colony: Aerial mass color in the Gray (or Red) colorseries. Two observers selected color tabs 3 fe or 5 fe (light brownish gray or light reddish grayish brown) from Gray color wheel as the nearest matching color on yeast-malt agar, oatmeal agar, salts -starch agar and glycerol-asparagine agar; the third observer selected $5 \mathrm{de}$ (grayish yellowish pink) from the Red color-series as the nearest matching color for the aerial mass color on these media.

Reverse side of colony: No distinctive pigments (nearly colorLess to pale yellow, orange-yellow or light yellowish brown) on yeastmalt agar, oatmeal agar, salts-starch agar and glycerol-asparagine agar.

Color in medium: Melanoid pigments are not formed in peptoneyeast-iron agar, tyrosine agar or tryptone-yeast broth. Yellow pigment is found in the medium in yeast-malt agar, oatmeal agar and glycerol-asparagine agar. This pigment is not $\mathrm{pH}$ sensitive when tested with $0.05 \mathrm{~N} \mathrm{NaOH}$ or $\mathrm{HCl}$.

Carbon utilization: D-Glucose, L-arabinose, D-xylose, i-inositol, D-mannitol, D-fructose, rhamnose and sucrose are utilized for growth; only a trace of growth is found with raffinose.

Streptomyces intermedius (Krager emend. Wollenweber) Waksman. Descriptions: Oospora intermedia Krager 1890, 1905 (original Kruger references not seen, cited in Hutter 1967, p. 220 and 248; Kra sil'nikov 1941, p. 35). Actinomyces intermedius (Krager) Wollenweber 1920, 16; 1922, 26. Streptomyces intermedius (Kruger emend. Wollenweber) Waksman in Waksman and Lechevalier 1953, 116. Type strain: CBS strain of Wollenweber (neotype), deposited by Wollenweber in 1921 (G.A. deVries, CBS, personal communication, Sept., 1966). ISP 5372 from G.A. deVries as CBS strain Wollenweber. JSP description by Group D-3.

Spore chain morphology: Section Rectiflexibiles (Fig. 90). Flexuous chains of 10 to 50 spores occur as tufts or clusters on yeastmalt agar, oatmeal agar, salts-starch agar and glycerol-asparagine agar, although production of sporulating aerial mycelium is not uniformly good in different laboratories with this strain. Spore surface: Smooth (Fig. 91).

Color of colony: Sporulating aerial mycelium is usually inadequate for determination of aerial mass color. When aerial mycelium is formed, it is in the Yellow color-series ( $1 \mathrm{cb}$, pale yellow-green; 2 ba, pale yellow) on yeast-malt agar, oatmeal agar, salts-starch agar and glycerol-asparagine agar. (Aerial mycelium is described as light green or light gray in the descriptions of Krasil'nikov, 1941 and Waksman, 1953.)

Reverse side of colony: No distinctive pigments (colorless to pale grayish yellow or light yellowish brown) on yeast-malt agar, oatmeal agar, salts-starch agar and glycerol-a sparagine agar. 


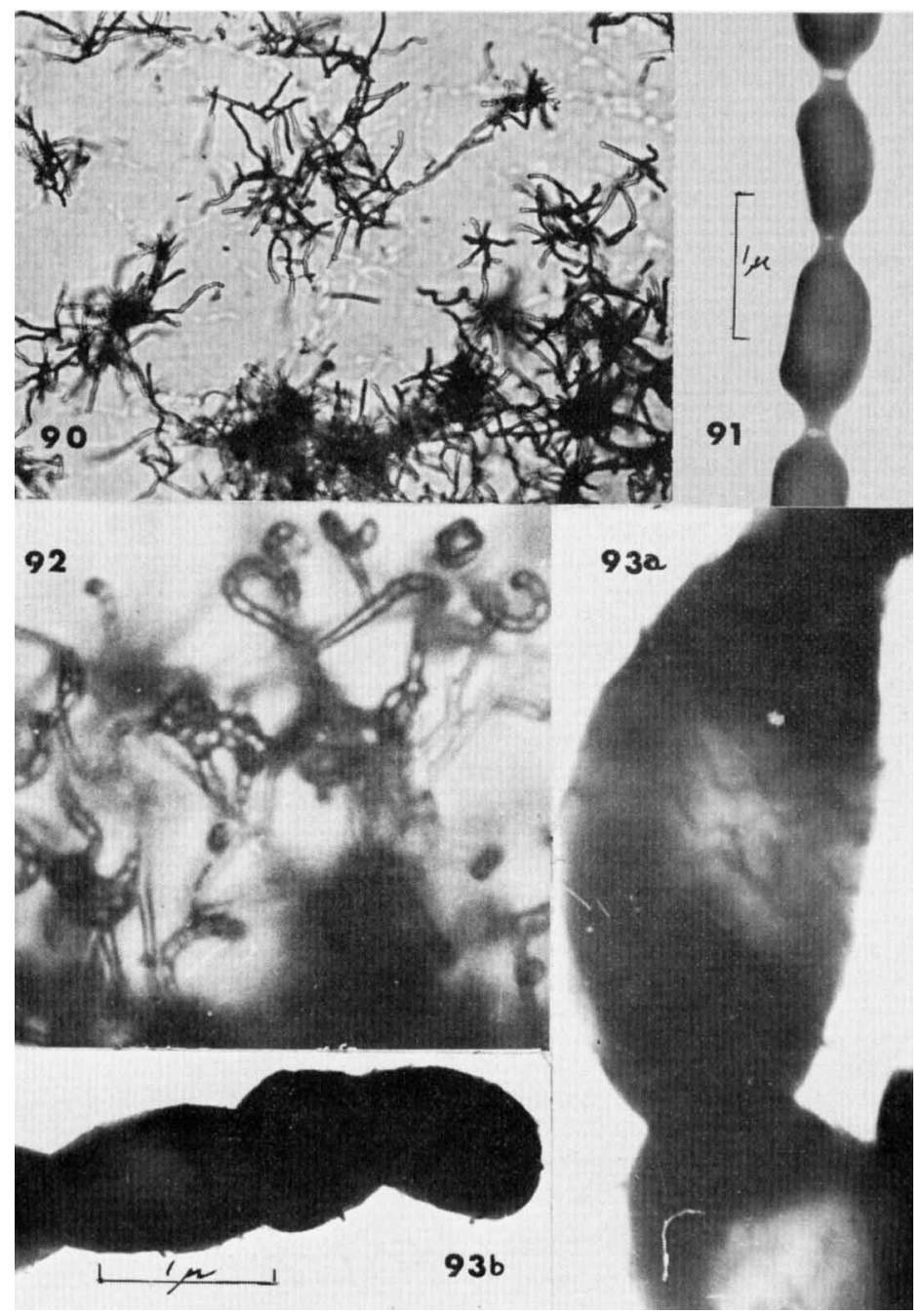

Figure 90. S. intermedius. RF spore chains (X 300) on yeast-malt agar, 14 days.

Figure 91. S. intermedius. Smooth spores; electron micrograph from 15 day culture on yeast-malt agar.

Figure 92. S. ipomoea. Spiral spore chains (X 1000) on oatmeal agar, 21 days.

Figure 93. S. ipomoea. Smooth spores with wrinkles or ridges.

(a) Sing $\bar{l}$ spore, much enlarged, from 16 day culture on salts starch agar. (b) Seven day culture on yeast-malt agar. 
Color in medium: Melanoid pigments are not formed in peptoneyeast iron agar, tyrosine agar or tryptone-yeast broth. No pigment, or only a trace of yellow, is found in the medium in yeast-malt agar, oatmeal agar, salts-starch agar or glycerol-asparagine agar.

Carbon utilization: D-Glucose, L-arabinose, D-xylose, D-mannitol and D-fructose are utilized for growth. No growth or only trace of growth with i-inositol, rhamnose, sucrose and raffinose.

Streptomyces ipomoea (sic) (Person and Martin) Waksman and Henrici. Descriptions: Actinomyces ipomoea Person and Martin 1940, 91 3-926; Streptomyces ipomoea (Person and Martin) Waksman and Henrici 1948, 958. (Spelling corrected to $\underline{\mathbf{S}}$. ipomoeae by Waksman 1957, 813. Type strain: Martin 9820 (neotype isolated by W.J. Martin in 1966). Personal communication from L.H. Person (Feb., 1966) and W.J. Martin (Aug., 1966) state that the ATCC strain of $\underline{\text { S. ipomoea }}$ (ATCC 11747, received from Waksman as IMRU 3476 = ETH 1 6704 ; PSA 219) is not representative of the Actinomyces ipomoea Person

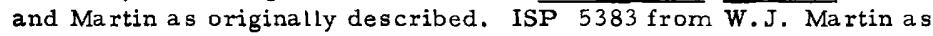
9820,1966 isolate. ISP description by Group D-2.

Spore chain morphology: Section Spirales (Fig. 92). Spore chains are usually short with 3 to 10 spores per chain and may give rise to hooks, loops, incomplete spirals or spirals of only 1 or 2 turns. This morphology is seen on yeast-malt agar, oatmeal agar and salts-starch agar, but typical aerial mycelium is usually not found on glycerolasparagine agar. Spore surface: Smooth (Fig. 93); wirinkles or folds may be present.

Color of colony: Aerial mass color in the Blue color-series on yeast-malt agar, oatmeal agar, salts-starch agar and glycerol-asparagine aga $\mathbf{r}$.

Reverse side of colony: Pale yellow or grayish yellow on yeastmalt agar and glycerol-asparagine agar; yellow may be modified by blue (very pale blue or pale green) on reverse side of mature growth on oatmeal agar and salts-starch agar. This pigment is not a $\mathrm{pH}$ indicator.

Color in medium: Melanoid pigments are not formed in peptoneyeast-iron agar, tyrosine agar or tryptone-yeast broth. Traces of yellow or green pigment may or may not be found in the medium in yeast-malt agar, oatmeal agar, salts-starchagar and glycerol-asparagine agar.

Carbon utilization: D-Glucose, L-arabinose, D-xylose, i-inositol, D-mannitol, D-fructose, rhamnose, sucrose and raffinose are all utilized for growth.

Streptomyces karnatakensis Pinto and Ramasarma. Descriptions: Pinto and Ramasarma 1960, British Pat. Specification 852,472, Oct. 26, 1960. (Description of strain $\mathrm{RBC}-5$, without name, in Indian Pat. Specification 57368, May 18, 1956.) Type strain: IMRU 3775 (ITCCF G.C. $977=$ RBC-5) (ibid.). ISP 5345 from R. Gordon as IMRU 3775 . ISP description by Group C-9.

Spore chain morphology: Section Spirales; well-defined spirals of 5 or more turns (Fig. 94). Mature spore chains moderately long with 10 to 50 spores per chain. This morphology is seen on yeast-malt agar, oatmeal agar, salts-starch agar and glycerol-a sparagine agar. Spore 


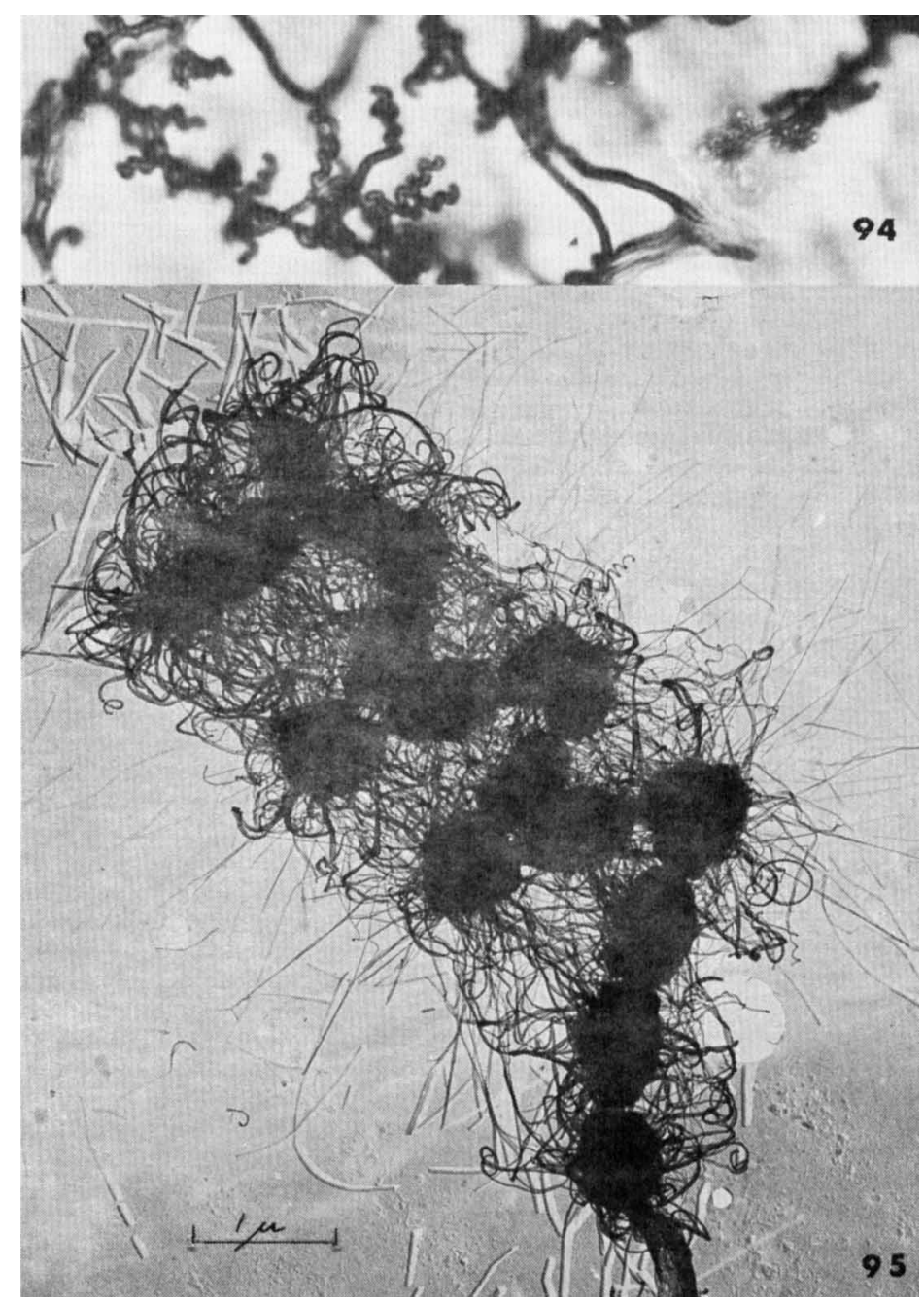

Figure 94. S. karnatakensis. Spiral spore chains (X 800) on glycerolasparagine agar, 4 days.

Figure 95. S. karnatakensis. Hairy spores; electron micrograph $\mathrm{Au} / \mathrm{Pd}$. shadowèd. 
surface: Hairy (Fig. 95).

Color of colony: Aerial mass color in the Gray color-series on yeast-malt agar, oatmeal agar, salts-starch agar and glycerolasparagine agar. One observer, only, found both Gray (color tab d) and Green (24ih, dark greenish gray) aerial mycelium on salts-starch agar and both Gray and Blue (19dc, pale blue) on glycerol-asparagine agar.

Reverse side of colony: No distinctive pigments (colorless to pale yellow, grayish greenish yellow or light olive brown) on yeastmalt agar, oatmeal agar, salts-starch agar and glycerol-asparagine agar.

Color in medium: Melanoid pigments are not formed in peptoneyeast-iron agar, tyrosine agar or tryptone-yeast broth. No pigment, or only a trace of yellow, is found in the medium in yeast-malt agar, oatmeal agar, salts-starch agar or glycerol-asparagine agar.

Carbon utilization: D-Glucose is utilized for growth; utilization of D-fructose is doubtful. No growth or only trace of growth with Larabinose, D-xylose, i-inositol, D-mannitol, rhamnose, sucrose and raffinose.

Streptomyces kishiwadensis Shinobu and Kayamura. Description: Shinobu and Kayamura 1964, 176-180. Type strain: Shinobu and Kayamura strain No. 738 (ibid.). ISP 5397 from R. Shinobu as No. 738. ISP description by Group D-6.

Spore chain morphology: Section Verticillati. Both nonoverticillate and umbellate monoverticillate (biverticillate) sporophores are found. Mature sporophores are usually umbellate monoverticillate (Fig. 96). Spore chains are short with 3 to 10 spores per chain. This morphology is seen on yeast-malt agar, oatmeal agar, salts-starch agar and glycerol-asparagine agar. Spore surface: Smooth (Fig. 97).

Color of colony: Aerial mass color in the Red color-series (5ca, light yellowish pink to $5 \mathrm{cb}$, grayish yellowish pink) on yeast-malt agar, oatmeal agar, salts-starch agar and glycerol-asparagine agar; white to pale yellow or pale orange-yellow (3ca) aerial mass color may also be seen on the se media.

Reverse side of colony: No distinctive pigments (pale grayish yellow to orange-yellow or yellowish brown) on yeast-malt agar, oatmeal agar, salts-starch agar and glycerol-asparagine agar.

Color in medium: Melanoid pigments are formed in peptone-yeastiron agar and tryptone-yeast broth, but only weakly or not at all in tyrosine agar. No pigment is found in the medium with yeast-malt agar, oatmeal agar, salts-starch agar or glycerol-asparagine agar.

Carbon utilization: D-Glucose, i-inositol, D-fructose and sucrose are utilized for growth. Utilization of D-xylose is doubtful and there is no growth or only a trace of growth with L-arabinose, D-mannitol, rhamnose and raffinose.

Streptomyces krainskii (Duché) Pridham, Hesseltine and Benedict. Descriptions: (Actinomyces 161 Waksman 1919, 112); Actinomyces krainskii Duché 1934, 306-31 1 . See also: Descriptions for Actinomyces erythreus Waksman 1923, 370; Streptomyces erythraeus (sic) (Waksman) Waksman and Henrici 1948, 938. Although both Streptomyces erythraeus (Waksman 1923) Waksman and Henrici 1948 and Streptomyces krainskii 
(Duche 1934) Pridham et al. 1958, 74 can be traced to Actinomyces 161 Waksman 1919, the original description for Actinomyces krainskii (op. "cit.) differs from the description of Actinomyces 161. Type strain: CBS 342.35 strain of Duché (identified by Duché, 1934, p. 311, as 161 Waksman) $=E T H$ 9520. ISP 5321 from G.A. deVries, CBS as CBS 34z. 35. ISP description by Group $\mathrm{C}-3$.

Spore chain morphology: Section Rectiflexibiles (Fig. 98). Flexuous spore chains generally have 10 to 50 or sometimes more than 50 spores per chain. This morphology is seen on yeast-malt agar, oatmeal agar, salts-starch agar and glycerol-asparagine agar. Spore surface; Smooth (Fig. 99).

Color of colony: Aerial mass color in the Yellow color-series (pale yellow to pale greenish yellow) on yeast-malt agar, oatmeal agar, salts - starch agar and glycerol-a sparagine agar.

Reverse side of colony: Orange-yellow on yeast-malt agar; strong yellow to light greenish yellow on oatmeal agar, salts-starch agar and glycerol-asparagine agar. Substrate pigment is not a $\mathrm{pH}$ indicator.

Color in medium: Melanoid pigments are not formed in peptoneyeast-iron agar, tyrosine agar or tryptone-yeast broth. Yellow or greenish yellow pigment is found in the medium in yeast-malt agar and oatmeal agar; this pigment is not $\mathrm{pH}$ sensitive when tested with 0.05 $\mathrm{N} \mathrm{NaOH}$ or $\mathrm{HCl}$.

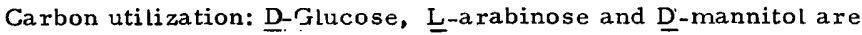
utilized for growth. Reports vary on utilization of D-xylose and D-fructose, but utilization of these sugars is doubtful. No growth or only trace of growth with $\underline{i}$-inositol, rhamnose, sucrose or raffinose.

Streptomyces lincolnensis Mason, Dietz and DeBoer. Description: Mason et al. 1962, 554-559; also Bergy, Herr and Mason U.S. Pat. $3,086, \overline{91}$ April 23, 1963. Type strain: NRRL 2936 = NCIB $9413=$ UC 2376 (Alma Dietz, Upjohn Company and T.G. Pridham, NRRL, personal communication, May 1966). ISP 5355 from T.G. Pridham as NRRL 2936. ISP description by Group D-2.

Spore chain morphology: Section Rectiflexibiles. Mature spore chains are long and flexuous, often with more than 50 spores per chain. This morphology is seen on yeast-malt agar, oatmeal agar, saltsstarch agar and glycerol-asparagine agar. Spore surface: Smooth (Fig. 100).

Color of colony: Aerial mass color in the Yellow or Red color series on yeast-malt agar, oatmeal agar, salts-starch agar and glycerolasparagine agar. Representative color tabs are 2 ba (pale yellow) from the Yellow color-series; $2 \mathrm{ca}$ (pale yellow) and 3ca (pale orange yellow) from the Red color-series.

Reverse side of colony: No distinctive pigments (pale grayish yellow to orange yellow on oatmeal agar and salts-starch agar; yellowish brown to brown on yeast-malt agar and olive brown to dark grayish brown on glycerol-asparagine aga $r$ ).

Color in medium: Melanoid pigments are formed in peptone-yeastiron agar, tyrosine agar and tryptone-yeast broth. A trace of yellow to greenish yellow pigment is found in the medium in oatmeal agar and glycerol-asparagine agar. This pigment is not $\mathrm{pH}$ sensitive when tested with $0.05 \mathrm{~N} \mathrm{NaOH}$ or $\mathrm{HCl}$. 


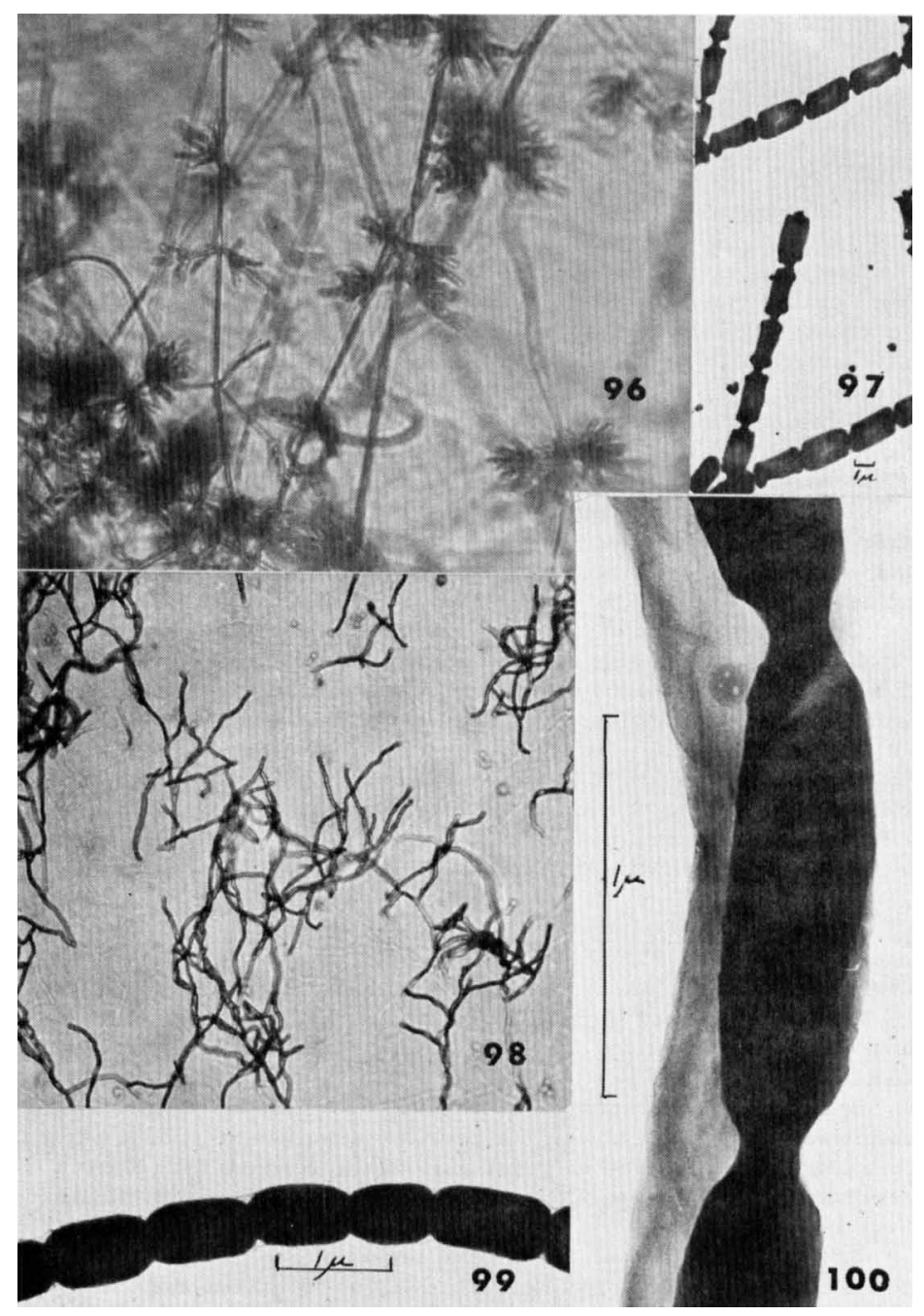

Figure 96. S. kishiwadensis. Umbellate monoverticillate sporophores (X 480) on oatmeal agar, 14 days.

Figure 97. S. kishiwadensis. Smooth spores; electron micrograph from 20 day culture on oatmeal agar.

Figure 98. S. krainskii. RF spore chains (X 300) on oatmeal agar, 7 days. Figure 99. $\overline{\mathrm{S}}$. $\overline{\text { krainskii. }}$ Smooth spores; electron micrograph from 7 day culture on yeast-malt agar.

Figure 100. S. lincolnensis. Smooth spores; electron micrograph from 7 day culture on salts-starch agar. 
Carbon utilization: D-Glucose, L-arabinose, D-xylose, $\underline{i}$-inositol, D-mannitol, D-fructose, rhamnose, sucrose and raffinose are all utilized for growth.

Actinomyces longissimus Krasil'nikov. Descriptions: Krasil'nikov I941, 38. Streptomyces longissimus (Krasil'nikov) Waksman 1953, 87. Type strain: INMI 2918 (N.A. Krasil'nikov, personal communication, Dec. 14, 1966). ISP 5435 from N.A. Krasil'nikov as INMI 291 8. ISP description by Group D-2.

Spore chain morphology: Section Rectiflexibiles (?). Mature spore chains generally not produced on yeast-malt agar, salts-starch agar or glycerol-asparagine agar. Thin sporulating aerial mycelium may or may not be present on oatmeal agar. When present, short flexuous hyphae may be seen or short flexuous spore chains may emerge from the tips of coremia-like structures. Krasil'nikov's original description (op. cit.) states, "Aerial mycelium poorly developed, or on certain media entirely absent; it develops best on potato, synthetic agar and paraffin." Spore surface: Not determined.

Color of colony: Sporulating aerial mycelium is inadequate for aerial mass color determination on yeast-malt agar, oatmeal agar, salts-starch agar and glycerol-a sparagine agar. Krasil'nikov's original description states that when aerial mycelium is present, it is yellowish white.

Reverse side of colony: Usually reddish orange, 'brownish orange or reddish brown; sometines grayish yellow or yellow-brown. Reverse mycelium pigment is not a $\mathrm{pH}$ indicator.

Color in medium: Melanoid pigments are formed in peptoneyeast-iron agar and tryptone-yeast broth, but not in tyrosine agar. No pigment or only a trace of yellow is found in the medium in yeastmalt agar, oatmeal agar, salts-starch agar and glycerol-asparagine agar.

Carbon utilization: D-Glucose, L-arabinose, D-xylose, $\underline{\text { i-inositol, }}$ D-mannitol, D-fructose, rhamnose, sucrose and raffinose are all utilized for growth.

Streptomyces Lucensis Arcamone, Bertazzoli, Canevazzi, Di Marco, Ghione and Grein. Description: Arcamone et al. 1957, 119-128. Type strain: Farmitalia $1163 \mathrm{Fl}=$ IMRU 3783 (B. Camerino, "Farmitalia", personal communication, Nov., 1965). ISP 5317 from B. Camerino, "Farmitalia", Milan, Italy as $1163 \mathrm{Fl}=\mathrm{IMRU} 3783$. ISP description by Group C -5 .

Spore chain morphology: Section Spirales. Flexuous spore chains and imperfect spirals are common together with some regular open spirals of 4 or more turns; Mature spore chains have 10 to 50 spores per chain. This morphology is seen on yeast-malt agar, oatmeal agar, salts-starch agar and glycerol-asparagine agar. Spore surface: Hairy to spiny (Fig. 101).

Color of colony: Aerial mass color in the Gray color-series (brownish gray) on yeast-malt agar, oatmeal agar, salts-starch agar and glycerol-a sparagine agar.

Reverse side of colony: No distinctive pigments (colorless to pale grayish yellow or light yellowish brown) on yeast-malt agar, oatmeal agar, salts-starch agar and glycerol-asparagine agar. 
Color in medium: Melanoid pigments are formed in peptone-yeastiron agar and tryptone-yeast broth, but not in tyrosine agar. No pigment is found in the medium in yeast-malt agar, oatmeal agar, saltsstarch agar or glycerol-asparagine agar.

Carbon utilization: D-Glucose, L-arabinose, D-xylose, D-mannitol, D-fructose and sucrose are utilized for growth. No growth or only trace of growth with $\underline{i}$-inositol, rhamnose and raffinose.

Streptomyces lute ofluorescens Shinobu. Description: Shinobu 1962, 115-122. Type strain: Shinobu 719 (ibid.). ISP 5398 from R. Shinobu as No. 719. ISP description by Group D-7.

Spore chain morphology: Section Spirales (?) or RF. Short chains of 3 to 10 spores tend to form loops, hooks or partial spirals, but chains are usually too short to form true spirals (Fig. 102). Sporulation is scant or sometines absent on yeast-malt agar, oatmeal agar, salts-starch agar and glycerol-asparagine agar. The tendency for cultures to become sterile and lose ability to form aerial mycelia is noted in Shinobu's original description (op. cit.). Spore surface: Warty (Fig. 103).

Color of colony: Production of mature sporulating aerial mycelium may be inadequate for mass color determination on various ISP media, or aerial mass color may be in the Yellow color-series (pale or light yellow) on yeast-malt agar or oatmeal agar and in the Red-colorseries (pale orange-yellow or light yellowish pink) on salts - starch agar or glycerol-asparagine agar.

Reverse side of colony: Strong to moderate yellow or brilliant greenish yellow on yeast-malt agar and oatmeal agar; reddish orange or yellowish pink on salts-starch agar and glycerol-asparagine agar. Reverse mycelium pigment is not a $\mathrm{pH}$ indicator.

Color in medium: Melanoid pigments are not formed in peptoneyeast-iron agar, tyrosine agar or tryptone-yeast broth. Yellow pigment may be found in the medium in yeast-malt agar, oatmea $L$ aga $r$ and glycerol-asparagine agar (two of three observers did not record soluble pigment production). Yellow pigment, when present, is not $\mathrm{pH}$ sensitive when tested with $0.05 \mathrm{~N} \mathrm{NaOH}$ or $\mathrm{HCl}$.

Carbon utilization: D-Glucose, L-arabinose,D-xylose, D-mannitol, D-fructose, rhamnose and sucrose are utilized for growth. Only a trace of growth or no growth with 1 -inositol and raffinose. Note: Three ISP collaborators are in close agreement on the carbon utilization pattern. Their reports differ significantly from the original description which states that trehelose, mannitol and inositol were utilized for growth and that xylose, rhamnose, fructose, galactose, lactose and raffinose were not utilized.

Streptomyces lydicus DeBoer, Dietz, Silver and Savage. Description: DeBoer et al. 1956, 886-892. Type strain: NRRL 2433 (Alma Dietz, Upjohn Co. and C.W. Hesseltine, NRRL, personal communica tion). ISP 5461 from C.W. Hesseltine as NRRL 2433. ISP description by Group D-7.

Spore chain morphology: Section Spirales (Fig. I 04). Spirals are sometimes at the tips of long spore chains suggesting RA morphology. Mature spore chains generally 10 to 50 or sometimes more than 50 spores per chain. This morphology is seen on yeast-malt agar, oatmeal 


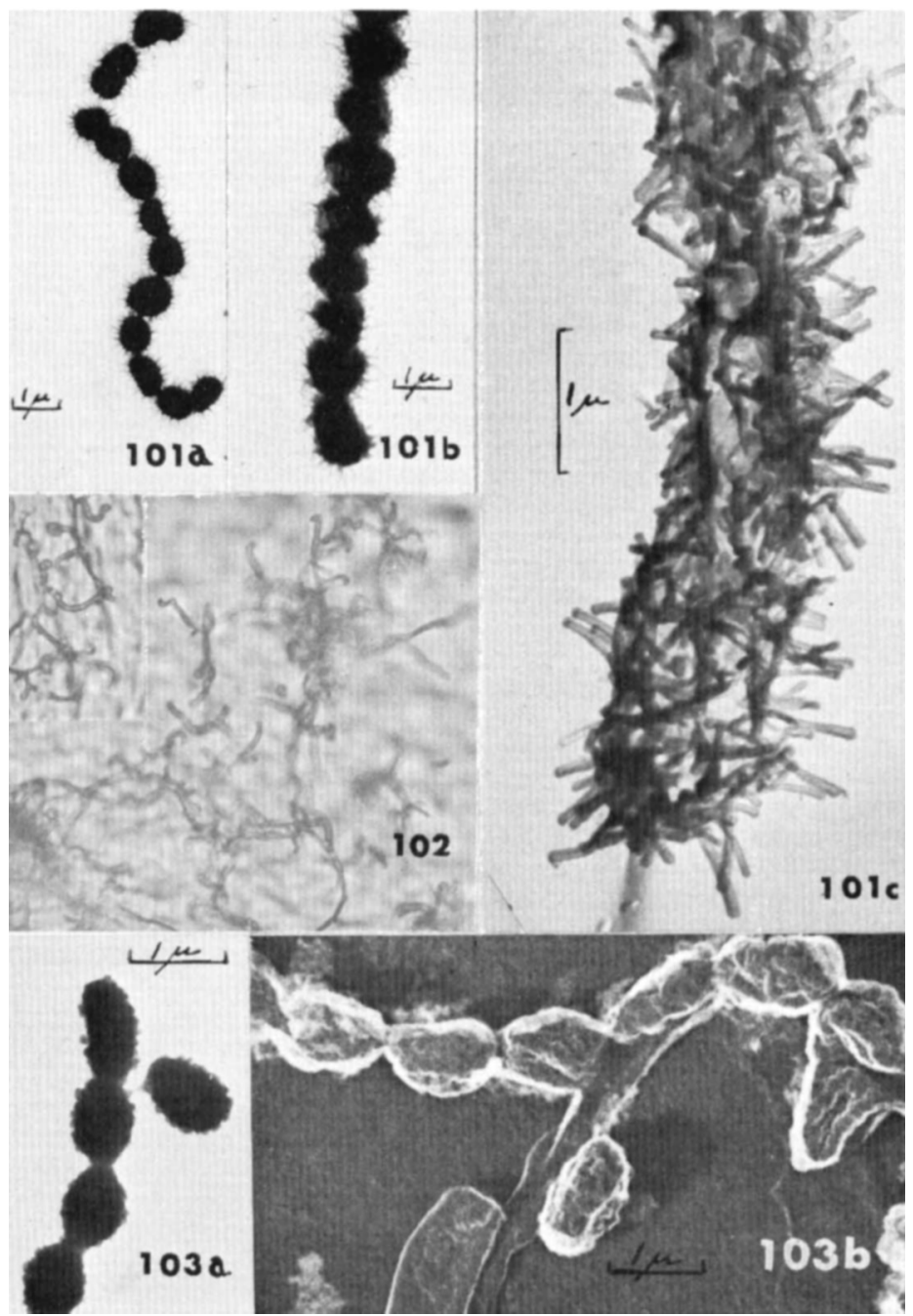

Figure 101. S. 1ucensis. Hairy to spiny spores. (a) Spore ornamentation with spiny appearance; electron micrograph from 14 day culture. (b) Spines are long and flexuous resembling short hairs; direct mount from 10 day culture on yeast-malt agar. (c) Carbon replica from same preparation.

Figure 102. S. luteofluorescens. Short spore chains with hooks and partial spirals (X 430) on glycerol-asparagine, 14 days.

Figure 103. S. luteofluorescens. Warty spores. (a) Electron micrograph from 2 I day culture on oatmeal agar. (b) Fourteen day culture on glycerol-asparagine agar. 
agar, salts-starch agar and glycerol-asparagine agar. Spore surface: Smooth (Fig. 105).

- Color of colony: Aerial mass color in the Gray color-series (3fe, light brownish gray, to $3 \mathrm{ih}$, dark gray) on yeast-malt agar and oatmeal agar; Gray or Yellow (2ba, pale yellow) or White color-series on saltsstarch agar and glycerol-asparagine agar.

Reverse side of colony: No distinctive pigments (colorless, pale grayish yellow or orange-yellow) on yeast-malt agar, oatmeal agar, salts-starch agar and glycerol-asparagine agar.

Color in medium: Melanoid pigments are not formed in peptoneyeast-iron agar, tyrosine agar or tryptone-yeast broth, according to two of three observers. The third observer records some darkening of peptone-yeast-iron agar and a trace of dark pigment in tyrosine agar, but no darkening of tryptone-yeast broth. No pigment (or only a trace of yellow) is found in the medium in yeast-malt agar, oatmeal agar, salts - starch agar or glycerol-asparagine agar.

Carbon utilization: D-Glucose, L-arabinose, D-xylose, $\underline{\text { i-inositol, }}$ D-mannitol, D-fructose, sucrose and raffinose are utilized for growth. Utilization of rhamnose is doubtful.

Actinomyces malachitofuscus Preobrazhenskaya, Maximova and Blinov. Description: Preobrazhenskaya et al. 1964, 963-970. Type strain: INA No. 739 (syntype ibid.: selected as type strain by G.F. Gauze, personal communication, Jan., 1966). ISP 5332 from G.F. Gauze as No. 739. ISP description by Group C-8.

Spore chain morphology: Section Spirales (Fig. 106). Mature spore chains generally 10 to 50 spores per chain on yeast-malt agar, oatmeal agar and salts-starch agar Shorter spore chains, especially on glycerol-asparagine agar, may form irregular or incomplete spirals, loops and hooks (Fig. 107). Spore surface: Spiny to hairy (Fig. 108).

Color of colony: Aerial mass color in the Gray color-series ( $3 \mathrm{fe}$, light brownish gray to $5 \mathrm{fe}$, light reddish grayish brown) on yeastmalt agar, oatmeal agar salts-starch agar and glycerol-asparagine agar.

Reverse side of colony: Nearly colorless to yellow or yellowish gray on oatmeal agar and salts-starch agar; dark greenish yellow to olive-green on yeast-malt agar; grayish olive to olive-brown on glycerolasparagine agar.

Color in medium: Melanoid pigments are formed in peptone-yeastiron agar, tyrosine agar and tryptone-yeast broth. No pigment is found in the medium in salts-starch agar and glycerol-asparagine agar; a trace of yellow or yellow-brown pigment may or may not be found in yeast-malt agar and oatmeal agar.

Carbon utilization: D-Glucose, L-arabinose, D-xylose, i-inositol, D-mannitol, D-fructose, rhamnose and sucrose are utilized for growth. No growth or only trace of growth with raffinose.

Actinomyces malachitorectus Preobrazhenskaya, Maximova and B linov. Description: Preobrazhenskaya et al. 1964, 963-970. Type strain: INA No. 8954 (syntype ibid.; selected as type strain by G.F. Gauze, personal communication, Jan., 1966). ISP 5333 from G.F. Gauze as No. 8954. ISP description by Group C-6. 


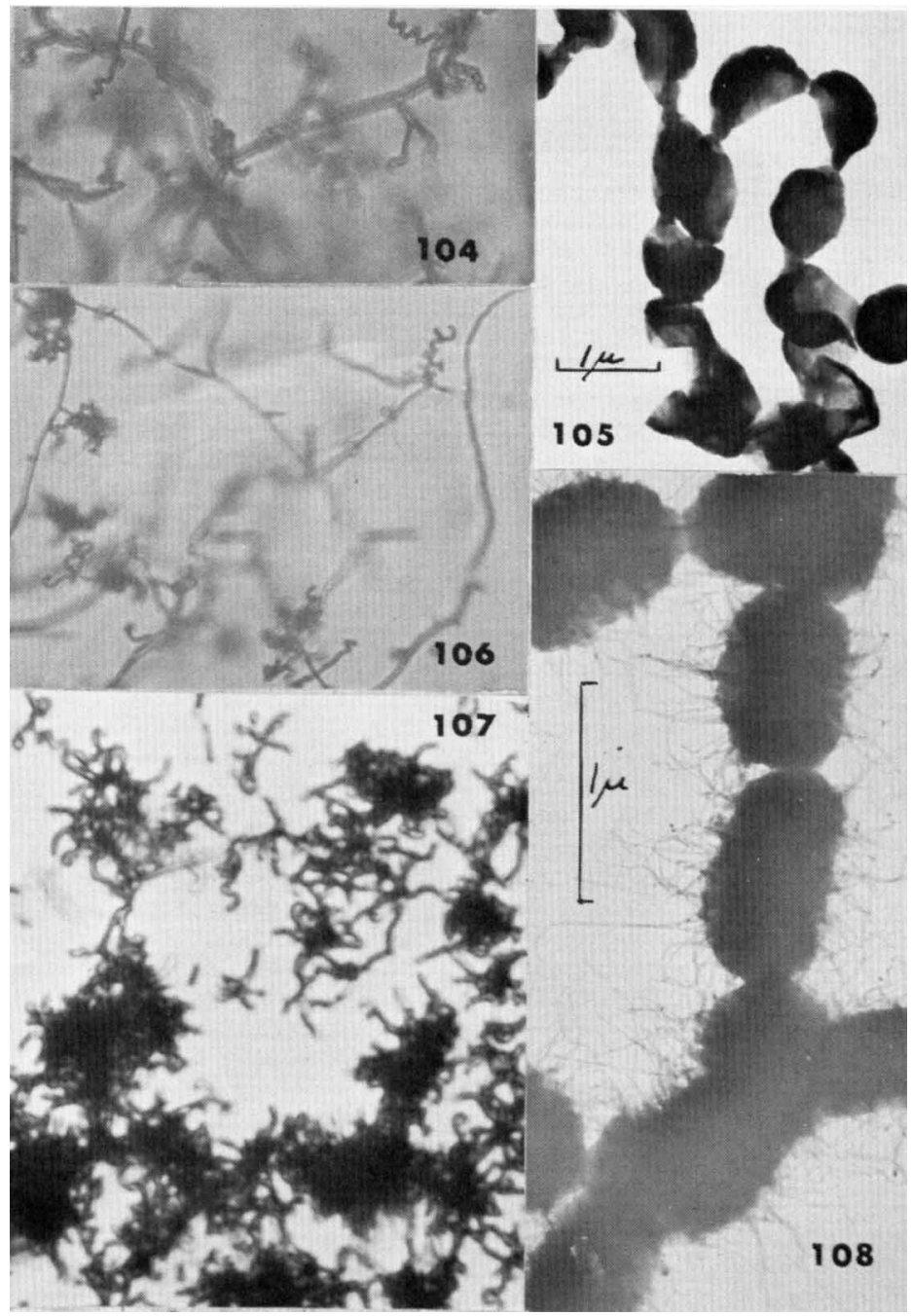

Figure 104. S. lydicus. Spiral spore chains (X 430) on oatmeal agar, 14 days.

Figure 105. S. lydicus. Smooth spores; electron micrograph from 14 day culture on glycerol-asparagine agar.

Figure 106. A. malachitofuscus. Spiral spore chains (X 900) on glycerol-as paragine agar, 21 days.

Figure 107. A. malachitofuscus. Short spore chains (X 500) forming incomplete spirals, loops and hooks on glycerol-asparagine agar, 14 days.

Figure 108. A. malachitofuscus. Spiny to hairy spores; electron micrograph from 20 day culture on yeast-malt agar. 
Spore chain morphology: Section Spirales. True spirals, flexuous chains and irregular or imperfect spirals are found (Fig. 109). Mature spore chains generally 10 to 50 spores per chain. This morphology is seen on yeast-malt agar, oatmeal agar, salts-starch agar and glycerolasparagine agar. Spore surface: Spiny (long flexuous spines, Fig. 110).

Color of colony. Aerial mass color in the Gray color-series on yeast-malt agar, oatmeal agar, salts-starch agar and glycerol-asparagine agar.

Reverse side of colony: Yellowish brown to olive-brown on yeastmalt agar; pale or grayish yellow-green to dark greenish yellow on oatmeal agar, salts-starch agar and glycerol-asparagine agar.

Color in medium: Melanoid pigments are formed in peptone-yeast iron agar, tyrosine agar and tryptone-yeast broth. No pigment is found in the medium in yeast-malt agar, oatmeal agar, salts-starch agar or glycerol-asparagine agar.

Carbon utilization: D-Glucose, L-arabinose, D-xylose, $\underline{i}$-inositol, D-mannitol, D-fructose, rhamnose and sucrose are utilized for growth. No growth or only trace of growth with raffinose. The three ISP collaborators who studied this strain found very good growth on all carbon sources tested except raffinose. The original description for this strain (Preobrazhenskaya et al. 으. cit., p. 968) shows no growth on arabinose, xylose, rhamnose, fructose, mannitol and raffinose.

Streptomyces melanosporeus (Krainsky) Waksman and Henrici. 1948, 955. (Not Streptomyces melanosporus (sic) Arcamone et al. 1959, 207-216. Not Streptomyces melanosporofaciens Arcamone et al. 1959, 207-216.) A type strain (holotype,) is not available for Streptomyces melanosporeus (Krainsky) Waksman and Henrici 1948.

Potential neotype strains are the CBS strain Pollacci (=ETH 20740) and strain IPV 583 (now IPV 1461, Baldacci, personal communication, May, 1967) (=ETH 28749). Since the se strains probably belong in the genus Micromonospora (Batdacci 1938, Baldacci and Locci 1961; see also: Hutter 1967, p. 321) they are not included in the ISP studies.

Streptomyces melanosporofaciens Arcomone, Bertazzoli, Ghione and Scotti. Description: Streptomyces melanosporus sive melanosporofaciens Arcamone et al. 1959, 207-216; see footnote on page 215. Type strain: Farmitalia No. 1573 (ibid.; also B. Camerino, personal communication, Nov., 1965). ISP 5318 from B. Camerino, Farmitalia as No. 1573. ISP description by Group C-6.

Spore chain morphology: Section Spirales (Fig. 111), but spore chain mórphology is sometines difficult to observe because of accumulations of moist exodate ("hygroscopic" masses) on the sporulating sur faces (Fig. 112 and 113 ). Identifiable spore chains are often short with only 3 to 10 spores per chain and may form loops or incomplete spirals as well as true spirals. This morphology is seen on yeast-malt agar, oatmeal agar, salts-starch agar and glycerol-asparagine agar. Spore surface: Smooth, or with unevenly ridged surface suggesting warty spores on some preparations (Fig. 116).

Special morphological characteristics: In 7 to 21 days sporulating 


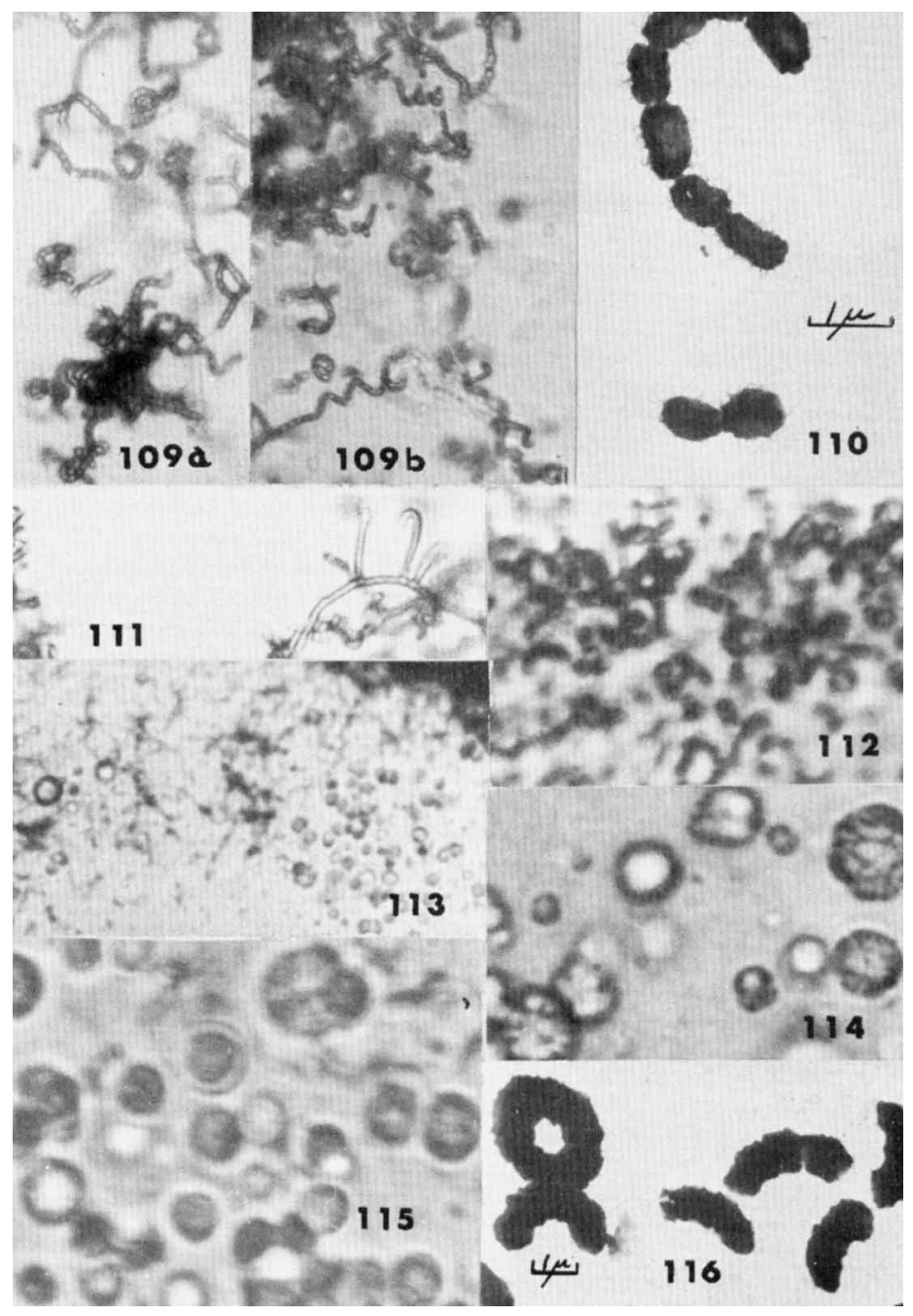

Figure 109. A. malachitorectus. Spiral spore chains (X 600), 21 day cultures. (a) On glycerol-asparagine agar. (b) On salts-starch agar.

Figure 110. A. malachitorectus. Spores with long flexuous spines or short hairs; electron micrograph from 14 day culture on salts-starch agar.

Figure 111. A. melanosporofaciens. Spiral spore chains (X 600) on glycerol-asparagine agar, 20 days.

Figure 112. A. melanosporofaciens. Spiral spore chains partially obscured by moist exudate (X 1478) on oatmeal agar, 21 days, Gram stain.

Figures 113, 114, 115. A. melanosporofaciens. Droplets of moist exudate (hygroscopic masses) on aerial mycelium, oatmeal agar, 21 days (Fig. 113, X 152; Fig. 114 and 115, X 600).

Figure 116. A. melanosporofaciens. Unevenly ridged spore surface suggesting warty spores; electron micrograph from 20 day culture on glycerol-asparagine agar. 
surfaces form globose accumulations of liquid exudate. These coalesce and may eventually give rise to a moist black surface containing loose spores (Fig. 113,114,115).

Color of colony: Aerial mass color in the Gray color-series on yeast-malt agar and oatmeal agar; poorly sporulating cultures on saltsstarch agar and glycerol-asparagine agar may appear to be in the Yellow color-series. Areas of sporulation are usually gray at first, but may become moist-black as spore masses coalesce in a liquid exudate on the aerial mycelium.

Reverse side of colony: Dark grayish yellow to orange-yellow on yeast-malt agar; light yellow to light grayish olive on oatmeal agar; nearly colorless to strong yellow on salts-starch agar and glycerolasparagine agar. Substrate pigment is not a $\mathrm{pH}$ indicator.

Color in medium: Melanoid pigments are not formed in peptoneyeast-iron agar, tyrosine agar or tryptone-yeast broth, but a reddish brown, rose, or yellow non-melanoid pigment may be found in tyrosine agar. No pigment is found in the medium in yeast-malt agar, oatmeal agar, salts-starch agar or glycerol-a sparagine agar.

Carbon utilization: D-Glucose, L-arabinose, D-xylose, i-inositol, D-mannitol, D-fructose, rhamnose and raffinose are utilized for growth. Only a trace of growth is found with sucrose.

Streptomyces melanosporus Arcamone, Bertazzoli, Ghione and Scotti, 1959. (Not Streptomyces melanosporeus (sic) (Krainsky) Waksman and Henrici 1948; not Actinomyces melanosporeus Krainsky 1914.) In the first published description for the melanosporin and elaiophylin producing strain No. 1573, the authors (Arcamone et al. 1959, p. 207-216) make perfectly clear that Streptomyces melanosporus sive melanosporofaciens is not an orthographic variant of Streptomyces melanosporeus (Krainsky) Waksman and Henrici and that the name they intend to apply under Rule 12c-1 is Streptomyces melanosporofaciens. The ISP description is given under the name $\underline{S}$. malanosporofaciens, Arcamone et al.

Streptomyces microflavus (Krainsky) Waksman and Henrici. Descriptions: Actinomyces microflavus Krainsky 1914, 680 and 686; Streptomyces microflavus (Krainsky) Waksman and Henrici 1948, 950. Type strain: CBS 124.18, received by CBS from Krainsky (Beijerinck's laboratory) March, 1918. (G.A. deVries, personal communication, Feb., 1966). Note: The type strain for $\underline{S}$. albidus (Duché) Waksman is a monospore isolate from CBS 124.18 (G. A. deVries, personal communication; see also comments under Streptomyces albidus ). ISP 5331 from G.A. deVries as CBS 124.18 . ISP description by Group C-7.

Spore chain morphology: Section Rectiflexibiles (Fig. 117). Mature spore chains generally 10 to 50 or more spores per chain. This morphology is seen on yeast-malt agar, oatmeal agar, salts-starch agar and glycerol-asparagine agar. Spore surface: Smooth (Fig. 118).

Color of colony: Aerial mass color in the Gray or Yellow color series ( $2 \mathrm{dc}$, yellowish gray; $2 \mathrm{db}$, pale yellow) on yeast-malt agar and oatmèal agar; Yellow color-series (2ba or $2 \mathrm{db}$, pale yellow) on salts starchagar and glycerol-asparagine agar. 
Reverse side of colony: No distinctive pigments (grayish yellow to yellowish brown, olive-brown or strong brown) on yeast-malt agar, oatmeal agar, salts-starch agar and glycerol-asparagine agar.

Color in medium: Melanoid pigments are not formed in peptoneyeast-iron agar, tyrosine agar or tryptone-yeast broth. No pigment is found in the medium in yeast-malt agar, oatmeal agar, salts-starch agar or glycerol-asparagine agar.

Carbon utilization: D-Glucose, D-xylose, D-mannitol, D-fructose and rhamnose are utilized for growth. Reports vary on the utilization of sucrose. Utilization of $\underline{L}$-arabinose is doubtful. No growth or only trace of growth with $\underline{i}$-inositol and raffinose.

Streptomyces misionensis Cercos, Eilberg, Goyena, Souto, Vautier and Widuczynski. Description: Cercós et al. 1962, 21-27. Type strain: No. 3944, Instituto de Microbiologia (INTA) = A TCC 14991 (I. L. Ca lot and A.P. Cercós, Equipo de Antibioticos, Inst. Microbiol. Ind. Agropecuarias, I.N.T.A., Castelar, Argentina, personal communication, May, 1965). ISP 5306 from 1. L. Calot and A.P. Cercós as No. 3944. ISP description by Group C-3.

Spore chain morphology: Section Spirales (Fig. 119). Mature spore chains moderately long, often with more than 50 spores per chain. This morphology is seen on yeast-malt agar, oatmeal agar, salts starch agar and glycerol-asparagine agar. Spore surface: Smooth (Fig. 120) or slightly warty (Fig. 121).

Color of colony: Aerial mass color in the Gray or Red color-series (4ig, light grayish brown in Gray series or $4 \mathrm{ge}$, light grayish reddish brown in the Red series) on yeast-malt agar, oatmeal agar, saltsstarch agar and glycerol-asparagine agar.

Reverse side of colony: Olive brown to moderate orange on yeastmalt agar; grayish yellow, yellowish brown or olive brown on oatmeal agar, salts-starch agar and glycerol-asparagine agar.

Color in medium: Melanoid pigments are not formed in peptoneyeast-iron agar, tyrosine agar or tryptone-yeast broth. No pigment is found in the medium in yeast-malt agar, oatmeal agar, salts-starch agar or glycerol-a sparagine agar.

Carbon utilization: D-Glucose, L-arabinose, --xylose, D-mannitol and $\underline{D}$-fructose are utilized for growth. Utilization of $\underline{i}$-inositol, rhamnose, sucrose and raffinose is doubtful.

Streptomyces nashvillensis McVeigh and Reyes. Description: McVeigh and Reyes 1961, 312-319. Type strain: McYeigh V-8 = NRRL B-2606 (Ilda McVeigh, Vanderbilt Univ., personal communication, Oct. 1965). ISP 5314 from Ilda McVeigh as V-8 = NRRL B-2606. ISP description by Group C -5 .

Spore chain morphology: Section Rectiflexibiles (Fig. 122). Long chains, often with more than 50 spores, are predominantly straight but a very small number of these chains may show RA morphology including some spirals. This morphology is seen on yeast-malt agar, oatmeal agar, salts-starch agar and glycerol-asparagine agar. Spore surface: Smooth (Fig. 123).

Color of colony: Aerial mass color in the Gray color-series (3fe, light brownish gray to $5 \mathrm{fe}$, light grayish reddish brown or $5 \mathrm{ih}$, brownish gray) on yeast-malt agar, oatmeal agar, salts-starch agar 


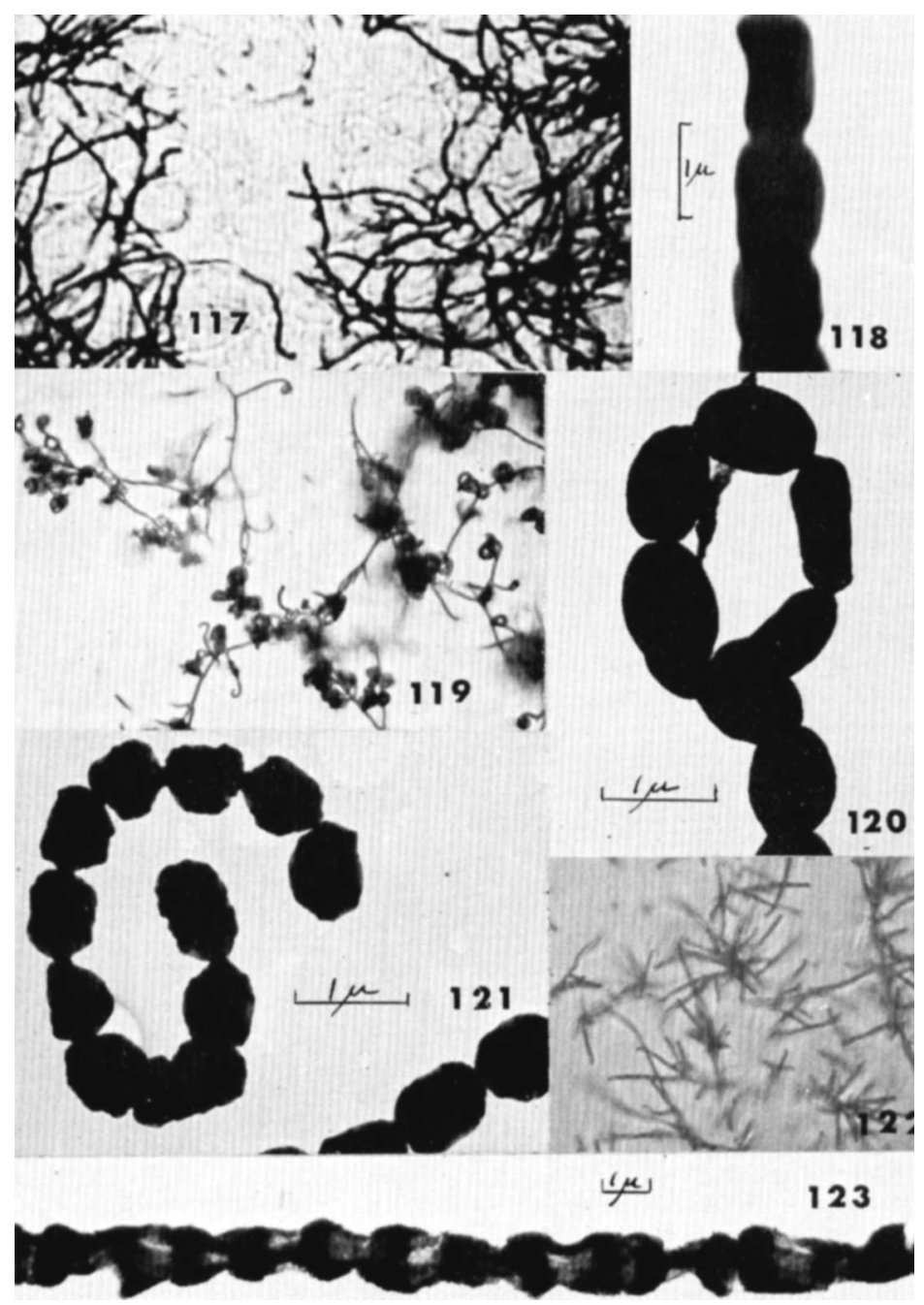

Figure 117. S. microflavus. RF spore chains (X 800) on yeast-malt agar, 14 days.

Figure 118. S. microflavus. Smooth spores; electron micrograph from 10 day cultture on glycerol-asparagine agar.

Figure 119. S. misionensis. Spiral spore chains (X 300) on glycerolasparagine agar, 7 days.

Figure 120. S. misionensis. Smooth spores; electron micrograph from 21 day culture on salts-starch agar. See also Fig. 121.

Figure 121. S. misionensis. Smooth to warty spores; electron micro-

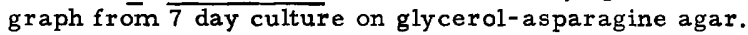

Figure 122. S. nashvillensis. RF spore chains (X 250) on glycerolasparagine agar, 14 days.

Figure 123. S. nashvillensis. Smooth spores; electron micrograph from 10 day culture on salts-starch agar. 
and glycerol-asparagine agar.

Reverse side of colony: Strong brown to light grayish brown on yeast-malt agar; grayish yellow, light olive gray or yellowish brown on oatmeal agar, salts-starch agar and glycerol-a sparagine agar. Reverse mycelium pigment is somewhat $\mathrm{pH}$ sensitive changing from yellowish brown to reddish brown with addition of $0.05 \mathrm{~N} \mathrm{NaOH}$ or from yellowish brown to yellow with addition of $0.05 \mathrm{~N} \mathrm{HCl}$.

Color in medium: Melanoid pigments are formed in peptone-yeast iron agar, tyrosine agar and tryptone-yeast broth, but melanin reaction may be delayed or weak in tyrosine agar. Yellow (to brown) pigment is found in the medium in yeast-malt agar and oatmeal agar and usually in salts-starch agar and glycerol-asparagine agar. This pigment is somewhat $\mathrm{pH}$ sensitive when tested with $0,05 \mathrm{~N} \mathrm{NaOH}$ or $\mathrm{HCI}$, showing the same color changes noted for the reverse mycelium pigment.

Carbon utilization: D-Glucose, L-arabinose, D-xylose and raffinose are utilized for growth. Utilization of $\underline{D}$-fructose is doubtful and there is no growth or only a trace of growth with $\underline{i}$-inositol, D-mannitol, rhamnose or sucrose.

Streptomyces noboritoensis Isono, Yamashita, Tomiyama and Suzuki. Descriptions: Name and antibiotic production with no description in Sumiki, Nakamura, Kawa saki, Yamashita, Anzai, Isono, Serizawa, Tomiyama and Suzuki 1955, 170; first published name with description in Isono et al. 1957, 21-30. Type strain: Strain 97 (selected by S. Suzuki and Y. Yagisawa, personal communication, May 1964). ISP 5223 from S. Suzuki, Inst. Physical and Chemical Res., Tokyo via Y. Yagisawa as Strain 97. ISP description by Group B - 7 . Spore chain morphology: Section Rectiflexibiles (Fig. 124). Mature spore chains moderately long, often with more than 50 spores per chain. This morphology is seen on yeast-malt agar, oatmeal agar, salts-starch agar and glycerol-a sparagine agar, although the aerial mycelium may be thin or poorly developed on some of the se media. Spore surface: Smooth (Fig. 125).

Color of colony: Aerial mass color in the Gray color-series on yeast-malt agar, oatmeal agar, salts-starch agar and glycerol-asparagine agar when mature sporulating mycelium is produced in adequate amount. Development of aerial mycelium may not be adequate for spore mass color determination on some of these media.

Reverse side of colony: Yellow to yellow brown modified to dark reddish brown or very dark brown on yeast-malt agar, oatmeal agar, salts-starch agar and glycerol-asparagine agar; substrate pigment is not a $\mathrm{pH}$ indicator.

Color in medium: Melanoid pigments are formed in peptone-yea stiron agar and tryptone-yeast broth, but may be absent or present only in trace amounts in tyrosine agar. Brown pigment is sometimes found in the medium in yeast-malt agar, oatmeal agar and salts-starch agar or pigment may be absent from these media. The brown pigment is not $\mathrm{pH}$ sensitive when tested with $0.05 \mathrm{~N} \mathrm{NaOH}$ or $\mathrm{HCl}$.

Carbon utilization: D-Glucose, L-arabinose, D-xylose, D-mannitol, D-fructose and raffinose are utilized for growth. Reports vary on the utilization of $\underline{i}$-inositol and utilization of sucrose is doubtful. No growth or only trace of growth with rhamnose. 
Actinomyces olivaceoviridis Preobrazhenskaya and Ryabova. Description: Preobrazhenskaya and Ryabova in Gauze et al. 1957 , 163-165. Type strain: INA 11584. (Gauze in Gottlieb, 1968). ISP 5334 from G.F. Gause as INA 11584. ISP Description by Group C-9.

Spore chain morphology: Section Retinaculiaperti or Spirales (Fig. 126). Hooks, loops and terminal spirals of only one or two turns are common; flexuous chains and primitive spirals may also be found. Mature spore chains generally contain 10 to 50 or more spores per chain. This morphology is seen on oatmeal agar, salts-starch agar and glycerol-asparagine agar; spore chains may be short or poorly developed on yeast-malt agar. Spore surface: Smooth (Fig. 127).

Color of colony: Aerial mass color usually in the Gray or Yellow color-series on yeast-malt agar, oatmeal agar, salts-starch agar and glycerol-asparagine agar. The aerial mass color is usually pale yellowish green to grayish yellow or even light grayish olive (tabs $1 \mathrm{cb}$ or $1 \mathrm{l} / 2 \mathrm{ec}$ from the Yellow color-series; 2dc or 2ge from the Gray colorseries or $3 \mathrm{ec}$ from the Red color-series; $1 \mathrm{l} / 2 \mathrm{ge}$ from the Green colorseries). Immature aerial mycelium may also appear to be in the White color-series.

Reverse side of colony: No distinctive pigments (pale yellow to orange-yellow on yeast-malt agar; pale yellow or grayish yellow on oatmeal agar, salts-starch agar and glycerol-asparagine agar).

Color in medium: Melanoid pigments are not formed in peptoneyeast-iron agar, tyrosine agar or tryptone-yeast broth. No pigment, or only a trace of yellow, is found in the medium in yeast-malt agar, oatmeal agar, salts-starch agar or glycerol-asparagine agar.

Carbon utilization: D-Glucose, L-arabinose, D-xylose, D-mannitol, D-fructose, rhamnose, sucrose and raffinose are utilized for growth. Some growth is also reported on 1 -inositol, but less than with the other carbon sources noted above.

Streptomyces olivochromogenes (sic) (Bergey, Harrison, Breed, Hammer and Huntoon) Waksman and Henrici. Descriptions: Actinomyces chromogenus Strain 205 Waksman 1919, 106-108; Actinomyces olivochromogenus (sic) Bergey et al. 1925, 368; Streptomyces olivochromogenus (Bergey et al.) Waksman and Henrici 1948, 941 (spelling of specific epithet changed to "olivochromogenes" acc. to Waksman

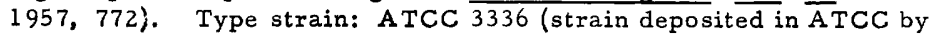
S.A. Waksman in 1945, E.F. Lessel, ATCC, personal communication, Feb. 1967). ISP 5451 from E.F. Lessel as ATCC 3336. ISP description by Group D-5.

Spore chain morphology: Section Spirales, but sporulating aerial mycelium is poorly developed and spore chains are generally short ( 3 to 10 spores per chain) so that flexuous chains, hooks, loops and imperfect or irregular spirals are common (Fig. $128 \mathrm{a}, \mathrm{b}$ ). This morphology is seen on yeast-malt agar, oatmeal agar, salts-starch agar, glycerol-asparagine agar, Czapek's sucrose agar and soil agar. The abundant cottony aerial mycellium mentioned in the original description (op. cit.) is not seen on ISP media. Spore surface: Smooth (Fig. 128).

Color of colony: Sporulation on yeast-malt agar, oatmeal agar, salts-starch agar and glycerol-asparagine agar is inadequate for accurate spore mass color determination. 


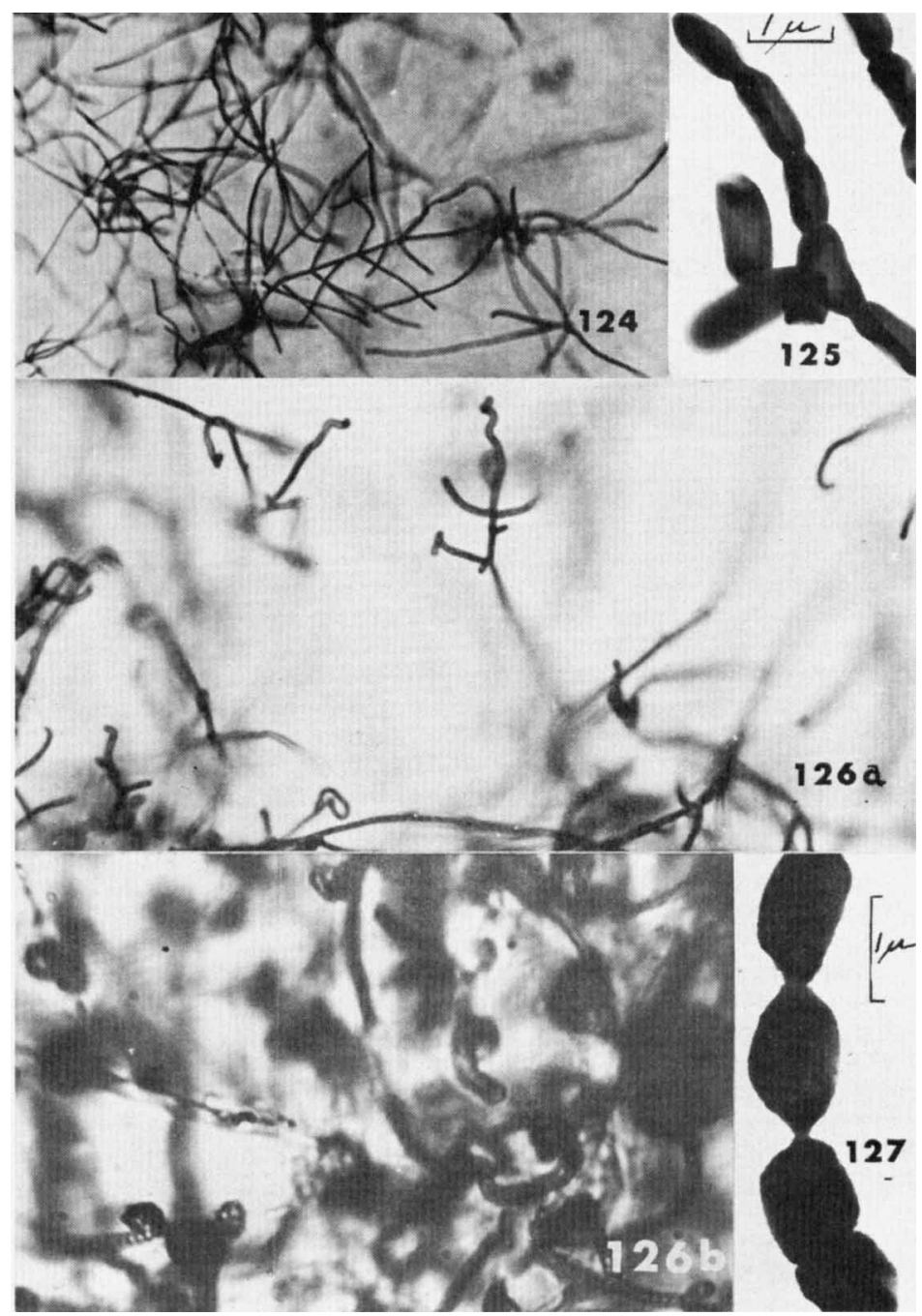

Figure 124. ‥ noboritoensis. RF spore chains on salts-starch agar, 12 days.

Figure 125. S. noboritoensis. Smooth spores; electron micrograph from 12 day culture on salts-starch agar.

Figure 126. A. olivaceoviridis, (a) Primitive spirals and hooks (X 400) suggesting RA morphology on yeast-malt agar, 5 days. (b) Terminal spirals $(X \overline{900})$ on glycerol-asparagine agar, 14 days.

Figure 127. A. olivaceoviridis. Smooth spores; electron micrograph from 6 day culture on oatmeal agar. 
Reverse side of colony: No distinctive pigments (nearly colorless or grayish yellow to grayish greenish yellow or moderate yellow) on yeast-malt agar, oatmeal agar, salts-starch agar and glycerol-asparagine agar.

Color in medium: Melanoid pigments are formed in peptoneyeast-iron agar and tryptone-yeast broth; a faint brown pigment may also be produced in tyrosine agar in 4 days. A trace of yellow or greenish pigment may or may not be found in the medium in yeastmalt agar, oatmeal agar, salts-starch agar and glycerol-asparagine agar.

Carbon utilization: D-Glucose, L-arabinose, D-xylose, $\underline{\text { i-inositol, }}$ D-mannitol, D-fructose, rhamnose and sucrose are utilized for growth. No growth or only trace of growth with raffinose.

Streptomyces olivoverticillatus Shinobu. Description: Shinobu 1956, 84-93. Type strain: Shinobu 383 (ibid.). ISP 5250 from R. Shinobu as strain.383. ISP description by Group B-7.

Spore chain morphology: Section not determined. The original description by Shinobu (1956, op. cit.) states: "The formation of aerial mycelium of this strain was generally not good, even on a suitable media for growth." ISP observers found some aerial mycelium with straight, flexuous and abortive spiral spore chains on oatmeal agar. Electron microscope preparations from yeast-malt agar, oatmeal agar and salts-starch agar contained some flexuous to spiral chains of 13 to 20 or more spores (Fig. 129). "Whirls" as described by Shinobu (1956, op. cit.) were not found by ISP observers. Spore surface: Spiny (Fig. $130 \mathrm{a}, \mathrm{b}$ ).

Color of colony: Aerial mass color probably in the Yellow or Gray color-series (ldb, pale yellow-green; 3fe, light brownish gray) when mature spores occur on yeast-malt agar, oatmeal agar or saltsstarch agar. Thin or immature aerial mycelium is white.

Reverse side of colony: No distinctive pigments (nearly colorless, yellow, greenish yellow or olive brown) on yeast-malt agar, oatmeal agar, salts-starch agar and glycerol-asparagine agar.

Color in medium: Melanoid pigments are not formed in peptoneyeast-iron agar, tyrosine agar or tryptone-yeast broth. Brown or yellow-brown pigment may be found in the medium in yeast-malt agar, oatmeal agar and salts-starch agar or the medium may remain unpigmented.

Carbon utilization: D-Glucose and $\underline{i}$-inositol are utilized for growth. Utilization of L-arabinose, D-xylose, D-mannitol, D-fructose, rhamnose, sucrose and raffinose is doubtful.

Streptomyces ornatus Calot and Cercos. Description: Calot and Cerc6s 1963a, 303-308; 1963b, 159-161. Type strain: Inst. Microbiol. I.N.T.A. 17044 (T.L. Calot and A.P. Cercós, Equipo de Antibioticos, Inst. Microbiol. Ind. Agropecuarias, I.N. T.A., Castelar, Argentina). ISP 5307 from L. Galot and A.P. Cercós as No. 17044. ISP description by Group C-8.

Spore chain morphology: Section Rectiflexibiles (Fig. 131 ). Mature spore chains moderately long with 10 to 50 or more spores per chain. This morphology is seen on yeast-malt agar, oatmeal agar, salts-starch agar and glycerol-asparagine agar. Spore surface: Smooth (Fig. 132). 


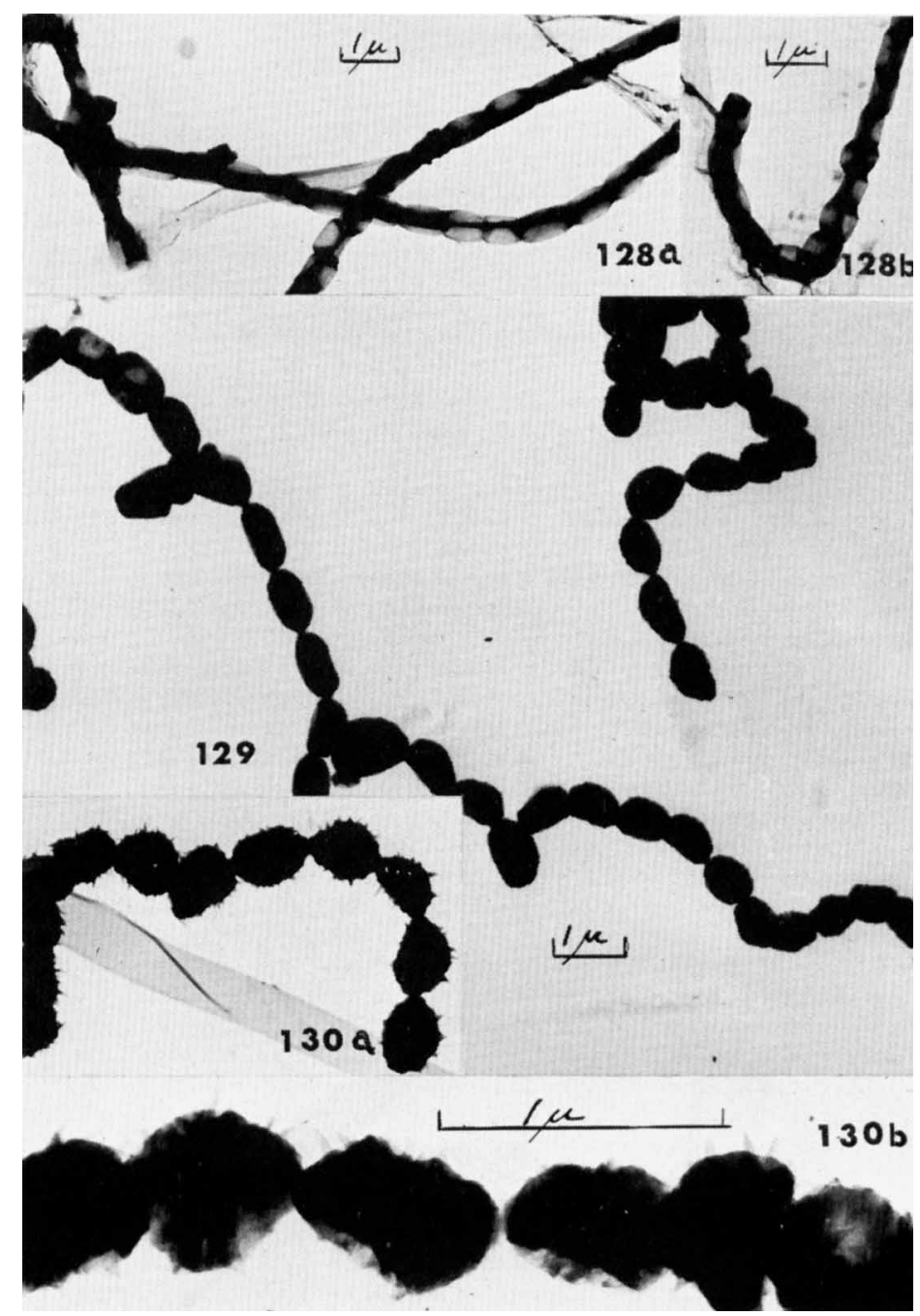

Figure $128 \mathrm{a}, \mathrm{b}$. A. olivochromogenes. Smooth spores; spore chains show evidence of imperfect spirals.

Figure 129. S. olivoverticillatus. Flexuous and spiral chains; spines on spores a re inconspicuous (see also Fig. $130 \mathrm{a}, \mathrm{b}$ ). Electron micrograph from 14 day culture on salts-starch agar.

Figure $130 \mathrm{a}, \mathrm{b}$. S. olivoverticillatus. Spiny spores; electron micro-

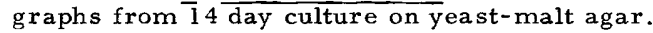


Color of colony: Aerial mass color in the Yellow color-series (pale greenish yellow or pale yellow-green on yeast-malt agar, oatmeal agar and salts-starch agar; pale yellow or pale yellow-green on saltsstarch agar).

Reverse side of colony: No distinctive pigments (grayed orangeyellow or yellow-brown on yeast-malt agar and oatmeal agar; light grayish yellow on salts-starch agar and glycerol-a sparagine agar).

Color in medium: Melanoid pigments are formed in tyrosine agar in 2 to 4 days, but not in peptone-yeast-iron agar or tryptone-yeast broth. No pigments other than traces of yellow are found in the medium in yeast-malt agar, oatmeal agar, salts-starch agar or glycerol-asparagine agar.

Carbon utilization: D-Glucose, D-xylose, D-mannitol and D-fructose are utilized for growth. No growth or only trace of growth on $\underline{L}$-arabinose, $\underline{i}$-inositol, rhamnose, sucrose or raffinose.

Streptomyces paucisporogenes Hagemann, Nominé and Pénasse. Descriptions: Hagemann et al. 1958, 585-586; Hagemann et al. U.S. Pat. 3,052,605 Sept. 4, 1962. Type strain: ATCC 12596 (ibid.) = Lab. Roussel-UCLAF T 4915 (G. Hagemann, personal communication, Nov. 1965). ISP 5315 from G. Hagemann as T 4915 (A TCC1 2596). ISP description by Group C-l.

Spore chain morphology: Section Verticillati, umbellate monoverticillate (biverticillate, Fig. 133). This morphology is sometimes seen on yeast-malt agar, oatmeal agar, salts-starch agar and glycerolasparagine agar, but two of three ISP observers record no sporulating aerial mycelium on these media. This observation is in agreement with the description of Hagemann et al. (op. cit.): "Streptomyces paucisporogenes grows only poorly on solid culture media.... and results in filaments whose more or less branched end portions show only exceptionally any growth of conidium chains". Spore surface: Smooth (Fig. 134).

Color of colony: Sporulation on yeast-malt agar, oatmeal agar, salts-starch agar and glycerol-asparagine agar is usually inadequate for accurate spore color determination. (The aerial mycelium may be white or pale yellow).

Reverse side of colony: Brown to reddish brown on yeast-malt agar; grayish yellow, orange-yellow or light yellowish brown on oatmeal agar, salts-starch agar and glycerol-asparagine agar. Reverse mycelium pigment is not a $\mathrm{pH}$ indicator.

Color in medium: Melanoid pigments are formed in peptone-yeastiron agar, tyrosine agar and tryptone-yeast broth. Orange or yellow pigment is found in the medium in yeast-malt agar, oatmeal agar and salts-starch agar. This pigment is not $\mathrm{pH}$ sensitive when tested with $0.05 \mathrm{~N} \mathrm{NaOH}$ or $\mathrm{HCl}$.

Carbon utilization: D-Glucose, i-inositol and $\mathrm{D}$-fructose are utilized for growth. No growth or only trace of growth on L-arabinose, D-xylose, D-mannitol, rhamnose, sucrose or raffinose.

Streptomyces plicatus (anonymous). Description: Parke, Davis and Co., British Pat. Specification 707, 332, April 1954. Type strain: PD No. 04918 (ibid.). ISP 5319 from Lucia Anderson, Parke, Davis and Co. as PD 04918 (= NRLL 2428). ISP description by Group C-6. 


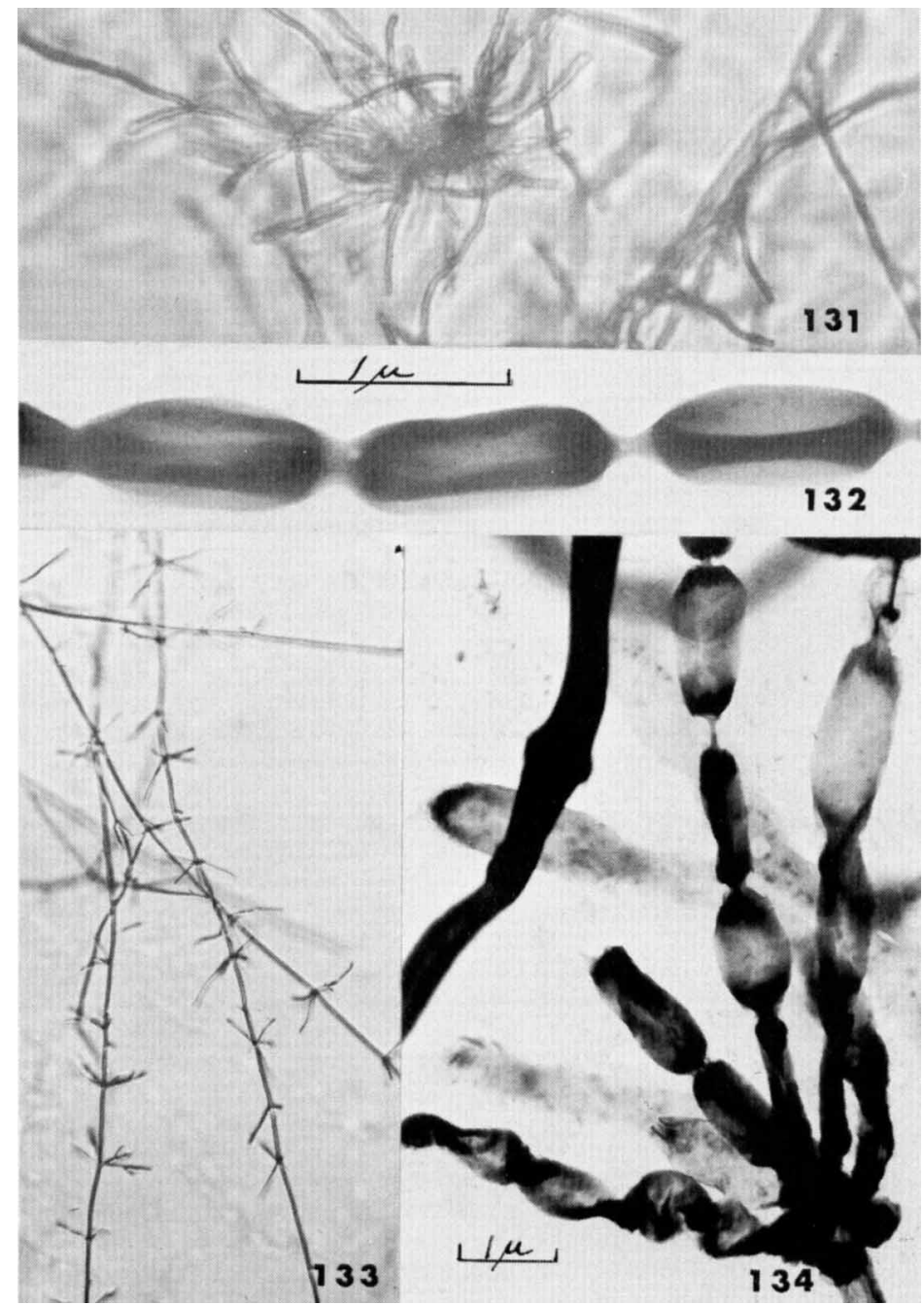

Figure 131. S. ornatus. RF spore chains (X 1800) on glycerol-asparagine agar, 21 days.

Figure 132. S. ornatus. Smooth spores; electron micrograph from 20 day culture on yeast-malt agar.

Figure 133. S. paucisporogenes. Umbellate monoverticillate sporophores $(\overline{\mathrm{X}} 200)$ on salts-starch agar, 21 days.

Figure 134. S. paucisporogenes. Smooth spores; electron micrograph from 21 day culture on salts-starch agar. 
Spore chain morphology: Section Spirales: Spirales are characteristically open (Fig. 135). Wavy spore chains or long flexuous chains terminating in hooks, loops or incomplete spirals may also suggest RA morphology (Fig. 136). Mature spore chains are generally long, often with more than 50 spores per chain. This morphology is seen on yeast-malt agar, oatmeal agar, salts-starch agar and glycerolasparagine agar. Spore surface: Smooth (Fig. 137).

Color of colony: Aerial mass color usually in the Gray colorseries ( $3 \mathrm{fe}$, light brownish gray or $5 \mathrm{fe}$, light grayish reddish brown) on yeast-malt agar, oatmeal agar, salts-starch agar and glycerolasparagine agar, but color similar to 5 dc (grayish yellowish pink) from the Red color-series may also be seen on yeast-malt agar and salts-starch agar.

Reverse side of colony: No distinctive pigments (pale grayish yellow, yellowish brown or occasionally dark grayish brown) on yeast-malt agar, oatmeal agar, salts-starch agar and glycerolasparagine agar.

Color in medium: Melanoid pigments are not formed in peptoneyeast-iron agar, tyrosine agar or tryptone-yeast broth. No pigment is found in the medium in yeast-malt agar, oatmeal agar, salts-starch agar or glycerol-asparagine agar.

Carbon utilization: D-Glucose, L-arabinose, D-xylose, i-inositol, D-mannitol, D-fructose and rhamnose are utilized for growth. No growth or only trace of growth with sucrose and raffinose.

Streptomyces polychromogenus Hagemann, Pénasse and Teillon. Description: Name and antibiotic production, only, without description in Hagemann et al. 1955, 240-243. Type strain: Roussel UCLAF T 4473 (ibid.). ISP 5316 from G. Hagemann as T 4473. ISP description by Group C-3.

Spore chain morphology: Characteristically in Section Rectiflexibiles with long, straight spore chains of more than 50 spores per chain on yeast-malt agar, oatmeal agar, salts-starch agar and glycerola sparagine agar (Fig. 138). A few spore chains may terminate in spirals (Fig. 139). Spore surface: Smooth (Fig. 140).

Special morphological characteristics: Knots and nest-like tangles may be seen in the aerial mycelium ( $F$ ig. 141). Some of these tangles fragment into spore-like bodies (Fig. 142) and one observer reports that spores may also be seen on the substrate mycelium.

Color of colony: Aerial mass color in the Red color-series (grayish yellowish pink) on yeast-malt agar, oatmeal agar, salts-starch agar and glycerol-asparagine agar.

Reverse side of colony: No distinctive pigments (nearly colorless to grayish yellow or light yellow on oatmeal agar, salts-starch agar and Elycerol-asparagine agar; light grayish reddish brown to strong brown on yeast-malt agar).

Color in medium: Melanoid pigments are formed in peptone-yeastiron agar and tryptone-yeast broth, but only weakly or not at all in tyrosine agar. No pigment, or only a trace of yellow, is found in the medium in yeast-malt agar, oatmeal agar, salts-starch agar and glycerol-asparagine agar.

Carbon utilization: D-Glucose, L-arabinose, D-xylose, D-fructose and sucrose are utilized for growth. Only a trace of growth is seen with $\underline{i}$-inositol, D-mannitol, rhamnose or raffinose. 


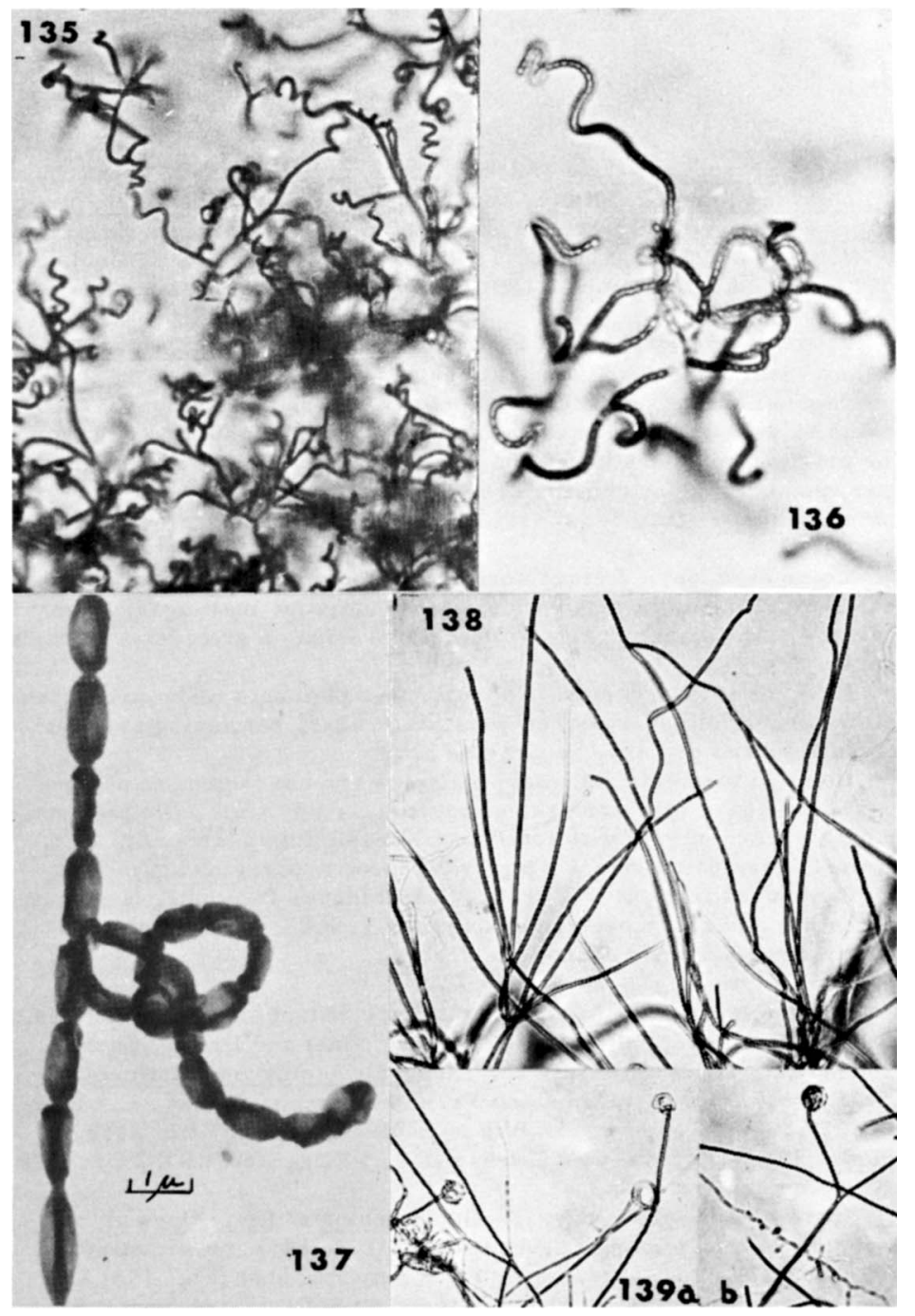

Figure 135. S. plicatus. Open spirals (X 300) on yeast-malt agar, 20 days.

Figure 136. S. plicatus. RA morphology (X 600) from same preparation as Fig. $1 \overline{35}$.

Figure 137. S. plicatus. Smooth spores; electron micrograph from 14 day culture.

Figure 138. S. polychromogenus. RF spore chains (X 300) on yeastmalt aga $\vec{r}, 21$ days.

Figure 139 a, b. S. polychromogenus. Long spore chains with terminal spirals $(\mathrm{X} 3 \overline{00})$ on yeast-malt agar. 
Streptomyces praecox (Millard and Burr) Waksman. Descriptions: Actinomyces praecox Millard and Burx 1926, 633-635; Streptomyces praecox (Millard and Burr) Waksman 1953, 107. Type strain: Strain 20 (Millard and Burr, ibid.); IMRU 3374 (Waksman 1961, 260). ISP 5393 from S.A. Waksman as IMRU 3374. ISP description by Group D-2.

Spore chain morphology: Predominantyy Section Rectiflexibiles (Fig. 143) on yeast-malt agar, oatmeal agar, silts-starch agar and glycerolasparagine agar. One of three ISP observers records strongly flexuous chains on yeast-malt agar to open spirals on oatmeal agar in 14 days. The original work of Millard and Burr (op. cit.) describes "widely open spirals". Spore chains are moderately long with 10 to 50 or sometimes more than 50 spores per chain. Spore surface: Smooth (Fig. 144).

Color of colony: Mature aerial mass color in the Yellow colorseries (pale yellow or pale yellow.green) on yeast-malt agar, oatmeal aga $\mathbf{r}$ and salts-starch agar; White color-series on glycerol-asparagine agar.

Reverse side of colony: No distinctive pigments (pale or grayish yellow to light olive-brown) on yeast-malt agar, oatmeal agar, saltsstarch agar and glycerol-asparagine agar.

Color in medium: Melanoid pigments are not formed in peptoneyeast-iron agar, tyrosine agar or tryptone-yeast broth. No pigment, or only a trace of yellow is found in the medium in yeast-malt agar, oatmeal agar, salts-starch agar or glycerol-asparagine agar.

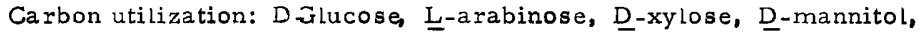
D-fructose and rhamnose are utilized for growth. Utilization of inositol, sucrose and raffinose is doubtful.

Streptomyces pristinaespiralis Mancy, Ninet and Preud'homme. Descriptions: Streptomyces 5647 Mancy, Ninet and Preud'homme, French Pat. 1,301,857 July 16, 1962; Streptomyces pristinaespiralis Mancy, Ninet, Ninet and Preud'homme, U.S. Pat. 3, 154, 475. Oct. 27, 1964. Type strain: Rhone-Poulenc $5647=$ NRRL 2958 (ibid.). ISP 5338 from C.W. Hesseltine, NRRL, as NRRL 2958. ISP description by Group C- 8 .

Spore chain morphology: Section Spirales to RA. Open or irregular spirals of one to several turns (Fig. 145) or sometimes

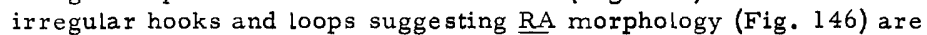
found on yeast-malt agar, oatmeal agar and salts-starch agar. Flexuous spore chains are common on glycerol-asparagine agar. Mature spore chains moderately long with 10 to 50 spores per chain. Spore surface: Warty (Fig. 147).

Color of colony: Aerial mass color in the Gray color-series on yeast-malt agar, oatmeal agar, salts-starch agar and glycerol-asparagine agar.

Reverse side of colony: No distinctive pigments (colorless to grayish yellow or light yellowish brown) on yeast-malt agar, oatmeal agar, salts-starch agar and glycerol-asparagine agar.

Color in medium: Melanoid pigments are not formed in peptoneyeast-iron agar, tyrosine agar or tryptone-yeast broth. No pigment, 


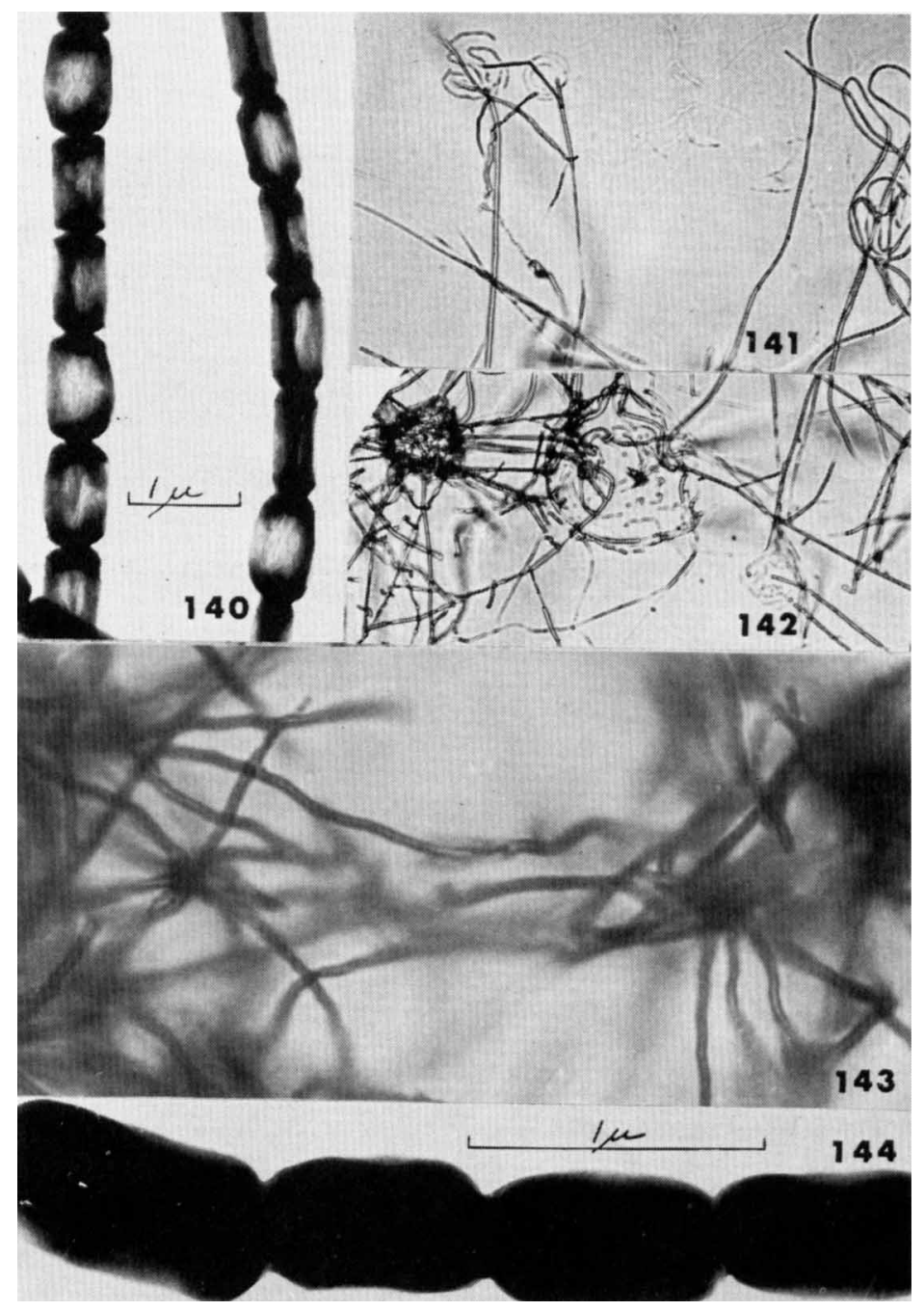

Figure 140. S. polychromogenus. Smooth spores; electron micrograph from 14 day culture on yeast-malt agar.

Figure 141. S. polychromogenus. Knots or tangles in aerial mycelium (X 300) on water agar, 7 days.

Figure 142. S. polychromogenus. Fragmentation of knots into sporelike bodies; same preparation as Fig. 141 .

Figure 143. S. praecox. RF spore chains (X 800) on glycerol-asparagine agar, 21 days.

Figure 144. S. praecox. Smooth spores; electron micrograph from 7 day culture on glycerol-asparagine agar. 
or only a trace of yellow, is found in the medium in yeast-matt agar, oatmeal agar, salts-starch agar or glycerol-asparagine agar.

Carbon utilization: D-Glucose, L-arabinose, D-xylose, $\underline{\text { I-inositol, }}$ D-mannitol, D-fructose, rhamnose, sucrose and raffinose are all utilized for growth.

Actinomyces prunicolor Ryabova and Preobrazhenskaya. Description: Ryabova and Preobrazhenskaya in Gauze et al. 1957, 184-185. Type strain: INA $8805 / 64$ (Suggested neotype, selected by G.F. Gauze, personal communication, Jan. 1966. Through a typographical error this strain is given as $8805 / 54$ in G.F. Gauze, cited by Gottlieb, 1968). ISP 5335 from G.F. Gauze as INA 8805/64. ISP description by Group C-9.

Spore chain morphology: Section Rectiflexibiles (Fig. 148). Straight to flexuous spore chains are generally long with 10 to 50 , or often more than 50 spores per chain. This morphology is seen on yeast-malt agar, oatmeal agar, salts-starch agar and glycerol-asparagine agar. Spore surface: Smooth (Fig. 149).

Special morphological characteristics: Long aerial hyphae may become entangled into knots or nest-like bodies (Fig. 150a, b).

Color of colony: Mature aerial mass color in the Red color-series ( $5 \mathrm{cb}$, grayish yellowish pink) on yeast-malt agar, salts-starch agar and glycerol-asparagine agar; immature aerial mycelium may be white to yellow on these media and sporulation on oatmeal agar is usually inadequate for accurate spore mass color determination.

Reverse side of colony: Light brown to reddish brown on yeast malt agar; grayish yellow, reddish gray, reddish purple or dark reddish purple on oatmeal agar, salts-starch agar and glycerol-asparagine agar. Reports vary on the production of the reddish purple reverse pigment. Reverse mycelium pigment is not a $\mathrm{pH}$ indicator, or is changed only slightly with addition of $0.05 \mathrm{~N} \mathrm{HCl}$.

Color in medium: Melanoid pigments are not formed in peptoneyeast-iron agar, tyrosine agar or tryptone-yeast broth. No pigment, or only a trace of pale brown, is found in the medium in yeast-malt agar, oatmeal agar, salts-starch agar or glycerol-asparagine agar.

Carbon utilization: $\underline{\text {-Glucose, }} \underline{\text {-arabinose, }}$-xylose, $\underline{\text { in-inositol, }}$ D-mannitol, D-fructose, rhamnose and raffinose a re utilized for growth. Reports vary on the utilization of sucrose.

Streptomyces psammoticus Virgilio and Hengeller. Descriptions: Virgilio and Hengellet 1960,164-174. (See also, S. feofaciens Bellenghi, German Pat. Appl. L 21111 , March 8, 1956 and British Pat. 755, 139. May 22, 1959). Type strain: Univ. Pavia S 4623/33= P-19= CBS 175.61 (personal communication: Lepetit S.p.a., Feb. 1966; G.A. deVries, CBS, March 1966). Note: These correspondents also call attention to the use of the binomial Streptomyces feofaciens in reference to this strain number in patent literaturs (loc. cit.). See Virgilio and Hengeller 1960, p. 165 (footnote) for explanation of change in epithet. ISP 5341 from G.A. deVries, CBS, as S 4623/33= P-19 (CBS 175.6L). ISP description by Group C-5.

Spore chain morphology: Section Rectiflexibiles to RA with 10 to 50 or more spores per chain on oatmeal agax and glycerol-asparagine agar. Spore chains may be flexuous or irregutarly turned in various 

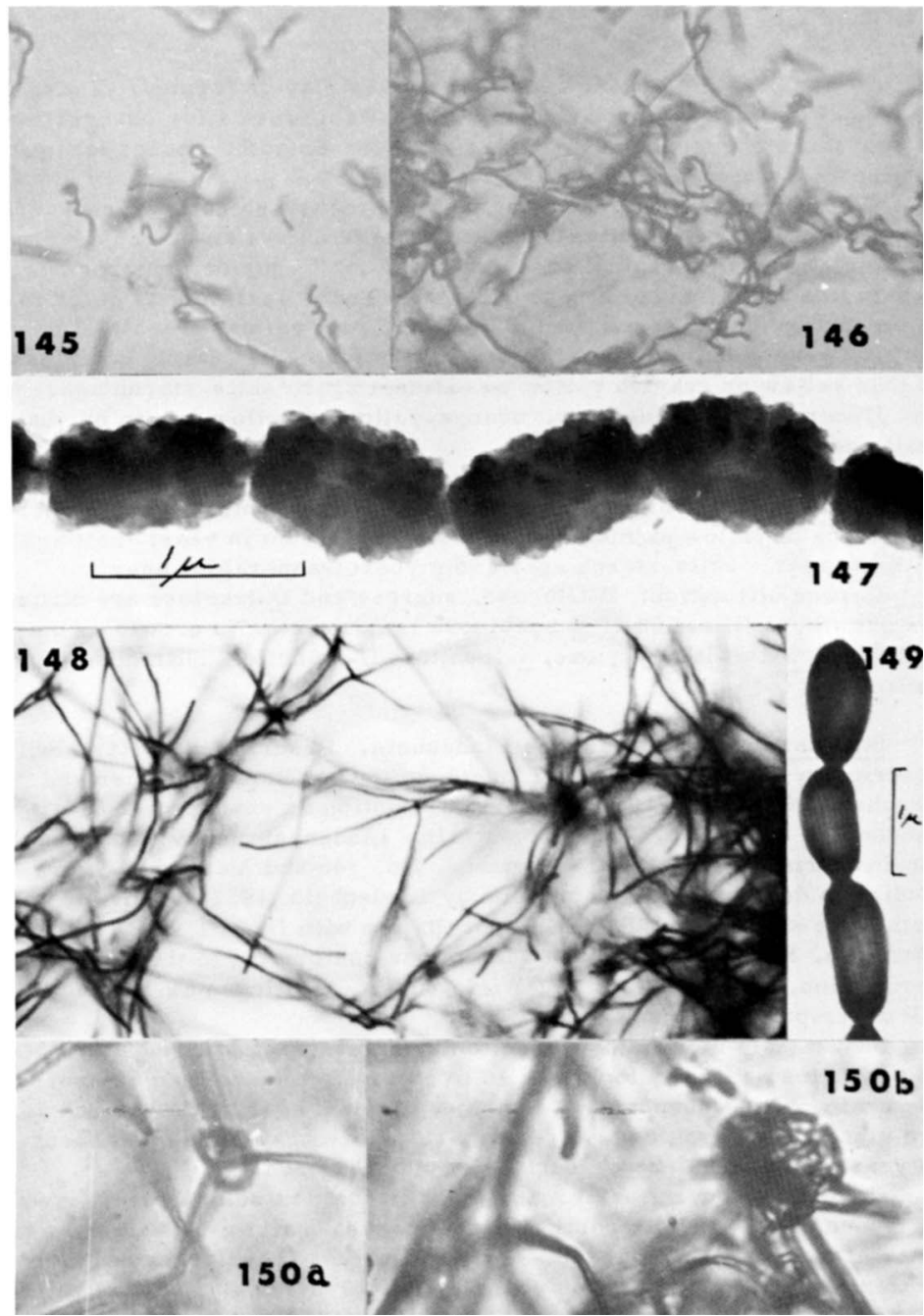

Figure 145. S. pristinaespiralis. Open spirals (X 900) on glycerolas paragine agar, 21 days.

Figure 146. S. pristinaespiralis. Irregular spirals, hooks and loops ( $\mathrm{X} 900$ ) on glycerol-asparagine agar, 21 days.

Figure 147. S. pristinaespiralis. Warty spores; electron micrograph from 20 day culture on salts-starch agar.

Figure 148. S. prunicolor. RF spore chains (X 400) on yeast-malt agar, 10 days.

Figure 149. A. prunicolor. Smooth spores; electron micrograph from 6 day culture on oatmeal agar.

Figure 150 a, b. A. prunicolor. (a) Knots in aerial mycelium; (b) nest-. like bodies; 14 day culture on yeast-malt agar (X 900). 
forms, and coremia or sclerotia-like bodies may be formed. Yeastmalt agar and salts-starch agar are not suitable media for observation of spore-chain morphology. Spore surface: Smooth; spores irregular in size and shape(Fig. 151).

Color of colony: Aerial mass color in the Green color-series ( $11 / 2$ ge, light grayish olive) on oatmeal aga $x$ and salts-starch agar, and sometimes in marginal areas on yeast-malt agar or glycerolasparagine agar. According to one observer the aerial mass color is in the Yellow color-series (color tab $1 \mathrm{dc}$, pale yellow-green).

Reverse side of colony: No distinctive pigments (nearly colorless to pale yellow or grayish yellow on oatmeal agar, salts-starch agar and glycerol-asparagine agar; orange-yellow to yellow-brown on yeastmalt agar).

Color in medium: Melanoid pigments are not formed in peptoneyeast-iron agar, tyrosine agar or tryptone-yeast broth. No pigment or a trace of yellow pigment is found in the medium in yeast-malt agar, oatmeal agar, salts-staxch agar and glycerol-asparagine agar.

Carbon utilization: D-Glucose, sucrose and D-fructose are utilized for growth. Utilization of $\underline{L}$-arabinose is doubtful. No growth or only

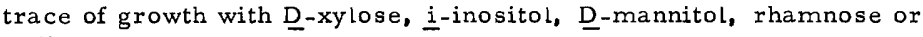
raffinose.

Streptomyces purpurascens Lindenbein. Descriptions: Name with description of antibiotic only, Lindenbein in Brockmann, Bauer and Borchers 1951,700-710; complete description as new species in Lindenbein 1952, $371-373$. Type strain: Lindenbein (Univ. Guttingen) strain Maria 515. Note: Two strains, No. 346 and Maria 515, were studied in detail for the description by Lindenbein (1952, op cit.). Both were studied by ISP and in consultation with Dr. P. Wilde of Univ. Gottingen, Maria 515 has been selected as conforming to the original description. ISP 5310 from P. Wilde, Univ. G ottingen as Maria 515. ISP description by Group C-5.

Spore chain morphology: Section Spirales (Fig. 152). Mature spore chains generally long with 10 to 50 or often more than 50 spores per chain. This morphology is seen on oatmeal agar, salts-starch agar, and glycerol-asparagine agar, but spiral spore chains may be absent on yeast-malt agar. Spore surface: Spiny (Fig. 153).

Color of colony: Aerial mass color in the Red color-series (grayish yellowish pink) or White color-series on yeast-malt agar, oatmeal agar, salts-starch agar and glycerol-asparagine agar. (Aerial mycelium may be thin and white or absent on yeast-malt agar or on glycerol-asparagine agar.)

Reverse side of colony: Grayish yellowish pink to reddish brown on yeast-malt agar, oatmeal agar, salts-starch agar and glycerol-asparagine agar. Reverse mycelium pigment is a $\mathrm{pH}$ indicator changing from red or purple to blue with addition of $0.05 \mathrm{~N} \mathrm{NaOH}$ and to red or orange with addition of $0.05 \mathrm{~N} \mathrm{HCl}$.

Color in medium: Melanoid pigments are formed in peptone-yeast iron agar and tryptone-yeast broth and may or may not develop after four days in tyrosine agar. Red to violet pigment is sometimes found in the medium in yeast-malt agar, oatmeal agar, salts-starch agar or glycerol-asparagine agar. When present, this pigment is pH sensitive showing the same color changes recorded for reverse mycelium pigments. 


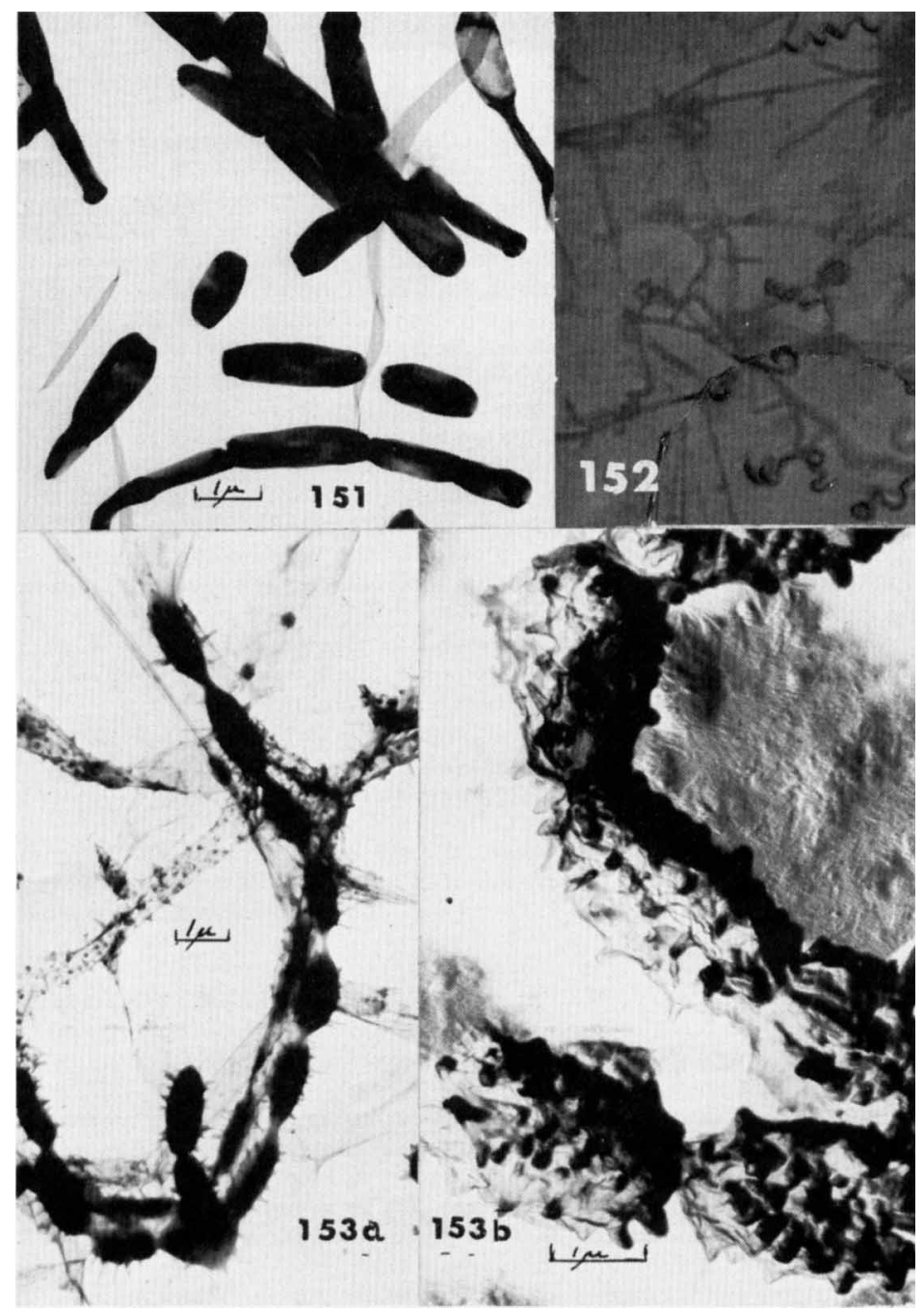

Figure 151. S. psammoticus. Smooth spores of irregular size and shape; electron micrograph from 14 day culture on oatmeal agar.

Figure 152. S. purpurescens. Spiral spore chains (X 537) on oatmeal agar, 14 days.

Figure 153. S. purpurescens. Spiny spores. (a) Electron micrograph from 10 day culture on salts-starch agar. (b) Carbon replica from same preparation. 
Carbon utilization: D-Glucose, L-arabinose, D-xylose, $\underline{\text { i-inositol, }}$ D-mannitol, D-fructose, rhamnose, sucrose and raffinose are all utilized for growth.

Streptomyces rangoon (Erickson) Pridham, Hesseltine and Benedict. Description: Actinomyces rangoon Erickson 1935, 33 and 37. See also, Nocardia rangoonensis Waksman and Henrici 1948, 911 ; Streptomyces rangoon $($ Erickson) Pridham et al. 1958, 61. Type strain: NCTC 1678 (Erickson 1935 op. cit.) = ATCC 6860 (E.F. Lessel, ATCC, personal communication). ISP 5452 from E.F. Lessel as ATCC 6860 . Note: This strain is listed in the ATCC Catalogue of Strains, 8th Ed. (1968) as Nocardia rangoonensis with the further comment that it is identical with Streptomyces albus A TCC 618. ISP description by Group D-6.

Spore chain morphology: Section Spirales (Fig. 154). Flexuous chains and irregular spirals are also common. Mature spore chains generally 3 to 10 or more spores per chain. This morphology is seen on yeast-malt agar, oatmeal agar, salts-starch agar and glycerolasparagine agar. Spore surface: Smooth (Fig. 155).

Color of colony: Aerial mass color in the White color-series on yeast-malt agar, oatmeal agar, salts-starch agar and glycerol-asparagine agar.

Reverse side of colony: No distinctive pigments (colorless to pale yellow on oatmeal agar, salts-starch agar and glycerol-asparagine agar; yellowish brown to light olive brown on yeast-malt agar).

Color in medium: Melanoid pigments are not formed in peptoneyeast-iron agar, tyrosine agar or tryptone-yeast broth. No pigment is found in the medium in yeast-malt agar, oatmeal agar, salts-starch agar or glycerol-asparagine agar.

Carbon utilization: D-Glucose, D-xylose, D-mannitol and $\underline{\text { D-fructose }}$ are utilized for growth. Utilization of L-arabinose is doubtful. Only a trace of growth or no growth is found on 1 -inositol, rhamnose, sucrose or raffinose.

Actinomyces rectiverticillatus Krasil'nikov and Yuan. Description: Krasil'nikov and Yuan in Krasil'nikov 1965, 49 and 51. Type strain: INMI 380 (ibid.). ISP 5436 from N.A. Krasil'nikov as INMI 380. ISP description by Group D-2.

Spore chain morphology: Section Verticillati, umbellate monoverticillate. (Fig. 156). Monoverticillate morphology is also common. Mature spore chains generally short with 3 to 10 or sometimes more than 10 spores per chain. This morphology is seen on yeast-malt agar, oatmeal agar, salts-starch agar and glycerol-asparagine agar. Spore surface: Smooth (Fig. 157).

Color of colony: Aerial mass color in the Red or White color series on yeast-malt agar, oatmeal agar, salts-starch agar and glycerola sparagine agar.

Reverse side of colony: Grayish yellowish pink to strong brown or reddish orange on yeast-malt agar, oatmeal agar, salts-starch agar and glycerol-asparagine agar. Reverse mycelium pigment is not a $\mathrm{pH}$ indicator.

Color in medium: Melanoid pigments are formed in peptone-yeastiron agar, tyrosine agar and tryptone-yeast broth, but may be weak in tyrosine agar. Yellow or red pigment is found in the medium in yeast - 


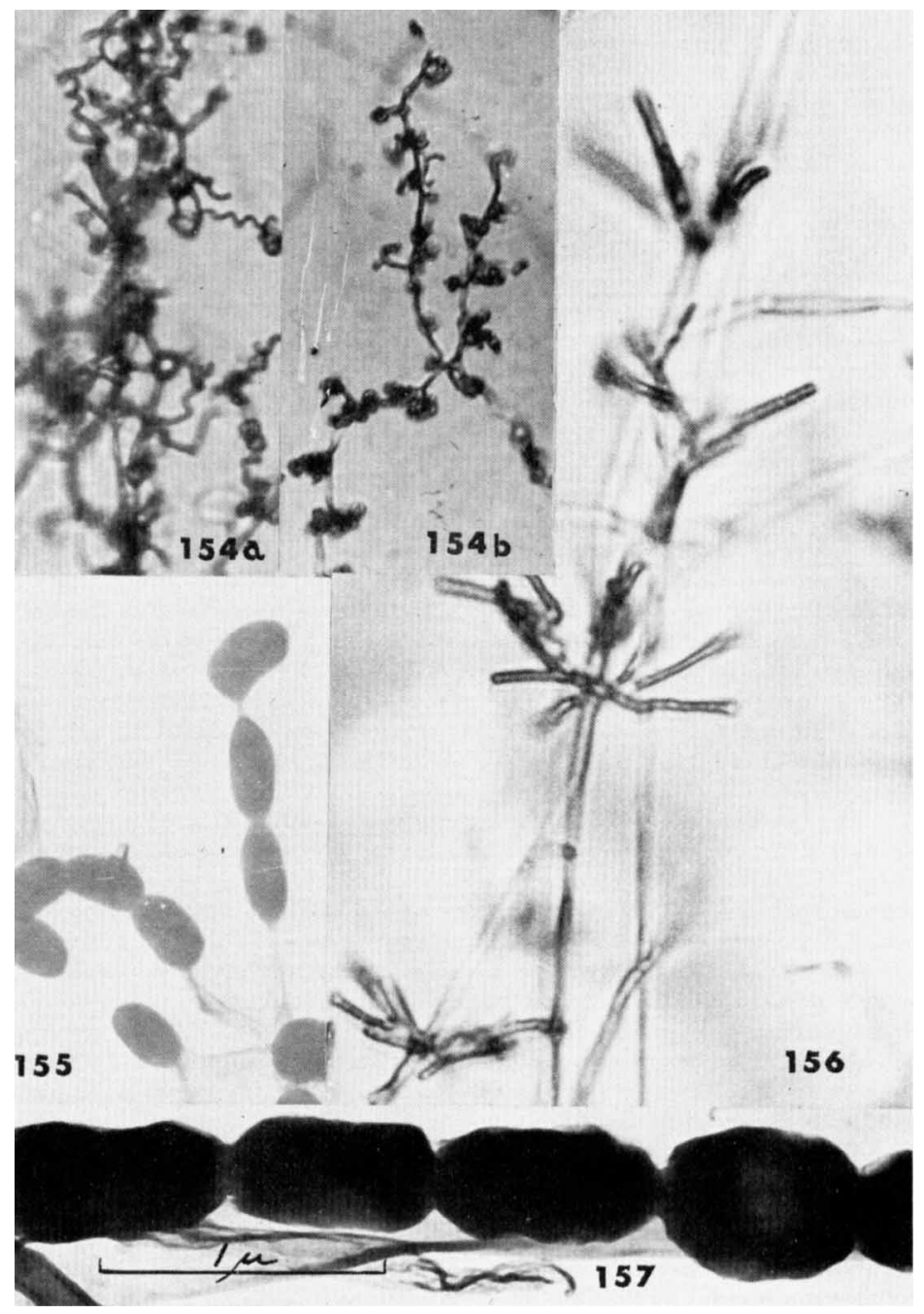

Figure 154. S. rangoon. Spiral spore chains (X 594). (a) Open and ir regular spirals on glycerol-asparagine agar, 21 days. (b) Tight spirals on glycerol-asparagine agar, 21 days.

Figure 155. S. rangoon. Smooth spores.

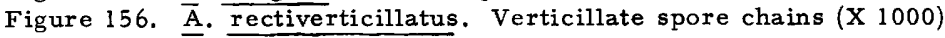
on glycerol-asparagine agar, 21 days.

Figure 157. A. rectiverticillatus. Smooth spores; electron micrograph from 21 day culture on glycerol-asparagine agar. 
malt agar and oatmeal agar. Traces of yellow may also be present in salts-starch agar and glycerol-asparagine agar. This pigment is not $\mathrm{pH}$ sensitive when tested with $0.05 \mathrm{~N} \mathrm{NaOH}$ or $\mathrm{HCl}$.

Carbon utilization: D-Glucose, $\underline{i}$-inositol and D-fructose are utilized for growth. Utilization of sucrose and raffinose is doubtful. No growth or only trace of growth with $\underline{L}$-arabinose, D-xylose, Dmannitol or rhamnose.

Streptomyces roseochromogenus (Jensen) Waksman and Henrici. Descriptions and nomenclature: First described as "Actinomyces

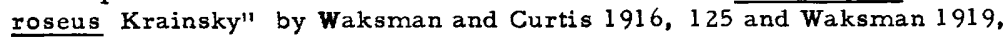
148. This description was based upon a Waksman isolate, not on Krainsky's original strain (Waksman 1916, op cit. ; Waksman 1961, 268). Jensen (1931, p. 359) changed the name of A. roseus (Krainsky) sensu Waksman 1916 to $\mathrm{A}$. roseochromogenus Jensen. Streptomyces roseochromogenus (Jensen) Waksman and Henrici 1948; S. roseochromogenes (sic.) (Jensen) Waksman 1957, 770. (See also: S. roseochromogenes (sic) in Waksman 1961, p. 268). Not Noca rdia rosea Chalmers and Christopherson 1916, 270. Type strain: Following Waksman 1961, p. 268 and 271, IMRU 3772 has been used as the neotype for S. roseus (Krainsky) Pridham et al. 1958, (= ISP 5076, Shirling and Gottlieb, 1968a, p. 168) and ATCC 13,400 (=IMRU 3689) is used here as suggested neotype for $\mathrm{S}$. roseochromogenus. IMRU 3689 was deposited in IMRU by R.W. Thoma, Squibb Inst. for Med. Res., April, 1954. ISP 5463 from S.A. Waksman as IMRU 3689. ISP description by Group D-8.

Spore chain morphology: Section Rectiflexibiles or Spirales.

Spirals are poorly developed or absent and strongly flexuous spore chains (Fig. 158) are usually found on yeast-malt agar, oatmeal agar, saltsstarch agar and glycerol-asparagine agar. Mature spore chains are generally short with 3 to 10 or more spores per chain. This morphology is seen on yeast-malt agar, salts-starch agar and glycerol-a sparagine agar; aerial mycelium is poorly developed or absent on oatmeal agar. Spore surface: Spiny (Fig. 159).

Color of colony: Aerial mass color in the White or Yellow (2ba, pale yellow) color-series on yeast-malt agar, salts-starch agar and glycerol-asparagine agar.

Reverse side of colony: Pale yellow to orange-yellow or light yellowish brown on yeast-malt agar, oatmeal agar, salts-starch agar and glycerol-asparagine agar.

Color in medium: Melanoid pigments are formed weakly or not at all in peptone-yeast-iron agar and are not produced in tyrosine agar or tryptone-yeast broth. Yellow pigment may be found in the medium in yeast-malt agar, oatmeal agar, salts-starch agar and glycerol-asparagine agar. This pigment is not $\mathrm{pH}$ sensitive when tested with $0.05 \mathrm{~N}$ $\mathrm{NaOH}$ or $\mathrm{HCl}$.

Carbon utilization: D-Glucose, D-xylose, D-mannitol and D-fructose are utilized for growth. No growth or only trace of growth with La rabinose, $\underline{i}$-inositol, rhamnose, sucrose or raffinose.

Actinomyces roseoviolaceus Sveshnikova. Description: Sveshnikova in Gauze et al، 1957, 67-68. Type strain: INA 1020/54 (Gauze in Gottlieb, 1968). A personal communication from Prof. G.F. 


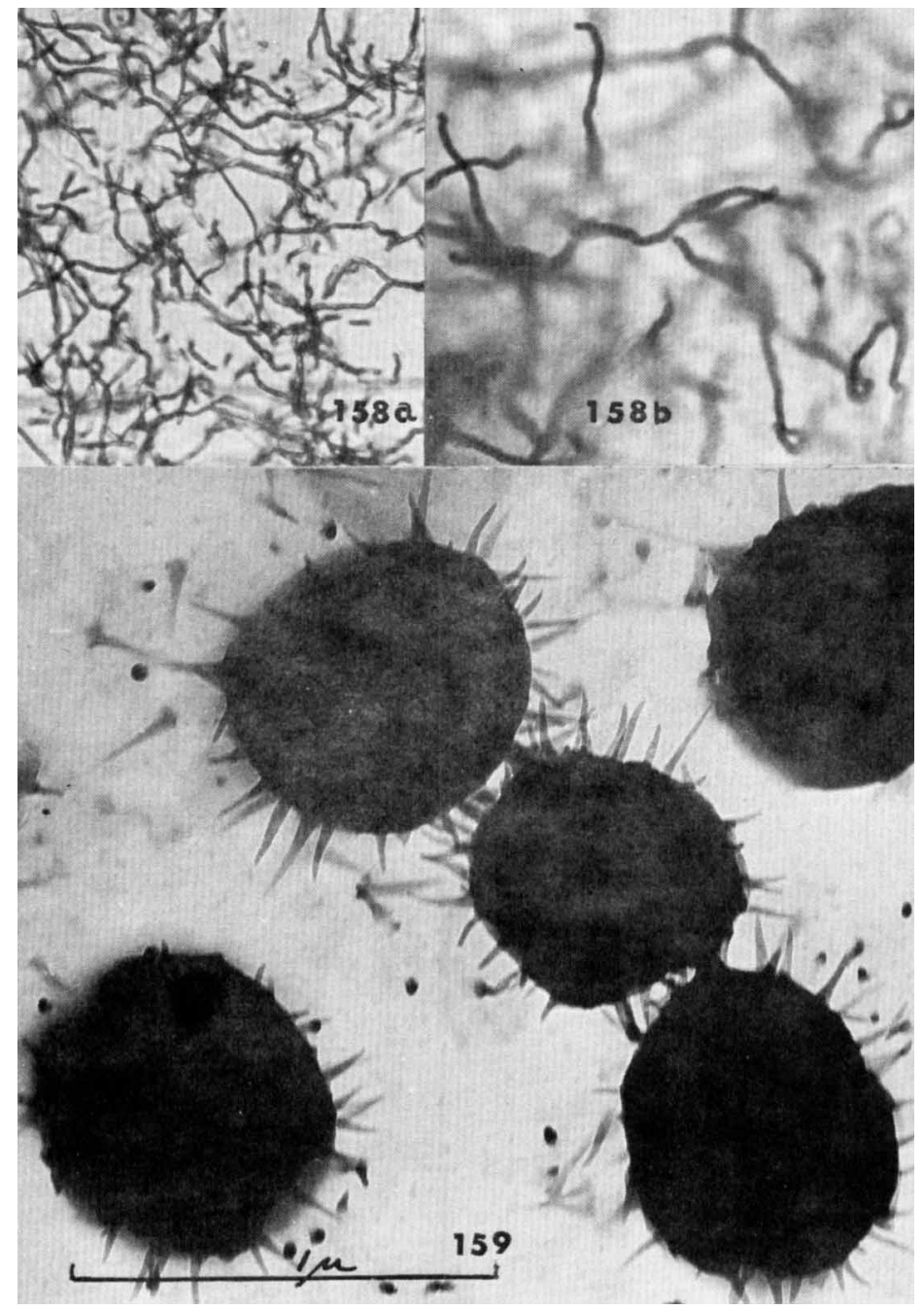

Figure 158. A. roseochromogenus. Strongly flexuous spore chains. (a) On glycerol-asparagine agar, 21 days (X 1200). (b) On potatocarrot agar, 7 days.

Figure 159. A. roseochromogenus. Spiny spores; electron micrograph from 21 day culture on glycerol-as paragine agar. 


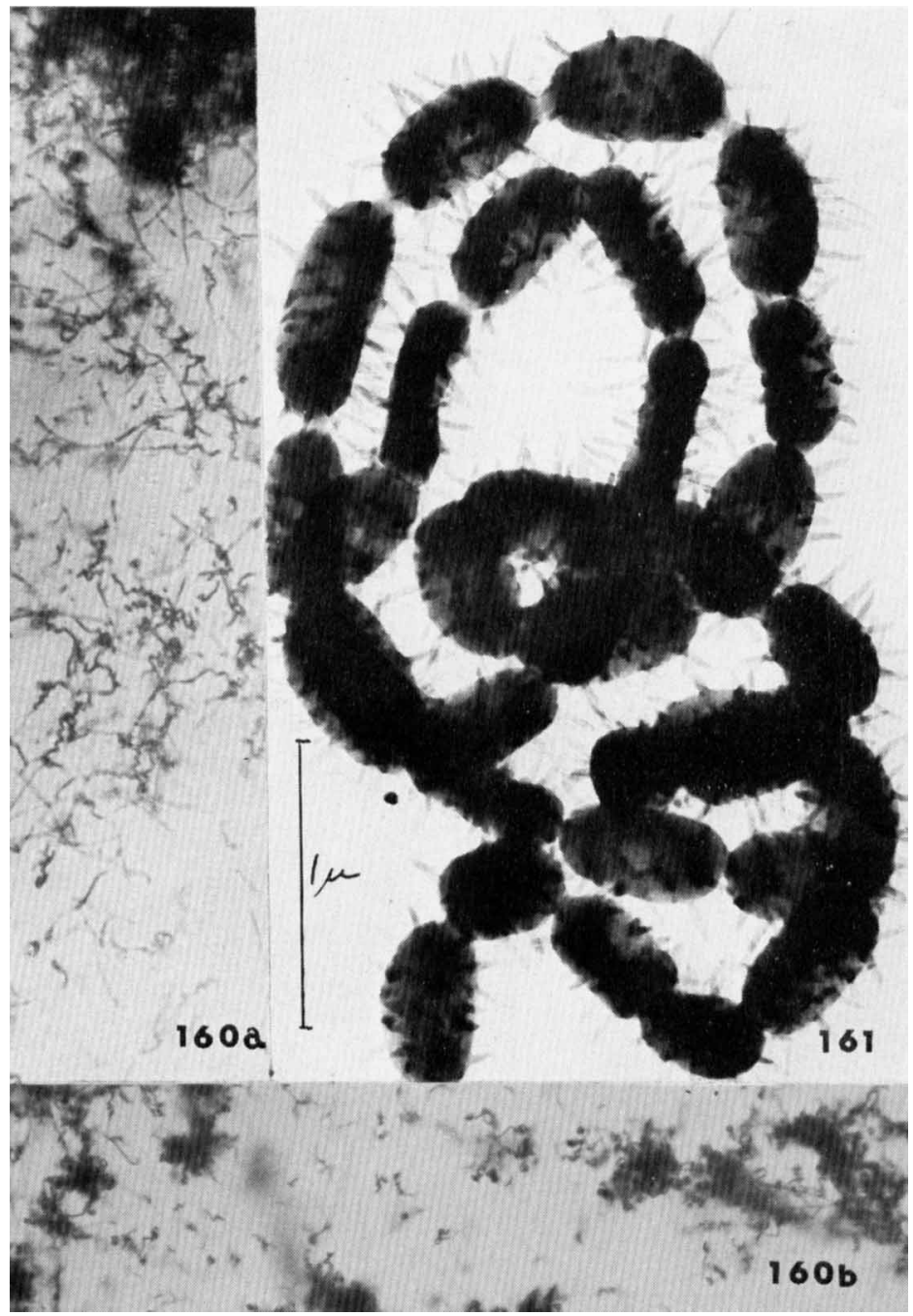

Figure 160. A. roseoviolaceus. (a) Spiral spore chains on oatmeal agair, 14 days. (b) On salts-starch agar, 14 days (X 300).

Figure 161. A. roseoviolaceus. Spiny spores and spiral spore chains; electron micrograph from 14 day culture on yeast-malt agar. 
Gauze, Nov. 1964, states that $\underline{A}$. roseoviolaceus as represented by the type strain 1020/54 is "now believed to be identical with Streptomyces purpurascens". Streptomyces roseoviolaceus (Sveshnikova) Pridham et al. 1958, 68. ISP 5277 from G.F. Gauze as INA $1020 / 54$. ISP description by Group B -7 .

Spore chain morphology: Section Spirales (Fig. 160, 161). Mature spore chains moderately long with 10 to 50 or more spores pex chain. This morphology is seen on yeast-malt agar, oatmeal agar, salts-starch agar and glycerol-asparagine agar. Spore surface: Spiny (Fig. 161).

Color of colony: Aerial mass color in the Red color-series on oatmeal agar and salts-starch agar; Red or Violet color-series on yeast-malt agar and glycerol-asparagine agar. The most representative color tabs in the Red color-series are $5 \mathrm{cb}$ or $5 \mathrm{ec}$, grayish yellowish pink and the most representative tab in the Violet color-series is $11 \mathrm{ca}$, very pale purple.

Reverse side of colony: Purplish pink or purplish red on yeastmalt agar, oatmeal agar, salts-starch agar and glycerol-asparagine agar. Reverse mycelium pigment is a pH indicator changing from red or pink to violet or blue-violet with addition of $0.05 \mathrm{~N} \mathrm{NaOH}$ and violet to red or pinkish orange with addition of $0.05 \mathrm{~N} \mathrm{HCl}$.

Color in medium: Melanoid pigments are formed in peptone-yeastiron agar, tyrosine agar and tryptone-yeast broth. Red to violet pigment is found in the medium in yeast-malt agar, oatmeal agar, saltsstarch agar and glycerol-asparagine agar. This pigment is $\mathrm{pH}$ sensitive, showing the same changes noted for the reverse mycelium pigment.

Carbon utilization: D-Glucose, L-arabinose, D-xylose, i-inositol, D-mannitol, D-fructose, rhamnose, sucrose and raffinose are all utilized for growth.

Streptoverticillium rubrireticuli (Waksman and Henrici) Baldacci. Descriptions: Actinomyces reticulus-ruber Waksman 1919, 146-147; Actinomyces reticulus Bergey et al. 1925, 373; Streptomyces rubrireticuli Waksman and Henrici 1948, 945; Streptoverticillium rubrireticuli (Waksman and Henrici) Baldacci 1958, 25. Type strain: IMRU 3631 (designated as neotype by Waksman 1961, p. 272); strain 3631 was deposited in the IMRU collection as A. reticulus-ruber by $T$. Ohtusaki in July, 1952 (personal communication, Ruth Gordon, IMRU, April, 1967). IMRU 3631 = NRRL B $1707=$ A TCC $12629=$ PSA 133. ISP 5464 from S.A. Waksman as IMRU 3631. ISP description by Group D-9.

Spore chain morphology: Section Umbellate Monoverticillate (= Streptomyces section Verticillati, biverticillate) (Fig. 162). Mature spore chains generally short with 3 to 10 or more spores per chain. This morphology is seen on oatmeal agar and glycerol-asparagine agar. Sporulating aerial mycelium may or may not be seen on yeast-malt agar and salts-starch agar. Spore surface: Smooth (Fig. 163).

Color of colony: Aerial mass color in the Red color-series on oatmeal agar, salts-starch agar and glycerol-a sparagine agar; gray and white aerial mycelium may also be seen on these media. Spore mass color usually cannot be observed on yeast-malt agar.

Reverse side of colony: Grayish yellow to yellowish brown on glycerol-asparagine agar; grayish yellow to strong brown on yeast- 


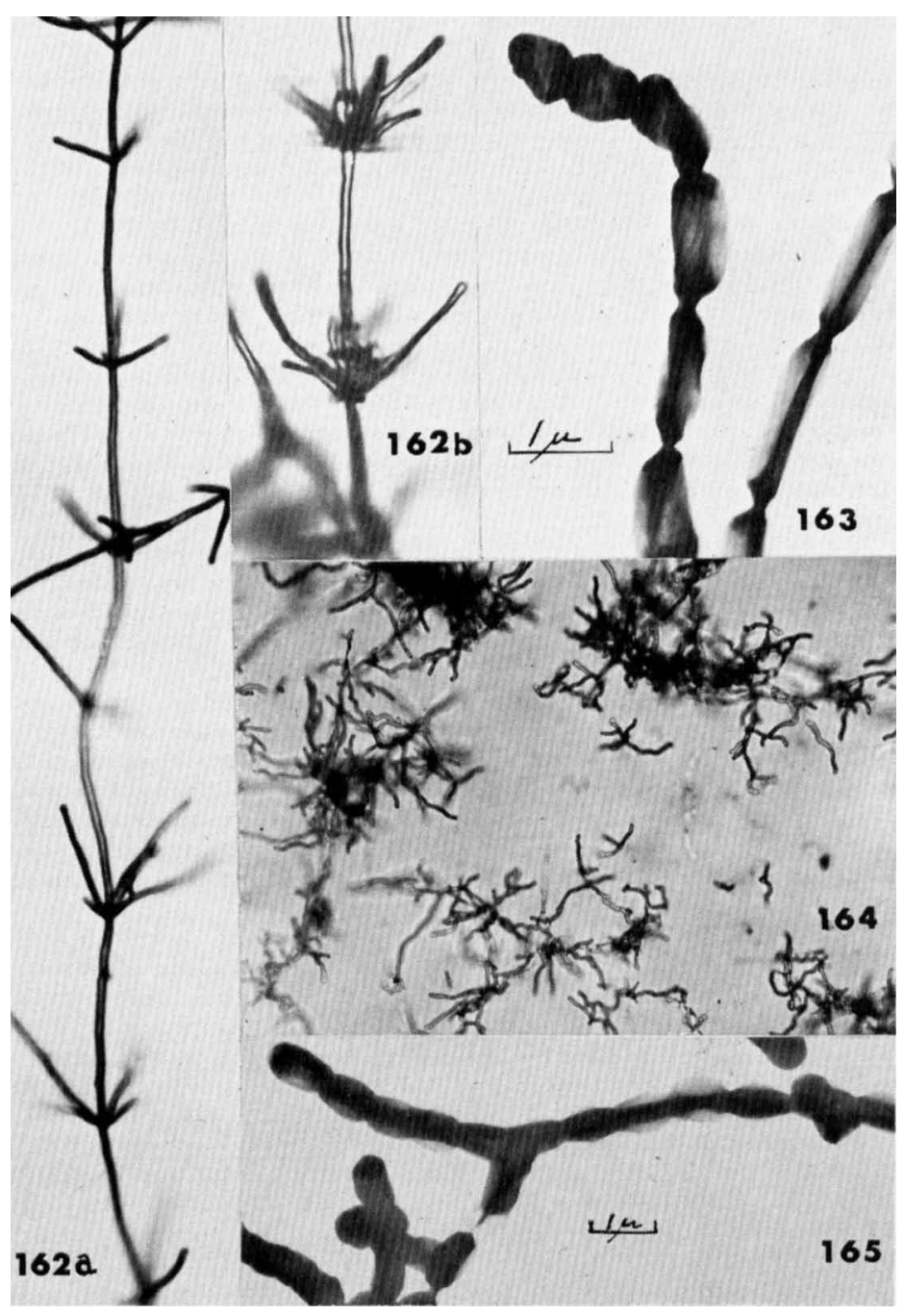

Figure 162. Streptoverticillium rubrirecticuli. Verticillate sporophores. (a) On salts-starch agar, 10 days (X 500). (b) On oatmeal agar, 14 days' (X 900).

Figure 163. Streptoverticillium rubrireticuli. Smooth spores; electron micrograph from 16 day culture on glycerol-asparagine agar.

Figure 164. S. sampsonii. RF spore chains (X 300) on glycerolasparagine agar, 7 days.

Figure 165. S. sampsonii. Smooth spores; electron micrograph from 15 day culture on glycerol-as paragine agar. 


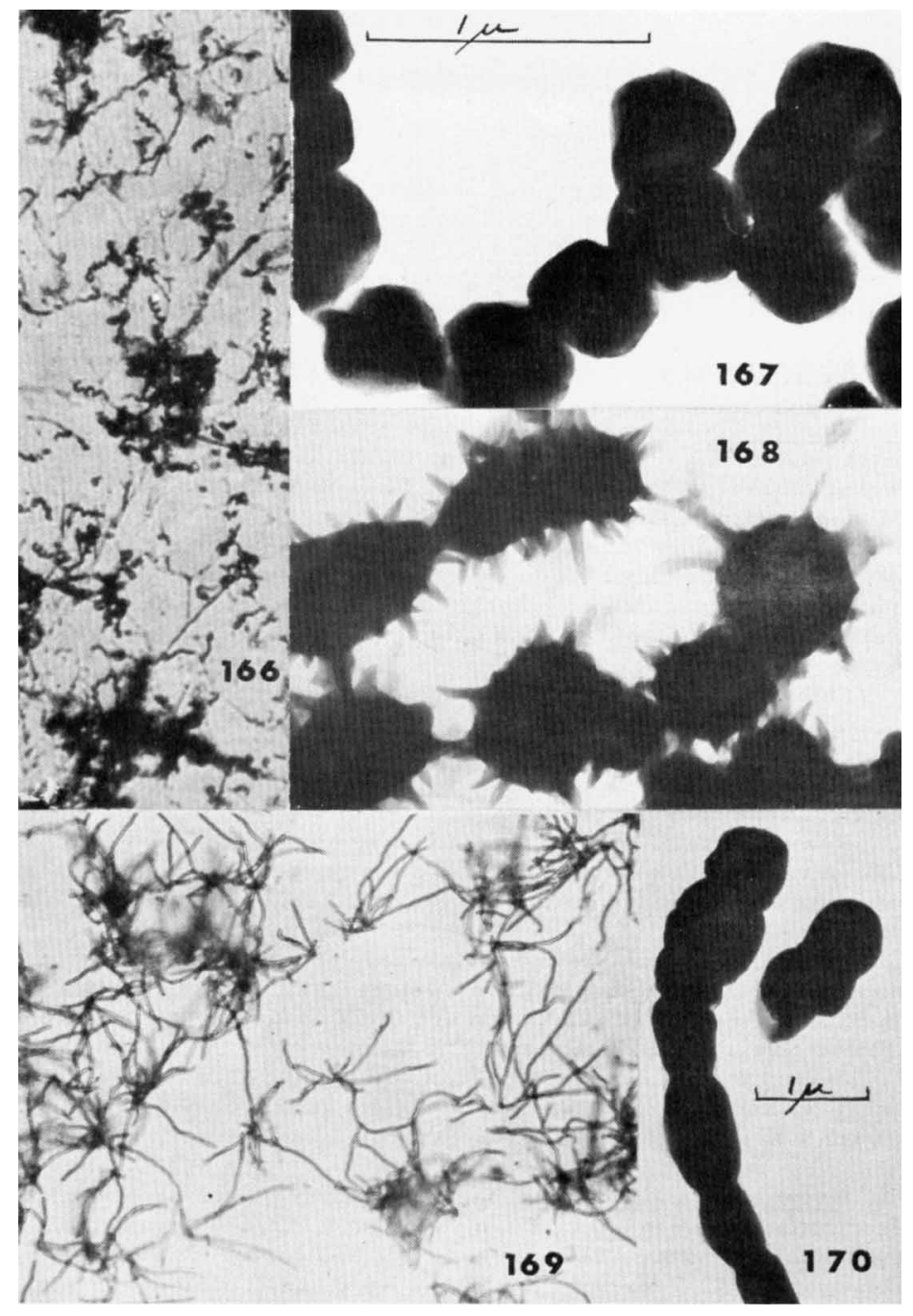

Figure 166. S. saraceticus. Spiral spore chains on oatmeal agar, 12 days.

Figure 167. S. saraceticus. Smooth spores (cf. Fig. 168); electron micrograph from 14 day culture.

Figure 168. S. saraceticus. Spiny spores (cf. Fig. 167); electron micrograph from 12 day culture on yeast-malt agar.

Figure 169. S. setonii. RF spore chains (X 300) on salts-starch agar, 21 days.

Figure 170. S. setonii. Smooth spores; electron micrograph from 21 day culture on yeast-malt agar. 
malt agar, oatmeal agar and salts-starch agar. The brown pigment is not a $\mathrm{pH}$ indicator.

Color in medium: Melanoid pigments are formed in peptone-yeastiron agar and tryptone-yeast broth, but not in tyrosine agar. No pigment, or only a trace of yellow, is found in the medium in yeast-malt agar, oatmeal agar, salts-starch agar and glycerol-asparagine agax.

Carbon utilization: D-Glucose, $\underline{i}$-inositol, D-mannitol and D-fructose are utilized for growth. No growth or only trace of growth with L-arabinose, D-xylose, rhamnose, sucrose or raffinose.

Streptomyces sampsonii (Millard and Burr) Waksman. Descriptions: Actinomyces sampsonii Millard and Burr 1926, 614-616; Streptomyces sampsonii (Millard and Burr) Waksman in Waksman and Lechevalier 1953, 115. Type strain: Strain Millard = IMRU 3371 (Waksman 1961, 273). ISP 5394 from S.A. Waksman as IMRU 3371. ISP description by Group D-3.

Spore chain morphology: Section Rectiflexibiles (Fig. 164). Mature spore chains generally long and flexuous with more than 50 spores per chain. This morphology is seen on yeast-malt agar, oatmeal agar, salts-starch agar and glycerol-asparagine agar. Spore surface: Smooth (Fig. 165 ).

Color of colony: Aerial mass color in the Yellow color-series (lba-2ba, pale yellow, or $1 \mathrm{db}$, pale yellowish green) on yeast-malt agar, oatmeal agar, salts-starch agar and glycerol-a sparagine agar; or sometimes inthe Gray color-series (2dc, yellowish gray) on yeastmalt agar and salts-starch agar.

Reverse side of colony: No distinctive pigments (pale yellow to light olive-brown on salts-starch agar and glycerol-a sparagine agar; strong yellow to orange-yellow or yellowish brown on yeast-malt agar and oatmeal agar).

Color in medium: Melanoid pigments are not formed in peptoneyeast-iron agar, tyrosine agar or tryptone-yeast broth. No pigment is found in the medium in yeast-malt agar, oatmeal agar, salts-starch agar or glycerol-asparagine agar.

Carbon utilization: D-Glucose, L-arabinose, D-xylose, D-mannitol and $\underline{D}$-fructose are utilized for growth. No growth or only trace of growth with $\underline{i}$-inositol, rhamnose, sucrose or raffinose.

Streptomyces saraceticus Berger, Goldberg, Sternbach and Muller. Description: Berger et al., German Patent L, 122, 670 August 1962. Type strain: Hoffman-LaRoche X-5079 = NRRL 2831 (ibid.). ISP 5241 from C.W. Hesseltine (NRRL) as NRRL 2831. ISP description by Group B-7.

Spore chain morphology: Section Spirales (Fig. 166). Mature spore chains moderately long with 10 to 50 ox more spores per chain. This morphology is seen on yeast-malt agar, oatmeal agar, saltsstarch agar and glycerol-asparagine agar. Spore surface: Two observers found smooth spores (Fig. 167); one observer found spiny spores (Fig. 168).

Color of colony: Aerial mass color in the Gray color-series on yeast-malt agar, oatmeal agar, salts-starch agar and glycerol-asparagine agar. 
Reverse side of colony: No distinctive pigments (pale or grayish yellow to light olive-gray or brown) on yeast-malt agar, oatmeal agar, salts-starch agar and glycerol-asparagine agar.

Color in medium: Melanoid pigments are not formed in peptoneyeast-iron agar, tyrosine agar or tryptone-yeast broth. No pigment is found in the medium in yeast-malt agar, oatmeal agar, salts-starch agar or glycerol-asparagine agar.

Carbon utilization: D-Glucose, L-arabinose, D-xylose, D-mannitol, D-fructose, sucrose and raffinose are utilized for growth. Utilization of rhamnose and $\underline{i}$-inositol is doubtful.

Streptomyces setonii (Millard and Burr) Waksman. Descriptions: Millard and Burr 1926,604-606. Waksman in Waksman and Lechevalier 1953, 107. Type strain: IMRU 3375 (Waksman 1961, 275). ISP 5395 from S.A. Waksman as IMRU 3375. ISP description by Group D-3.

Spore chain morphology: Section Rectiflexibiles (Fig. 169). Mature spore chains generally long, often with 50 or more spores per chain. This morphology is seen on yeast-malt agar, oatmeal agar, salts-starch agar and glycerol-asparagine agar. Spore surface: Smooth (Fig. 170).

Color of colony: Aerial mass color in the Yellow (2ba, pale yellow) or Gray (2dc, yellowish gray) color-series on yeast-malt agar and glycerol-asparagine agar; White color-series on oatmeal agar and salts-starch agar.

Reverse side of colony: No distinctive pigments (pale or grayish yellow to light yellowish brown) on yeast-malt agar, oatmeal agar, salts-starch agar and glycerol-asparagine agar.

Color in medium: Melanoid pigments are not formed in peptoneyeast-iron agar, tyrosine agar or tryptone-yeast broth. No pigment is found in the medium in yeast-malt agar, oatmeal agar, salts-starch agar or glycerol-asparagine agar.

Carbon utilization: D-Glucose, L-arabinose, D-xylose, D-mannitol, D-fructose and rhamnose are utilized for growth. No growth or only trace of growth with $\underline{i}$-inositol, sucrose and raffinose.

Streptomyces sparsogenes Owen, Dietz and Camiener. Description: Owen, Dietz and Camiener 1962, 772-779. Type strain: UC $2474=$ NRRL $2940=$ NCIB 9449. ISP 5356 from T.G. Pridham (NRRL) as NRRL 2940. ISP description by Group D-3.

Spore chain morphology: Section Spirales (Fig. 171). Aerial hyphae and spirals may emerge from coremia-like structures (Fig. 172). Mature spore chains moderately long with 10 to 50 or more spores per chain. This morphology may be seen on yeast-malt agar, oatmeal agar, salts-starch agar and glycerol-asparagine agar, although sporulat ion is not always uniformly good on these media. One observer notes autolysis or lysis on media in 14 days. Spore surface: Spiny: individual spores indistinct (Fig. 173).

Color of colony: Aerial mass color in the Gray color-series (2dc, yellowish gray or $3 \mathrm{fe}$, light brownish gray to 5 fe, light grayish reddish brown) on yeast-malt agar, oatmeal agar, salts-starch agar and glycerol-asparagine agar; aerial mycelium in the Yellow color-series (2ba, pale yellow) may also be seen on yeast-malt agar and glycerola sparagine agar. 


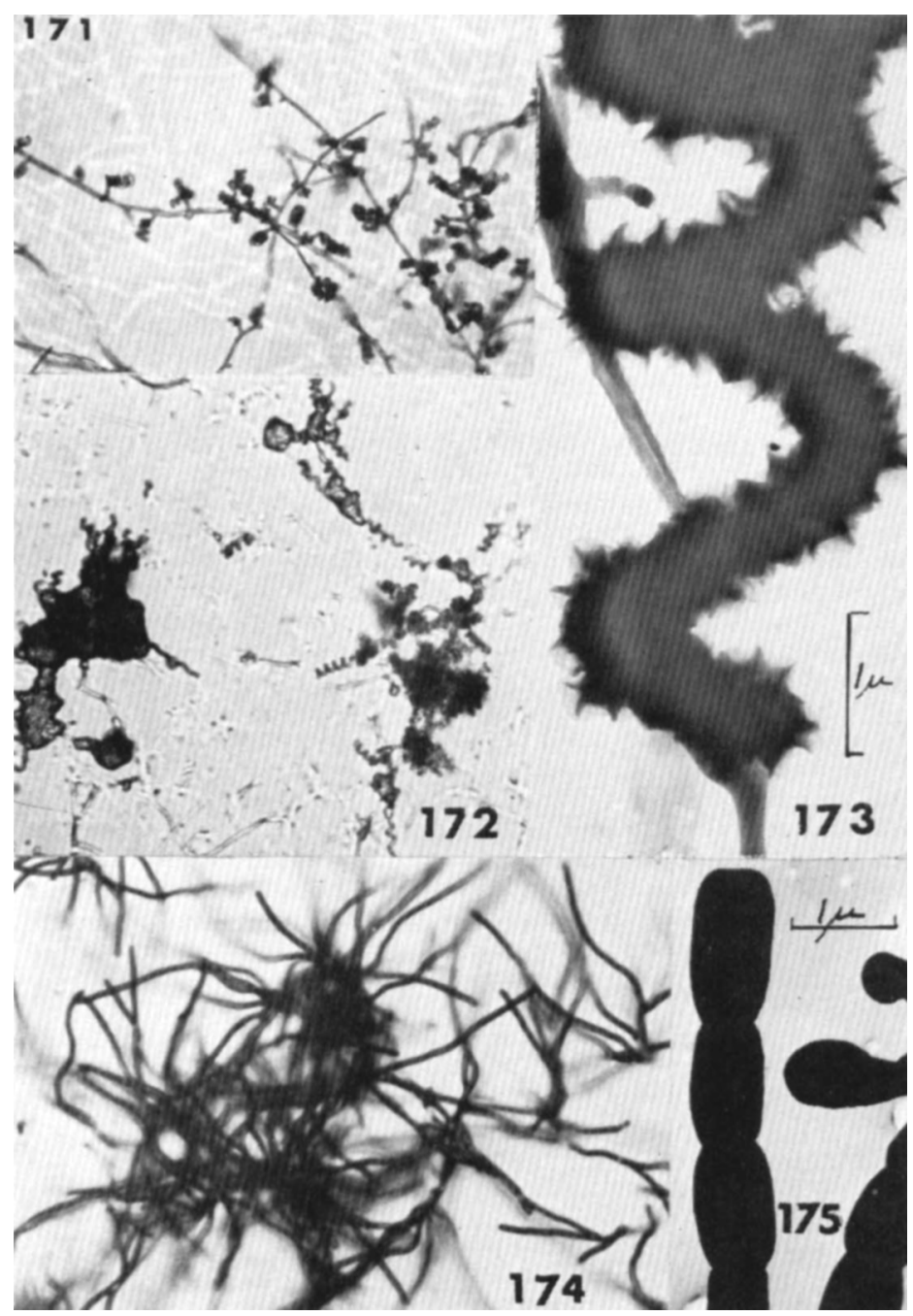

Figure 171. S. sparsogenes. Spiral spore chains (X 300) on salts-starch agar, 7 days.

Figure 172. S. sparsogenes. Spiral spore chains extended from coremia-like structures (X 300) on oatmeal agar, 21 days.

Figure 173. S. sparsogenes. Coiled spiny spore chains, individual spores are indistinct. Electron micrograph from 15 day culture on oatmeal atar.

Figure 174. S. termitum. RF spore chains (X 400) on salts-starch agar, 10 days.

Figure 175. S. termitum. Smooth spores; electron micrograph from 10 day culture on oatmeal agar. 
Reverse side of colony: No distinctive pigments (light or pale yellow to moderate yellow or orange-yellow) on yeast-malt agar, oatmeal agar, salts-starch agar and glycerol-asparagine agar.

Color in medium: Melanoid pigments are not formed in peptoneyeast-iron agar, tyrosine agar or tryptone-yeast broth. No pigment is found in the medium in yeast-malt agar, oatmeal agar, salts-starch agax or glycerol-asparagine agar.

Carbon utilization: D-Glucose, L-arabinose, D-xylose, D-mannitol, D-fructose, rhamnose, sucrose and raffinose are utilized for growth. Utilization of $\underline{i}$-inositol is doubtful.

Streptomyces termitum Duche, Heim and Lavoureur. Description: Duché et al. 1951, 359-363. Type strain: L.C. Paris 620 (Madame J. Nicot, personal communication, 1966). ISP 5329 from Madame J. Nicot as L.C., Paris 620. ISP description by Group C-9.

Spore chain morphology: Section Rectiflexibiles (Fig. 174). Mature spore chains generally long and flexuous with 10 to 50 or often more than 50 spores per chain. This morphology is seen on yeast-malt agar, oatmeal agar, salts-starch agar and glycerol-asparagine agar. Spore surface: Smooth (Fig. 175).

Color of colony: Aerial mass color in the Red color-series (3ca, pale orange-yellow to $5 \mathrm{cb}$, grayish yellowish pink) on yeast-malt agar, oatmeal agar, salts-starch agar and glycerol-a sparagine agar.

Reverse side of colony: No distinctive pigments (colorless to pale or grayish yellow) on yeast-malt agar, oatmeal agar, salts-starch agar and glycerol-asparagine agar.

Color in medium: Melanoid pigments are not formed in peptoneyeast-iron agar, tyrosine agar or tryptone-yeast broth. No pigment is found in the medium in yeast-malt agar, oatmeal agar, salts-starch agar or glycerol-asparagine agar.

Carbon utilization: D-Glucose, and D-xylose are utilized for growth. Utilization of D-fructose is doubtful. Reports vary on utilization of sucrose and rhamnose (two of three observers find no growth on these two carbon sources). No growth or only trace of growth with Larabinose, i-inositol, D-mannitol or raffinose.

Streptomyces thermotolerans Pagano, Donovick, Dutcher and Heuser. Description: Pagano et al. U.S. Patent 2, 902, 412 Sept. l, 1959. Not Actinomyces thermotolerans Lieske, 1921. Type strain: Squibb S.C. $2355=M 4209=$ ATCC $11416=$ IMRU 3628 (ibid. and F. Arnow, Squibb Culture Collection, personal communication, August, 1964). ISP 5227 from F. Arnow, Squibb Culture Collection as S.C. $2355=\mathrm{M} \mathrm{4209}=\mathrm{ATCC} 11416$. ISP description by Group B - 4 .

Spore chain morphology: Section Spirales. Well defined spirals of 4 or more turns may be formed (Fig. 176) or imperfect spirals, hooks and flexuous chains may suggest RA morphology (Fig. 177). Mature spore chains short to moderately long with 10 to 50 or more spores per chain. This morphology is seen on yeast-malt agar, oatmeal agar, salts-starch agar and glycerol-asparagine agar. Spore surface: Spiny (Fig. 178).

Color of colony: Aerial mass color in the Red color-series (5dc or 5ec, grayish yellowish pink) on yeast-malt agar, oatmeal agar, salts starch agar and glycerol-asparagine agar. (One observer placed this strain in the Gray color-series.) 


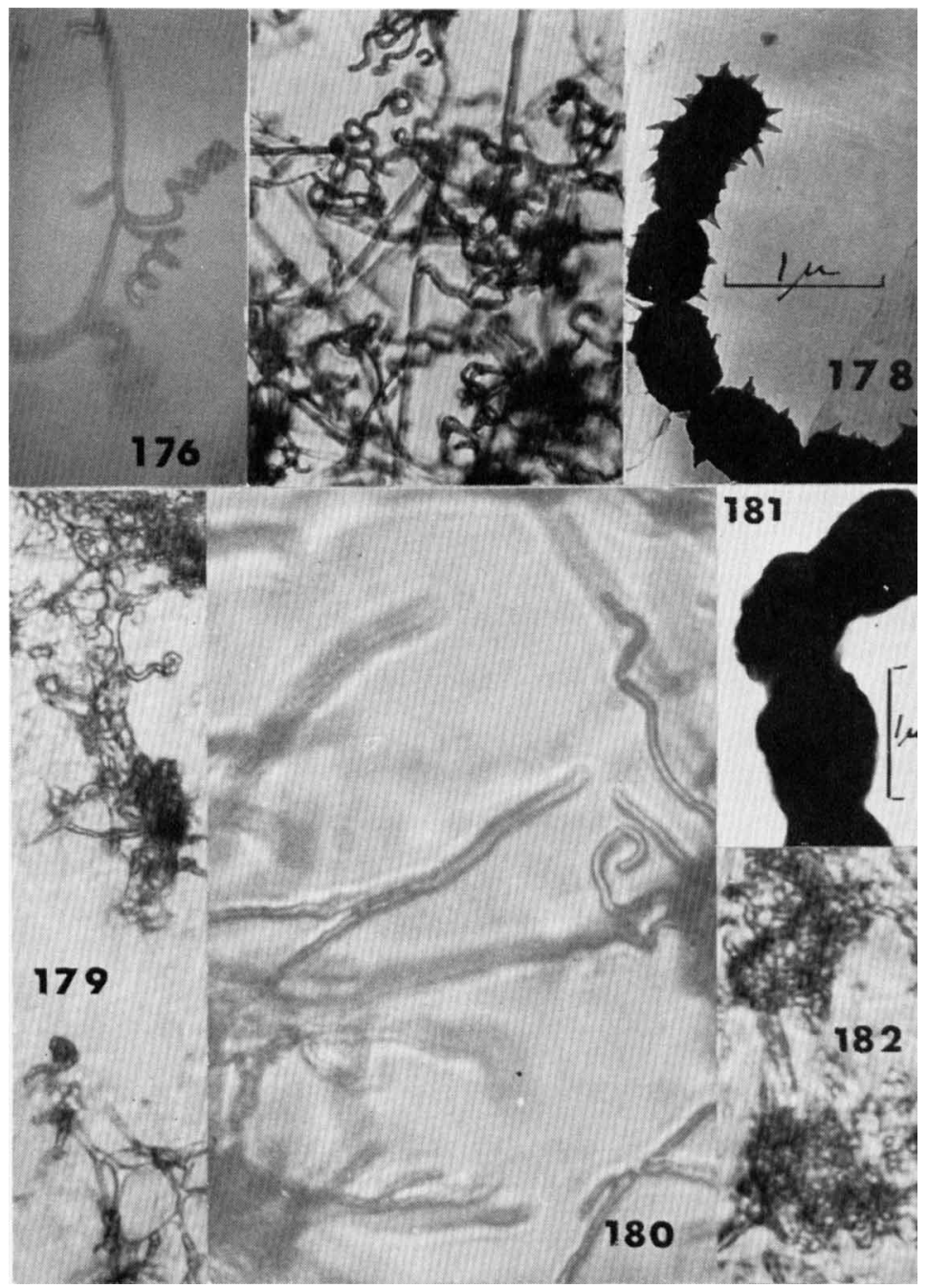

Figure 176. S. thermotolerans. Spiral spore chains (X 812) on saltsstarch agar, 14 days.

Figure 177. S. thermotolerans. Imperfect spirals and flexuous chains (X.400) on yeast-malt agar, 17 days.

Figure 178. S. thermotolerans. Spiny spores; electron micrograph from 14 day culture on yeast-malt agar.

Figure 179. S. thermovulgaris. Imperfect spirals and suggestion of formation of sclerotia-like masses (X 800) on salts-starch agar, 21 days at $40^{\circ} \mathrm{C}$.

Figure 180. S. thermovulgaris. Flexuous chains and primitive spirals on salts-starch agar, 14 days at $28^{\circ} \mathrm{C}$.

Figure 181. S. thermovulgaris. Smooth spores; electron micrograph from 21 day culture on salts-starch agar at $40^{\circ} \mathrm{C}$.

Figure 182. S. thermovulgaris. Sclerotia-like masses on glycerola sparagine agar, 21 days at $38^{\circ} \mathrm{C}$. 
Reverse side of colony: No distinctive pigments (pale or grayish yellow to brown) on yeast-malt agar, oatmeal agar, salts-starch agar and glycerol-asparagine agar.

Color in medium: Melanoid pigments are formed in peptone-yeastiron agar, tryptone-yeast broth and Gauze Medium No. 2, but may not be produced in tyrosine agar. No pigment or only a trace of yellow is found in the medium in yeast-malt agar, oatmeal agar, salts-starch agar or glycerol-asparagine agar.

Carbon utilization: D-Glucose, L-arabinose, D-xylose, $\underline{\text { i-inositol, }}$ D-mannitol, D-fructose, rhamnose, sucrose and raffinose are all utilized for growth.

Streptomyces thermovulgaris Henssen. Description: Henssen 1957, 391-393. Type strain: $\mathrm{R}_{10}=$ A TCC 19284 = CBS 276.66 (Henssen 1967, 218; Henssen, personal communication, April 1966). ISP 5444 from Aino Henssen as Henssen $R_{10}$. ISP Description by Group D-4.

Spore chain morphology: Section Spirales on yeast-malt agar, oatmeal agar, salts-starch agar and glycerol-asparagine agar when incubated at $40 \mathrm{C}$ to $50 \mathrm{C}$ for 14 days (Fig. 179). Retinaculiaperti or flexuous spore chains may also be found (Fig. 180). At $28 \mathrm{C}$ some flexuous spore chains (only) may be found on these media, but aerial mycelium is usually absent or poorly developed at $28 \mathrm{C}$. Spore surface: Smooth (Fig. 181).

Special physiological and morphological characteristics: Thermophilic with optimum growth at 40-50 C. Sclerotia-like masses of spore chains are common (Fig. 179 and 182).

Color of colony: Aerial mass color in the Gray color-series (usually $3 \mathrm{ig}$ or $4 \mathrm{ig}$, light grayish brown; $3 \mathrm{fe}$, light brownish gray or 2dc, yellowish gray) on yeast-malt agar, oatmeal agar, salts-starch agar and glycerol-asparagine agar. At suboptimal temperatures the aerial mycelium is white.

Reverse side of colony: No distinctive pigments (light yellow or pale grayish yellow to olive-brown) on yeast-malt agar, oatmeal agar, salts - starch agar and glycerol-asparagine agar.

Color in medium: Melanoid pigments are not formed in peptoneyeast-iron agar, tyrosine agar or tryptone-yeast broth. No pigment is found in the medium in yeast-malt agar, oatmeal agar, salts-starch agar or glycerol-asparagine agar.

Carbon utilization: D-Glucose, L-arabinose, D-xylose, D-mannitol, D-fructose, rhamnose, sucrose and raffinose are all utilized for growth, but growth on rhamnose or raffinose may be less than on the other carbon sources tested.

Streptomyces tubercidicus Nakamura. Description: Nakamura 1961, 90-93. Type strain: Nakamura No. 585 (ibid.). ISP 5261 from S. Suzuki, Tokyo as No. 585. ISP description by Group B -9.

Spore chain morphology: Section Spirales (Fig. 183). Mature spore chains generally 3 to 10 or more spores per chain. This morphology is seen on yeast-malt agar, oatmeal agar, salts-starch agar and glycerolasparagine agar. Spore surface: Smooth (Fig. 184).

Color of colony: Aerial mass color in the Gray color-series (d, light gray to $3 \mathrm{fe}$, light brownish gray) on yeast-malt agar, oatmeal 
agar and salts-starch agar in 14 days. One observer places 21 day cultures in the Red color-series ( $5 \mathrm{dc}$, grayish yellowish pink) on yeastmalt agar, oatmeal agar and glycerol-asparagine agar. The original description notes a tendancy for the aerial mycelium to become moist and black; this hygroscopic characteristic is not recorded by ISP observers.

Reverse side of colony: Grayish yellow to yellowish brown or olive-brown on oatmeal agar, salts-starch agar and glycerol-a sparagine agar; moderate brown to dark brown on yeast-malt agar. Reverse mycelium pigment is $\mathrm{pH}$ indicator, changing from Yellow or yellowbrown to pale pink with addition of $0.05 \mathrm{~N} \mathrm{NaOH}$ and from pink or grayish brown to yellow with addition of $0.05 \mathrm{~N} \mathrm{HCl}$.

Color in medium: Melanoid pigments are not formed in peptoneyeast-iron agar, tyrosine agar or tryptone-yeast broth. Yellow to pink or violet-pink (depending upon $\mathrm{pH}$ ) pigment is found in the medium in yeast-malt agar, salts-starch agar, oatmeal agar and glycerol-asparagine agar. This pigment is $\mathrm{pH}$ sensitive showing the same changes noted for the reverse mycelium pigment.

Carbon utilization: D-Glucose, i-inositol, D-mannitol, D-fructose, sucrose and raffinose are utilized for growth. No growth or only trace of growth with L-arabinose, D-xylose or rhamnose.

Actinomyces umbrinus Sveshnikova. Description: Sveshnikova in Gauze et al. 1957, 59 and 62. Streptomyces umbrinus (Sveshnikova) Pridham et al. 1958, 61. Type strain: INA 1703/53 (ibid.; G.F. Gauze cited by Gottlieb 1968, 20. A personal communication from G.F. Gauze, Sept. 1964, identifies $1703 / 53$ as the type strain for A. umbrinus but adds the comment "now believed to be identical with $\mathrm{s}$. phaechromogenes"). ISP 5278 from G.F. Gauze as INA 1703/53. ISP description by Group B - 8 .

Spore chain morphology: Section Rectiflexibiles (Fig. 185). Mature spore chains moderately long with 10 to 50 or more spores per chain. This morphology is seen on yeast-malt agar, oatmeal agar, salts-starch agar and glycerol-asparagine agar. Spore surface: Smooth (Fig. 186).

Color of colony: Aerial mass color in the Red color-series (3ca, pale orange-yellow to $5 \mathrm{cb}$, grayish yellowish pink) on yeast-malt agar, oatmeat agar, salts-starch agar and glycerol-asparagine agar.

Reverse side of colony: Reddish brown on yeast-malt agar, light brown to strong brown on oatmeal agar and salts-starch agar, gray to reddish black on glycerol-asparagine agar. Reverse mycelium pigment is not a $\mathrm{pH}$ indicator.

Color in medium: Melanoid pigments are formed in peptone-yeastiron agar, tyrosine agar and tryptone-yeast broth. Yellow pigment may be found in the medium in yeast-malt agar, oatmeal agar, salts-starch agar or glycerol-asparagine agar. This pigment is not $\mathrm{pH}$ sensitive when tested with $0.05 \mathrm{~N} \mathrm{NaOH}$ or $\mathrm{HCl}$.

Carbon utilization: D-Glucose, L-arabinose, D-xylose, i-inositol, D-mannitol, D-fructose, rhamnose, sucrose and raffinose are all utilized for growth.

Streptomyces umbrosus Schmidt-Kastner. Descriptions: Name and type strain designation only, without description, in Schmidt-Kastner 


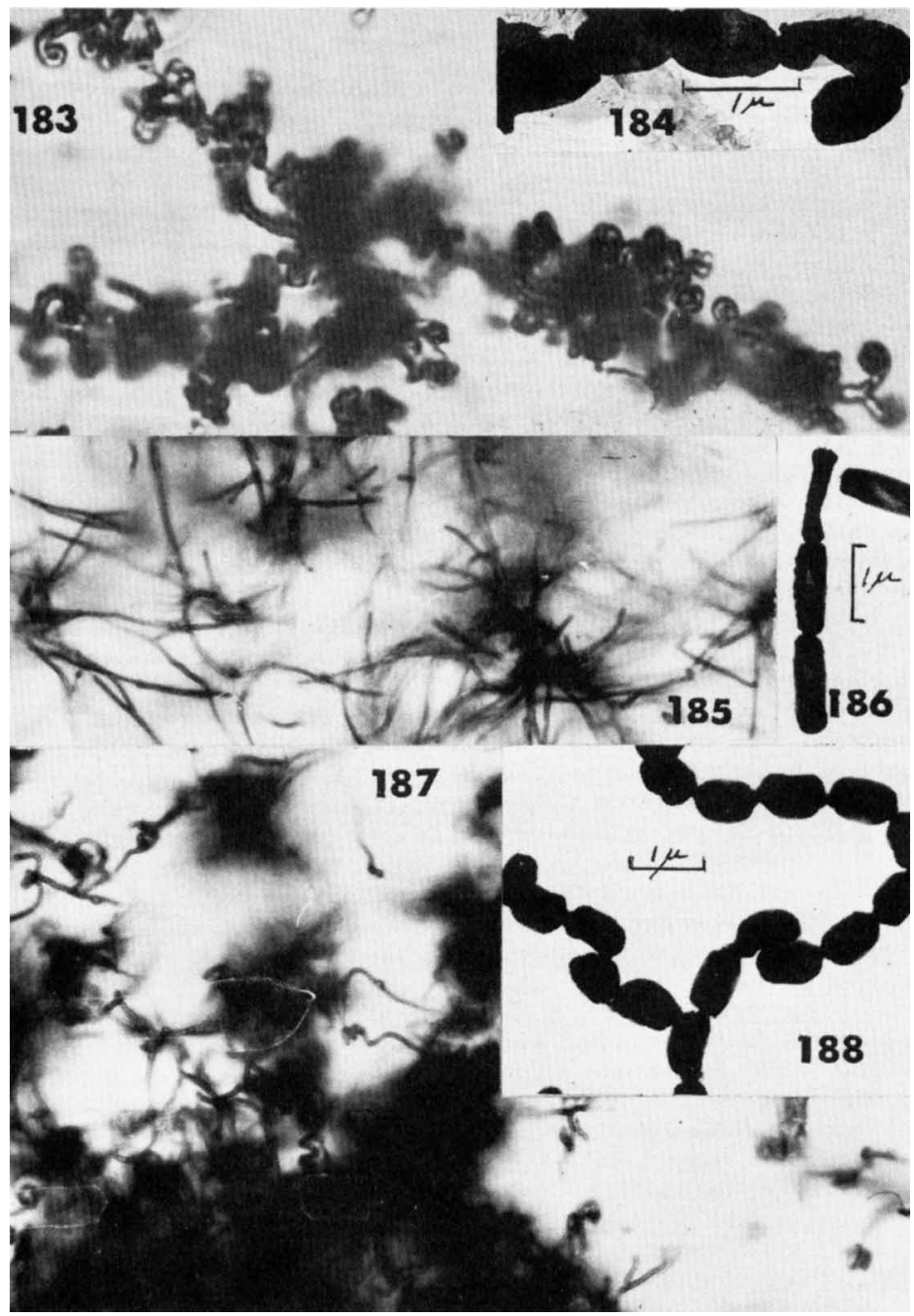

Figure 183. S. tubercidicus. Spiral spore chains (X 1100) on yeastmalt agar, 14 days.

Figure 184. S. tubercidicus. Smooth spores; electron micrograph from 14 day culture on yeast-malt agar.

Figure 185. A. umbrinus. RF spore chains (X 800) on yeast-malt agar, 2 days.

Figure 186. A. umbrinus. Smooth spores; electron micrograph from 14 day culture on salts-starch agar.

Figure 187. A. umbrosus. Spore chains with terminal spirals on saltsstarch agar, 14 days (X 800).

Figure 188. A. umbrosus. Smooth spores; electron micrograph from 14 day culture on oatmeal agar. 
1963, 122-128; name and description in Schmidt-Kastner et al. 1957. German Pat. Not. 1061 964; see also Schmidt-Kastner et al. 1958. Belgian Pat. 569390 and Farbenfabriken Bayer Artiengesellschaft 1961. British Pat. Specif. 864, 814. Type strain: NRRL 2791 (6chmidt-Ka stner 1963, 122 and British Pat. Specif. 864, 814, loc cit.). ISP 5242 from C.W. Hesseltine (NRRI) as NRRL 2791. ISP description by Group B-8.

Spore chain morphology: Section Spirales or Retinaculiaperti. Terminal spirals of several turns are common on long flexuous spore chains (Fig. 187). Open spirals and strongly flexuous chains may also be found. Mature spore chains generally 10 to 50 or more spores per chain. This morphology is seen on yeast-malt agar, oatmeal agar, salts-starch agar and glycerol-asparagine agar. Spore surface: Smooth (Fig. 188).

Color of colony: Aerial mass color in the Gray color-series (3ig or 3ge, grayish yellowish brown to $3 \mathrm{fe}$, light brownish gray) on yeast-malt a'gar, oatmeal agar, salts-starch agar and glycerol-asparagine agar.

Reverse side of colony: No distinctive pigments (olive-brown to yellowish brown) on yeast-malt agar, oatmeal agar, salts-starch agar and glycerol-asparagine agar.

Color in medium: Melanoid pigments are formed in peptoneyeast-iron agar, tyrosine agar and tryptone-yeast broth, although pigment may be less distinct on tyrosine agar. Yellow pigment is found in the medium in yeast-malt agar, oatmeal agar and salts-starch agar. This pigment is not $\mathrm{pH}$ sensitive when tested with $0.05 \mathrm{~N} \mathrm{NaOH}$ or $\mathrm{HCl}$.

Carbon utilization: $\underline{D}-G$ lucose, L-arabinose, $\underline{D}$-xylose, $\underline{\text { i-inositol, }}$ D-mannitol, D-fructose and rhamnose are utilized for growth. No growth or only trace of growth with sucrose or raffinose.

Actinomyces (Streptomyces) varsoviensis Kuryłowicz and Woźnicka. Description: Kuryłowicz and Woźnicka 1967, 1 -9; see also Kuryłowicz and Ulak 1959. Polish Pat. 43565 and 1964, British Pat. Specif. 963, 886. Type strain: A TCC $14631 \mathrm{c}=$ CBS $357.64=$ NCIB 9522 (Kuryłowicz and Woźicka 1967, 2; Kuryłowicz and Woźnicka, personal communication, May 1966). ISP 5346 from W. KuryXowicz as ATCC $14631 \mathrm{c}=13-1$ ( $=$ NCIB 9522; CBS 357.64). ISP description by Group C -4 .

Spore chain morphology: Section Spirales, Retinaculiaperti or Rectiflexibiles. Spiral spore chains are abundant on yeast-malt agar (Fig. 189); straight to flexuous chains (Fig. 190) are most common on glycerol-asparagine agar. Flexuous, spiral or intermediate (RA) forms (Fig. 191) may be found on oatmeal agar and salts-starch agar but sporulating aerial mycelium is usually poorly developed on these media. Spore surface: Smooth (Fig. 192).

Color of colony: Aerial mass color in the White or Yellow (2ba, pale yellow) color-series on yeast-malt agar and glycerol-asparagine agar. Sporulation on oatmeal agar and salts-starch agar is usually inadequate for spore mass color determination.

Reverse side of colony: Yellow to yellow-brown is modified by red (to yellowish pink, orange, grayish reddish orange or strong brown) on yeast-malt agar, salts-starch agar and glycerol-asparagine agar. Substrate pigment is not a $\mathrm{pH}$ indicator or is modified only slightly by 


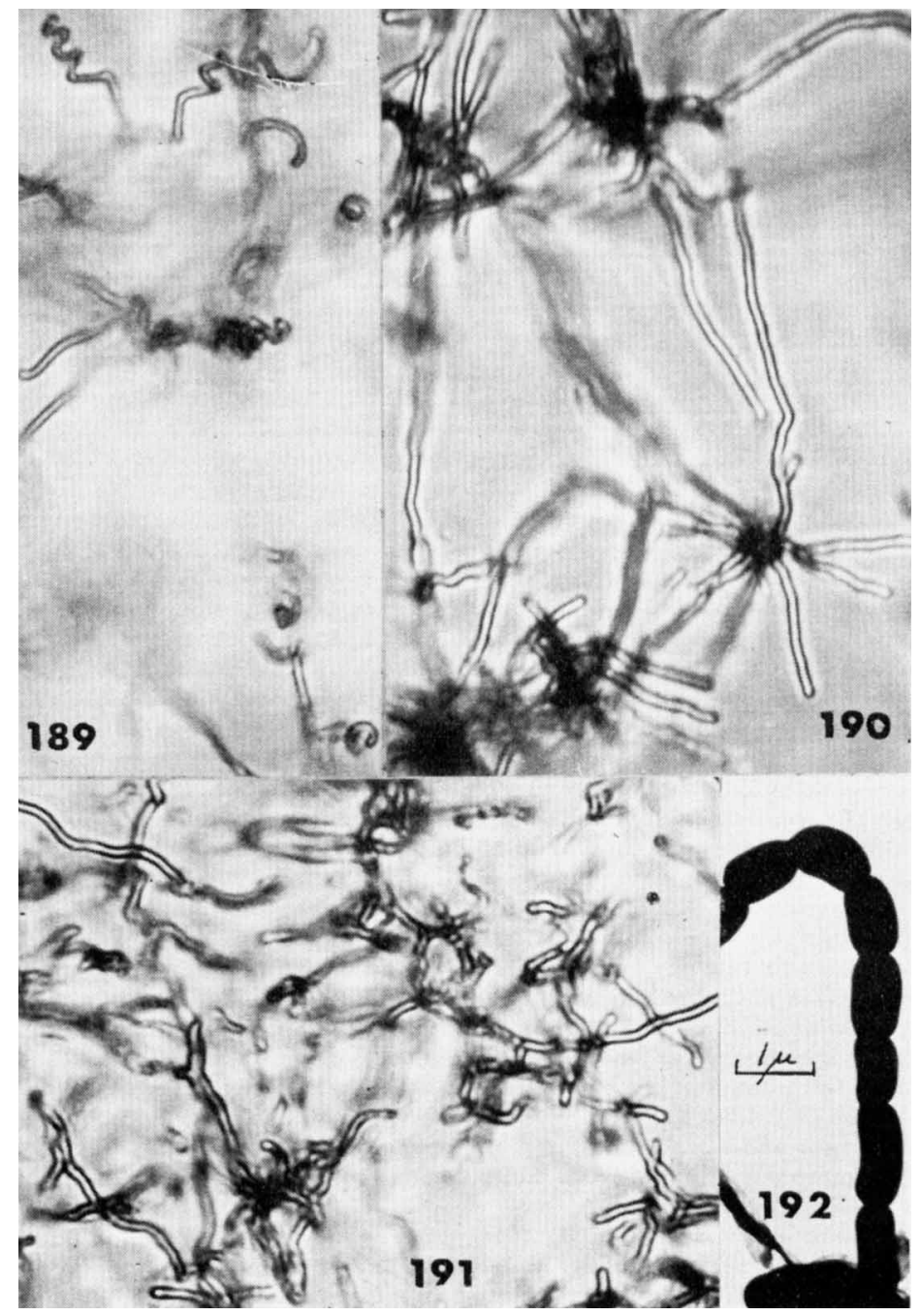

Figure 189. A. varsoviensis. Spiral spore chains (X 800) on yeast-malt agar, 7 days (see also Fig. 190 and 191).

Figure 190. A. varsoviensis. Straight to flexuous spore chains (X 800) on oatmeal agar, 15 days (see also Fig. 189 and 191).

Figure 191. A. varsoviensis. Flexuous and crooked spore chains ( $\mathrm{X} 800$ ) on glycerol-asparagine agar, 15 days.

Figure 192. A. varsoviensis. Spore surface: electron micrograph from 14 day culture on yeast-malt agar. 
addition of $0.05 \mathrm{~N} \mathrm{NaOH}$ or $\mathrm{HCl}$.

Color in medium: Reports vary on production of melanoid pigments. Some darkening of peptone-yeast-iron agar, tyrosine agar or tryptone-yeast broth may be seen in 4 days, but usually not in 2 days. Gauze's organic Medium No. 2 is not darkened in 2-4 days. No pigment is found in the medium in yeast-malt agar, oatmeal agar, salts-starch agar or glycerol-asparagine agar.

Carbon utilization: D-Glucose, and D-mannitol are utilized for growth. Utilization of fructose is doubtful. No growth or only trace

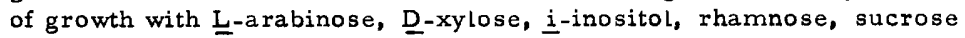
or raffinose.

Streptomyces vastus Szab6 and Marton. Description: Szab6 and Marton 1958, 243-262. Type strain: Szab6 and Marton A-10/a-f (ibid.); CBS strain Szab6 A-10. ISP 5309 from G.A. deVries as Szabo A-10. ISP description by Group C-1.

Spore chain morphology: Section Spirales. Open, terminal spirals of only 1 to 3 turns may be seen on yeast-malt agar, oatmeal agar and salts-starch agar, but sporulating aerial mycelium is usually poorly developed on these media. Sporulation may be absent on glycerola sparagine agar and Gauze Medium No. 1. Poor sporulation of this strain on various media is noted in Szabo's and Marton's original description (op. cit.). Spore chains are often short with 3 to 10 or more spores per chain. Spore surface: Smooth (Fig. 193).

Color of colony: Aerial mass color in the White or Gray colorseries on yeast-malt agar and oatmeal agar when mature sporulating aerial mycelium is formed. Thin, white aerial mycelium may also be seen on salts-starch agar and glycerol-asparagine agar but is inadequate for accurate color determination.

Reverse side of colony: Grayish green on yeast-malt agar; colorless to pale blue or grayish blue on oatmeal agar and salts-starch agar.; colorless to pale yellow on glycerol-asparagine agar. Reverse mycelium pigment is not a $\mathrm{pH}$ indicator.

Color in medium: Melanoid pigments are not formed in peptoneyeast-iron agar, tyrosine agar or tryptone-yeast broth. No pigment is found in the medium in oatmeal agar or glycerol-asparagine agar. Traces of yellow or green pigment may or may not be found in yeastmalt agar and a trace of blue pigment may be found in salts-starch agar. This pigment, if present, is not $\mathrm{pH}$ sensitive when tested with 0.05 $\mathrm{N} \mathrm{NaOH}$ or $\mathrm{HCl}$.

Carbon utilization: D-Glucose, L-a rabinose, $\underline{i}$-inositol, D-mannitol, D-fructose, rhamnose, sucrose and raffinose are utilized for growth. Reports vary on utilization of D-xylose.

Streptomyces vendargensis $(=S$. vendargus) anonymous. Descriptions: Streptomyces vendargus, A.P. Struyk and A.A. Stheeman 1957, Australian Pat. Specif. 206, 799; Streptomyces vendargensis Koninklijke Nederlandsche Gist-en Spiritusfabriek N.V. 1956, British Pat. Specif. 764,198; 1964, Netherland Pat. 109006. Change of name from $S$. vendargus to $\underline{S}$. vendargensis is noted in footnote to Netherland Pat. 109006 and verified by J.C. Hoogerheide of Koninklijke Nederlandsche Gist-en Spiritusfabriek, personal communication Sept. 1966. Type strain: CBS 154.57 (J.C. Hoogerheide, personal communi- 
cation Sept. 1966). ISP 5379 from G.A. deVries (CBS) as CBS 154.57. ISP description by Group D.5.

Spore chain morphology: Section Rectiflexibiles. Only a few spore chains can be found on yeast-malt agar. Sporulating aerial mycelium is absent or very thin on oatmeal agar, salts-starch agar and glycerolasparagine agar and Czapek's sucrose agar. The original descriptions (op cit.) note good aerial mycelium development only on Emerson's agar which was not included in the ISP tests. Poor development of aerial mycelium on most media is a characteristic of this strain. Spore surface: Not observed.

Color of colony: Aerial mass color not determined; sporulation is inadequate for color determination on yeast-malt agar, oatmeal agar, salts-starch agar or glycerol-asparagine agar. In the original descriptions (Op. cit.) white aerial mycelium is recorded on Emerson's agar.

Reverse side of colony: No distinctive pigments (pale or grayish yellow to light yellowish brown) on yeast-malt agar, oatmeal agar, salts starch agar and glycerol-asparagine agar.

Color in medium: Melanoid pigments are not formed in peptoneyeast-iron agar, tyrosine agar or tryptone-yeast broth. Some yellow pigment is found in the medium in yeast-malt agar, oatmeal agar and salts-starch agar.

Carbon utilization: D-Glucose, $\underline{i}$-inositol, D-mannitol, D-fructose and raffinose are utilized for growth. No growth or only a trace of growth with $\underline{\text { L-arabinose, }}$-xylose, rhamnose or sucrose.

Streptomyces venezuelae Ehrlich, Gottlieb, Burkholder, Anderson and Pridham. Description: Ehrlich et al. 1948, 467-477. Type strain: Burkholder No. A65 = P.D. No. 04745 (ibid.) $=$ ATCC 10712. ISP 5230 from Lucia Anderson (Parke, Davis Co.) as P.D. No. $04745=$ ATCC 10712. ISP description by Group B -7.

Spore chain morphology: Section Rectiflexibiles (Fig. 194).

Straight spore chains are generally long, often with more than 50 spores per chain. This morphology is seen on oatmeal agar, salts-starch agar and glycerol-asparagine agar; sporulation may be poor on yeast-malt agar. One observer only, records fragmentation of substrate mycelium on glycerol-asparagine agar. Spore surface: Smooth (Fig. 195).

Color of colony: Aerial mass color is in the Gray color-series (2dc, yellowish gray to $5 f e$, light grayish reddish brown) on oatmeal agar, salts-starch agar and glycerol-asparagine agar; a good spore mass is usually not produced on yeast-malt agar.

Reverse side of colony: No distinct pigments (grayish yellow) on yeast-malt agar, oatmeal agar, salts-starch agar and glycerol-asparagine agar.

Color in medium: Melanoid pigments are formed in peptone-yea stiron agar and tryptone-yeast broth, but only weakly or not at all in tyrosine agar. No pigment is found in the medium in yeast-malt agar, oatmeal agar, salts - starch agar or glycerol-asparagine agar.

Carbon utilization: D-Glucose, L-arabinose, D-xylose, D-fructose and rhamnose are utilized for growth. A trace of growth is usualty found

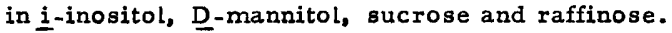




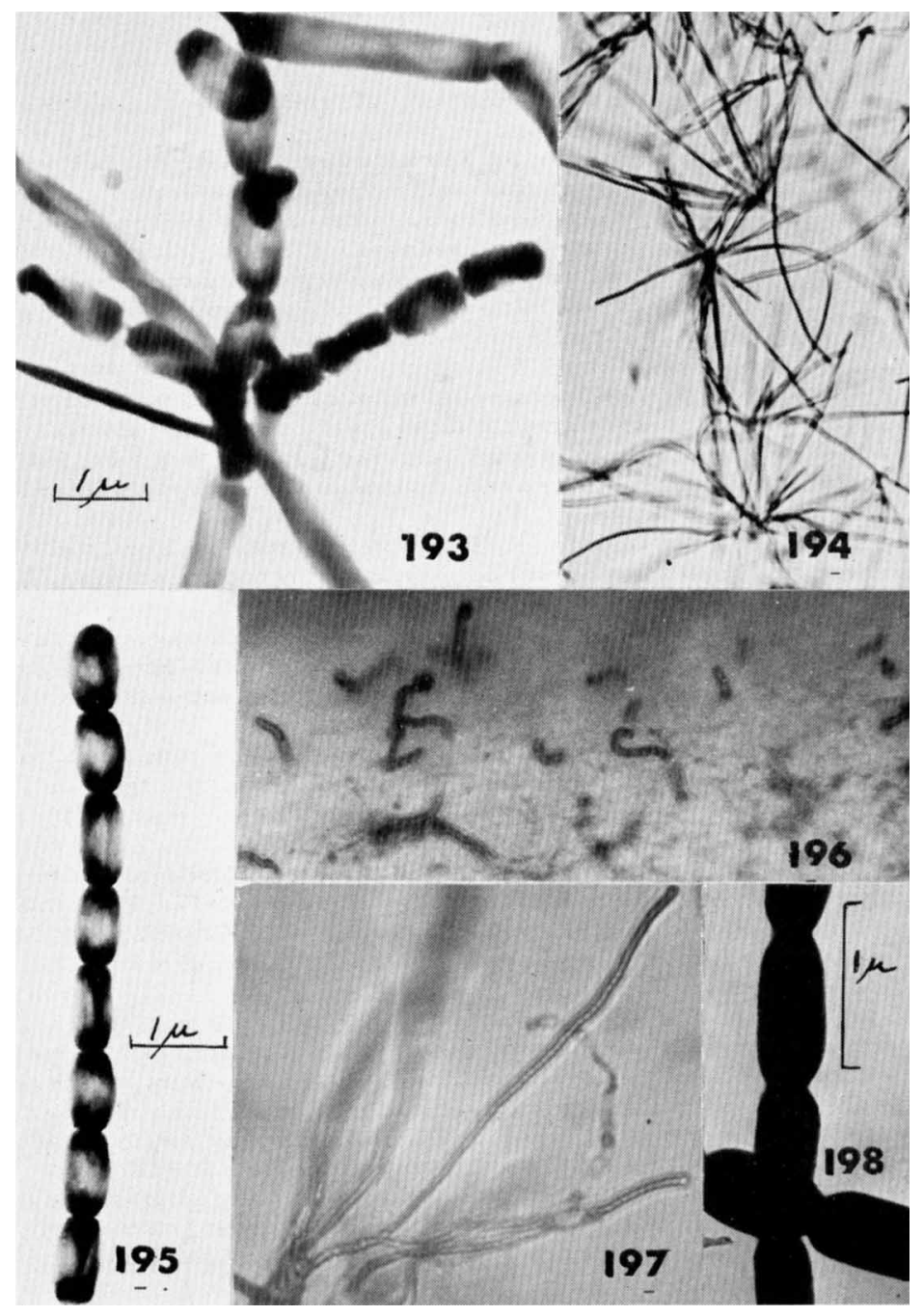

Figure 193. S. vastus. Smooth spores; electron micrograph from 21 day culture on oatmeal agar.

Figure 194. S. venezuelae. RF spore chains on oatmeal agar, 12 days.

Figure 195. $\bar{S}$. venezuelae. Smooth spores; electron micrograph from 14 day culture on yeast-malt agar.

Figure 196. S. verne. Isolated aerial hyphae (X 800) on yeast-malt agar, 21 days.

Figure 197. S. vinaceus. RF spore chains (X 812) on oatmeal agar, 14 days.

Figure 198. S. vinaceus. Smooth spores; electron micrograph from 14 day culture on yeast-malt agar. 
Streptomyces verne (Waksman and Curtis) Waksman and Henrici. Descriptions: Actinomyces verne Waksman and Curtis 1916, 120-121; Waksman 1919, 156-158. Streptomyces verne (Waksman and Curtis) Waksman and Henrici 1948, 936. Type strain: IMRU 3353 (Waksman 1961, 281). ISP 5079 from S.A. Waksman as IMRU 3353. ISP description by Group B -8 .

Spore chain morphology: Section not determined. Waksman's early descriptions for this species (op. cit.) state that no true aerial mycelium could be demonstrated. This observation is confirmed by ISP observers who find no aerial mycelium or only isolated aerial hyphae (Fig. 196) on yeast-malt agar, oatmeal agar, salts-starch agar and glycerol-a sparagineagar. Spore surface: Not determined.

Color of colony: Aerial mass color can not be determined because of absence of sporulating aerial mycelium (see above).

Reverse side of colony: No distinctive pigments (grayish yellow) on yeast-malt agar, oatmeal agar, salts-starch agar and glycerolasparagine agar.

Color in medium: Melanoid pigments are not formed in peptoneyeast-iron agar. Brown or yellow pigment may be found in the medium in tyrosine agar, tryptone-yeast broth, Bennett's agar, yeast-malt agar and salts-starch agar. This pigment is not $\mathrm{pH}$ sensitive when tested with $0.05 \mathrm{~N} \mathrm{NaOH}$ or $\mathrm{HCl}$.

Carbon utilization: D-Glucose, L-arabinose, D-xylose, $\underline{\text { i-inositol, }}$ D-mannitol, D-fructose, rhamnose, sucrose and raffinose a re all utilized for growth.

Streptomyces vinaceus (Mayer, Crane, deBoer, Konopka, Marsh and Eisman) Waksman. Descriptions: Actinomyces vinaceus Mayer et al. 1951. Streptomyces vinaceus (Mayer et al.) Waksman in $\overline{W a k s m a n}$ and Lechevalier $1 \overline{953,42 . ~ N o t ~ S . ~ v i n a c e u s ~ J o n e s ~} 1 \overline{952}$,

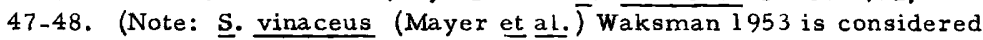
a later homonym of $\mathrm{S}$. vinaceus Jones 1952 according to Buchanan, Holt and Lessel 1967, Index Bergeyana, p. 1125. Burkholder et al. 1955, 108-117 considered S. vinaceus (Mayer et al.) Waksman (NRRL $B$ 2285) to be a strain of S. griseus (Krainsky) Waksman and Henrici var. purpureus Burkholder et al. 1955. S. vinaceus Jones 1952 will also be described by ISP collaborators.) Type strain for $\underline{S}$ vinaceus (Mayer et al.) Waksman 1953: NRRL B-2285 (U.S. Pat. $\frac{2}{2}, \frac{633,445)}{\text { (U) }}$ ISP 5257 from T.G. Pridham (NRRL) as NRRL B-2285. ISP description by Group B-4.

Spore chain morphology: Section Rectiflexibiles (Fig. 197). Mature spore chains moderately long with 10 to 50 or often more than 50 spores per chain. This morphology is seen on yeast-malt agar, oatmeal agar, salts-starch agar and glycerol-asparagine agar. Spore surface: Smooth (Fig. 198).

Color of colony: Aerial mass color in the Red color-series $(5 \mathrm{cb}$, grayish yellowish pink) on yeast-malt agar, oatmeal agar, salts-starch agar and glycerol-asparagine agar; or sometimes in the Gray colorseries (2dc, yellowish gray) on yeast-malt agar and oatmeal agar or Xellow color-series ( $2 \mathrm{db}$, pale yellow; $1 \mathrm{cb}$, pale yellowish green) on salts-starch agar.

Reverse side of colony: Reddish brown to reddish purple on yeastmalt agar; grayish yellowish pink to purplish pink or pale purple on 
oatmeal agar, salts-starch agar and glycerol-asparagine agar. Reverse mycelium pigment is not a $\mathrm{pH}$ indicator or is changed only slightly by addition of $0.05 \mathrm{~N} \mathrm{NaOH}$ or $\mathrm{HCl}$.

Color in medium: Melanoid pigments are not formed in peptoneyeast-iron agar, tyrosine agar or tryptone-yeast broth. Red or yellow pigment may be found in the medium in oatmeal agar, salts-starch agar and glycerol-asparagine agar. This pigment is not $\mathrm{pH}$ sensitive when tested with $0.05 \mathrm{~N} \mathrm{NaOH}$ or $\mathrm{HCl}$.

Carbon utilization: D-Glucose, D-xylose, D-fructose and D-mannitol are utilized for growth. No growth or only trace of growth with L-arabinose, i-inositol, rhamnose, sucrose or raffinose.

Streptomyces vinaceus-drappus anonymous. Descriptions: Upjohn Co. 1954. British Pat. 708, 688; DeBoer and Hinman (Uphohn Co.) 1959. U.S. Patents 2,909,463; 2, 909, 464; 2,909,517. Type strain: Upjohn D-1 3 = NRRL 2363 (ibid.) (=U.C. 2007, Alma Dietz, Upjohn Co., personal communication, April 1967). ISP 5470 from C.W. Hesseltine (NRRL) as NRRL 2363. ISP description by Group D-10. Spore chain morphology: Section Spirales (Fig. 199). Mature spore chains generally long, often with more than 50 spores per chain. This morphology is seen on yeast-malt agar, oatmeal agar, salts-starch agar and glycerol-asparagine agar. Spore surface: Smooth (Fig. 200).

Color of colony: Aerial mass color in the Red color-series (5dc, grayish yellowish pink to 4 ge, light grayish reddish brown) on yeastmalt agar, oatmeal agar, salts-starch agar and glycerol-asparagine agar. One of three observers places this strain in the Gray colorseries ( $5 \mathrm{fe}$, light grayish reddish brown or $3 \mathrm{fe}$, light brownish gray).

Reverse side of colony: No distinctive pigments (grayish yellow to yellowish or olive-brown) on yeast-malt agar, oatmeal agar, saltsstarch agar and glycerol-asparagine agar.

Color in medium: Melanoid pigments are not formed in peptoneyeast-iron agar, tyrosine agar or tryptone-yeast broth. No pigment is found in the medium in yeast-malt agar, oatmeal agar, salts-starch agar or glycerol-asparagine agar.

Carbon utilization: D-Glucose, L-arabinose, D-xylose, $\underline{\text { i-inositol, }}$ D-mannitol, D-fructose, rhamnose, sucrose and raffinose are all utilized for growth.

Actinomyces violaceochromogenes (Krasil'nikov) Ryabova and Preobrazhenskaya. Descriptions: Actinomyces violaceus subsp. chromogenes Krasil'nikov 1949, 55. Elevated to species and neotype described: A. violaceochromogenes (Krasil'nikov) Ryabova and Preobrazhenska ya by Ryabova and Preobrazhenskaya in Gauze et al. 1957, 183-184 and 179. (Note: See also ISP description for A. violochromogenes Artamonova and Krasil'nikov 1960, which is also based on A. violaceus subsp. chromogenes, but a different neotype specimen). Type strain: INA 425 (neotype selected by Preobrazhenskaya from strains listed in Gauze et al. 1957, p. 184 and approved by Krasil'nikov, personal communication, Jan. 1968). ISP 5181 from T.P. Preobrazhenskaya as INA 425. ISP description by Group B-8.

Spore chain morphology: Section Retinaculiaperti or Spirales. Short chains form incomplete or imperfect spirals, hooks and flexuous 


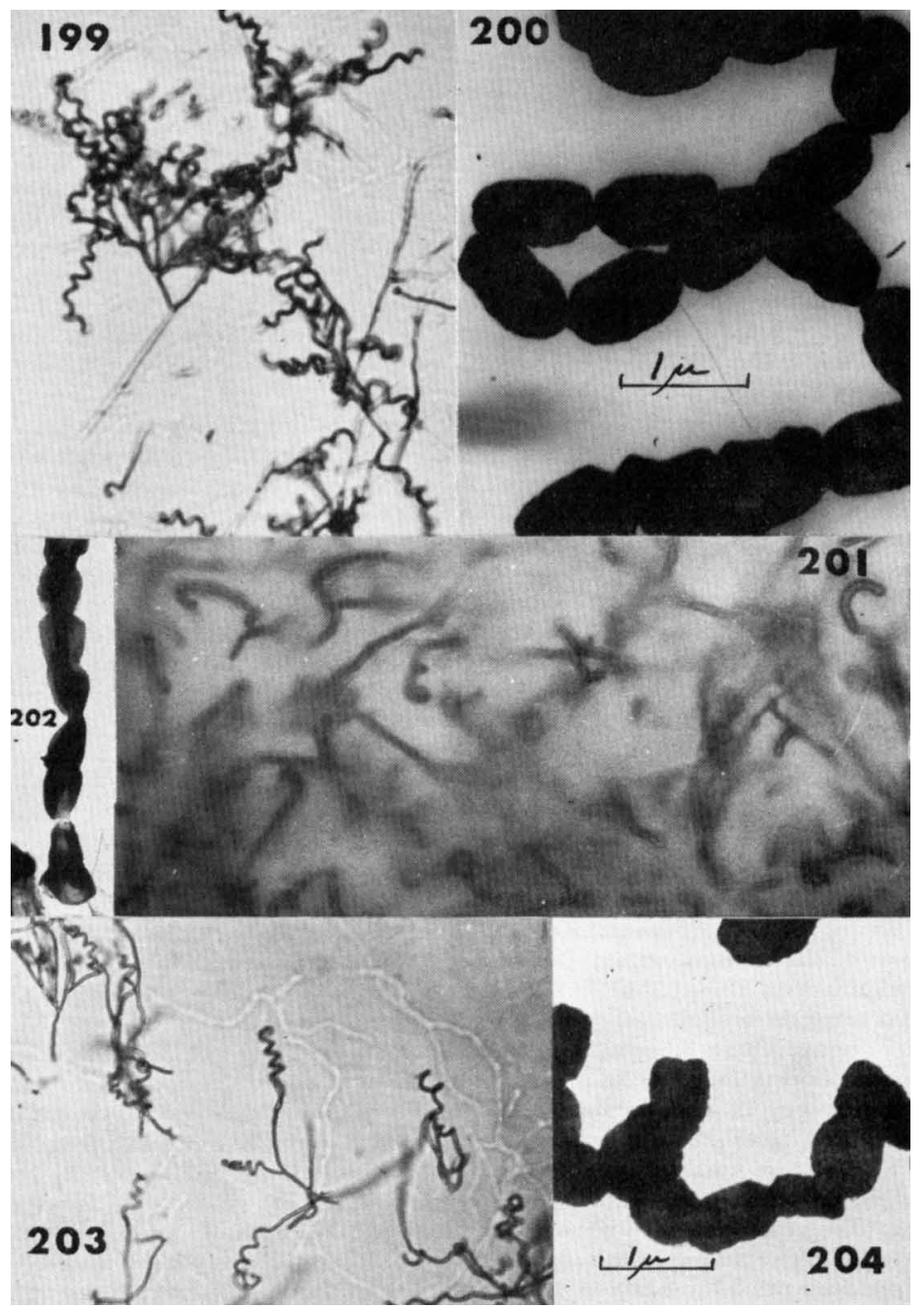

Figure 199. S. vinaceus-drappus. Spiral spore chains on yeast-malt agar, 20 days.

Figure 200. S. vinaceus-drappus. Smooth spores; electron micrograph from 14 day culture on yeast-malt agar.

Figure 201. A. violaceochromogenes. Short flexuous spore chains including imperfect spirals and hooks (X 800) on salts-starch agar, 21 days.

Figure 202. A. violaceochromogenes. Smooth spores; electron micrograph from 14 day culture on yeast-malt agar.

Figure 203. A, violaceolatus. Spiral spore chains (X 300) on oatmeal agar, 7 days.

Figure 204. A. violaceolatus. Smooth spores; electron micrograph from 21 day cūlture on salts-starch agar. 
chains (Fig. 20l). These are neither typically spiral nor representative of the long chains with open loops and spirals on true RA cultures. Some longer chains bear terminal spirals suggesting RA morphology. Mature spore chains generally short with 3 to 10 , or sometimes more than 10, spores per chain. This morphology is seen on yeast-malt agar, oatmeal agar, salts-starch agar and glycerol-asparagine agar. Spore surface: Smooth (Fig. 202).

Color of colony: Aerial mass color in the Red $(5 \mathrm{cb}$, grayish yellowish pink) or Gray ( $5 \mathrm{fe}$, light grayish reddish brown) color-series on yeast-malt agar, oatmeal agar, salts-starch agar and glycerola sparagine agar.

Reverse side of colony: No distinctive pigments (grayish yellow to strong brown) on yeast-malt agar and salts-starch agar; but yellow to yellow-brown may or may not be modified by red on oatmeal agar and glycerol-asparagine agar. If red reverse mycelium pigment is present, it is $\mathrm{pH}$ sensitive, changing from red to violet or purple with addition of $0.05 \mathrm{~N} \mathrm{NaOH}$ or from violet to red with addition of $0.05 \mathrm{~N} \mathrm{HCl}$.

Color in medium: Melanoid pigments axe formed in peptone-yeastiron agar and tryptone-yeast broth, but only weakly or not at all in tyrosine agar. Yellow or yellow-brown pigment is found in the medium in yeast-malt agar and salts-starch agar. This pigment is not $\mathrm{pH}$ sensitive when tested with $0.05 \mathrm{~N} \mathrm{NaOH}$ or $\mathrm{HCl}$.

Carbon utilization: D-Glucose, L-arabinose, D-xylose, $\underline{\text { i-inositol, }}$ D-mannitol, D-fructose, rhamnose, sucrose and raffinose are all utilized for growth.

Actinomyces violaceolatus Krasil'nikov, Sorokina, Alferova and Bezzubenkova. Description: Krasil'nikov et al. in Krasil'nikov 1965, 113-114. Type strain: INMI 4 (selected by N.A. Krasil'nikov, personal communication, December 1966, from strains listed in original description, ibid.). ISP 5438 from N.A. Krasil'nikov as INMI 4. ISP description by Group D-3.

Spore chain morphology: Section Spirales (Fig. 203). Mature spore chains long, usually with more than 50 spores per chain. This morphology is seen on yeast-malt agar, oatmeal agar salts-starch agar and glycerol-a sparagine agar. Spore surface: Smooth (Fig. 204).

Color of colony: Aerial mass color in the Gray color-series (3fe, light brownish gray; $5 \mathrm{fe}$, light grayish reddish brown or $3 \mathrm{ge}$, light grayish yellowish brown) on yeast-malt agar, oatmeal agar, saltsstarch agar and glycerol-asparagine agar. Color may sometimes approach tab 5dc, grayish yellowish pink in the Red color-series on glycerol-asparagine agar.

Reverse side of colony: Blue, purple or red, depending upon pH and ranging from grayed colors to almost black, depending upon intensity of pigment. Reverse mycelium pigment is a $\mathrm{pH}$ indicator, changing from red or violet to blue with addition of $0.05 \mathrm{~N} \mathrm{NaOH}$ and from blue or violet to red or pink with addition of $0.05 \mathrm{~N} \mathrm{HCl}$.

Color in medium: Melanoid pigments are not formed in peptoneyeast-iron agar, tyrosine agar or tryptone-yeast broth. Blue, violet or red pigment, depending upon. $\mathrm{pH}$, is found in the medium in yeastmalt agar, oatmeal agar, salts-starch agar and glycerol-asparagine agar. This pigment is $\mathrm{pH}$ sensitive, showing the same changes noted for the reverse mycelium pigment. 
Carbon utilization: D-Glucose, L-arabinose, D-xylose, $\underline{\text { i-inositol, }}$ D-mannitol, D-fructose, rhamnose, sucrose and raffinose are all utilized for growth, but growth on sucrose may be somewhat less than on any other carbon sources.

Actinomyces violaceorectus Ryabova and Preobrazhenskaya. Description: Ryabova and Preobrazhenskaya in Gauze et al. 1957 , 179 and 182 . Type strain: INA 506 (G.F. Gauze, personal communication, November, 1964; Gauze in Gottlieb 1968). Streptomyces viola ceorectus (Ryabova and Preobrazhenskaya) Pridham et al. 1958, 63. ISP 5279 from G.F. Gauze as INA 506. ISP description by Group B -9.

Spore chain morphology: Section Rectiflexibiles (Fig. 205).

Mature spore chains generally long and straight, often with more than 50 spores per chain. This morphology is seen on yeast-malt agar, oatmeal agar, salts-starch agar and glycerol-asparagine agar. Spore surface: Smooth (Fig. 206).

Color of colony: Aerial mass color in the Gray or Red colox-series on yeast-malt agar, oatmeal agar, salts-starch agar and glycerolasparagine agar. (Representative color tab from the Gray color-series is $5 \mathrm{fe}$, light grayish reddish brown; representative tabs from the Red color-series are 5dc, 5ec or 6ec, grayish yellowish pink.)

Reverse side of colony: Grayish yellow to brown or grayish reddish brown on yeast-malt agar; yellowish pink or reddish brown to dark purplish pink or dark purplish red on oatmeal agar, salts-starch agar and glycerol-asparagine agar. Reverse mycelium pigment is a $\mathrm{pH}$ indicator, changing from orange or pink to violet or purple with addition of $0.05 \mathrm{~N} \mathrm{NaOH}$ and from violet to pink or orange with addition of $0.05 \mathrm{~N} \mathrm{HCl}$.

Color in medium: Melanoid pigments are formed in peptone-yeast iron agar and tryptone-yeast broth, but not in tyrosine agar. Traces of yellow to pinkish brown pigment may be found in the medium in yeast malt agar, oatmeal agar, salts-starch agar or glycerol-asparagine agar. Pink or pinkish brown pigment, when present, is $\mathrm{pH}$ sensitive, changing from pink or brown to pale violet or gray with addition of $0.05 \mathrm{~N} \mathrm{NaOH}$.

Carbon utilization: D-Glucose, L-a rabinose and $\underline{D}$-xylose are utilized for growth. Limited growth also may occur on D-fructose and sucrose. No growth or only a trace of growth with $\mathbf{i}$-inositol, D-mannitol, rhamnose and raffinose.

Streptomyces violaceus (Rossi-Doria) Waksman and Henrici = Actinomyces violaceus (Rossi-Doria) Gasperini 1894, emend. Krasil'nikov 1941. Descriptions: Streptotrix (sic) violacea Rossi-Doria 1891, 411-415; Actinomyces violaceus (Rossi-Doria) Gasperini 1894, 84; Actinomyces violaceus (Gasperini) Krasil'nikov 1941, 15-16; Streptomyces violaceus (Rossi- Doria) Waksman in Waksman and Lechevalier 1953,43. Type strain: INMI-1 = USSR-RIA 656 = ATCC 15888 (suggested neotype, N.A. Krasil'nikov, personal communication, Nov. 1963; see also Krasil'nikov 1941, 16). ISP 5082 from V.D. Kuznetsov (USSR-RIA) as INMI-1 = RIA 656. ISP description by GroupB -1 .

Spore chain morphology: Section Spirales (Fig. 207). Mature spore chains moderately long with 10 to 50 or more spores per chain. This 


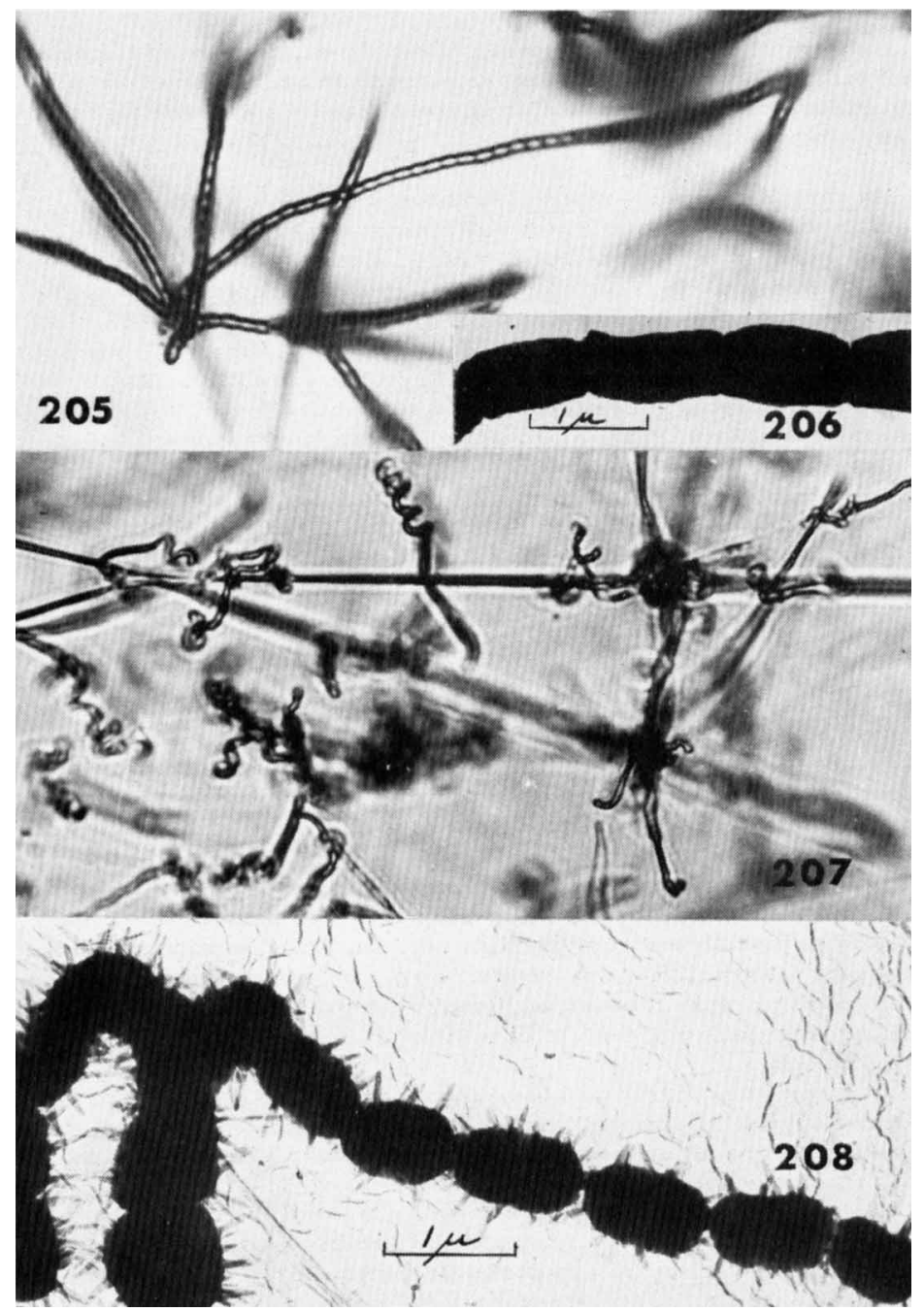

Figure 205. A. violaceorectus. RF spore chains (X 1100) on glycerolasparagine agar, 14 days.

Figure 206. A. violaceorectus. Smooth spores; electron micrograph from 14 day culture on yeast-malt agar.

Figure 207. S. violaceus. Spiral spore chains (X 640) on oatmeal agar, 14 days.

Figure 208. S. violaceus. Spiny spores; electron micrograph from 14 day culture on salts-starch agar. 
morphology is seen on yeast-malt agar, oatmeal agar, salts-starch agar and glycerol-asparagine agar. Spore surface: Spiny (Fig. 208).

Color of colony: Aerial mass color in the Red color-series ( $5 \mathrm{cb}$, grayish yellowish pink or 7ca, light yellowish pink) on salts-starch agar and glycerol-asparagine agar; White or Red on yeast-malt agar; White color-series on oatmeal agar. When aerial mycelium is thin, the red to violet color of the substrate mycelium may be evident.

Reverse side of colony: Reddish orange to purplish pink or pale purple, depending upon $\mathrm{pH}$. Reverse mycelium pigment is a $\mathrm{pH}$ indicator, changing from red to violet (purple) with addition of $0.05 \mathrm{~N} \mathrm{NaOH}$ or from violet to red (pink) with addition of $0.05 \mathrm{~N} \mathrm{HCl}$.

Color in medium: Melanoid pigments are formed in peptone-yeastiron agar and tryptone-yeast broth, but not in tyrosine agar. Red or violet pigment, depending on $\mathrm{pH}$, is found in the medium in yea st-malt agar, oatmeal agar, salts-starch agar and glycerol-asparagine agar. This pigment is $\mathrm{pH}$ sensitive showing the same changes noted for the reverse mycelium pigments.

Carbon utilization: D-Glucose, L-arabinose, D-xylose, $\underline{\text { in-inositol, }}$ D-mannitol, D-fructose, rhamnose, sucrose and raffinose are all utilized for growth.

Actinomyces violarus Artamonova and Krasil'nikov. Description: Artamonova and Krasil'nikov 1960, 334 (see also English translation, 327 and 296-300). Type strain: INMI 1212 = USSR-RIA 157 (N.A. Krasil'nikov, personal communication, April 1964). (Note: INMI 1212 is also given as the type strain for Chainia violens Kalakutsky and Krasil'nikov 1960, 51). ISP 5205 from N.A. Krasil'nikov as INMI $1212=$ USSR-RIA 157. ISP description by Group B -7.

Spore chain morphology: Section Spirales. Spirals of 3 to 4 turns may be formed or poorly developed irregular spirals, hooks or loops may become entangled. Mature spore chains moderately long with 10 to 50 spores per chain. This morphology is seen on yeast-malt agar, oatmeal agar, salts-starch agar and glycerol-asparagine agar. Spore surface: Spiny (Fig. 209).

Color of colony: Aerial mass color in the Red or Violet colorseries on yeast-malt agar, oatmeal agar, salts-starch agar and glycerol-asparagine agar. Nearest matching color tabs are $5 \mathrm{cb}, 5 \mathrm{ec}$ or 6ec, grayish yellowish pink from the Red color-series or $11 \mathrm{ca}$, very pale purple, from the Violet color-series.

Reverse side of colony: Reddish orange or reddish brown to pur plish pink or purple depending upon $\mathrm{pH}$. Reverse mycelium pigment is a $\mathrm{pH}$ indicator, changing from pink or violet to blue-violet or blue with addition of $0.05 \mathrm{~N} \mathrm{NaOH}$ and from violet to pink or red with addition of $0.05 \mathrm{~N} \mathrm{HC1}$.

Color in medium: Melanoid pigments are formed in peptone-yeastiron agar and tryptone-yeast broth, but only weakly or not at all in tyrosine agar. Red or violet pigment, depending upon $\mathrm{pH}$, is found in the medium in yeast-malt agar, oatmeal agar, salts-starch agar and glycerol-asparagine agar. This pigment is $\mathrm{pH}$ sensitive, showing the same changes noted for reverse mycelium pigment.

Carbon utilization: D-Glucose, L-arabinose, D-xylose, $\underline{\text { i-inositol, }}$ D-mannitol, D-fructose, rhamnose, sucrose and raffinose are all utilized for growth. 
Actinomyces violochromogenes Artamonova and Krasil'nikov. Descriptions: Actinomyces violaceus subsp. chromogenes Krasil'nikov 1949, 55; elevated to species and described as Actinomyces violochromogenes Artamonova and Krasil'nikov 1960, 257-337 (See also English translation, 327 and 306-311). (Note: See also ISP description for $A$. violaceochromogenes Ryabova and Preobrazhenskaya 1957, which is also based on $A$. violaceus subsp. chromogenes but different neotype specimens.) Type strain: INMI $2929=$ USSR-RIA 657 (selected by N.A. Krasil'nikov, personal communication April 1964, as type strain from two specimens studied in Artamonova and Krasil'nikov 1960). ISP 5207 from N.A. Krasil'nikov as INMI $2929=$ USSR-RIA 657. ISP description by Group B -9 .

Spore chain morphology: Section Spirales. Spirals usually have only one or two turns (Fig. 210) and incomplete spirals, hooks and flexuous chains are also common. Morphology may be obscurred by accumulation of moisture droplets (hygroscopic droplets) around spirals; droplets often coalesce and may contain large masses of spores. Coremia may also be found. Mature spore chains generally short with 3 to 10 or more spores per chain. This morphology is seen on yeast malt agar, oatmeal agar, salts-starch agar and glycerol-asparagine agar. Spore surface: Smooth (Fig. 211).

Color of colony: Aerial mass color in the Red color-series (5cb, grayish yellowish pink) on yeast-malt agar, oatmeal agar, saltsstarch agar and glycerol-asparagine agar; or sometimes in the White or Gray ( $5 \mathrm{fe}$, grayish reddish brown) color-series on the se media.

Reverse side of colony: Grayish red or reddish brown to grayish yellow on yeast-malt agar, oatmeal agar, salts-starch agar and glycerola sparagine agar. Reverse mycelium pigment is not a $\mathrm{pH}$ indicator or is modified only slightly from pale reddish brown to pale yellow with addition of $0.05 \mathrm{~N} \mathrm{HCl}$.

Color in medium: Melanoid pigments are formed in peptone-yeastiron agar; reports vary on darkening of tyrosine agar and tryptoneyeast broth. Yellow to orange or pink pigment is found in the medium in yeast-malt agar, oatmeal agar, salts-starch agar and glycerolasparagine agar. This pigment is only slightly $\mathrm{pH}$ sensitive, changing from pale brown or orange to pale yellow with addition of $0.05 \mathrm{~N} \mathrm{HCl}$.

Carbon utilization: D-Glucose, L-arabinose, D-xylose, i-inositol, D-mannitol, D-fructose, rhamnose, sucrose and raffinose are all utilized for growth.

Actinomyces virido-diastaticus (sic) Baldacci, Grein and Spalla. Descriptions: Actinomyces virido-diastaticus Baldacci et al. 1955 , 133-134; Streptomyces virido-diastaticus (Baldacci, Grein and Spalla) Pridham et al. 1958, 67. Type strain: IPV 334a (selected as type strain from several strains included in the original description, Baldacci et al. 1955 op cit., E. Baldacci, personal communication, August $1 9 6 4 \longdiv { ) . ~ I S P ~ } 5 \overline { 2 4 9 }$ from $\mathrm{E}$. Baldacci as IPV $334 \mathrm{a}$. ISP description by Group B-7.

Spore chain morphology: Section Spirales (Fig. 212) but abundant open spirals and flexuous chains also suggest RA morphology (Fig. 213). Spirals are most abundant on salts-starch agar. Mature spore chains moderately long with 10 to 50 spores per chain. This morphology is seen on yeast-malt agar, oatmeal agar, salts-starch agar anc' glycerol- 


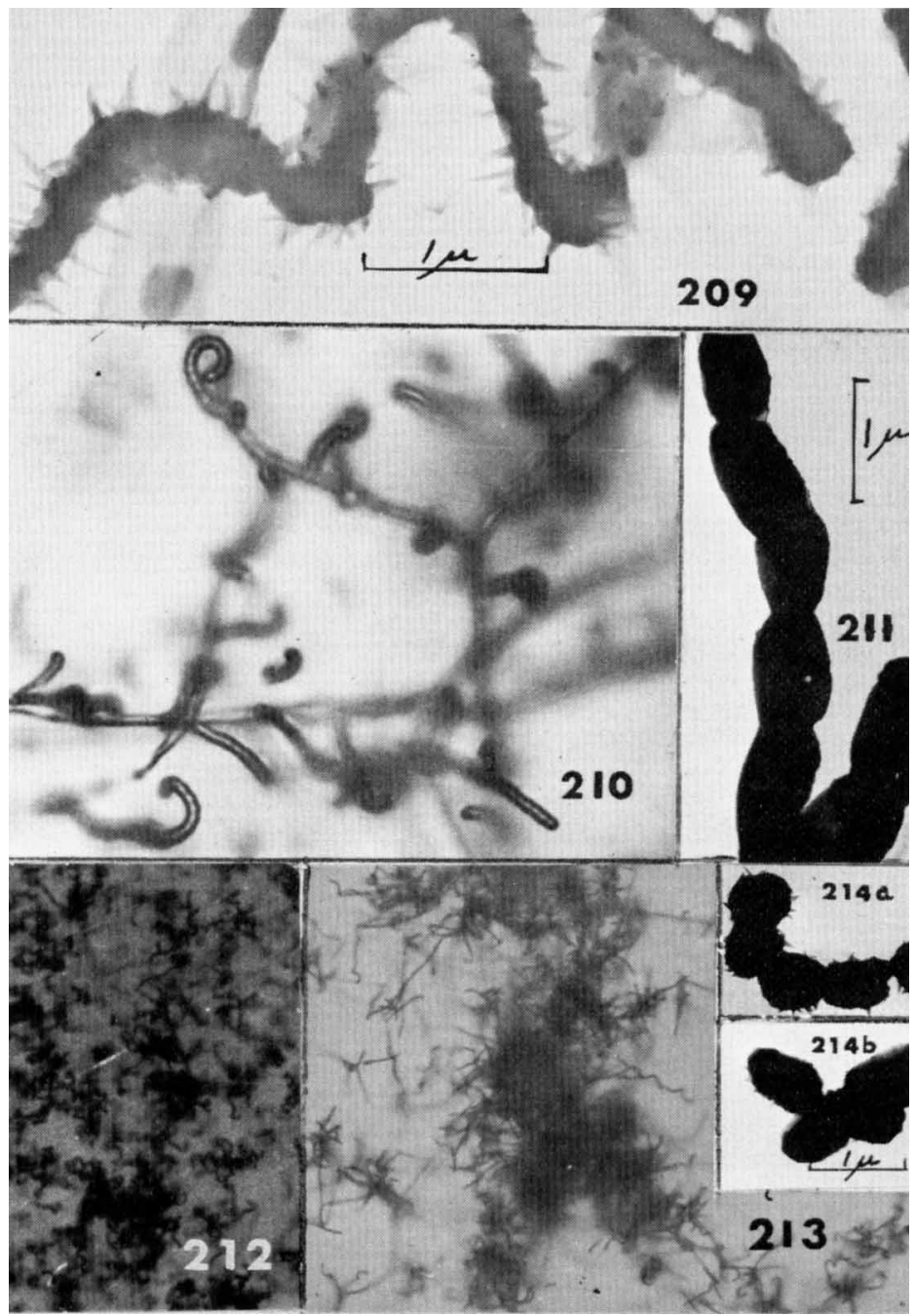

Figure 209. A. violarus. Spiny spores in spiral chains; electron micrograph from 14 day culture on glycerol-asparagine agar.

Figure 210. A. violochromogenes. Incomplete spirals (X 1100) on saltsstarch agar, 14 days.

Figure 211. A. violochromogenes. Smooth spores; electron micrograph from 14 day culture on yeast-malt agar.

Figure 212. A. virido-diastaticus. Spiral spore chains (X 300) on oatmeal agar, 12 days.

Figure 213. A. virido-diastaticus. RA morphology (X 300) on glycerolasparagine agar.

Figure 214. A. virido-diastaticus. (a) Spiny spores. (b) Spines may be inconspicuous or absent on some spores. Electron micrograph from 14 day culture on yeast-malt agar. 
asparagine agar. Spore surface: Spiny, but spines may not be apparent on some spores (Fig. 214).

Color of colony: Aerial mass color in the Gray color-series (2fe, medium gray to $2 \mathrm{ih}$, light olive-gray or $3 \mathrm{ig}$, grayish yellowish brown) on yeast-malt agar, oatmeal agar, salts-starch agar and glycerolasparagine agar.

Reverse side of colony: No distinctive pigments (yellowish brown to olive-brown on yeast-malt agar; pale yellow-green or pale yellow and grayish yellow on oatmeal agar, salts-starch agar and glycerolasparagine agar).

Color in medium: Melanoid pigments are not formed in peptoneyeast-iron agar, tyrosine agar or tryptone-yeast broth. No pigment is found in the medium in yeast-malt agar, oatmeal agar, salts-starch agar or glycerol-asparagine agar.

Carbon utilization: D-Glucose, L-arabinose, D-xylose, $\underline{\text { in-inositol, }}$ D-mannitol, D-fructose and rhamnose are utilized for growth. Reports vary on utilization of sucrose and raffinose.

Actinomyces vulgaris Nikitina, Korenyako and Krasil'nikov. Description: Nikitina et a $.1960,104-115$. Type strain: INMI $1034=$ USSR-RIA $334=$ ATCC 15895 (selected as type strain by N. A. Krasil' nikov from several strains included in the original description, ibid.). ISP 5201 from N.A. Krasil'nikov as INMI 1034 = USSR-RIA 334. ISP description by Group B -4 .

Spore chain morphology: Section Rectiflexibiles (Fig. 215). Mature spore chains generally long with 10 to 50 or often more than 50 spores per chain. This morphology is seen on yeast-malt agar, oatmeal agar, salts-starch agar and glycerol-asparagine agar. Spore surface: Smooth (Fig. 216).

Color of colony: Aerial mass color in the Yellow color-series ( $2 \mathrm{db}$ or $2 \mathrm{ba}$, pale yellow) on yeast-malt agar, oatmeal agar, salts starch agar and glycerol-asparagine agar.

Reverse side of colony: No distinctive pigments (grayish or greenish yellow to olive-brown) on yeast-malt agar, oatmeal agar, saltsstarch agar and glycerol-asparagine agar.

Color in medium: Melanoid pigments are not formed in peptoneyeast-iron agar, tyrosine agar or tryptone-yeast broth. No pigment or only a trace of yellow is found in the medium in yeast-malt agar, oatmeal agar, salts-starch agar or glycerol-asparagine agar.

Carbon utilization: D-Glucose, L-arabinose, D-xylose, D-mannitol, D-fructose and rhamnose are utilized for growth. Utilization of tol is doubtful and there is no growth or only a trace of growth with sucrose and raffinose.

Streptomyces yokosukanensis Nakamura. Description: Nakamura 1961, 94-97. Type strain: Nakamura B-34 (ibid.). ISP 5224 from S. Suzuki, Inst. Phys, and Chem. Res., Tokyo as strain B-34. ISP description by Group B -8.

Spore chain morphology: Section Spirales or Retinaculiaperti. Tight spirals are common at the ends of long spore chains (Fig. 2l 7). Open spirals, hooks and flexuous chains are also found. Spore surface: Spiny (Fig. 218) according to one observer; another observer finds only smooth spores (Fig. 219). 


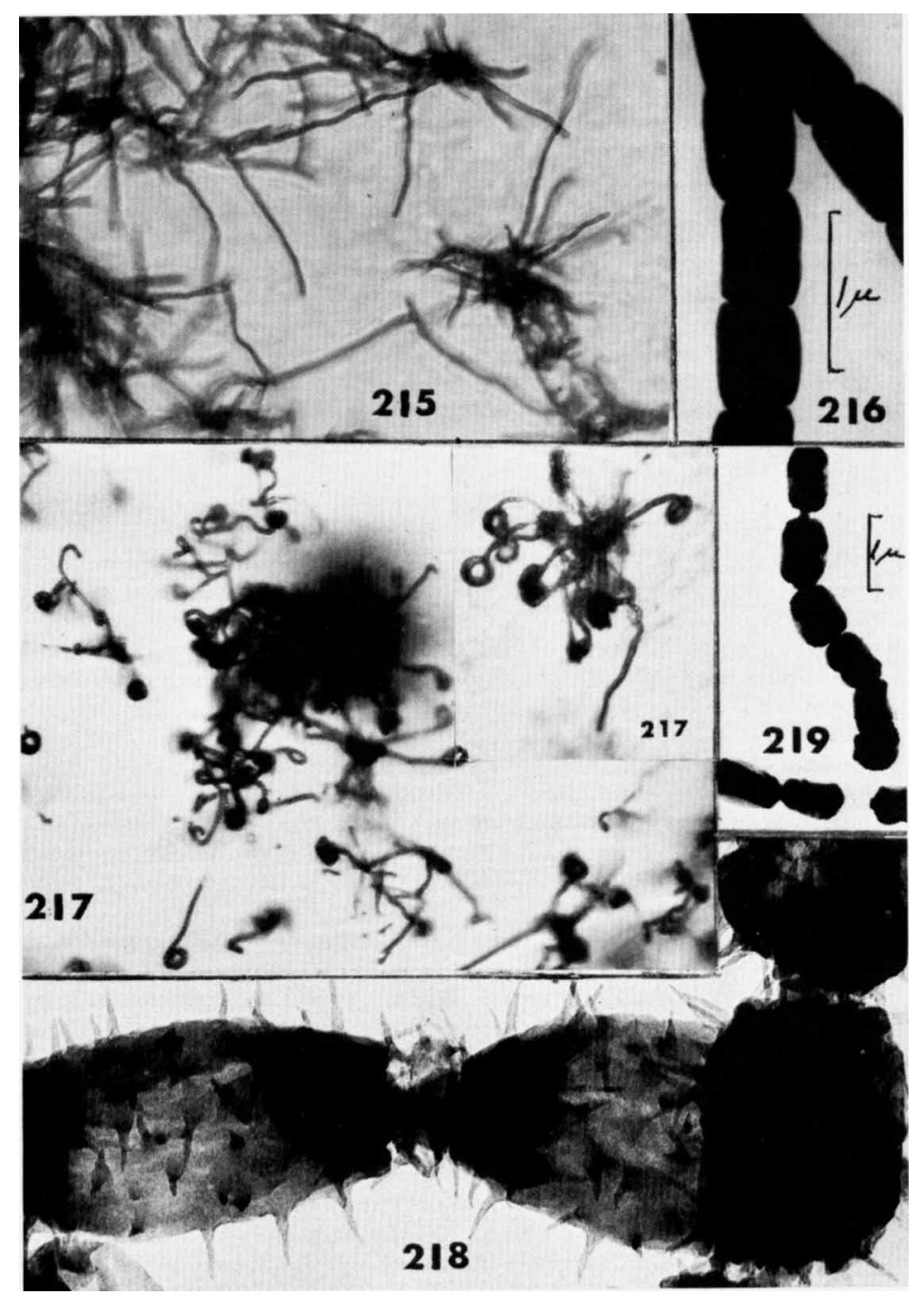

Figure 215. A. vulgaris. RF spore chains (X 400) on oatmeal agar, 17 days.

Figure 216. A. vulgaris. Smooth spores; electron micrograph from 21 day culture on oatmeal agar.

Figure 217 a,b. S. yokosukanensis. Tight terminal spirals at ends of long spore chains (X 800), on oatmeal agar, 14 days.

Figure 218. S. yokosukanensis. Spiny spores; electron micrograph from 14 day culture on oatmeal agar.

Figure 219. S. yokosukanensis. Smooth spores (see also Fig. 218); electron micrograph from 14 day culture on yeast-malt agar. 
Color of colony: Aerial mass color in the Red color-series (grayish yellowish pink) on yeast-malt agar, oatmeal agar, salts-starch agar and glycerol-asparagine agar.

Reverse side of colony: No distinctive pigments (grayish yellow, light yellowish brown, olive-brown or strong brown) on yeast-malt agar, oatmeal agar, salts-starch agar and glycerol-asparagine agar.

Color in medium: Melanoid pigments are formed in peptone-yeastiron agar, tyrosine agar and tryptone-yeast broth. No pigment or only a trace of yellow is found in the medium in yeast-malt agar, oatmeal agar, salts-starch agar or glycerol-a sparagine agar.

Carbon utilization: D-Glucose, L-arabinose, D-xylose, i-inositol, D-mannitol, D-fructose, rhamnose and raffinose are utilized for growth. No growth or only a trace of growth with sucrose.

\section{BIB LIOGRAPHY}

Ahmad, K. and A. M. Bhuiyan. 1958. A new antifungal Streptomyces species, Streptomyces corchorusii. Pakistan J. Biol. and Agr. Sci. $1: 37-143$.

Arcamone, F., C. Bertazzoli, G. Canevazzi, A. Di Marco, M. Ghione and A. Grein. 1957. La etruscomicina, nuovo antibiotico antifungino prodotto dallo Streptomyces lucensis n. sp. (in Italian, English summary). G. Microbiol. 4:119-128.

Arcamone, F., C. Bertazzoli, M. Ghione and T. Scotti. 1959. Melanosparin and Elaiophylin, new antibiotics from Streptomyces melanosporus (sive melanosporofaciens) n. sp. G. Microbiol. 7:207-216.

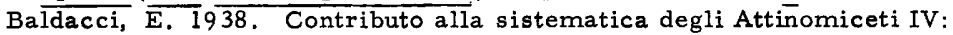
Sull' Actinomyces melanosporeus Krainsky. Atti Ist. Bot. Univ. Pavia, Ser. IV 10:321-329.

- 1958. Development in the classification of actinomycetes. Giorn. Microbiol. 6:10-27.

, G. Farina, R. Locci and G. Ragni. 1965. Description of a new species of Streptomyces: Streptomyces capuensis sp. nov. Giorn. Microbiol. 13:45-62.

, A. Grein and C. Spalla. 1955. Studio di una "serie" di specie di attinomiceti: A. diastaticus. Giorn. Microbiol. 1:127-143. and R. Locci. 1961. Osservazioni e ricerche su Micromonospora melanosporea comb. nov., e descrizione di una nuova sottospecie: M. melanosporea subsp. corymbica. Ann. Microbiol. 11:1-12. and G. Farina. 1965. On the proposal for a neotype of Streptomyces albus: Identity of the present description with the original ones by Gasperini and Rossi Doria. Intern. Bull. Bacteriol. Nom. Tax. 15:1-11.

Beijerinck, M. W. 1912. Mutation bei Mikroben. Folia Microbiol., Delft 1:1-100.

Bellenghi, M. 1956. German Pat. Appl. L 21111 , March 8 . . 1957. British Pat. 755, 139, May 22.

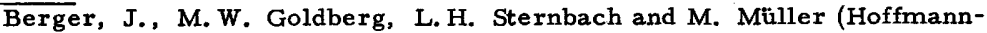
LaRoche and Co.). 1962. German Pat. 1, 122, 670 August 16. Deutsches Patentamt.

Bergey, D.H., F.C. Harrison, R.S. Breed, B. W. Hammer and F. M. Huntoon. 1925. Bergey's Manual of Determinative Bacteriology. 2nd Ed. The Williams and Wilkins Co., Baltimore. 462 p. 
Bergy, M., R. R. Herr and D.J. Mason. 1963. Antibiotic Lincolnensin and method of production. U.S. Pat. 3, 086, 912 April 23, U.S. Pat. Office.

British Patent 755, 139. May 22, 1957.

Brockman, H., K. Bauer and Ilse Borchers. 195.1. Rhodomycin, ein rotes Antibioticum (Antibiotica aus Actinomyceten, VII. Mitteil.). Chem. Ber. 84:700-710.

Buchanan, R., J. Holt and E. Lessel. 1966. Index Bergeyana. The Williams and Wilkins Co., Baltimore. $1472 \mathrm{pp}$.

Burkholder, P.R., S.H. Sun, Lucia Anderson and J. Ehrlich. 1955. The identity of viomycin-producing cultures of Streptomyces. Bull. Torry Bot. Club 82:108-117.

Calot, L. and A.P. Cercós. 1963a. Streptomyces ornatus, nov. sp. and Streptomyces erumpens, nov. sp. productores de los antibioticos

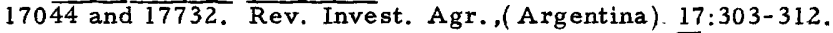
and $\quad$ 1963b. Streptomyces ornatus, nov. sp. et Streptomyces erumpens, nov. sp. producteurs d'ornamacine et antibiotique 17732. Ann. Inst. Pasteur 105:159-161.

Cercós, A. P., B. L. Eilberg, Julia G. Goyena, J. Souto, E. E. Vautier and I. Wibuczynski. 1962. Misionina: Antibiotico polienico producido por Streptomyces misionensis n. sp. II. Descripcion de Streptomyces misionensis n. sp. Rev. Invest. Agr. (Argentina) 16:2 $\overline{1-27}$.

Chalmers, A. J. and J. B. Christopherson. 1916. A Sudanese actinomycosis. Ann. Trop Med. Parasit. 10:223-282.

DeBoer, C., A. Dietz, W.S. Silver and G.M. Savage. 1956. Streptolydigin, a new antimicrobial antibiotic. I. Biologic studies of streptolydigin, p. 886-892. In Antibiotics Annual 1955-56. Medical Encyclopedia, Inc., New York.

and J. Hinman. 1959. U.S. Patents: Amicetin and its production $(2,909,517)$; Amicetin $A$ and its salts $(2,909,463)$; Amicetin C and its salts $(2,909,464)$ Oct. 20. U.S. Pat. Office.

Duché, J. 1934. Les actinomyces du groupe albus. Encycl. Mýcol., VI. Paul LeChevalier and Sons, Paris. 1-375.

, R. Heim and P. Laboureur. 1951. IV. Étude du Streptomyces termitum n. sp., associé a I'Antennopsis, p. 359-363. In R. Heim, Mémoire sur l'Antennopsis, ectoparasite du termite de siaintonge. Bull. Soc. Mycol. France 67 (4).

Ehrlich, J., D. Gottlieb, P.R. Burkholder, Lucia Anderson and T.G. Pridham. 1948. Streptomyces venezuelae, n. sp., the source of chloromycetin. J, Bacteriol, 50:467-477.

Erickson, D. 1935. The pathogenic aerobic organisms of the Actinomyces group. Med. Res. Coun. Spec. Rep. Ser., No. 203:5-61.

Ettlinger, L., R. Corbaz and R. Hütter. 1958. Zur Systematik der Actinomyceten. 4. Eine Arteinteilung der Gattung Streptomyces Waksman et Henrici. Arch. Mikrobiol. 31:326-358.

Farbenfabriken Bayer Aktiengesellschaft. $1 \overline{96}$. A new antibiotic Phyllomycin. British Pat. Specif. 864,814 April 6. Patent Off., London.

Gasperini, G. 1892. Ricerche morfologiche e biologiche sul genere Actinomyces Harz come contributo allo studio delle relative micosi. Ann. Instituto Igiene sper. R. Univ. Roma 2:167-231.

. 1894. Ulteriori ricerche sul genere Actinomyces. P. V. Soc.

Tosc. Sci. nat. (Pisa) 9:64-89. 
Gauze, G.F., T.P. Preobrazhenskaya, E.S. Kudrina, N.O. Blinov, I. D. Ryabova and M. A. Sveshnikova. 1957. Problems of classification of atinomycetes-antagonists [in Russian]. Government Publishing House of Medical Literature, Medgiz, Moscow. 1-398.

Giolitti, G. 1958a. Studies on two strains of streptomyces producers of flavensomycin, an antibiotic with fungicidal and insecticidal activity. Abst. VII Intern. Congr. Microbiol. (Abstr. 22k).

- 1958b. Belgian Pat. 560, 930 March 18.

- 1960. Production of a new antibiotic flavensomycin. British

Pat. 850, 325 Oct. 5.

- 1961. Streptomyces cavourensis, p. 191. In S. A. Waksman, The Actinomycetes. Vol. II. Classification, identification and descriptions of genera.and species. The Williams and Wilkins Co. Baltimore.

Gottlieb, D. 1968. Communication from G. F. Gauze. Int. J. Syst. Bacteriol. 18:20.

Hagemann, G., G. Nominé and L. Pénasse. 1958. Sur un antibiotique, l'hydroxymycin, produit par un Streptomyces. Ann. Pharm. francaises 16:585-596.

U.S. Pat. Office. and J. Teillon. 1965. U.S. Pat. 3, 052, 605 Sept. 4. , L. Pénasse and J. Teillon. 1955. Sur un térivé de la sérine, la O-carbamyl-D-sérine, produit par un Streptomyces. Biochim. et Biophys. Actā 17:240-243.

Henssen, Aino. 19 $\overline{57}$. Beitrage zur Morphologie und Systematik der thermophilen Actinomyceten. Arch. Mikrobiol. 26:373-414.

and E. Schnepf, 1967. Zur kenntnis thermophiler actinomyceten. Arch. Mikrobiol. 57:214-231.

Hutter, R. 1961. Zur Systematik der Actinomyceten Nr.5. Die Art Streptomyces albus (Rossi-Doria emend Krainsky) Waksman et Henrici 1943. Arch. Mikrobiol. 38:367-383.

- 1967. Systematik der Streptomyceten. S. Karger, Basel. 382 p.

Isono, K. , S. Suzuki, T. Sawazaki, G. Nakamura, M. Kawasaki, T. Yamashita, K. Anzai, Y. Serizawa and Y. Sekiyama. 1955. An antibiotic produced by Streptomyces chromogenus sp. J. Antibiotics, Tokyo Ser, A, 8:19-21.

, S. Yamashita, Y. Tomiyama, S. Suzuki and H. Sakai. 1957. Studies on Homomycin. II. J. Antibiot:, Tokyo Ser. A, 10:21-30.

Jensen, H. L. 1931. Contributions to our knowledge of the Actinomycetales. II. The definition and subdivision of the genus Actinomyces, with a preliminary account of Australian soil actinomycetes. Proc. Linn. Soc. N. S. Wales 56:345-370.

Jones, K. L. 1952. A new Streptomyces that produces vitamin $B_{12}$ actively. Papers Michigan Acad. Sci. Arts and Letters 37:47-48.

Judicial Commission of the International Committee on Bacteriological Nomenclature. 1963. Opinion 29. Designation of strain ATCC 3004 (IMRU 3004) as the neotype strain of Streptomyces albus (RossiDoria) Waksman and Henrici. Intern. Bull. Bacteriol. Nom. Tax. 13:123-124.

Kalakutsky, L. V. and N.A. Krasil'nikov, 1960. Formation of sclerotia in actinomycetes and the systematic position of genus Chainia. Biology of special groups of actinomycetes (producers of antibiotics) [in Russian]. Trud. Inst. Mikrobiol., Akad. Nauk. S.S.S.R. 8:4555 [Engl. transl, p. 41-52]. 
Koninklijke Nederlandsche Gist-en Spiritusfabriek N. V. 1956a, A new antibiotic B-Mycin and processes for its preparation. British Pat. Specification 762,736 , Dec. 5 .

- 1956b. The antibiotic Vengicide and process for preparation of the antibiotics oxytetracycline and vengicide. British Pat. Specif. 764,198 . December 19. Patent Office, London.

- 1964. Werkwijze voor de bereiding van antibiotica met behulp van een Streptomyces-soort. Netherland Pat. 109006 July 15. Patent Office, Nederland.

K. ainsky, A, 1914. Die Aktinomyceten und ihren Bedeutung in der Natur. Zbl. Bakt. Abt. 2, 41:649-688.

Krasil'nikov, N.A. 1941. (jide to the actinomycetes [in Russian]. Akad. Nauk. S.S.S.R., Moscow. 140 p. (Engl. transl. by Israel Prog. for Sci. transl. Clearing House for Federal Scientific and Technical Information, U.S. Dept. Commerce, Springfield, Va. 174 p.)

- 1949. Guide to the bacteria and actinomycetes [in Russian ].

Akad. Nauk. S.S.S.R., Moscow. 1-830.

. [ed.] 1965. Biology of special groups of actinomycetes [in Rus-

sian]. Inst. Mikrobiol., Akad. Nauk, S.S.S.R., Izd. Nauka, Moscow. $370 \mathrm{p}$.

, A. I. Korenyako and N.I. Nikitina. 1965. Actinomycetes of the yellow group, p.205-229. In N.A. Krasil'nikov [ed.]. Biology of special groups of actinomycetes [in Russian]. Inst. Mikrobiol., Akad. Nauk., S.S.S. R., Izd. Nauka, Moscow.

E.J. Sorokina, V.A. Alferova and A. P. Bezzubenkova. 1965. Classification of blue actinomycetes, p.74-123. In N. A. Krasil'nikov [ed.] Biology of special groups of actinomycetes [in Russian]. Inst. Mikrobiol. Akad. Nauk., S.S.S. R., Izd. Nauka, Moscow.

and Yuan Tsi-shen. 1965. Characteristics of species of orange colored actinomycetes, p. 28-57. In N.A. Krasil'nikov (ed.). Biology of special groups of actinomycetes [in Russian]. Inst. Mikrobiol., Akad. Nauk, S.S.S.R., Izd. Nauka, Moscow.

Kudrina, E.S. 1957a. Characteristics of antagonistic actinomycetes of the Helvolus series [in Russian], p. 77-100. In Gauze, G. F., T.P. Preobrazhenskaya, E.S. Kudrina, N.O. Blinov, E. D. Ryabova and M. A. Sveshnikova. Problems of classification of actinomycetesantagonists. Government Publishing House of Medical Literature, Medgiz, Moscow.

- 1957b. Characteristics of antagonistic actinomycetes of the Albosporeus series [in Russian], p.112-118. In Gauze, G. F., T.P. Preobrazhenskaya, E.S. Kudrina, N.O. Blinov, I. D. Ryabova and M. A. Sveshnikova. Problems of classification of actinomycetesantagonists. Government Publishing House of Medical Literature, Medgiz, Moscow.

Kuryłowicz, W. and F. Ulak. 1959. Polish Pat. 43565. and 1964. British Pat. Specif. 963, 886 July 15, The

Patent $\overline{\text { Office, }}$ London. 
and Wanda Woźnicka. 1967. Actinomyces (Streptomyces) varsoviensis. I. Taxonomic studies (I. Badania Taksonomiczne) [ in Polish and English]. Exp. Med. and Microbiol. (Med. Dosw. I Mikrobial.) 19(1):1-9.

Lieske, R. 1921. Morphologie und biologie der Strahlenpilze. Borntrager, Leipzig.

Lindenbein, W. 1952. Über einige chemisch interessante Aktinomycetenstämme und ihre Klassifizierung. Arch. Mikrobiol. 17:361-383.

Lyons, A. J. Jr. and T. G. Pridham. 1961. Proposal to designate strain ATCC 618 as the neotype strain of Streptomyces albus (Rossi-Doria) Waksman et Henrici. Bacteriol. Proc. GI0.

and 1962. Proposal to designate strain ATCC 3004 (IMRU 3004) as the neotype strain of Streptomyces albus (Rossi-Doria) Waksman and Henrici. J. Bacteriol. 83:370-380.

McVeigh, Ilda and C.R. Reyes. 1961. A new species of Streptomyces and its antibiotic activity. Antibiotics and Chemotherapy 11:312-319.

Mancy, Denise, C. Ninet, L. Ninet and Jean Preud'homme. 1964. Process for the production of pristinamycin. U.S. Pat. 3, 154, 475. Oct. 27. U.S. Pat. Office.

F. Ninet and Jean Preud'homme. 1962. Procédé de préparation $\mathrm{d}^{\prime} u$ antibiotique par culture $\mathrm{d}^{\prime}$ une nouvelle souche de Streptomyces. French Patent 1, 301, 857 July 16, 1962. Ministere de L'industrie, Republique Francaise.

Mason, D. J., A. Dietz and C. DeBoer. 1962. Lincomycin, a new antibiotic I. Discovery and biological properties. Antimicrobial Agents and Chemotherapy - 1962: 554-559.

Mayer, R. L., D. Crane, C.J. deBoer, E.A. Konopka, J.S. Marsh and P.C. Eisman. 1951. Antibiotics from A. vinaceus (nov. sp.). Microbiological Studies, 12 th Int. Congr. Pure Appl. Chem. (Abstracts of Papers) 283-284.

Millard, W.A. and S. Burr. 1926. A study of twenty-four strains of Actinomyces and their relation to types of common scab of potato. Ann. Appl. Biol. 13:580-644.

Nakamura, G. 1961 a. Studies on antibiotic actinomycetes. II. On Streptomyces producing a new antibiotic tubercidin. J. Antibiot., Tokyo Ser. A, 14:90-93.

. 1961 b. Studies on antibiotic actinomycetes. III. On Strepto-

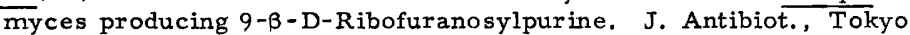
Ser. A, 14:94-97.

Nikitina, N. I., A.I. Korenyako and N.A. Krasil'nikov. 1960. Actinomyces vulgaris. Biology of special groups of actinomycetes producers of antibiotics (Biologiya otdel'nykh gruppe aktinomitsetovprodut-sentov antibiotikov.) Akad. Nauk S.S.S.R. Trud. Inst. Microbio1. 8:85-115.

Owen, S. P., A. Dietz and G.W. Camiener. 1962. Sparsomycin, a new antitumor antibiotic. I. Discovery and biological properties. Antimicrobial Agents and Chemotherapy - 1962: 772-779.

Pagano, J., R. Donovick, J. D. Dutcher and L. J. Heuser. 1959. Fermentative carbomycin production. U.S. Pat. 2,902, 412 Sept. 1. U.S. Pat. Office.

Parke, Davis and Co. 1954. Antibiotics and methods for obtaining same. British Pat. Specification 707, 332 April 14. Pat. Office, London.

Person, L.H. and W. J. Martin. 1940. Soil rot of sweet potatoes in Louisiana. Phytopathology 30:913-926. 
Pinnert, S., L. Ninet and J. Preud'homme. 1964. Antibiotic and production thereof. U.S. Pat. 3, 155,581 Nov. 3. U.S. Pat. Office; also French Patent 1, 392, 453 Aug. 2, 1965.

Pinto, P. V.C. and G. B. Ramasarma. 1956. Indian Pat. Specification 57368 May 18.

and 1960. A new antibiotic Karnatakin and a process for the production and isolation thereof. British Pat. Specification 852,472 Oct. 26. Pat. Office, London.

Preobrazhenskaya, T.P., T.S. Maximova and N.O. Blinov. 1964. A study of green pigments from some actinomycetous species by the method of paper chromatography (in Russian, English summary). Antibiotiki 11:963-970.

and I. D. Ryabova. 1957. Characteristics of antagonistic actinomycetes of the Chrysomallus series [in Russian], p. 162-168. In Gauze, G.F., T.P. Preobrazhenskaya, E.S. Kudrina, N.O. Blinov, I. D. Ryabova and M. A. Sveshnikova. Problems of classification of actinomycetes-antagonists. Government Publishing House of Medical Literature, Medgiz, Moscow.

Pridham, T.G., C.W. Hesseltine and R. G. Benedict. 1958. A guide for the classification of streptomycetes according to selected groups: placement of strains in morphological sections. Appl. Microbiol. $6: 52-79$.

and A.J. Lyons, Jr. 1961. Streptomyces albus (Rossi-Doria) Waksman et Henrici: Taxonomic study of strains labelled Streptomyces albus. J. Bacteriol. 81:431-441.

Rossi-Doria, T. 1891. Su di alcune specie di "Streptotirix" trovate nell' aria studiate in rapporto a quelle gia note e specialmente all' "actinomyces." Ann. Instituto Igiene sper. R. Univ. Roma 1:399-438.

Ryabova, I. D. and T.P. Preobrazhenskaya. 1957. Characteristics of antagonistic actinomycetes of the Violaceus series [in Russian], p. 178-197. In Gauze, G. F., T. P. Preobrazhenskaya, E. S. Kudrina, N. O. Blinov, I. D. Ryabova and M.A. Sveshnikova, Problems of classification of actinomycetes-antagonists. Government Publishing House of Medical Literature, Medgiz, Moscow.

Schmidt-Kastner, G. 1963. Phyllomycin, ein antibioticum aus actinomyceten. Liebigs Ann. Chem. 668:122-128.

, J. Schmid, F. Grewe and B. Flück. 1957. Herstellung des Antibiotikums Phyllomycen. German Pat. Not. (DAS) 1061964 July 13. German Patent Office.

and 1958. Procedé de preparation d'un antibiotique. Belgian Pat. 569390 July 12.

Shinobu, R. 1956. Three new species of Streptomyces forming whirls. Mem. Osaka Univ. Lib. Arts and Educ., B. Nat. Sci., No. 5: 84-93. - 1962. A new Streptomyces species producing fluorescent-yellow soluble pigment. Mem. Osaka Univ. Lib. Arts and Educ., B. Nat. Sci. No. 11: 115-122.

and Y. Kayamura. 1964. On a new whirl-forming species of Streptomyces. Bot. Mag. Tokyo 77:176-180.

Struyk, A.P. and A. A. Stheeman. 1957. Process for the preparation of antibiotics. Commonwealth of Australia Patent Specif. 206, 799. Feb. 20 .

Sumiki, Y. 1957. Jap. Pat. 32-6296. Aug. 15. 
, G. Nakamura, M. Kawasaki, S. Yamashita, K. Anzai, K. Isono, Y. Serizawa, Y. Tomiyama and S. Suzuki. 1955. A new antibiotic, Homomycin. J. Antibiot. Tokyo Ser. A. 8:170.

Sveshnikova, M.A. 1957a. Characteristics of antagonistic actinomycetes of the Fuscus series [in Russian], p. 58-66. In Gauze, G. F., T. P. Preobrazhenskaya, E.S. Kudrina, N.O. Blinov, I. D. Ryabova and M.A. Sveshnikova. Problems of classification of actinomycetesantagonists. Government Publishing House of Medical Literature, Medgiz, Moscow.

- 1957b. Characteristics of antagonistic actinomycetes of the Roseoviolaceus series [in Russian], p.67-71. In Gauze, G.F., T. P. Preobrazhenskaya, E.S. Kudrina, N.O. Blinov, I. D. Ryabova and M. A. Sveshnikova. Problems of classification of actinomycetesantagonists. Government Publishing House of Medical Literature, Medgiz, Moscow.

Szabó, I. and M. Marton. 1958. A Streptomyces vastus és a Streptomyces viridoniger új sugárgomba fajokról (Adatok a szikestalajok mikrobiologiajához) [in Hungarian, Russian and German summaries]. Agrokémia és Talajtan 7:243-262

Upjohn Co. 1954. Antibiotic D-13 and its production. British Pat. Specif. 708, 686 May 5. Patent Office, London.

Virgilio, A. and C. Hengeller, 1960. Produzione di detra ciclina con Streptomyces psammoticus. II. Farmaco, Ed. Sci. 15:164-174.

Waksman, S.A. 1919. Cultural studies of species of Actinomyces. Soil Sci. 8:71-215.

- 1923. In Bergey, Harison, Breed, Hammer and Huntoon, Bergey's Manual of Determinative Bacteriology, lst ed. 1-442.

- 1953. In Waksman and Lechevalier. Guide to the classification and identification of the actinomycetes and their antibiotics. The Williams and Wilkins Co., Baltimore. 1-162.

- 1957. Family Actinomycetaceae Buchanan and family Streptomycetaceae Waksman and Henrici in Breed, Murray and Smith, Bergey's Manual of Determinative Bacteriology, 7th ed., 744-825. - 1961. The actinomycetes. Vol.2. Classification, identification and descriptions of genera and species. The Williams and Wilkins Co., Baltimore, 1-363. and R.E. Curtis. 1916. The actinomyces of the soil. Soil Sci. $1: 99-134$. and A. T. Henrici. 1943. The nomenclature and classification of the actinomycetes. J. Bacteriol. 46:337-341. and 1948. Family Actinomycetaceae Buchanan and Family Streptomycetaceae Waksman and Henrici p. 892-980. In Breed, Murray and Hitchens, Bergey's Manual of Determinative Bacteriology, 6th ed., The Williams and Wilkins Co., Baltimore. and $H$. Lechevalier. 1953. Guide to the classification and identification of the actinomycetes and their antibiotics. The Williams and Wilkins Co., Baltimore. 246 p.

Wollenweber, H.W. 1920. Der Kartoffelschorf. Arb. Forsch. Kartoffelbau 2:1-102.

- 1922. Zur Systematisierung der Strahlenpilze (Gattung Actinomyces harz.) Ber. Deut. Bot. Ges. 39:26.

Yuan, Chi-Shen. 1962. The biology of actinomycetes of the orange group. Candidate of Biol. Sci. Thesis, Inst. Mikrobiol., Akad. Nauk, S. S.S. R. Abstr. in Mikrobiolgiya 31:188. (Also Engl. transl. 31:150). 


\section{SOURCES OF ILLUSTRATIONS}

1. Elio Baldacci, G. Farina and R. Locci. Instituto Di Patologie, Vegetale del1' Universita', Via Celoria N. 2, Milano, Italia. Figures 6, 7, 34, 35, 71, 92, 93, 100, 143, 144, 156, 157, 207, 208.

2. Carol S. Cassidy and K.E. Crook, Jr. Bristol Labs., Inc., Syracuse, New York, U.S.A. Figures 176, 197.

3. T. Cross and Miss A. Maciver. Bradford Inst. of Technology, Bradford 7, Yorkshire, England. Figures 14, 64, 66, 158b, 189, 190,191 .

4. Alma Dietz. Upjohn Co., Kalamazoo, Mich. 49001, U.S.A. Figures 24, 72, 87, 122, 152.

5. (J. Elliott) J. Spyvee. Boots Pure Drug Co., Ltd., Antibiot. and Ferm. Div., Nottingham, England. Figures 185, 187, 196, 201, $217 \mathrm{a}$.

6. J. O. Falcão de Morais, Inst. de Quimica da Univ. Fed. de Pernambuco, Recife, Pernambuco, Brazil. Figures 5, 10, 77, 109b, 112, $113,114,115,154$.

7. A. Feltynowski and Wanda Woźnika, Panstwowy Zakład Higieny, U1. Chocimska 24, Warszawa 12, Poland. Figures 184, 206, 211.

8. W. Hodgkiss and T. G. Mitchell. Torry Res. Sta., Aberdeen, Scotland. Figures 51,95.

9. A. L. Houwink and G. A. deVries. Lab. f. Microbiol., Delft, Netherlands. Figures $30,76,81,86,101 \mathrm{a}, 128,130,151,161,167,195$, 214.

10. R. E. Kastner and C.E. Higgens. Eli Lilly and Co., Indianapolis, Indiana, U.S.A. Figures 21, 23, 80b, 102, 103b, 104.

11. N.A. Krasil'nikov. Inst. Microbiol., Acad. Sciences, Moscow, U.S.S.R. Figures 36, 37, 38, 90, 98, 99, 119, 120,121, 138, 139, 140, $141,142,164,169,170,171,172,203,204$.

12. V.D. Kuznetsov and A. Sokolov. USSR Res. Inst. for Antibiotics, Moscow and Lab. of Electronmicroscopy, Acad. Sci., U.S.S.R. Figures 15, 42, 53, 84, 192 .

13. P. Lockwood and W. Parfitt. Postgraduate School of Studies and Textile Technology, Univ, of Bradford (for T. Cross and A. Maciver), Bradford, England. Figures 54, 65, 159.

14. F. Mach. Inst. für Mikrobiologie, Griefswald, Ludwig-jahn-str., 15, German Democratic Republic. Figures 39, 40, 44, 45, 58, 59, $60,61,62,63,67,68,70,177,178,198,199,200,215,216$.

15. J. Mathews and A. Dietz. The Upjohn Co., Kalamazoo, Mich. 49001 , U.S.A. Figures 20,25, 73, 85, 101, 123, 153 .

16. M. Mayama and K. Terada. Div. of Bacteriol., Shionogi Research Lab., Shionogi and Co., Ltd., Fukushima-ku, Osaka, Japan. Figures 17, 134, 193.

17. M. Mayama and K. Tawara. Div. of Bacteriol., Shionogi Research Lab., Shionogi and Co., Ltd., Fukushima-ku, Osaka, Japan. Figures 16, 133 .

18. N. M. McClung. Dept. Bot. and Bacteriol., Univ. of South Florida, Tampa, Florida, U.S.A. Figure $217 \mathrm{~b}$.

19. G. Michaels. Dept. Microbiol., Univ. of Georgia, Athens, Georgia, U.S.A. Figures $8,33,69,218$.

20. K. Nakazawa. Takeda Chem. Ind., Ltd., Juso-Higashiyodogawaku, Osaka, Japan. Figures 106, 131, 145, 146, 158a, 186, 188, 202, 219. 
21. H. Nonomura and Y. Ohara. Faculty of Engineering, Yamanashi Univ., Kofu, Japan. Figures $126 \mathrm{~b}, 150,162 \mathrm{~b}, 183,205,210$.

22. H. Prauser. Inst. Mikrobiol. Exptl. Therapie, Beuthenbergstr, 11, Jena, German Democratic Republic. Figures 31, 32, 46, 47, $48,49,50,55,56,57,94,126 \mathrm{a}, 127,148,149,162 \mathrm{a}, 163,174,175$.

23. J. Routien. Chas. Pfizer and Co., Inc., Groton, Conn., U.S.A. Figures 89a, 91, 108, 129, 132, 147, 160b, 165, 173, 209, 212.

24. O.P. Srivastava. Antibiotics Div., Central Drug Res. Inst., Lucknow (U.P.), India. Figures $52,180,182$.

25. M.A. Sveshnikova. Acad. Med. Sciences of U.S.S.R., Inst. of New Antibiotics, Moscow, U.S.S.R. Figure 22.

26. W.A. Trejo. E.R. Squibb and Sons, New Brunswick, New Jersey, U.S.A. Figures 3, 9, 18a, 78, 88, 89b, 96, 107, 110, 137, 155.

27. V.A. Tsyganov. Res. Inst. of Antibiotics, Leningrad, L-20, U.S.S.R. Figures 4, 11, 12, 13, 18b, 19, 27, 109a, 111, 116, 135, 136.

28. Karl H. Wallhaüsser. Mikrobiolog. Unters, Labor CH 26, Farbwerke Hoechst AG, Frankfurt a/M - Höchst, Germany. Figures $28,29,75,117,124,125,160$ a, 166, 168, 194, 213.

29. S. T. Williams. Hartley Botanical Laboratories, Univ. of Liverpool, Liverpool, England. Figures 41, 43, 82, 83, 179, 181.

30. Wanda Wó́nicka and Irena Wojewódzka. Panstwowy Zakład Higieny, Warszawa 12, ul. Chocimska 24, Poland. Figures 1, 2, 26, 27, $74,79,80 a, 103 a, 105,118$. 